\title{
STRUCTURAL PERFORMANCE OF LINK SLABS SUBJECTED TO MONOTONIC AND FATIGUE LOADING INCORPORATING ENGINEERED CEMENTITIOUS COMPOSITES
}

\author{
By: \\ Shirin Ghatreh Samani \\ Bachelor of Engineering in Civil Engineering, \\ Ryerson University, Toronto, Ontario, 2013
}

\begin{abstract}
A Thesis
Presented to Ryerson University

In Partial Fulfillment of the Requirements for the

Masters of Applied Science in the Program of Civil Engineering
\end{abstract}

Toronto, Ontario, Canada, 2015

(c) Shirin Ghatreh Samani 2015 


\section{AUTHOR'S DECLARATION}

I hereby declare that I am the sole author of this thesis. This is a true copy of the thesis, including any required final revisions, as accepted by my examiners.

I authorize Ryerson University to lend this thesis to other institutions or individuals for the purpose of scholarly research.

I further authorize Ryerson University to reproduce this thesis by photocopying or by other means, in total or in part, at the request of other institutions or individuals for the purpose of scholarly research.

I understand that my thesis may be made electronically available to the public. 


\title{
STRUCTURAL PERFORMANCE OF LINK SLABS SUBJECTED TO MONOTONIC AND FATIGUE LOADING INCORPORATING ENGINEERED CEMENTITIOUS COMPOSITES
}

\author{
Shirin Ghatreh Samani, Masters of Applied Science, 2015 \\ Department of Civil Engineering \\ Ryerson University, Toronto, Canada
}

\begin{abstract}
This research presents the results of experimental investigation conducted on $1 / 4^{\text {th }}$ scale link slabs subjected to monotonic and fatigue loading incorporating different ECC mixtures and selfconsolidating concrete (SCC). The structural performance for the link slabs are evaluated based on the load-deformation/moment-rotation responses, strain developments, cracking patterns, ductility index and energy absorption capacity. Test results of a $1 / 6^{\text {th }}$ scale full bridge with ECC link slab tested under monotonic loading up to service stage is also described. The experimental link slab moment resistance and its length are compared with those obtained from theoretical and design specifications. The ECC link slabs demonstrated superior performance exhibiting high residual strength and energy absorbing capacity and prolonged life (associated with enduring large number of fatigue cycles) compared to their SCC even though subjected to higher fatigue stress levels. This research confirmed the viability of ECC link slab to construct joint-free bridges satisfying serviceability and design specifications.
\end{abstract}




\section{ACKNOWLEDGEMENTS}

I would like to express my deepest gratitude to my supervisor, Dr. Khandaker. M. Anwar Hossain, for his excellent guidance, support and patience during the development of this research. He provides me countless opportunities to learn while gaining experience through his effective training. Without his time and countless efforts, this thesis would not have been completed. I consider myself very fortunate to have the opportunity to work with him. Aside engineering principles, he has taught me life learning lessons that I will carry through my life.

I am also deeply grateful to $\mathrm{PhD}$ Candidate Mohammed Sherir for helping me in casting test specimens despite his busy schedule. His help in the design and implementation of the test set-ups were instrumental for successful completion of the tests. I also would like to thank Mr. Nidal Jaalouk, Mr. Min Yao, Mr. Mohammad Aldardari, for assisting me in casting and testing in the concrete and structural laboratories.

I also extend my special thanks to examining committee members: Dr. Sennah and Dr. Shehata for their feedbacks and guidance. Finally, heartiest appreciations to my parents who always supported and encouraged me in every moment of my life. 


\section{DEDICATIONS}

To My Parents

That Sacrificed their Life for My Greatest Success 


\section{TABLE OF CONTENTS}

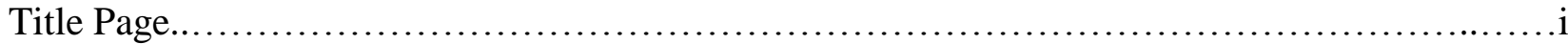

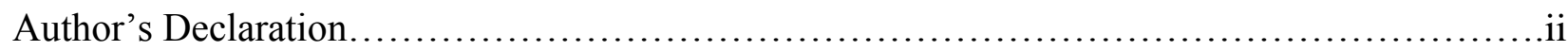

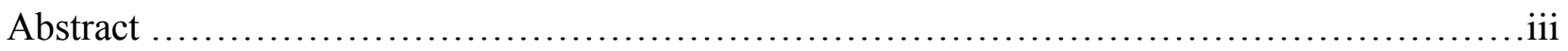

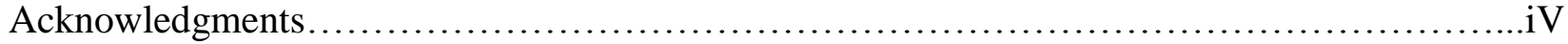

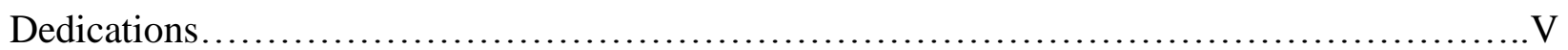

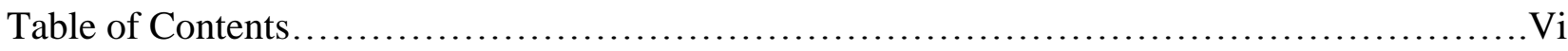

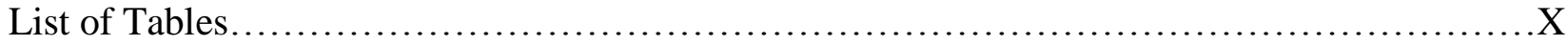

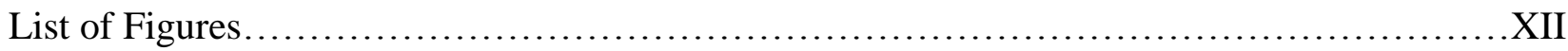

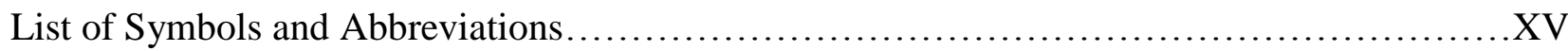

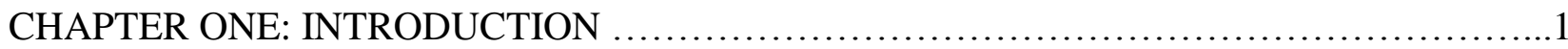

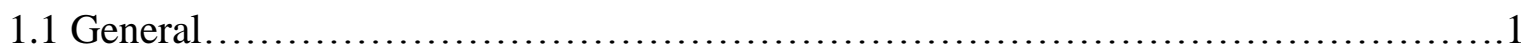

1.2 Research Significant...............................................................

1.3 Research Objectives and Scopes.............................................

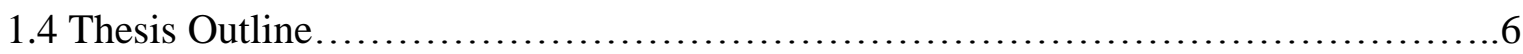

CHAPTER TWO: LITERATURE REVIEW ............................................. 8

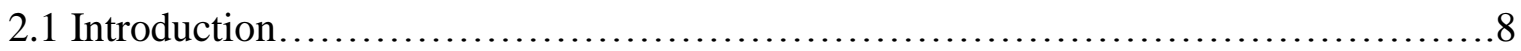

2.2 Pervious Research on Link Slab for Joint-free Bridge Construction...................8

2.3 Existing Design Guidelines for ECC Link Slab.................................12

2.4 Engineered Cementitious Composites (ECC) ..................................16

2.4.1 Material for ECC ................................................. 18

2.4.1.1 Role of Fibers..................................................19

2.4.1.2 Fly Ash................................................... 19

2.4.1.3Role of Aggregates.............................................20

2.4.2 Mechanical Properties..................................................21

2.4.2.1 Compressive Strength........................................21

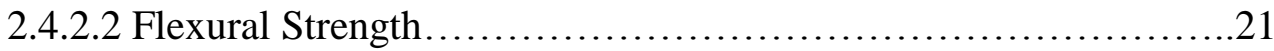

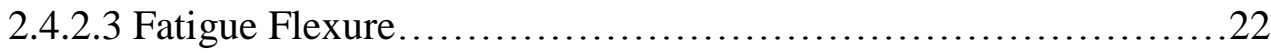

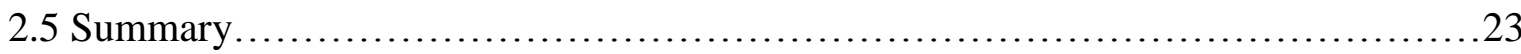


CHAPTER THREE: EXPERIMENTAL PROGRAM AND THEORETICAL ANALYSIS......24

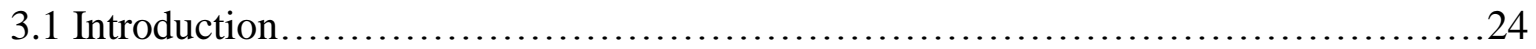

3.2 Design of Link Slabs and Full Bridge Models and Geometric Dimensioning

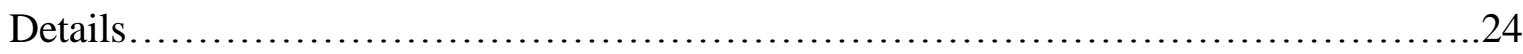

3.2.1 One Fourth Scale Link Slab Design and Configuration..................25

3.2.2 One Sixth Scale Full Bridge Specimen..............................29

3.3 Material Properties........................................................

3.3.1 Engineered Cementitious Composite.................................32

3.3.2 Self Consolidating Concrete......................................... 34

3.3.3 Steel Girder..................................................... 34

3.3.4 Shear Stud Connector................................................ 35

3.4 Construction Model Specimens......................................... 36

3.4.1 Mixing Sequences and Production of ECC and SCC .................... 36

3.4.2 Fabrication and Casting of Model Specimens........................... 37

3.5 Test Set-Ups, Instrumentation and Testing Procedure ...........................39

3.5.1 Strength Properties of Concretes................................... 39

3.5.2 One Fourth Scale Link Slab Subjected to Monotonic Loading..............40

3.5.3 One Fourth Scale Link Slab Subjected to Flexural Fatigue Loading.........42

3.5.4 One Sixth Scale Full Bridge Subjected to Monotonic Loading..............43

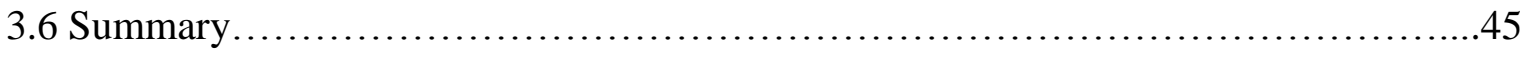

\section{CHAPTER FOUR: STRUCTURAL PERFORMANCE OF LINK SLABS UNDER}

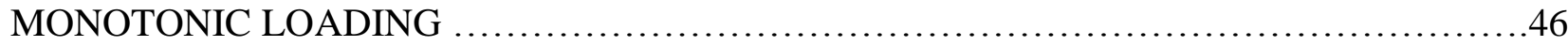

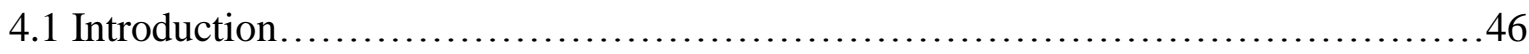

4.2 Properties of ECC and SCC mixtures................................... 46

4.3 Structural Performance of $1 / 4^{\text {th }}$ Scale Link Slabs With Different ECC Mixes Subjected

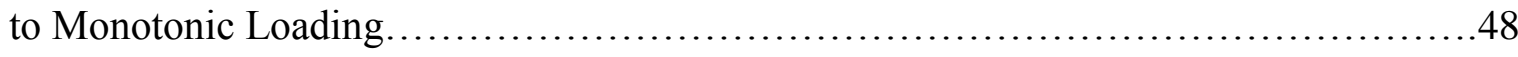

4.3.1 Experimental Load-Deflection/Moment-Rotation Responses and Theoretical Code Based Analysis..................................................49

4.3.1.1 Performance of ECC and SCC Link Slab....................51

4.3.1.2 Influence of Fly Ash on Link Slab Behaviour...................53

4.3.1.3 Influence of Different Aggregate Sizes.........................53 


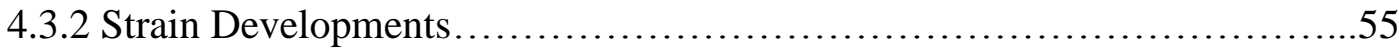

4.3.2.1Performance of ECC and SCC Link Slab.......................57

4.3.2.2 Influence of Different Fly Ash Replacement .....................58

4.3.2.3 Different Aggregate Size.........................................59

4.3.3 Crack Characterization...............................................60

4.3.4 Energy Absorbing Capacity and Ductility of Link Slabs....................63

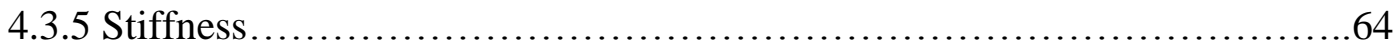

4.4 Structural Performance and Evaluation of a Scaled Down Full Bridge with ECC Link

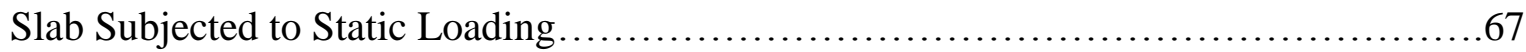

4.4.1 Load-Deformation/Moment-Rotation Rotation Responses and Theoretical/ Code Based Analysis........................................................

4.4.2 Strain Development Characteristic..................................72

4.4.3 Comparative Analysis of Experimental and Theoretical Location of Inflection

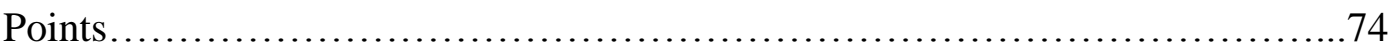

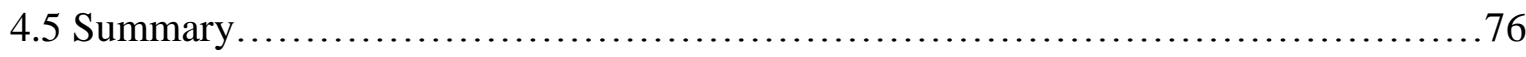

CHAPTER FIVE: FATIGUE PERFORMANCE OF ONE FOURTH SCALE LINK SLABS......77

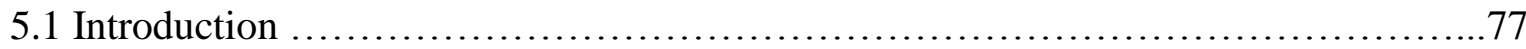

5.2 Performance of Link slabs at Different Fatigue Stress Levels..........................78

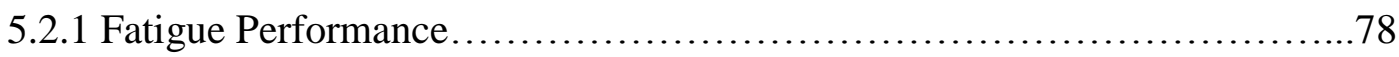

5.2.1.1 Load-Deflection Responses and Deflection Evolution..............78

5.2.1.2 Strain Developments....................................... 81

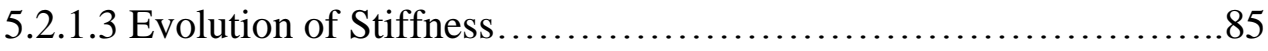

5.2.1.4 Crack Characterization......................................... 86

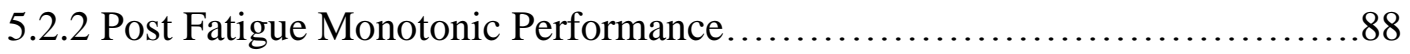

5.2.2.1 Load-Deflection/Moment-Rotation Responses and Comparison with

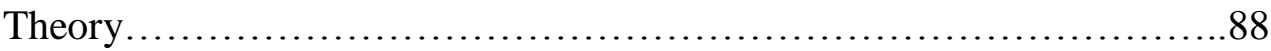

5.2.2.2 Post Fatigue Strain Developments...............................93

5.2.2.3 Energy Absorbing Capacity and Ductility Index...................99 
5.3 Behaviour of ECC Link Slabs Subjected to Fatigue Cycles at Constant Fatigue Stress

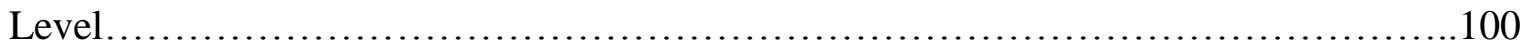

5.3.1 Fatigue Performance........................................... 101

5.3.1.1 Load-Deflection Response and Deflection Evolution..............101

5.3.1.2 Strain Developments..................................103

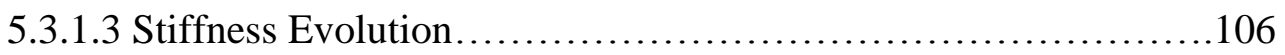

5.3.1.4 Crack Characterization..................................107

5.3.2 Post Fatigue Monotonic Performance of ECC Link Slabs at Different Fatigue

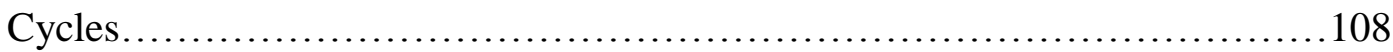

5.3.2.1 Experimental Load-Deflection/Moment-Rotation Responses and Theoretical-Code Based Analysis.................................109

5.3.2.2 Strain Developments......................................111

5.3.2.3 Energy Absorbing Capacity and Ductility Index................114

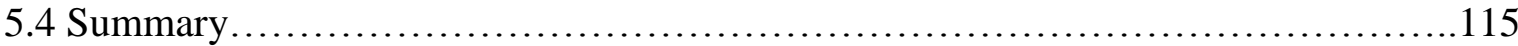

CHAPTER SIX: CONCLUSION............................................... 116

6.1 General................................................................ 116

6.2 Conclusion......................................................... 117

6.3 Recommendations for Future Work .................................... 119

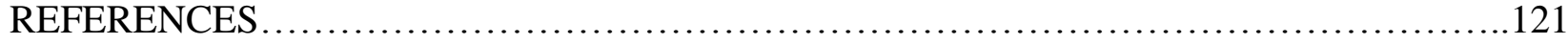

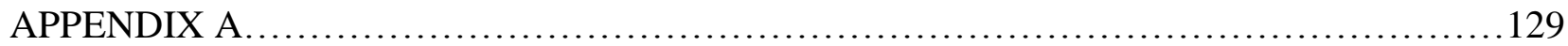

Resisting Moment Capacity for $1 / 4^{\text {th }}$ Scale ECC Link Slab.........................129

Resisting Moment Capacity for $1 / 6^{\text {th }}$ Scale Full Bridge Model.......................133 


\section{LIST OF TABLES}

Table 2.1: Typical Mix Design Proportion of ECC by Weight................................17

Table 2.2: Geometrical and Mechanical Properties of PVA fiber........................... 19

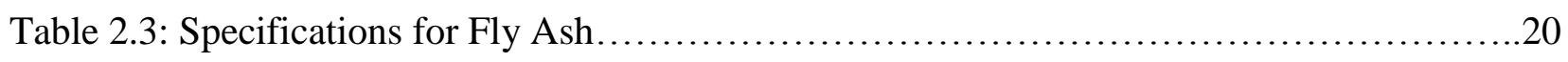

Table 3.1: Link Slab Specimens Configuration Subjected to Monotonic and Fatigue Loading....27

Table 3.2: Geometric Properties and Reinforcement Detailing for Each Segment of Full Bridge

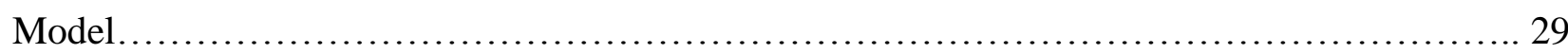

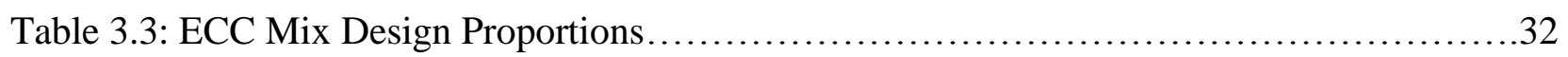

Table 3.4: Physical and Chemical Properties of Portland cement, fly ash F and CI..............33

Table 3.5: Properties of W100x19 Structural Steel section............................. 35

Table 4.1: Compressive and Flexural Strength of ECC and SCC Mixes......................47

Table 4.2: Summary of Load-Deflection and Moment Rotation Responses....................49

Table 4.3: Summary of Strain Development for Different Link Slabs..................... 55

Table 4.4: Crack Characterization for Different Link Slabs..............................61

Table 4.5: Energy Absorption and Ductility Responses of Link Slabs.........................64

Table 4.6: Summary of Link Slab's stiffness........................................65

Table 4.7: Key results from Load-Deformation/Moment Responses of the Full Bridge Models

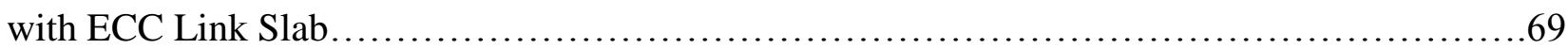

Table 4.8: Strain Developments for the Full Bridge with ECC Link Slab.....................72

Table 5.1: Mid-Span Deflection Evolution at Different Fatigue Stress Level...................79

Table 5.2: Strain Development of Link Slab During Fatigue Performance at Different Fatigue

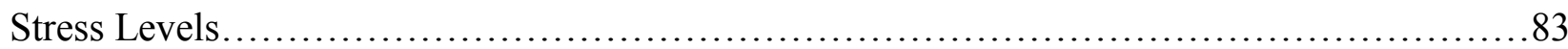

Table 5.3: Stiffness Degradation of Link Slabs at Different Fatigue Stress Level..............85

Table 5.4: Crack Characterization of Link Slabs at Different Fatigue Stress Level...............87

Table 5.5a: Summary of Post Fatigue Load-Deflection and Moment-Rotation Responses of the

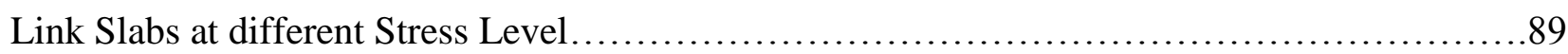

Table 5.5b: Load levels at Allowable Rotation Limit at different Stress Level..................89

Table 5.6: Post Fatigue Strain Developments for the Link Slabs at Different Fatigue Stress

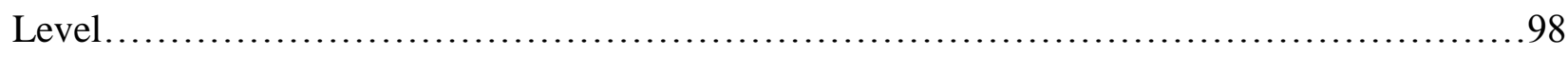

Table 5.7: Energy Absorption and Ductility Index of Link Slabs at Different Fatigue Stress

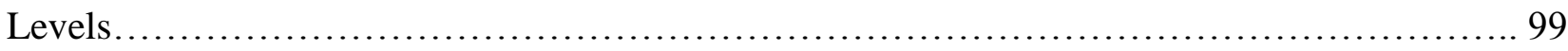


Table 5.8: Mid-Span Deflection Evolution at Different Fatigue Cycles...

Table 5.9: Strain Development of Link Slab During Fatigue Performance at Different Fatigue

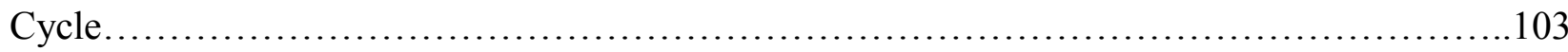

Table 5.10: Stiffness Degradation of Link Slab Specimens at Different Fatigue Cycles.............107

Table 5.11: Crack Characterization of the ECC Link Slab at Different Fatigue Cycle................107 Table 5.12: Residual Load-Deformation and Moment-Rotation Responses of ECC Link Slabs at

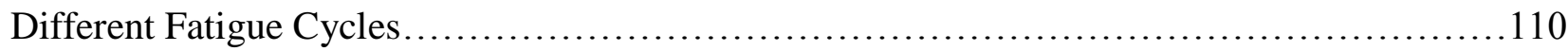

Table 5.13: Residual Strain Development of the ECC Link Slab at Different Fatigue Cycle......114 Table 5.14: Residual Energy Absorbing Capacity and Ductility Index of the ECC Link Slabs at Different Fatigue Cycle........................................................... 114 


\section{LIST OF FIGURES}

Figure 1.1 Joint Free Bridge Deck with Link Slab.........................................2

Figure 1.2 Schematic of Link Slab showing Components.....................................

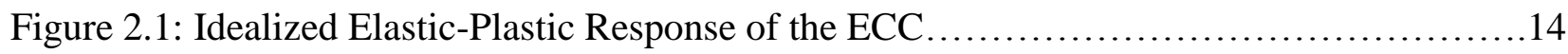

Figure 2.2: Strain, Stress Distribution of ECC Link Slab for Non-Linear Sectional Analysis......14

Figure 2.3: Tensile Stress-Strain Curve and Crack Width Development........................ 17

Figure 2.4: Ductile Response of ECC under Flexural Loading................................18

Figure 2.5: Typical Flexural Strength-Mid Span Deflection of Green ECC ...................22

Figure 3.1: Two Span Bridge Deformation with Focus on Link Slab Section....................25

Figure 3.2: Geometry and Reinforcement Details of Link Slab............................28

Figure 3.3: Geometry and Reinforcement Details of Full Bridge ...............................

Figure 3.4: Schematic Representation of W100x19 Section as Girder..........................34

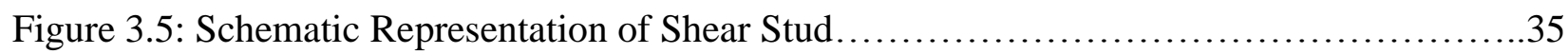

Figure 3.6: Mixing Sequences of ECC Mixtures.......................................... 36

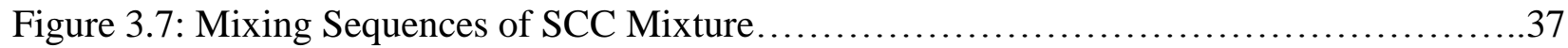

Figure 3.8: Casting Process of $1 / 4^{\text {th }}$ Scale Link Slab Model.................................. 38

Figure 3.9: Casting Sequence of Full Bridge Model..............................................39

Figure 3.10: Monotonic Test Set-Ups for $1 / 4^{\text {th }}$ Scale Link Slab Specimen........................41

Figure 3.11: Testing and Instrumentation of $1 / 4^{\text {th Scale }}$ Link Slab Specimen.......................42

Figure 3.12: Monotonic Test Set-Ups for 1/6th Scale Full Bridge Model........................44

Figure 3.13: Testing Instrumentation of $1 / 6^{\text {th }}$ Scale Full Bridge Model...........................45

Figure 4.1: Comparison of Load-Deflection Response of Different Concrete Mixes...............50

Figure 4.2: Comparison of Moment-Rotation Responses of Different Concrete Mixes............51

Figure 4.3: Comparison of Load-Deflection and Moment-Rotation Response of ECC and SCC

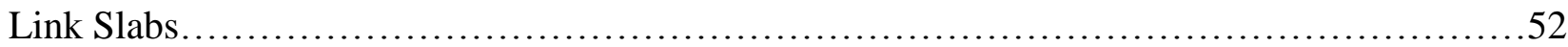

Figure 4.4: Load-Deflection Responses for ECC mixes with variable FA Replacement...........53

Figure 4.5: Load-Deflection Responses for ECC mixes with Different Sand Size.................54

Figure 4.6: Concrete Strain Developments for Different Concrete Mixes........................56

Figure 4.7: Rebar Strain Developments for Different Concrete Mixes..........................57

Figure 4.8: Strain Developments for ECC and SCC Link Slabs............................57

Figure 4.9: Concrete and Rebar Strain Development for ECC with Different FA Replacement...59 
Figure 4.10: Concrete Strains Development for ECC Link Slabs with Different Sand Sizes..... 59 Figure 4.11: Rebar Strain Developments for ECC Link Slabs with Different Sand Sizes.........60

Figure 4.12: Crack Characterization in Transition Zone.................................62

Figure 4.13: Crack Propagation and Failure of ECC and SCC link slabs....................62

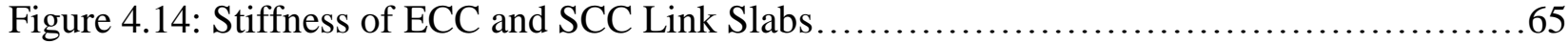

Figure 4.15: Stiffness evolution of ECC Link Slabs with Load...........................66

Figure 4.16: Schematic Representation instrumentations locations and designations for the $1 / 6^{\text {th }}$

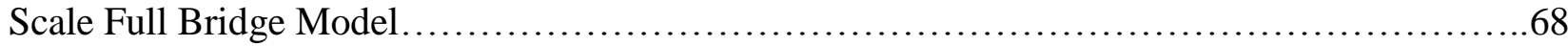

Figure 4.17: Load-Deflection Response of a Full Bridge with ECC Link Slab.................69

Figure 4.18: Load-Rotation Response of Full Bridge with ECC Link Slab...................71

Figure 4.19: Strain Developments for a Full Bridge with ECC Link Slab.....................73

Figure 4.20: Top Fiber Strain Profile for Full Bridge with ECC Link Slab at Different

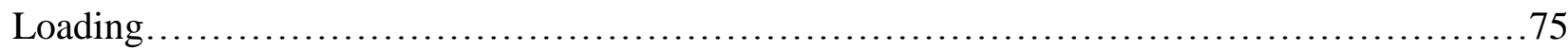

Figure 4.21: Schematic Representation for Location of Inflection Points .....................76

Figure 5.1: Load-Deflection Responses of Link Slabs at Different Fatigue Stress Level..........79

Figure 5.2: Mid-span Deflection Responses at Different Fatigue Stress Level...................81

Figure 5.3: Strain Developments for the Link Slab specimens at Different Fatigue Stress

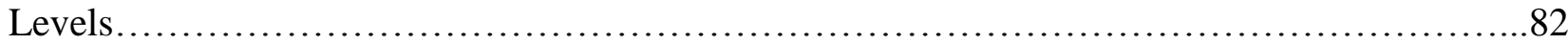

Figure 5.4: Strain Development Evolution for Link Slabs Subjected to Different Fatigue Stress

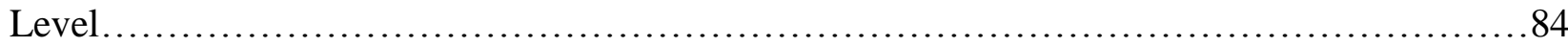

Figure 5.5: Stiffness Degradation of Link Slabs at Different Fatigue Stress Level..............85

Figure 5.6: Crack Propagation of Link Slabs at Different Fatigue Stress Level.................88

Figure 5.7: Post Fatigue Load-Deflection Responses of the Link Slabs......................90

Figure 5.8: Post Fatigue Moment-Rotation Responses of the Link Slabs.....................91

Figure 5.9: Concrete Strain Development at Pre-Fatigue, Fatigue and Post-Fatigue of Link Slabs

at Different Fatigue Stress Levels...............................................95

Figure 5.10: Rebar Strain Development at Pre-Fatigue, Fatigue and Post Fatigue of Link Slabs at

Different Fatigue Stress Level................................................. 96

Figure 5.11Summary of Post Fatigue Strain Developments for Link Slabs Subjected to Different

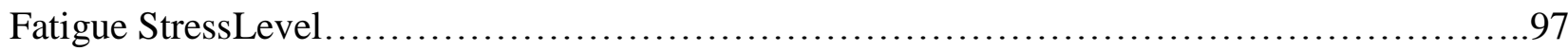

Figure 5.12: Load-Deformation Responses of ECC Link Slabs at Different Fatigue Cycles......101 
Figure 5.13:Mid-Span Deflection Evolution of ECC Link Slabs at Different Fatigue Cycles....102 Figure 5.14: Strain Development for ECC Link Slabs at Different Fatigue Cycles..............104 Figure 5.15: Strain Development Evolution of ECC Link Slabs at Different Fatigue Cycle.....105 Figure 5.16: Stiffness Degradation of Link Slab Specimens at Different Fatigue Cycles........106 Figure 5.17: Crack Characterization of ECC Link Slabs at Different Fatigue Cycle.............108 Figure 5.18: Post Fatigue Load-Deformation Response of ECC Link Slabs at Different Fatigue

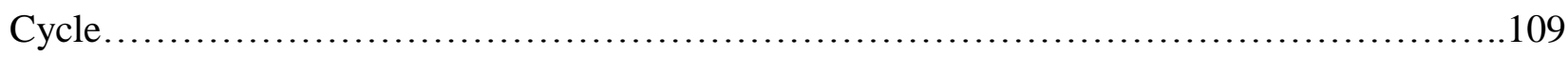

Figure 5.19: Residual Moment-Rotation Responses of ECC Link Slab at Different Fatigue Cycle. 110

Figure 5.20: Post Fatigue Concrete Strain Development for the ECC Link Slabs at Different

Fatigue Cycle. 112

Figure 5.21: Post Fatigue Rebar Strain Development for the ECC Link Slabs at Different Fatigue Cycle 113

Figure A.1: Stress and Strain Distribution in the ECC Link Slab Cross Section.................130

Figure A.2: Resisting Forces along the Depth of the SCC Section..........................134

Figure A.3: Resisting Forces along the Depth of the SCC Section for Location of Plastic Neutral Within Steel Girder. 135 


\section{LIST OF SYMBOLS AND ABBREVIATIONS}

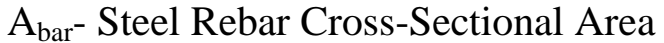

$\mathrm{A}_{\mathrm{s}}-$ Steel Area

$\mathrm{A}_{\mathrm{sc}}-$ Cross Sectional Area of one Stud

AASHTO- American Association of State Highway and Transportation Officials

$\mathrm{B}_{\mathrm{ls}}-$ Width of Link Slab

CS: Crushed Sand

$\mathrm{E}_{\mathrm{ECC}}$-Modulus of Elasticity

ECC: Engineered Cementatious Composite

FA: Fly Ash

FRC-Fiber Reinforced Concrete

$\mathrm{f}_{\mathrm{y} \text {-steel- }}$ Yielding Stress

GU- General Use

$\mathrm{I}_{1 \mathrm{~s}}$-Uncracked Moment of Inertia

ITZ: Interfacial Transition Zone

$\mathrm{L}_{\mathrm{dz}}$ - Length of the Debond Zone

$\mathrm{L}_{1 \mathrm{~s}}$ - Length of the Link Slab

LVDT: Linear Variable Differential Transformers

$\mathrm{M}_{\mathrm{ls}}$ - Applied Moment

MAS: Maximum Aggregate Size

MOR-Modulus of Rupture

MS: Mortar Sand

PE-Polyethylene

PVA: Poly-Vinyl-Alcohol

RC-Reinforced Concrete

SS: Silica Sand

SCC: Self-Consolidating Concrete

SCM: Supplementary Cementing Material

$\mathrm{t}$ :Thickness

$\mathrm{T}_{\text {steel: }}$ Tensile Force

$\theta_{\max }:$ Maximum End Rotations 
$\Delta_{\max -s h o r t}:$ Maximum Allowable Deflection

$\mathrm{n}_{\varepsilon}$ :Yield Strain Ratio

$\varepsilon_{\mathrm{y}-\mathrm{ECC}}:$ Yield Strain of ECC

$\varepsilon_{\mathrm{y}-\text { Steel }}:$ Yield Strain of Steel

$\rho:$ Steel Reinforcing Ratio 


\section{CHAPTER ONE INTRODUCTION}

\subsection{General}

Many highway bridges are designed as multi-span simply supported (over piers or abutments) steel or pre-stressed concrete girders supporting concrete bridge deck. At the end of each simple span deck, a mechanical expansion joints are installed for allowing a free deformation caused by girder's deflection, shrinkage, temperature variation and creep effect (Figure 1.1a). Aside from a high installation cost of these expansion joints, constant maintenance is required due to their low durability performance. The leakage of chloride-containment water through these mechanical expansion joints leads to corrosion of the steels girders and deterioration of the substructures (Kim et al. 2004). The accumulative debris reduces the strength and functionality of the bridge structures and eventually leading to a catastrophic failure. In fact the mechanical expansion joints are a major source of bridge deterioration in Canada (Au et al. 2013). The possible approach for improving the durability performance of the bridge structures is the elimination of the mechanical expansion joints. Different design methodologies have been proposed by scholars and ministry of transportation authorities for substituting these mechanical expansion joints (Au et al. 2013; Alampalli \& Yannotti, 1998; Gilani, 2001; Zia et al. 1995). The first approach is to use the haunched deck for developing a continuous deck system over the piers while keeping the girders as simply supported span. The second method is the construction of integral concept with continuity of the girders and the third approach is the implementation of the link slabs on the deck for developing a joint-free bridge deck with simply supporting spans (Figure 1.1b). The joint free-bridge deck is the most economical and efficient rehabilitation strategy in comparison to other proposed methods (Alampalli \& Yannotti, 1998). 


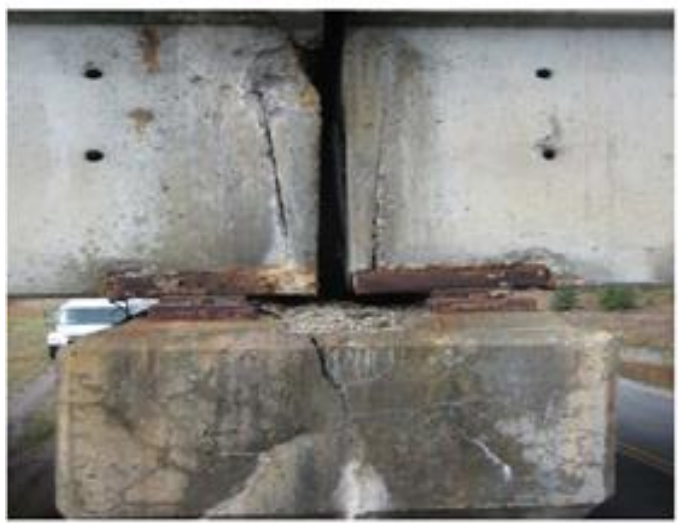

(a) Bridge deck with joint

\section{Bridge deck Conventional joint}
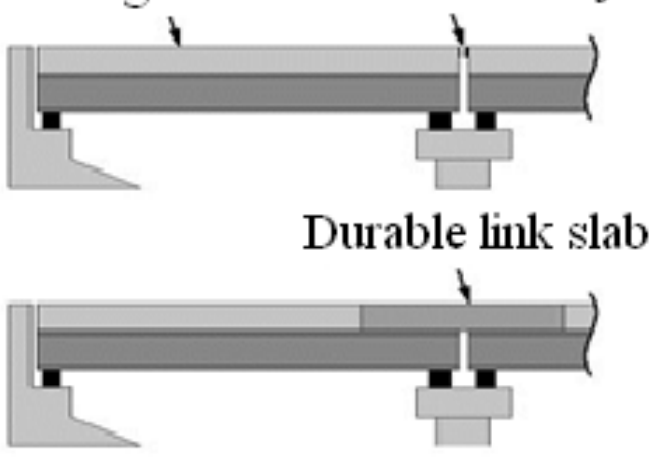

(b) Bridge deck with link slab

Figure 1.1: Joint Free Bridge Deck with Link Slab (Hossain \& Anwar 2014)

The link slab is defined as a section of the deck connecting the two adjacent simple-span girders (Figure 1.2). The total length of the link slab consists of the debonding and transition zone. The length of the debonding zone (where all the shear connectors are removed and debonding mechanism is placed on top of the flange's girder) is limited to 5\% of each adjacent bridge span. For reducing the stress concentration on the debonding zone, transition zone was introduced with additional design of $2.5 \%$ increase in length and $50 \%$ additional shear stud connectors than required by AASHTO design code (Caner \& Zia, 1998; Qian et al. 2009). Caner and Zia (1998) experimentally analyzed the performance of the joint-free bridge decks and proposed a design method for the normal concrete link slab.

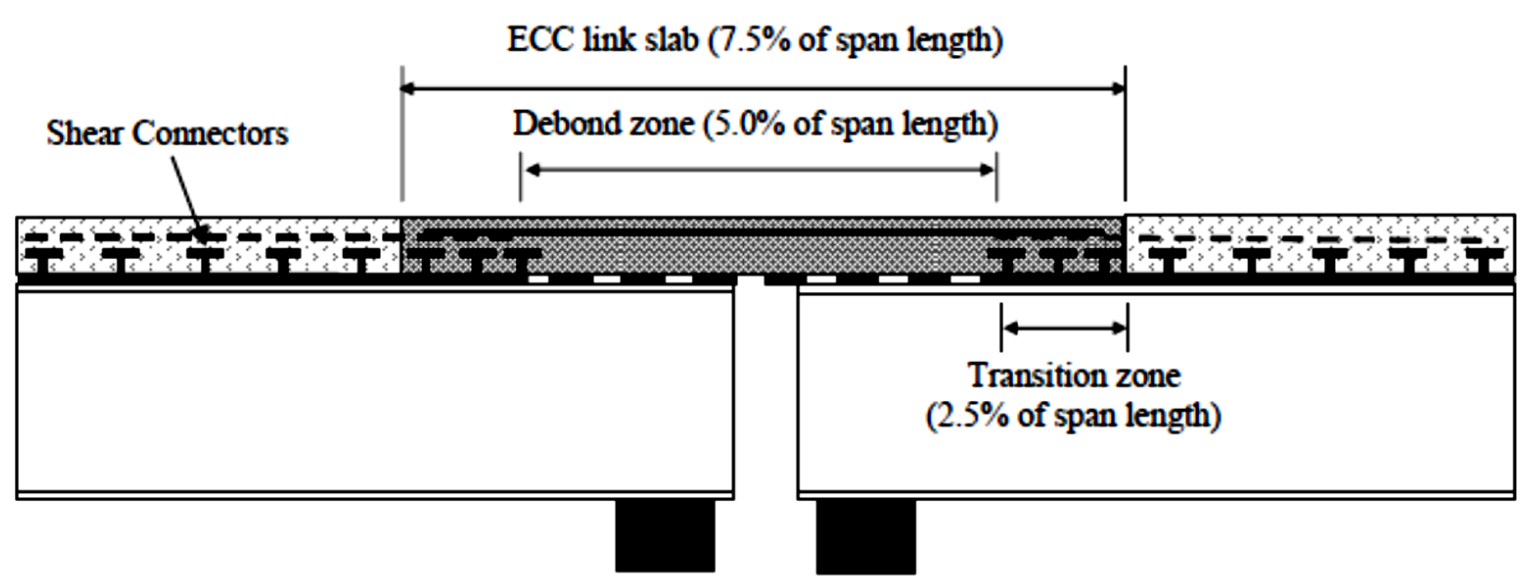

Figure 1.2: Schematic of Link Slab showing Components 
Although the use of link slab improved the durability performance of the bridge deck to some extent, but development of large tensile cracks in link slab segment for normal concrete caused degradation of structural (Caner \& Zia, 1998). These cracks, similarly to the expansion joints, allow salt water to contact the steel girder and rebar, causing corrosion and eventually leading to structural failure.

Engineered cementitious composite (ECC) is a special type of high performance fiber reinforced concrete that offers significant potential for resolving the durability performance of reinforced and pre-stressed concrete structures (Li \& Kanda, 1998; Li et al. 2002; Li, 2003). The high strain hardening characteristic and multiple micro-cracking behavior under tension and flexure while minimizing the amount of the reinforcing fibers (less than $2 \%$ by volume) makes it an ideal material for the link slab application (Sahmaran et al. 2010; Fischer \& Li, 2003). Comprehensive research studies have been conduct on material properties of the ECC by incorporating different supplementary cementitious material and sand aggregates (Sahmaran et al. 2010, Hossain \& Anwar, 2014; Sherir, 2012). ECC mixtures have been developed by incorporating industrial by-products/natural pozzolans such as fly ash, slag and metakaolin as replacement of cement (up to 60\%) as well as fibers of different types and configurations. Introduction of such supplementary cementitious materials has an inevitable influence on the microstructure of matrix and interface, and in turn on the micromechanical properties governing the fiber bridging behavior and cracking behavior of green ECCs. The presence of SCM, in fact, leads to improved strain-hardening behavior and durability of ECC. Tensile strain capacity exceeding 5\% has been demonstrated on ECC materials reinforced with polyethylene and polyvinyl alcohol fibers. ECC strain hardens after first cracking, similar to a ductile metal, and demonstrates a strain capacity 300 to 500 times greater than normal concrete. Even at large imposed deformation, crack widths of ECC remain small (less than $60 \mu \mathrm{m}$ ). Although ECC performance under monotonic loading has investigated to date, limited research has been conducted on its flexural fatigue performance (Sherir, 2012; Suthiwarapirak et al. 2004). Repetitive fatigue loading (normal to bridge structures) could result in the deterioration in the flexible ECC link slab used for construction of joint-free bridge decks. There is a lack of research studies on the structural performance of link slabs made of green cost-effective ECC mixtures subjected to monotonic and fatigue loadings for the development of design guidelines/specifications. 


\subsection{Research Significance}

The rehabilitation of the bridge structure is a major concern for reinforced and pre-stressed concrete structures due to accelerating deterioration with increasing traffic volumes, stress levels, environmental and time-dependent damages. Further, as the bridge structure ages, the rehabilitation cost increases even though billions of dollars are already spent every year in the USA and Canada for bridge repair and maintenance. The decreasing budget allocations and increasing need for bridge rehabilitation specifically in Canada due to poor durability performance of bridge structure are becoming a major problem for highway transportation authorities.

The leaking expansion joints are a major source of multi-span bridge deteriorations in North America. For reducing the pre-mature deterioration, the expansion joints can be replaced by flexible ECC link slabs forming a joint free bridge decks (Kim et al. 2004). The high strain hardening characteristic and multiple micro-cracking behavior of ECC can improve the durability and extends the service life of the bridge decks (Keoleian et al. 2005, Hossain \& Anwar, 2014).

During the past few years at Ryerson University, the locally available aggregates and supplementary cementitious material (SCM) have been incorporated for the production of sustainable and cost effective ECC mixes for structural applications (Shamaran et al. 2010, Sherir, 2012, Maulin, 2012; Hossain \& Anwar, 2014). The use of ECC link slab has been a new emerging technology, however limited research has been conducted on its flexural monotonic and fatigue performance. The lack of research studies specifically in Canada requires a detailed investigation on link slabs subjected to flexural monotonic and fatigue loading using greener ECC mixes to understand structural behaviour and to develop design guidelines and specifications. The findings of this research will surely benefit engineers, builders and local authorities when designing and constructing joint-free bridges with ECC link slabs. 


\subsection{Research Objectives and Scopes}

The main objectives of this research program are to:

- Evaluate the structural performance of model link slab specimens of $1 / 4^{\text {th }}$ scale by conducting tests under flexural monotonic loading (to failure) by incorporating seven different ECC mixes incorporating different types/content of fly ash (FA) namely $\mathrm{CI}$ and F and size/type of sand aggregates (such as silica (SS), crushed (CS) and mortar sand (MS)) through the load-deformation/moment-rotation responses, stiffness, strain developments, crack characterization, crack width, energy absorbing capacity and ductility. Study the performance of ECC link slabs compared to their self-consolidating concrete (SCC) (considered in this investigation as normal concrete made with coarse and fine aggregates) counterparts under monotonic loading based on the above criteria. Evaluate also the influence of various ECC mixtures and SCC on link slab performance.

- Study the structural response of link slabs made of a selected high performance ECC mixture (using class CI fly ash and local mortar sand) subjected to flexural fatigue loading by conducting tests based on two different approaches: applying two different fatigue stress levels $(40 \% \pm 20 \%, 55 \% \pm 20 \%)$ at a fixed fatigue cycles of 400000 and applying different fatigue cycles of up to 1 million at a fixed stress level of $40 \% \pm 20 \%$. Conduct flexural fatigue tests on $1 / 4^{\text {th }}$ scale link slabs in three different stages under pre-fatigue monotonic, fatigue and post-fatigue monotonic loading. Study the fatigue performance of ECC link slabs for both approaches (variable fatigue stress levels and number cycles) compared to their SCC counterparts based on load-deformation responses, strain developments, crack characterization, energy absorbing capacity, ductility index and stiffness. Evaluate the postfatigue resistance of ECC link slabs (compared to their SCC counterparts) based on residual strength, stiffness, ductility, energy absorbing capacity and crack development and crack width characteristics.

- Compare the experimentally obtained moment resistance of link slab to those obtained from theoretical analyses. Also compare experimental link slab rotation to those prescribed by previous researchers and design specifications. 
- Conduct test on $1 / 6^{\text {th }}$ scale full bridge with ECC link slab tested under monotonic loading (up to service load) to demonstrate the link slab performance in actual joint-free bridge consisting of two simply supported adjacent spans based on load-deflection/moment-rotation response and strain development as well as inflection point identification. Compare experimentally obtained location of inflection points and girder rotation compared with those suggested by researchers and design specifications such as Lepech and Li (2009), AASHTO LRFD (2012) and CHBDC (2006).

- Make recommendations for the ECC link slab performance and development of design guidelines. Describe the viability of designing and constructing joint-free bridges with ECC link slabs.

\subsection{Thesis Outline}

This thesis consists of 6 chapters presenting a comprehensive investigation on the structural performance of link slabs (made of ECC and SCC) for joint-free bridge construction.

Chapter 1 introduces the link slab for the joint-free bridge deck construction, ECC materials and relevant research studies. It describes the objectives and scopes of this research.

Chapter 2 presents the comprehensive literature review on material, mix design and properties of ECC and SCC with especial reference to supplementary cementing materials, fibers and aggregates. It also describes relevant research studies on link slab, link slab structural behaviour, and available design guidelines for link slabs as well as implementation and application of link slabs in joint-free bridge decks.

Chapter 3 describes the experimental program and theoretical analysis including material properties, geometric dimensioning of scaled down link slabs and full bridge models, experimental instrumentation and testing procedures.

Chapter 4 presents the results of the experimental investigation on $1 / 4^{\text {th }}$ scale link slab specimens subjected to monotonic loadings. The performance is described based on the loaddeflection/moment-rotation response, strain developments, cracking/crack propagation, energy absorption, ductility and failure modes. The influence of seven ECC mixes and aggregate types/size on the link slab structural performance under monotonic loading is described 
compared with those made with SCC. In addition, results of a test conducted on $1 / 6^{\text {th }}$ scale full bridge with ECC link slab tested under monotonic loading is described based on loaddeflection/moment-rotation response and strain development as well as inflection point identification. Experimentally obtained location of inflection points, moment resistance and girder rotation are compared with those obtained from theoretical formulations and design specifications.

Chapter 5 presents the results of the flexural fatigue performance of the $1 / 4^{\text {th }}$ scale link slabs tested in three different stages under pre-fatigue monotonic, fatigue and post-fatigue monotonic loadings. The fatigue performance of link slabs is evaluated based on load-deformation responses, strain developments, crack characterization, energy absorbing capacity, ductility index and stiffness degradation. Experimental results are compared with those obtained from theoretical formulations and design specifications.

Chapter 6 summarizes the findings of the research and provides recommendation for future research studies on the link slabs. 


\section{CHAPTER TWO \\ LITERATURE REVIEW}

\subsection{Introduction}

This chapter presents a literature review on the performance of link slabs used in the joint-free bridge deck construction using normal concrete and engineered cementitious composites (ECCs) subjected to monotonic and fatigue loading as well as ongoing research on the material and mechanical properties of the incorporated concretes especially ECCs.

\subsection{Pervious Research on Link Slab for Joint-free Bridge Construction}

Back in 1970's many bridge structures were designed as simply supported girders supporting a simply span concrete decks. A mechanical expansion joints were provided at the end of each deck spans for allowing a girders to deform freely under internal and external stresses (Lam et al. 2008). The low durability performance of mechanical expansion joints in the bridge deck led the engineers to develop an efficient design of joint-less bridge structure known as link slab (Caner \&Zia, 1998). Experimental research has been conducted on developing design guidelines for durability and structural performance of link slabs using different concretes (normal concrete and ECC), varying reinforcing ratio and debonding length (Caner \& Zia, 1998; Gilani, 2001; Zia et al. 1995; Maulin, 2012; Lepech \& Li, 2009). Limited research has also been conducted on the fatigue performance of link slab as well its implementation and performance in a real bridge structure. Kim et al. (2004) investigated the durability performance of the traditional ECC link slab subjected to flexural fatigue loading only up to maximum allowable AASHTO's rotation of 0.00375 radian at 100000 fatigue cycles. Caner and Zia (1998) tested the performance of normal concrete link slab in reduced scale bridge structure and proposed some design guidelines.

Since the early 1980's, researchers have investigated the performance of joint-free bridge decks

in a multiple simply-supported girders. Zuk (1981) analyzed the effects of expansion and contraction joints in joint-free bridge deck, but due to lack of experimental results, his model was not implemented in an actual application. Gastel and Zia (1989) developed a finite element model for joint-free bridge decks using a linear strain theory along the depth of the link slab, but once again the model was not validated due to lack of experimental results. 
The first experimental investigation of the joint-free bridge deck with connecting link slab was conducted by Caner and Zia (1998). Two reduced scale bridge specimens with simply supported steel and pre-stressed girders and a connecting link slab were tested under monotonic loading. The first experimental investigation revealed that link slabs were subjected to flexural stresses under typical traffic loading rather than elongation like a mechanical expansion joints. Tensile cracks were formed on top of the link slab under service condition due to development of negative moment. It was pointed out that in addition to applied loading, additional tensile stresses were imposed on the link slab due to creep, shrinkage and temperature loading. For enhanced durability performance of link slab, they suggested to use epoxy coated reinforcement or carbon fiber reinforced polymer (FRP) bar to avoid corrosion. Further, it was proposed to reduce the stiffness of the link slab by limiting the debonding length to $5 \%$ of the adjacent bridge for maintaining the simply support performance of the girder with a continuous deck as per Equation 2.1.

$L_{d z}=5 \%\left(L_{1}+L_{2}\right)$

where $\mathrm{L}_{\mathrm{dz}}$ denotes the total length of the debondig zone, and $\mathrm{L}_{1}, \mathrm{~L}_{2}$ are the lengths of adjacent bridge spans.

Aside limiting the length of the link slab, Caner and Zia (1998) also suggested to minimize the reinforcing ratio of the link slab based on the stress criterion (Equation 2.2) at girder's end rotation of 0.0015 radian (AASHTO, 2012) for maintaining low structural stiffness.

$f_{s}<0.4 f_{y}$

where $\mathrm{f}_{\mathrm{s}}$ and $\mathrm{f}_{\mathrm{y}}$ are denoting the allowable stress and yielding stress of the reinforcing bar.

Many problems were associated with the experiments conducted by Caner and Zia (1998). The major problem was development of large tensile crack widths on top of the link slab due to use of normal concrete. Although heavily steel reinforced link slab would have reduced the crack's width to the acceptable limits, but it would increase the stiffness of the link slabs. Weak 
interfaces were formed between the concrete bridge deck and link slab joint because the applied tensile stresses were resisted only by the link slab rather than a composite actions of deck and girder. Also there was a lack of experimental and analytical results on the fatigue performance of the link slabs.

Experimental investigations were conducted on the full scale link slabs subjected to both monotonic and fatigue loading using ECC (Kim et al. 2004; Li et al. 2003; Kim \& Li, 2004). Experimental results of ECC based link slabs were compared to the conventional reinforced concrete (RC) link slab. While previous research was focused on the reduced scale full bridge models using conventional RC, the new investigation focused on the full-scale link slab portion only. Therefore the imposed end rotations of the link slabs caused by adjacent bridge spans were replicated in the laboratory. The reinforcing ratio for the ECC and RC link slabs was adopted from the guidelines proposed by Caner and Zia (1998) for satisfying the stress criterion of RC link slab at the end rotation of 0.0015 radian. Monotonic and fatigue test results revealed the suitability of ECC material for the link slab application developing a low structural stiffness for allowing the hinge formation, while keeping the crack widths below the acceptable limits at the ultimate loading. The yielding of reinforcing bar was delayed in comparison to the conventional RC because of high tensile strain capacity and ductility of ECC that allowed a compatible deformation of the composite with reinforcing bar. Based on the analysis, it was suggested to reduce the amount of the steel reinforcement further for the ECC link slab to maintaining the simply supporting behaviour of the girders with lower structural stiffness. The stiffness of the ECC links slabs remained unchanged after cyclic testing at 100000 fatigue cycles. All ECC link slabs formed multiple micro-cracks (with width below $130 \mu \mathrm{m}$ ) within the debonding zone only. Unlike previous experiments, no cracking was observed within the interface of the concrete and the ECC link slab, since additional shear studs were provided only within the interface for reducing the stress concentration by the composite action of the girder and the deck.

The first field application of the ECC link slab was designed and implemented in the State of Michigan in 2005 (Li et al. 2005). The design procedure adopted by previous researchers (Caner \& Zia, 1998; Kim et al. 2004) was validated by the strong correlation of the girders end-rotation and strain development on the link slab surface. The maximum tensile strain development of the ECC link slab was less than the elastic limits with the proposed end-rotation below the maximum 
allowable AASHTO's rotation of 0.00375 radian. Also the simply supporting behaviour of the girders was maintained with the continuous deck slab. The major encountered problem was the early shrinkage of the ECC that caused additional stresses followed by micro-cracking formation specifically within the link slab and deck interface before the applied loading.

Qian et al. (2009) finalized the design procedure for the effective length of the ECC link slab, after extensive testing with different debonding zone length. Based on the analysis, it was suggested that length of the link slabs falls between the inflection points. The locations of the inflection points vary from 0 to $20 \%$ based on the stiffness of the link slab. With a low structural stiffness of the ECC, Qian et al. (2009) recommended 7.5\% of adjacent span's length for the total length of the ECC link slab (Equation 2.3).

$L_{l s}=7.5 \%\left(L_{1}+L_{2}\right)$

where $L_{1 s}$ denotes the total length of the link slab and $L_{1}$ and $L_{2}$ represents the length of the adjacent bridge spans.

They have also suggested adding a transition zone within the interface of the concrete deck and the link slab for shifting the stress concentration to debond zone only. The length of the transition zone with installation of additional $50 \%$ shear connector was set as $2.5 \%$ of the span's length (Figure 1.2).

The high production cost of the ECC encouraged the scholars to develop an economical and greener mixture using locally available crushed sand and supplementary cementitious material for the purpose of the link slab application (Sahmaran et al. 2009 ; Maulin, 2012; Sherir, 2012). Maulin (2012) investigated the structural performance of the scaled down link slab with different reinforcing ratios (0.01 and 0.012), and using the green ECC mix incorporating crushed sand and fly ash $\mathrm{F}$ at $70 \%$ replacement of cement. The experimental investigation revealed that number of micro-cracking was reduced at higher reinforcing ratio due to increased structural stiffness. Also there was apparent difference for structural performance due to the change of aggregate type and size as well as use of fly ash.

Sherir (2012) reported the creep performance for a duration of six months (monitoring still continues at Ryerson University for the last three years) of the link slabs by comparing the 
influence of the crushed and micro-silica sand based ECC to a normal concrete. The experimental investigation revealed that more cracks were formed for the crushed sand based ECC link slab compared to those with micro-silica sand. The link slab with normal underwent less creep damage due to the presence of larger aggregates with higher modulus of elasticity. ECC link slabs showed more deformation due to the high strain hardening capacity due to the presence of polyvinyl alcohol (PVA) fibers.

Hossain and Anwar (2014) conducted experimental investigations by introducing different ECC mixtures made with different types of sand (crushed and micro-silica sand) and supplementary cementitious material (fly ash, volcanic ash and volcanic pumice) for the link slab application. The influence of crushed sand, volcanic ash and ground pumice on the structural performance of the link slabs was evaluated based on the load-deformation, ductility and energy absorbing capacity. The analysis revealed that crushed sand developed higher ultimate load and energy absorbing capacity compared to silica sand, whereas the pumice based ECC link slabs developed higher bending deflection but lower ultimate load capacity.

\subsection{Existing Design Guidelines for ECC Link Slab}

After experimental investigation and field demonstration, Lepech and Li (2009) developed a design guideline for the ECC link slab. The overall length of the link slab and the debonding zone based on the pervious experimental research was modified further to calculate length of the link slab and debonding zone as per Equations 2.4 and 2.5 respectively.

$L_{l s}=7.5 \%\left(L_{1}+L_{2}\right)+G_{1-2}$

$L_{d z}=5 \%\left(L_{1}+L_{2}\right)+G_{1-2}$

where $\mathrm{L}_{\mathrm{ls}}$ and $\mathrm{L}_{\mathrm{dz}}$ denote the length of the link slab and debonding zone respectively; $\mathrm{L}_{1}$ and $\mathrm{L}_{2}$ represent the length of the adjacent spans and $\mathrm{G}_{1-2}$ symbolizes the length of the gap between the girders of the adjacent spans.

Equation 2.6 is proposed for determining the applied moment on the link slab $\left(\mathrm{M}_{\mathrm{ls}}\right)$ imposed by the maximum end rotation of the adjacent bridge spans: 
$M_{l s}=\frac{2 E_{E C C} I_{l s}}{L_{d z}} \theta_{\max }$

where $\mathrm{E}_{\mathrm{ECC}}$ is the modulus of elasticity of the ECC, $\theta_{\max }$ is the maximum end rotations and $\mathrm{I}_{\mathrm{ls}}$ represents the uncracked moment of inertia as per Equation 2.7.

$I_{l s}=\frac{B_{l s} t^{3}}{12}$

where $\mathrm{B}_{\mathrm{ls}}$ and $\mathrm{t}$ denotes the width and thickness of the link slab, respectively.

Based on American Association of State Highway and Transportation Officials (AASHTO's, 2012 design code), the maximum end rotation caused by the live load depends on the maximum allowable deflection of the adjacent simply supporting bridge spans can be obtained as per Equation 2.8.

$\theta_{\max }=\Delta_{\text {max }- \text { short }}\left(\frac{3}{L_{\text {short }}}\right)$

where $\theta_{\max }$ represents the maximum end-rotation angle of the adjacent bridge spans, measured in radians, $\Delta_{\text {max-short }}$ denotes the maximum allowable deflection of the shorter spans in $\mathrm{mm}$ and $\mathrm{L}_{\text {short }}$ is the shorter adjacent spans length in $\mathrm{mm}$. With the maximum allowable deflection based on the AASHTO's code is limited to L/800, the maximum end rotation imposed by adjacent spans will be equivalent to 0.00375 radian.

Lepech and Li (2009) used iterative design procedure for determining the adequate reinforcing ratio, starting with the minimum reinforcement. Through the analysis, the selected reinforcing ratio was adjusted accordingly to resist the applied moment imposed by the girders end-rotation. Unlike conventional RC link slab, the resisting moment was based on the structural loading capacity rather than serviceability requirements due to micro-cracking behaviour of the ECC (Lepech \& Li. 2006). The resisting moment capacity of the link slab was determined based on the non-linear sectional analysis with the assumption of a perfectly elastic-plastic response for the ECC. For the conservative design practice, the linear tensile strength of the ECC was used while ignoring the strain hardening characteristic (as seen in the typical stress-strain characteristics, Figure 2.1) after the first cracking (Lepech \& Li. 2009). After extensive tensile test results on ECC, Lepech and Li (2008\& 2009) proposed a yielding stress and strain of $3.45 \mathrm{MPa}$ and $0.02 \%$, respectively based on the first cracking responses. 


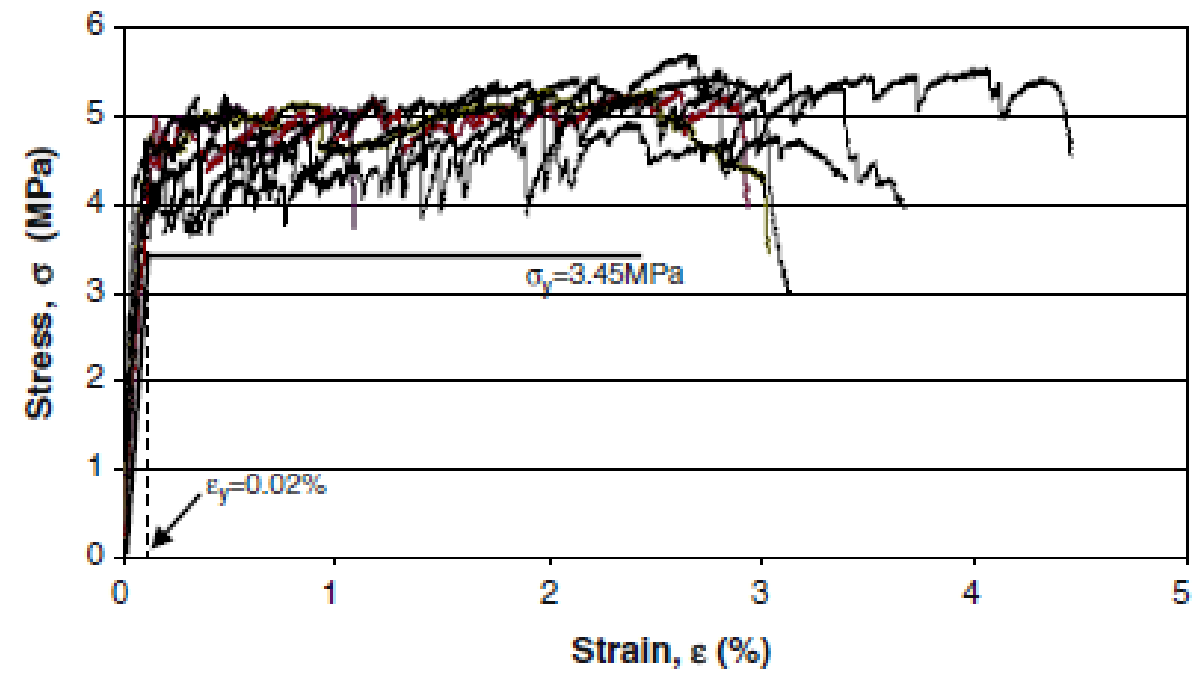

Figure 2.1: Idealized Elastic-Plastic Response of the ECC (Lepech \&Li 2009)

For finding resisting moment capacity, the same stress criterion was adopted by Caner and Zia (1998) using $40 \%$ of the yield strength of the reinforcement as a conservative working stress (Equation 2.2). The elastic and plastic responses of the ECC section develop a tension kink for the concrete's tensile stress. The location of the tension kinks for the ECC and the resisting strains and stresses across the depth of the ECC link slab are illustrated in Figure 2.2.

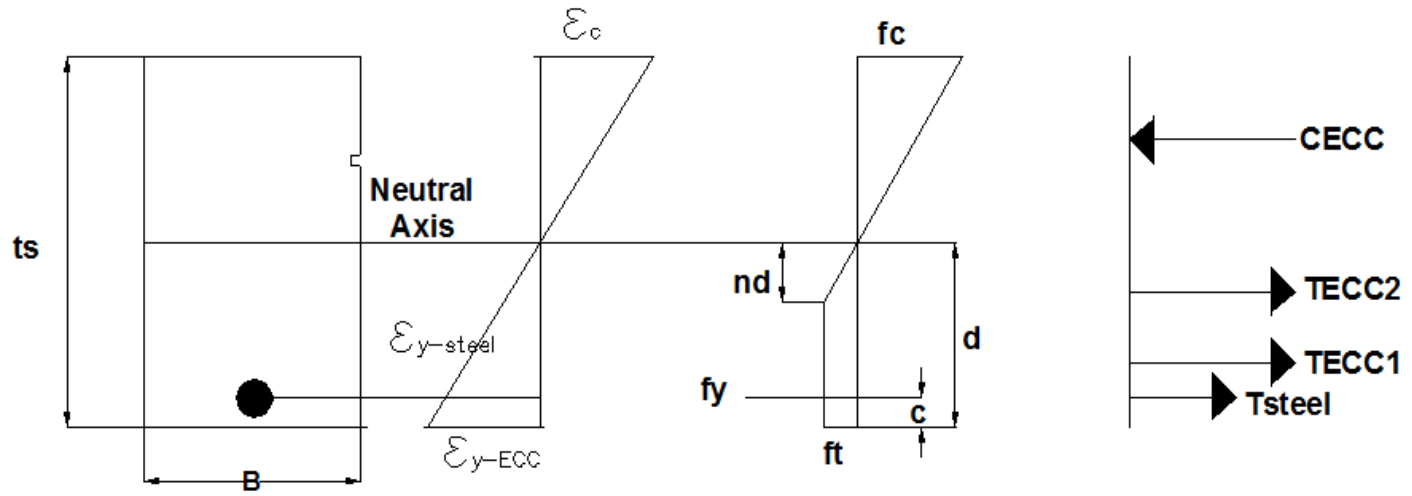

Figure 2.2: Strain, Stress Distribution of ECC Link Slab for Non-Linear Sectional Analysis (Lepech \& Li 2009)

$\mathrm{B}$ and $\mathrm{t}_{\mathrm{s}}$ in Figure 2.2 represent the width and the depth of the link slab, respectively, $\varepsilon_{\mathrm{c}}, \varepsilon_{\mathrm{y}-\mathrm{steel}}$, and $\varepsilon_{\mathrm{y}-\mathrm{ECC}}$ represent the compressive strain and yielding strain of reinforcing steel and ECC, 
respectively. ' $d$ ' symbolizes the distance from the neutral axis to the rebar and ' $C$ ' denotes the distance from the tension face to centroid of the rebar.

The proposed stress criterion by Caner and Zia (1998) was used to determine the corresponding tension kink and neutral axis for calculating the resisting moment capacity. The modular ratio is presented by Equation 2.9.

$\mathrm{n}_{\varepsilon}=\frac{\varepsilon_{\mathrm{y}-\mathrm{ECC}}}{0.4 \varepsilon_{\mathrm{y}-\text { Steel }}}$

The $\mathrm{n}_{\varepsilon}$ represents the yield strain (modular) ratio, $\varepsilon_{\mathrm{y}-\mathrm{ECC}}$ and $\varepsilon_{\mathrm{y}-\text { Steel }}$ denote the yield strain of the elastic-plastic behaviour of ECC and steel reinforcement, respectively.

The depth of the neutral axis was determined based on the modular ratio and the equilibrium of resisting forces across the depth of ECC link slab. Lepech and Li (2009) proposed equations for calculating the ECC tensile forces. The resisting forces across the depth of the ECC link slab and their equilibrium are presented through Equations 2.10 to 2.13 and 2.14, respectively.

$\mathrm{T}_{\text {steel }}=\left(0.4 \mathrm{f}_{\mathrm{y} \text {-steel }}\right) \mathrm{A}_{\mathrm{s}}$

$\mathrm{T}_{\mathrm{ECC}-1}=\mathrm{f}_{\mathrm{t}}\left[\left(1-\mathrm{n}_{\varepsilon}\right) \mathrm{d}+\mathrm{c}\right] \mathrm{B}$

$\mathrm{T}_{\mathrm{ECC}-2}=0.5 \mathrm{f}_{\mathrm{t}} \mathrm{n}_{\varepsilon} \mathrm{dB}$

$\mathrm{C}_{\mathrm{ECC}}=0.5$

$\mathrm{ft}_{\mathrm{t}}$ $\left(\frac{1}{n_{\varepsilon} d}\right)\left(\mathrm{t}_{\mathrm{s}}-\mathrm{d}-\mathrm{c}\right)^{2} \mathrm{~B}$

(2.13)

$\mathrm{T}_{\text {steel }}+\mathrm{T}_{\mathrm{ECC} 1}+\mathrm{T}_{\mathrm{ECC} 2}=\mathrm{C}_{\mathrm{ECC}}$

The $T_{\text {steel}}, f_{y-s t e e l}$ and $A_{s}$ are denoting the tensile force, yielding stress and total area of the provided steel reinforcement. The $\mathrm{T}_{\mathrm{ECC}-1}, \mathrm{~T}_{\mathrm{ECC}-2}, \mathrm{f}_{\mathrm{t}}$ and $\mathrm{C}_{\mathrm{ECC}}$ are representing the tensile forces, tensile stress and compressive force of the ECC, respectively.

The resisting moment capacity, $\mathrm{M}_{\mathrm{r}-\mathrm{ls}}$ is calculated by summing the contribution of all forces about the neutral axis and is presented in Equation 2.15. 
$M_{r-l s}=\left\{T_{\text {Steel }} d+T_{E C C-1}\left(\frac{(1-n) d+c}{2}+n d\right)+T_{E C C-2}\left(\frac{2}{3}\right) n d+C_{E C C}\left(\frac{2}{3}\right)\left(t_{s}-d-c\right)\right\}$

The selected reinforcing ratio is adjusted accordingly so that the resisting moment is greater than the applied moment. With the finalized reinforcing ratio, the adequate spacing of the longitudinal rebar is determined by Equation 2.16.

$S=\frac{A_{b a r}}{\rho t_{S}}$

where $\mathrm{S}$ represents the bar spacing, $\mathrm{A}_{\mathrm{bar}}, \rho, \mathrm{t}_{\mathrm{s}}$ represent the cross-sectional area of the selected rebar, reinforcing ratio and link slab thickness, respectively.

Further, the transition zone is designed with additional 50\% shear stud connectors in accordance with AASHTO design procedure for accounting the large shear transfer within the bridge deck and link slab interface (Qian et al. 2009).

\subsection{Engineered Cementitious Composite (ECC)}

ECC, a new generation of high performance fiber reinforced cementitious composite, has been designed with unique micro-mechanical properties for achieving a high ductility and damage tolerance under tensile and shear loading( Li \& Kanda 1998; Li 1998; Li 2003; Li et al. 2001). The major characteristic that distinguishes ECC from other types of fiber reinforced concrete (FRC) is its high tensile strain capacity of 3 to $5 \%$. The systematically engineered micromechanical parameters associated with fiber, matrix and control of interfacial properties lead to high strain hardening characteristic with multiple micro-cracking behaviors (Li 1993; Li 1998; Lin et al. 1999). A unique fracture property of ECC is attained through the careful customization and proportioning of the material such as selecting specific fiber properties (suitable strength, modulus of elasticity and aspect ratio) along with effective interfacial properties of fiber and the matrix (Li 2003). In compare to other HPFRC, a short discontinuous fiber with $2 \%$ volume is used in the ECC mix for achieving a high performance concrete for structural applications. The 
typical mixing proportion of a first generation of ECC using polyvinyl alcohol (PVA) fiber is presented in Table 2.1.

Table2.1: Typical Mix Design Proportion of ECC by Weight (Li 2003)

\begin{tabular}{|c|c|c|c|c|c|}
\hline Cement & Fly Ash & Sand & Water & HRWRA & Fiber (\%) \\
\hline 1 & 1.2 & 0.8 & 0.58 & 0.013 & 2 \\
\hline
\end{tabular}

Different types of fibers have been incorporated into ECC mixtures, but PVA fibers were found to be most effective and efficient for achieving the strain hardening characteristic after the first crack formation (Weimann \& Li 2003). The typical uniaxial tensile stress-strain curve and cracking development of the ECC at 2\% PVA fiber is presented in Figure 2.3.

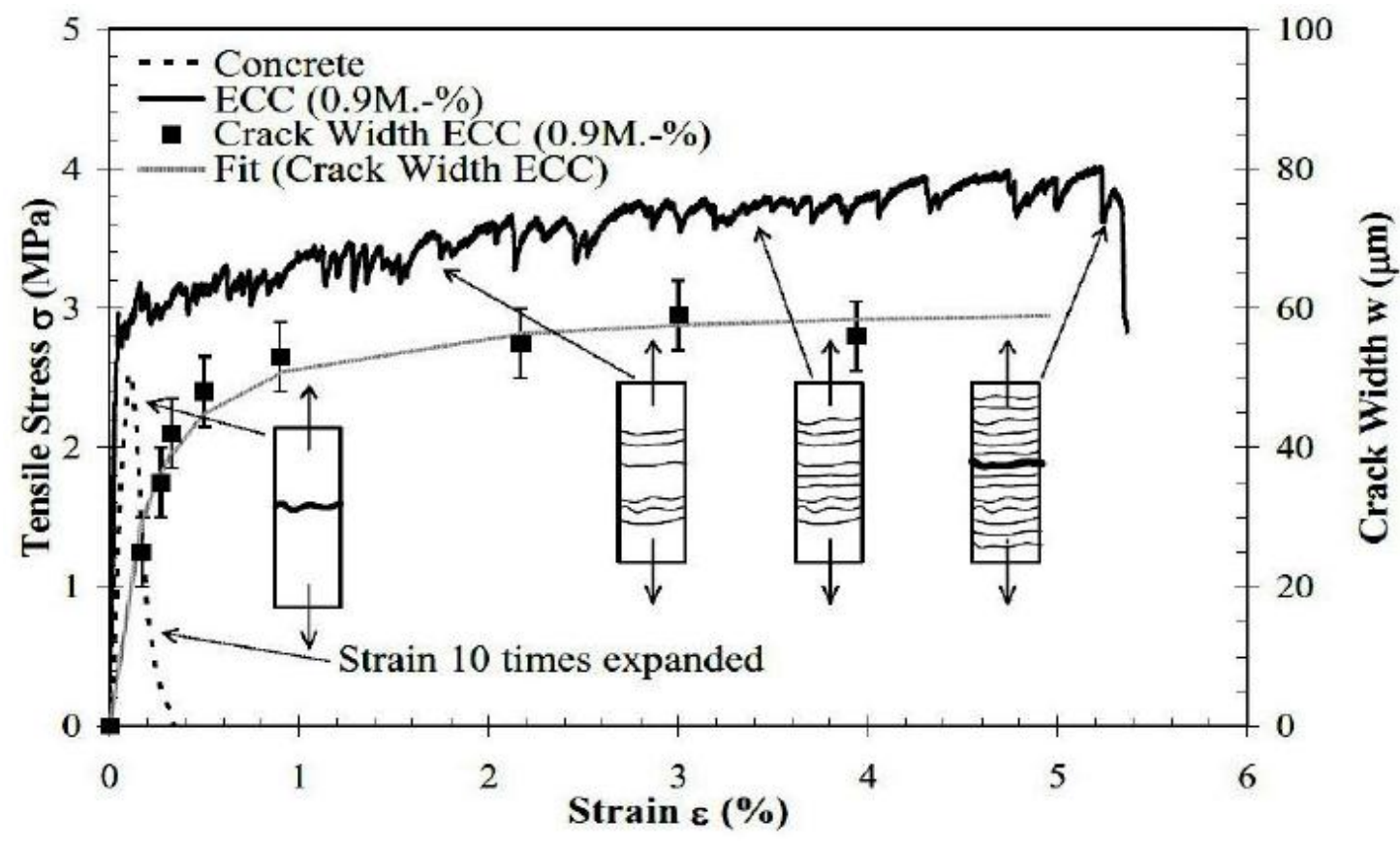

Figure2.3: Tensile Stress-Strain Curve and Crack Width Development (Weimann \& Li. 2003)

After first crack formation, ECC's tensile stress is increased further due to its unique strain hardening characteristic. The crack widths at ultimate loading are remained below $80 \mu \mathrm{m}$. The steady-state cracking behaviour is independent to the type of the loading and amount of fiber reinforcement (Özbay et al. 2013; Ranade et al. 2014). The strain hardening characteristic and 
micro-cracking behaviour are attained by the strength and fracture energy criteria proposed by Kanda and $\mathrm{Li}$ (1998). The satisfaction of the criterion will ensure the initiation of micro-cracking from initial flaw sites in the composites before the tensile loading reach the fiber bridging capacity (Kanda \& Li 1998, Yang \& Li 2006). The use of these micromechanical models for tailoring ECC material ensures the strain hardening characteristic and large bending capacity (Figure 2.4) similar to a ductile metal plate at its plastic deformation phase (Li 2011; Nawy 2008).

Using the same strength and fracture energy criteria, Sahmaran et al. (2009) further developed a greener ECC by incorporating locally available crushed sand aggregates and fly ash as a replacement of cement. Although each material influenced the mechanical and durability properties of the hardened ECC, but similar responses were attained as observed in experimental results.

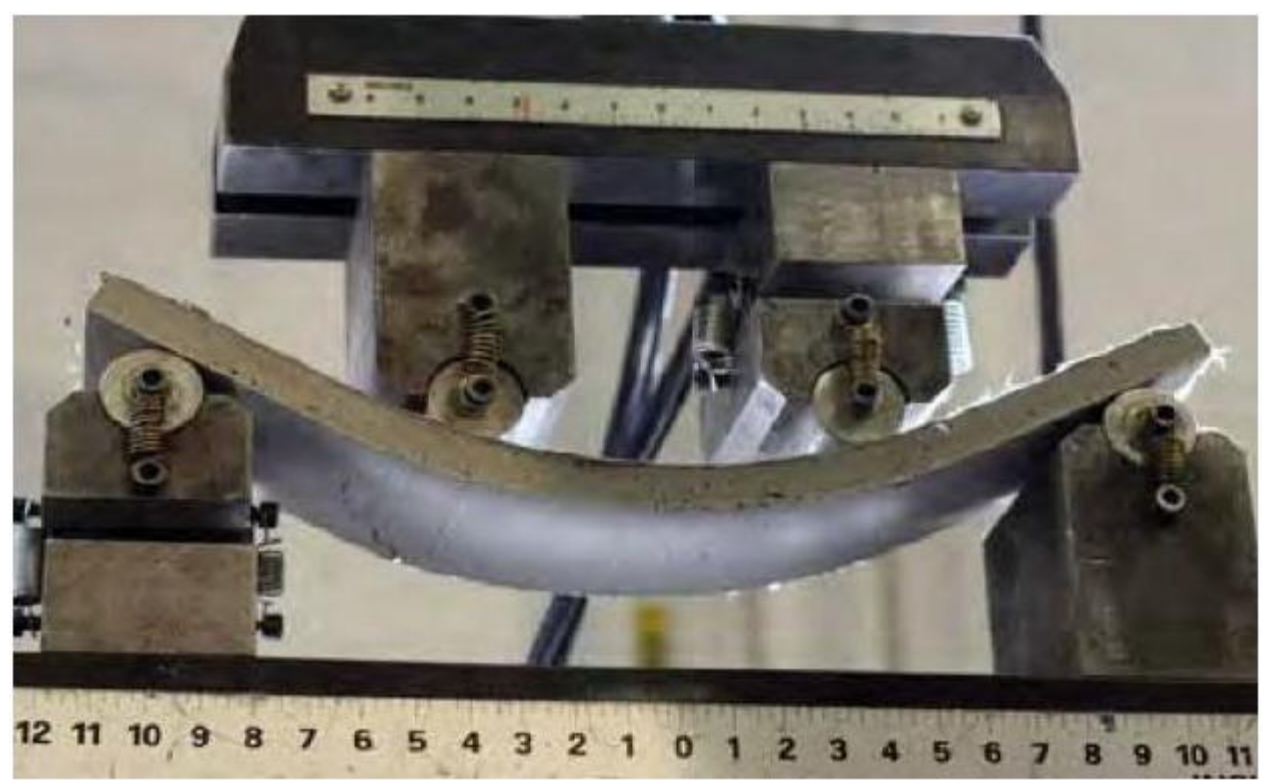

Figure2.4: Ductile Response of ECC under Flexural Loading (Li 2011)

\subsubsection{Materials for ECC}

The multiple micro-cracking behaviour and strain hardening characteristic of the ECC are mainly influenced by the proportion and behaviour of the incorporated materials. Further, with 
advancement of greener ECC, a great depth of knowledge and literature review is required to understand the fundamental role of each material for tailoring effective matrix and fiber interface for maintaining the strain hardening characteristic. The roles of fibers, fly ash replacement and influence of sand aggregates within the ECC mixes are discussed below.

\subsubsection{Role of Fibers}

The most common type of fiber used for production of ECC is Polyvinyl Alcohol (PVA) fibers at $2 \%$ volumes. The short, discontinuous PVA fiber with high tensile strength and modulus of elasticity enhance the matrix's toughness while carries tensile stresses after the first crack formation through the fiber bridging characteristic. The fiber bridging transfers the stresses across the crack for maintaining the low crack widths (JCI-DFRCC Committee 2003). The surface of the PVA fiber is oil coated (by $1.2 \%$ of mass) to tailor the interfacial properties among the fiber and matrix for strain hardening performance (Li 2003; Li et al. 2002). The oil coating reduces the interfacial bonding, while increasing the tensile strain capacity of the ECC mix, therefore under tensile stresses; the fiber tends to be ruptured rather than pull out like other FRC (Li et al. 2002). Table 2.2 summarizes the essential properties of the PVA fiber for maintaining the strain hardening characteristic of the ECC mix.

Table 2.2: Geometrical and Mechanical Properties of PVA fiber

\begin{tabular}{|c|c|c|c|}
\hline Diameter $(\mu \mathrm{m})$ & Length $(\mathrm{mm})$ & $\begin{array}{c}\text { Nominal Strength } \\
(\mathrm{MPa})\end{array}$ & $\begin{array}{c}\text { Modulus of } \\
\text { Elasticity }(\mathrm{GPa})\end{array}$ \\
\hline 39 & 6 to 12 & 1620 & 42.8 \\
\hline
\end{tabular}

\subsubsection{Fly Ash}

Fly ash has been incorporated into ECC mixtures at different replacement rate of the cementing material. Fly ash is a fine powder (typically 20 to $50 \mu \mathrm{m}$ in size) produced through the byproduct of pulverized coal blown into a fire furnace at a power generating plant. The chemical compositions similar to the cementing material with much higher surface area typically between 250-600 $\mathrm{m}^{2} / \mathrm{kg}$ allows a better reaction with calcium hydroxide (Kosmatka \& Panarese 1988; Neville 2002). The use of fly ash in the ECC mix leads to reduction of interfacial bonding among 
the PVA fiber and the matrix while increasing the frictional bonding among them (Wang \& Li 2007; Sahmaran et al. 2009; Peled \& Shah 2003). These characteristic are responsible for the tight crack width, improved ductility, durability and sustainability of the ECC mix (Yang et al. 2007; Bisaillon et al. 1994; Hussian \& Rasheeduzzafar 1994; Kuroda et al. 2000; Lepech \& Li 2005b; Karahan et al. 2012).

Depending on the type, physical and chemical composition of the fly ashes, the characteristic and performance within the mix could influence the mechanical properties. According to American Society for Testing and Materials (ASTM), there are two classes of the fly ashes. There is class $\mathrm{C}$ fly ash with a high calcium content and class $\mathrm{F}$ with lower calcium content. The high calcium content of class $\mathrm{C}$ allows a self-hardening process of the mix without the presence of any cement (ASTM C618 2012). The specification for fly ashes in accordance to ASTM C618 is presented in Table 2.3.

Table 2.3: Specifications for Fly Ash

\begin{tabular}{|c|c|}
\hline Class of Fly Ash & ASTM Specification \\
\hline Class C & $\mathrm{SiO}_{2}+\mathrm{Al}_{2} \mathrm{O}_{3}+\mathrm{Fe}_{2} \mathrm{O}_{3}>50 \%$ \\
\hline Class F & $\mathrm{SiO}_{2}+\mathrm{Al}_{2} \mathrm{O}_{3}+\mathrm{Fe}_{2} \mathrm{O}_{3}>70 \%$ \\
\hline
\end{tabular}

\subsubsection{Role of Aggregates}

The aggregate type and size plays a significant role for fiber dispersion within the ECC mix to obtain a strain hardening and micro-cracking behaviour. The uniform fiber dispersion becomes more difficult with increasing maximum aggregate size. The clumping and interaction of fibers would occur at higher volume and maximum aggregate size and simultaneously the increase in interface toughness reduces the ductility of the ECC mix (Sahmaran et al. 2009). As a result, the standard ECC incorporates micro-silica sand (maximum size of $110 \mu \mathrm{m}$ ) with an aggregate to binder ratio of 0.36 to maintain adequate stiffness and volume stability (Li et al. 1995). Researches revealed that using crushed sand with maximum aggregate size of $1.19 \mathrm{~mm}$ did not significantly influence the fiber dispersion and similar ductility responses and strain hardening characteristic of using micro-silica sand were attained (Sahmaran et al. 2009; Maulin 2012; Sherir 2012). 


\subsubsection{Mechanical Properties}

\subsubsection{Compressive Strength}

ECC exhibits a similar compressive strength as high performance concrete (HPC), typically ranging from 40 to $60 \mathrm{MPa}$ depending to the mix design parameters (Sherir 2012; Hossain \& Sherir 2014). While a low young's modulus of $20.4 \mathrm{GPa}$ is employed, a linear behaviour under compression prior to failure similar to HPC is attained (Wang \& Li 2003).

The compressive strength of the ECC mix is reduced at higher fly ash content due to slow reactivity and development of hydration products at initial early ages (Hossain \& Sherir 2014; Mindess et al. 2003). The compressive strength of the ECC mix is improved by using larger sand aggregates such as crushed sand. The increase in maximum size results as a higher volume and dense interfacial transition zone among the sand particle and the matrix (Hossain \& Sherir 2014; Mehta \& Monteiro 2006).

\subsubsection{Flexural Strength}

The unique micro-structure of the ECC allows a high tensile strain capacity with multi microcracking and strain hardening characteristic (Li 2011). Based on the mix design parameters, the flexural strength of the ECC varies from 5 to $16 \mathrm{MPa}$ (Wang \& $\mathrm{Li} 2003$ ).

Through extensive experimental investigations, it was confirmed that flexural strength of the ECC is reduced with increasing fly ash content due to reduced interface toughness among the PVA and the mortar, while the bending capacity is enhanced with improved frictional bonding. Using larger sand aggregates such as mortar or crushed sand, improved the flexural strength capacity, whereas the ductility was reduced due to increased interface toughness (Hossain \& Sherir 2014; Sahmaran et al. 2009; Li et al. 1995). Figure 2.5 illustrates the typical flexural strength response of a green ECC mix with high volume of fly ash at replacement levels of 55\% and $70 \%$. 


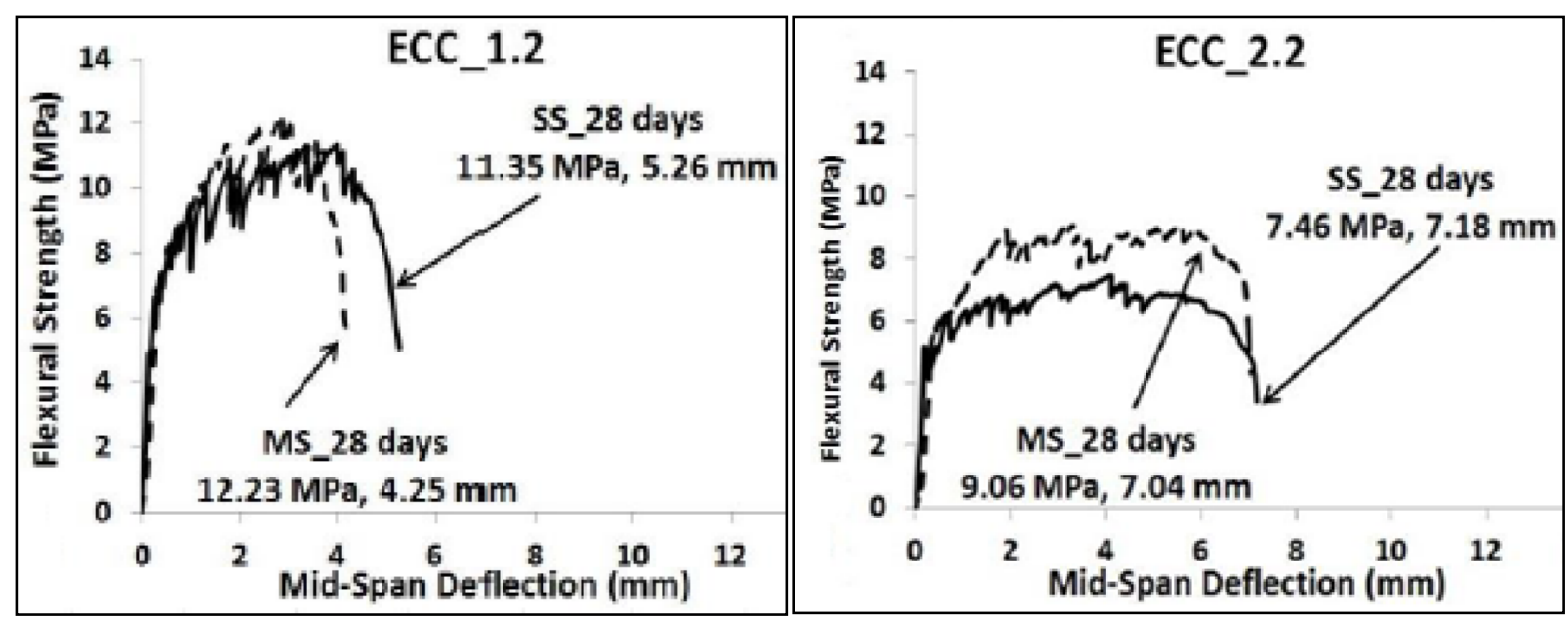

Figure 2.5: Typical Flexural Strength-Mid Span Deflection of Green ECC (Hossain \& Sherir 2014)

\subsubsection{Fatigue Flexure}

Many scholars have investigated the durability and mechanical properties and failure mechanism of the ECC subjected to monotonic loading. However few studies have been conducted on the flexural fatigue performance and failure mechanism of the ECC mix. The fatigue flexure behaviour of ECC is important for its application in bridge structures.

Matsumoto (1998) investigated the flexural fatigue performance of the polyethylene fiber based ECC (PE-ECC) and normal concrete by their failure modes, associated failure mechanism and fatigue strength life cycle analysis ( $\mathrm{SN}$-curve). The test results revealed that unlike normal concrete, PE -ECC formed multiple micro-cracking under fatigue loading until the fibers were ruptured to their ultimate strength. Due to the lack of experimental data, Matsumoto was not able to develop a S-N curve, predicting the life cycle analysis of the ECC mix. Zhang and Li (2002) explored the performance of the ECC/concrete overlay within the rigid pavement subjected to constant fatigue stress induced by truck loading. The flexural fatigue test monitoring confirmed that ECC overlay improved the strength and deformability capacity, at least double the concrete over concrete overlay.

Suthiwarapirak et al. (2004) conducted experimental research on the fatigue performance of shotcreted PVA-ECC repairing material. Similar to PE-ECC, multiple micro-cracking was observed until the fibers were ruptured. The test results demonstrate a bilinear function stress life 
relationship (SN-curve) with similar response, shape and mode of failure close to metal fatigue fracture.

Sherir (2012) performed an extensive flexural fatigue testing on different ECC specimens, incorporating $70 \%$ fly ash content and use of fine aggregates of micro-silica and crushed sand. He adopted two different approaches; variable fatigue stress level (40\%, 55\% and 70\%) and different fatigue cycles (100000, 200000, 300000, 1 million) for investigating the flexural fatigue performance of ECC mixtures. The experimental investigation revealed that mid-span deflection evolution, number of micro-cracking and damage level was significantly increased at higher fatigue stress levels and cycles. For both approaches, the damage level was higher for silica-sand based ECC in compare to crushed sand. It is found that fly ash behaved as a filler material instead of hydrating products with larger sand aggregate size. Therefore, the densification of the matrix improved the flexural fatigue performance of the crushed sand based ECC.

\subsection{Summary}

Extensive experimental investigation have been performed on material properties of ECC mix incorporating locally available sands and fly ashes for tailoring enhanced mechanical and durability properties similar to HPC. With extensive material engineering, there is a lack of experimental validation of using green ECC mixtures in structural applications such as link slabs for joint free bridge deck structures. For more than a decade different scholars have performed theoretical and experimental investigations on structural and durability performance of link slab by varying geometrical dimensions and using normal concrete and traditional ECC mix. Limited equations were proposed for designing a link slab based on the field demonstration of the ECC link slab in State of Michigan. However, there is a lack of experimental results for tailoring the optimized green ECC mix and developing design equations for the fatigue performance of the link slab. 


\section{CHAPTER THREE EXPERIMENTAL PROGRAM}

\subsection{Introduction}

An extensive experimental program has been planned for studying the structural performance of the link slabs subjected to monotonic static and flexural fatigue loading. Seven types of ECC mixtures with different types/dosage of fly ash and sand aggregates were used to construct $1 / 4^{\text {th }}$ scale model link slab specimens. For a comparative structural performance evaluation, link slab specimens made with a ready-mix SCC were also constructed and tested under static and flexural fatigue loading conditions. In addition, a $1 / 6^{\text {th }}$ scale full joint-free bridge model having two simply supported spans connected together with ECC link slab was also tested under monotonic loading up to the service load.

This chapter describes full details of the experimental investigations on $1 / 4^{\text {th }}$ scale link slab specimens and $1 / 6^{\text {th }}$ scale joint-free full bridge with ECC link slab illustrating materials used for ECC/SCC mix designs, geometric dimensions of link slabs/full bridge specimens, design of link slabs/full bridge, casting and curing of specimens, testing scheme, instrumentation of specimens, test set-up, testing procedure, ECC/SCC properties and steel properties. This chapter also describes the design of link slab and full bridge specimens and calculation procedures of moment resistance of link slab and full bridge model specimens based on theoretical and design specifications.

\subsection{Design of Link Slabs and Full Bridge Models and Geometric Dimensioning Details}

The design of the link slabs and full bridge model specimens was conducted as per Caner and Zia (1998). The typical deformed shape and moment distribution due to the applied loading for a two span simply supported bridge structure with a link slab is schematically represented in Figure 3.1. Flexural crack formations were expected at the top of the link slab due to the development of tensile stresses. The link slab section is designed between the points of inflections. Based on the stiffness of the link slab, the location of the inflection points varies from 0 to $20 \%$ of the adjacent span's length (Kim et al. 2004; Caner \& Zia, 1998). 


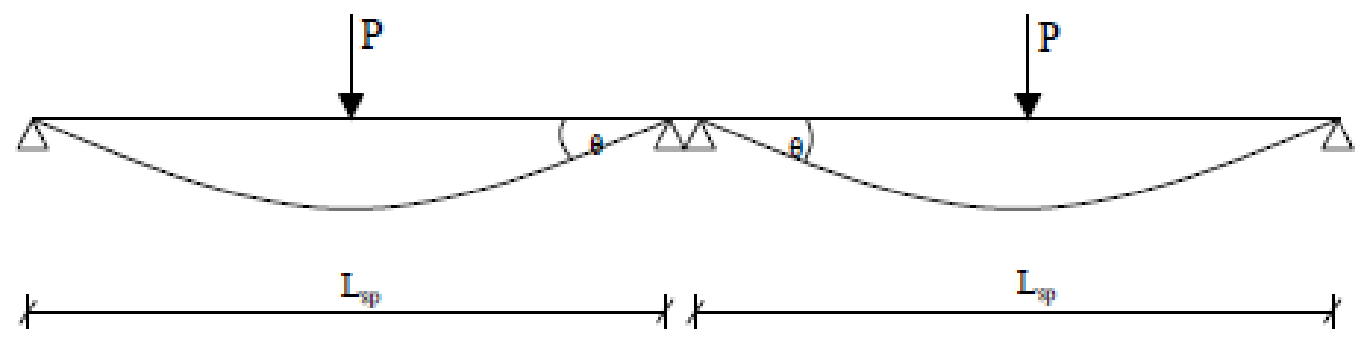

(a) Deformed Shape of the bridge

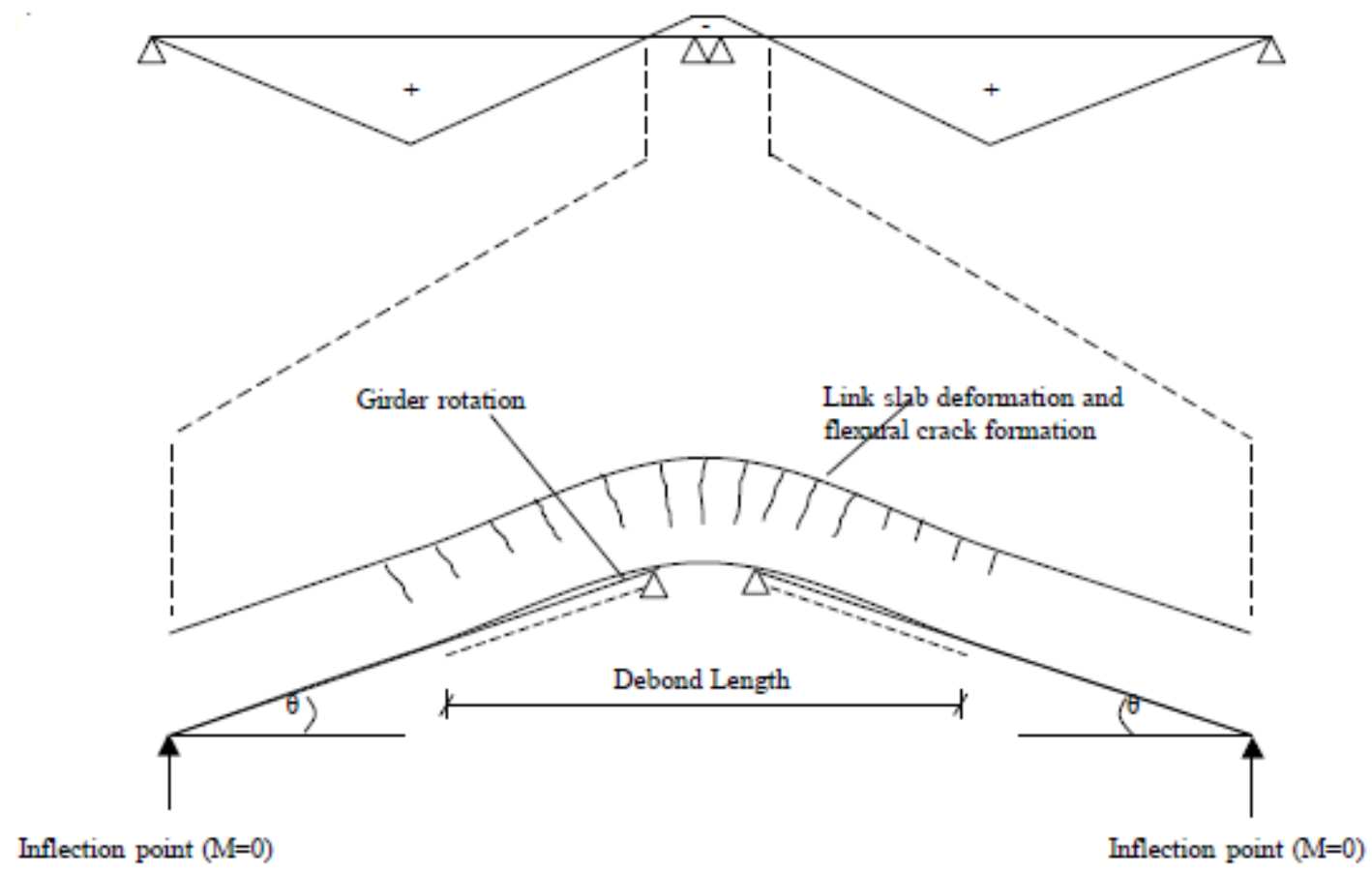

(b) Moment Distribution and flexural crack formation on link slab

Figure3.1: Two Span Bridge Deformation with Focus on Link Slab Section (Kim et al. 2004)

\subsubsection{One Fourth Scale Link Slab Design and Configurations}

The model was focused on the link slab section within the inflection points as shown in Figure 3.1. The location of inflection points (length of the link slab) based on the stiffness of the section (ECC and the steel rebar) was determined as 6.5\% of the adjacent span's length. The summary of the link slab specimen's configurations, reinforcement detailing and concrete mixtures are presented in Table 3.1. Overall, the total length of the link slab for the 1/4th scale model was 810 $\mathrm{mm}$ as shown Figure 3.2 and Table 3.1. The length of the debonding zone based on the proposed 
design guidelines by Caner and Zia (1998), was set as 5\% of simple spans - a total length of 330 $\mathrm{mm}$. The length of the transition zone with additional 50\% shear stud connector (total of 16 studs) was selected as $300 \mathrm{~mm}$ following Qian et al. (2009). The cross-sectional dimensions for the 1/4th link slab models were $175 \mathrm{~mm}$ in width and $60 \mathrm{~mm}$ in depth. A minimum longitudinal steel reinforcing ratio of $1.1 \%$ (three $6 \mathrm{~mm}$ bars) were provided for maintaining a low structural stiffness of the link slab. Additional transverse reinforcements at $210 \mathrm{~mm} \mathrm{c} / \mathrm{c}$ spacing were provided using $6 \mathrm{~mm}$ bars (Figure 3.2 and Table 3.1). In total 13 link slab specimens were cast - 9 specimens for monotonic and 4 specimens for flexural fatigue testing. The link slab designation shown in Table 3.1 has two parts: First Part "LS-*" represents specimen number and the second part such as "ECC-**-**_**" or "concrete type-fly ash type - \% of fly ash as cement replacement-type of sand" represents concrete mixture that is used in the debonding zone. For Example: ECC-CI-1.2-SS where ECC means engineered cementitious composite, CI means class of fly ash, 1.2 represents 55\% cement replacement by fly ash and SS means silica sand. 
Table3.1: Link Slab Specimens Configuration Subjected to Monotonic and Fatigue Loading

\begin{tabular}{|c|c|c|c|c|c|c|c|c|c|c|}
\hline \multicolumn{2}{|c|}{ Link Slab Designation } & $\begin{array}{l}\text { Length } \\
(\mathrm{mm})\end{array}$ & \multicolumn{2}{|c|}{$\begin{array}{l}\text { Debonding } \\
\text { Zone Length } \\
5 \%(\mathrm{~mm})\end{array}$} & \multicolumn{2}{|c|}{$\begin{array}{l}\text { Transition } \\
\text { Zone Length } \\
2.5 \%(\mathrm{~mm})\end{array}$} & \multicolumn{2}{|c|}{$\begin{array}{l}\text { Concrete } \\
\text { in } \\
\text { Transition } \\
\text { Zone }\end{array}$} & \multicolumn{2}{|c|}{$\begin{array}{c}\text { Concrete in Debonding } \\
\text { Zone }\end{array}$} \\
\hline \multicolumn{11}{|c|}{ Tests under monotonic loading 1/4 Scale Link Slab } \\
\hline \multicolumn{2}{|c|}{ LS2-ECC-CI-1.2-SS } & 810 & \multicolumn{2}{|c|}{330} & \multicolumn{2}{|c|}{150} & \multicolumn{2}{|c|}{ SCC } & \multicolumn{2}{|c|}{ ECC-CI-1.2-SS } \\
\hline \multicolumn{2}{|c|}{ LS3-ECC-F-2.2-SS } & 810 & \multicolumn{2}{|l|}{330} & \multicolumn{2}{|c|}{150} & \multicolumn{2}{|c|}{ SCC } & \multicolumn{2}{|c|}{ ECC-F-2.2-SS } \\
\hline \multicolumn{2}{|c|}{ LS4-ECC-F-1.2-SS } & 810 & \multicolumn{2}{|l|}{330} & \multicolumn{2}{|c|}{150} & \multicolumn{2}{|c|}{ SCC } & \multicolumn{2}{|c|}{ ECC-F-1.2-SS } \\
\hline \multicolumn{2}{|c|}{ LS6-ECC-F-2.2-CS } & 810 & \multicolumn{2}{|l|}{330} & \multicolumn{2}{|c|}{150} & \multicolumn{2}{|c|}{$\overline{\mathrm{SCC}}$} & \multicolumn{2}{|c|}{ ECC-F-2.2-CS } \\
\hline \multicolumn{2}{|c|}{ LS10-ECC-CI-2.2-SS } & 810 & \multicolumn{2}{|l|}{330} & \multicolumn{2}{|c|}{150} & & SCC & ECC-C & $2.2-\mathrm{SS}$ \\
\hline LS11-ECC-C & $2-\mathrm{CS}$ & 810 & 330 & & 15 & & & SCC & $\overline{\mathrm{ECC}-\mathrm{Cl}}$ & $2.2-\mathrm{CS}$ \\
\hline LS28-ECC-C & $.2-\mathrm{MS}$ & 810 & 330 & & 15 & & & $\mathrm{SCC}$ & ECC-CI & $.2-\mathrm{MS}$ \\
\hline LS25-S & & 810 & 330 & & 15 & & & $\overline{\mathrm{SCC}}$ & $\mathrm{SC}$ & \\
\hline LS32-S & & 810 & \begin{tabular}{l|l|} 
& 330 \\
\end{tabular} & & 15 & & & SCC & $\mathrm{SC}$ & \\
\hline & & Test un & der Fatigue lo & ading & $\mathrm{g}-1 / 4 \mathrm{Sc}$ & le Link & Slab & & & \\
\hline $\begin{array}{l}\text { Link Slab } \\
\text { Designation }\end{array}$ & $\begin{array}{l}\text { Length } \\
(\mathrm{mm})\end{array}$ & $\begin{array}{l}\text { Debond } \\
\text { Zone } \\
\text { Length } \\
2.5 \% \\
(\mathrm{~mm})\end{array}$ & $\begin{array}{l}\text { Transition } \\
\text { Zone } \\
\text { Length 5\% } \\
\text { (mm) }\end{array}$ & & $\begin{array}{l}\text { oncrete } \\
\text { in } \\
\text { ansition } \\
\text { zone }\end{array}$ & $\begin{array}{l}\text { Concr } \\
\text { in } \\
\text { Debo } \\
\text { zon }\end{array}$ & & $\begin{array}{l}\text { Number } \\
\text { of Cycle }\end{array}$ & $\begin{array}{l}\text { Mean } \\
\text { Fatigue } \\
\text { Stress } \\
\text { Level } \\
(\%)\end{array}$ & $\begin{array}{c}\text { Fatigue } \\
\text { Stress } \\
\text { Range } \\
(\%)\end{array}$ \\
\hline $\begin{array}{c}\text { LS29-ECC-CI- } \\
1.2-\mathrm{MS}\end{array}$ & 810 & 330 & 150 & & SCC & $\begin{aligned} \text { ECC- } \\
1.2-\mathrm{N}\end{aligned}$ & & 400,000 & 40 & \pm 20 \\
\hline $\begin{array}{c}\text { LS30-ECC-CI- } \\
1.2-\mathrm{MS}\end{array}$ & 810 & 330 & 150 & & SCC & $\begin{aligned} \text { ECC- } \\
1.2-\mathrm{N}\end{aligned}$ & & 400,000 & 55 & \pm 20 \\
\hline $\begin{array}{c}\text { LS31-ECC-CI- } \\
\text { 1.2-MS } \\
\end{array}$ & 810 & 330 & 150 & & SCC & $\begin{aligned} \text { ECC- } \\
1.2-\mathrm{N} \\
\end{aligned}$ & & $\begin{array}{c}1 \\
\text { million } \\
\end{array}$ & 40 & \pm 20 \\
\hline LS33-SCC & 810 & 330 & 150 & & SCC & $\mathrm{SCC}$ & & 400,000 & 40 & \pm 5 \\
\hline
\end{tabular}




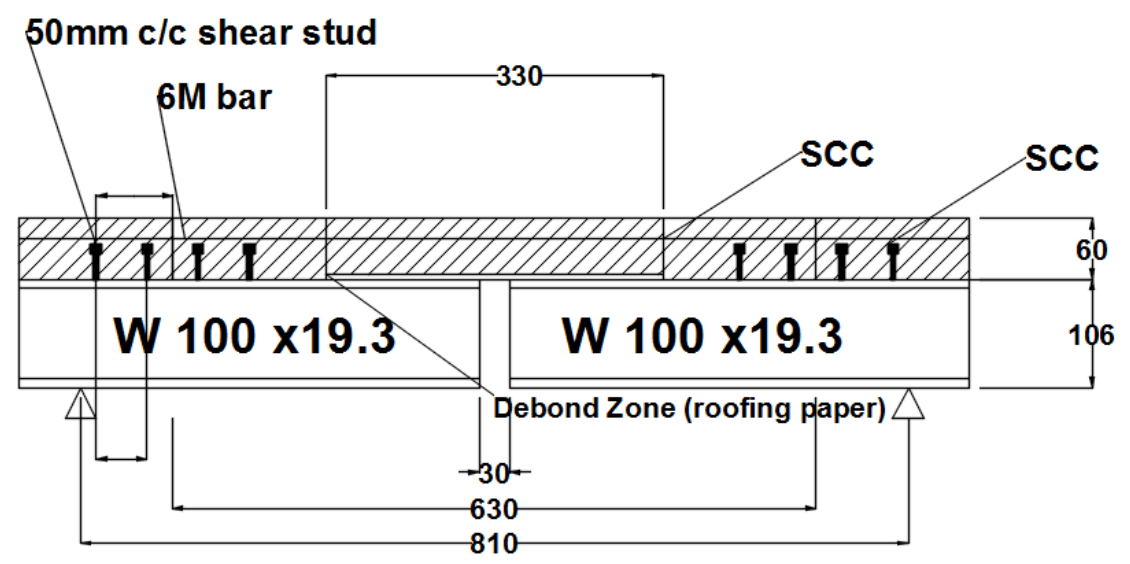

(a) SCC Link Slab

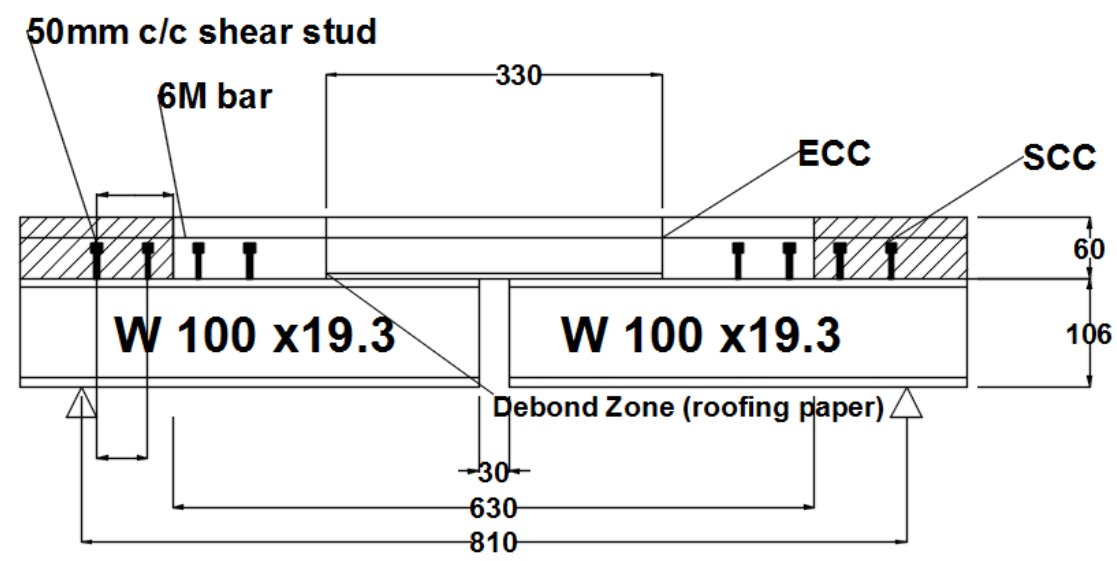

(b) ECC Link Slab

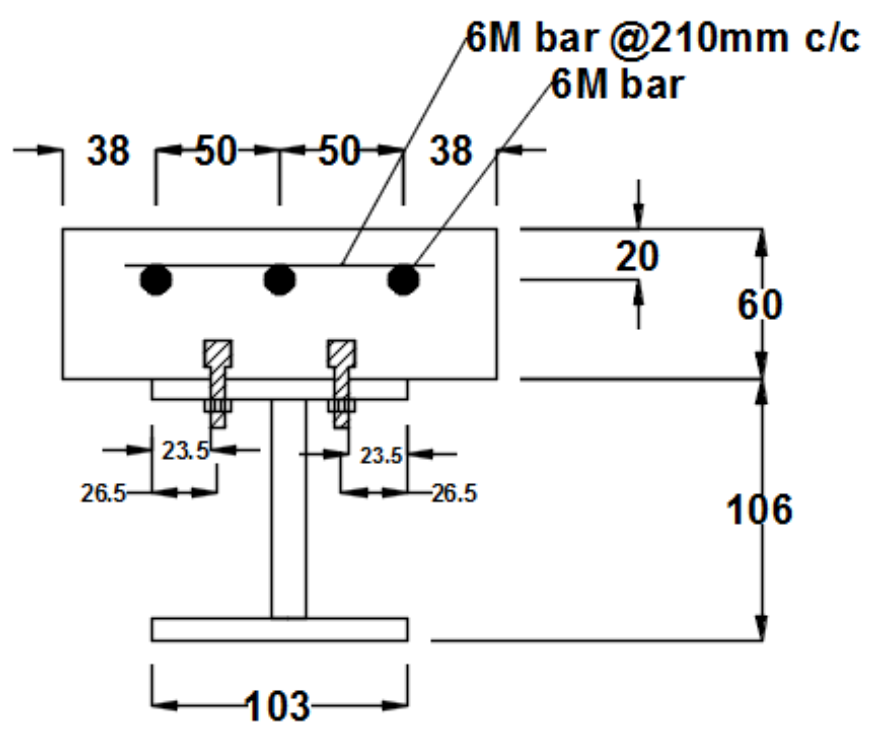

(c) Link Slab Cross-Section

Figure 3.2: Geometry and Reinforcement Details of Link Slab (Dimensions in mm) 


\subsubsection{One Sixth Scale Full Bridge Specimen}

The $1 / 6^{\text {th }}$ scale full bridge model consists of two simply supported composite spans (Span 1 and Span 2: made of steel I-beam and concrete decking connected through shear studs) with connecting ECC link slab. The two simply supported bridge spans are denoted as SP1-SCC and SP2-SCC, and the connecting ECC link slab is designated as LS-ECC. The dimensions, reinforcement detailing and selected mixtures for each segment of the full bridge model are presented in Table 3.2.

Table 3.2: Geometric Properties and Reinforcement Detailing for Each Segment of Full Bridge Model

\begin{tabular}{|c|c|c|c|c|c|c|c|}
\hline Section & $\begin{array}{c}\text { Length } \\
(\mathrm{mm})\end{array}$ & $\begin{array}{c}\text { Debond } \\
\text { Zone } \\
\text { Length } \\
5 \%\end{array}$ & $\begin{array}{c}\text { Transition } \\
\text { Zone } \\
\text { Length } \\
2.5 \%\end{array}$ & Concrete \\
$(\mathrm{mm})$ & $\begin{array}{c}\text { Longitudinal } \\
\text { Reinforcing } \\
\text { Ratio }\end{array}$ & $\begin{array}{c}\text { Number } \\
\text { of } 10 \mathrm{M} \\
\text { shear Stud }\end{array}$ & $\begin{array}{c}\text { Center to } \\
\text { center Shear } \\
\text { Stud } \\
\text { Spacing } \\
(\mathrm{mm})\end{array}$ \\
\hline SP1-SCC & 1000 & 0 & 0 & SCC & 0.01 & 24 & 75 \\
\hline LS-ECC & & 240 & 100 & ECC-CI-1.2-MS & 0.01 & 8 & 45 \\
\hline SP2-SCC & 1000 & 0 & 0 & SCC & 0.01 & 24 & 75 \\
\hline
\end{tabular}

The $1 / 6^{\text {th }}$ scale full bridge model was $300 \mathrm{~mm}$ in width and $55 \mathrm{~mm}$ in depth with overall length of $2190 \mathrm{~mm}$. The simply supported adjacent SCC spans (SP1-SCC \& SP2-SCC) were designed in accordance to Canadian Highway Bridge Design Code (CHBDC, 2006). The code requires a minimum longitudinal reinforcing ratio of 0.01 , therefore the minimum ratio was provided at the bottom of the SCC segments (with $19 \mathrm{~mm}$ clear cover) due to the development of positive bending moment. Mechanical shear studs (10 $\mathrm{mm}$ in diameter) were provided at $75 \mathrm{~mm}$ center to center spacing for maintaining the composite actions of the SCC with the steel girder in accordance to CHBDC (2006). The equations based on CHBDC guidelines for shear stud capacity are presented in Equations 3.1 to 3.3. 
Minimum $\left\{\mathrm{P}=\emptyset_{s} A_{s} F_{y} \quad\right.$ and $\left.\mathrm{P}=0.85 \emptyset_{c} f_{c} \mathrm{~B} t_{c}+\emptyset_{r} A_{r} F_{y} \quad\right\}$

Minimum $\left\{q_{r}=0.5 \emptyset_{s c} A_{s c} \sqrt{f_{c} E_{c}}\right.$ and $\left.q_{r}=\emptyset_{s c} A_{s c} \quad F_{u}\right\}$

$\mathrm{N}=\mathrm{P} / \mathrm{q}_{\mathrm{r}}$

where P represents the applied shear force at the interface; $A_{s}, F_{y}, \phi_{s}$ denote cross-sectional area of steel girder, yielding stress and factor of safety (0.95), respectively; $B, t_{c}, f_{c}, \phi_{c}$ symbolize width, thickness, compressive stress, and factor of safety for the concrete deck, respectively; $A_{r}$, $\mathrm{F}_{\mathrm{y}}, \phi_{\mathrm{r}}$ denote the steel reinforcing area, reinforcement yielding stress and factor of safety for the rebar, respectively; $\mathrm{q}_{\mathrm{r}}$ denotes the capacity of one shear stud; $\mathrm{A}_{\mathrm{sc}}, \mathrm{F}_{\mathrm{u}}, \phi_{\mathrm{sc}}$ are symbolizing the cross sectional area of one stud, the ultimate tensile resistance of one stud and resisting factor of 0.85 , respectively; $\mathrm{N}$ represents the total number of required shear stud.

The ECC link slab connecting the simply supported SCC decks were designed in accordance to the design guide proposed by Lepech and $\mathrm{Li}$ (2009). The total length of the ECC link slab was $7.5 \%$ of the adjacent SCC spans, in total of $340 \mathrm{~mm}$ (Equation 2.4). The length of the debonding zone, similar to pervious link slab specimens, was set as $5 \%$ of simply supported spans; a total length of $240 \mathrm{~mm}$ (Equation 2.5). The total length of the transition zone based on Lepech and $\mathrm{Li}$ (2009) was $100 \mathrm{~mm}$ (2.5\% of adjacent spans). A minimum longitudinal steel reinforcing ratio of $1.1 \%(4,6 \mathrm{~mm}$ bars) was provided for maintaining a low structural stiffness of the link slab, while resisting the developed negative moment due to the applied loading. Additional transverse reinforcements were provided at $130 \mathrm{~mm} \mathrm{c} / \mathrm{c}$ spacing using $6 \mathrm{~mm}$ bars. The schematic representation of the $1 / 6^{\text {th }}$ scale full bridge model, including geometric dimensioning, reinforcement detailing and concrete mixtures are presented in Figure 3.3. 


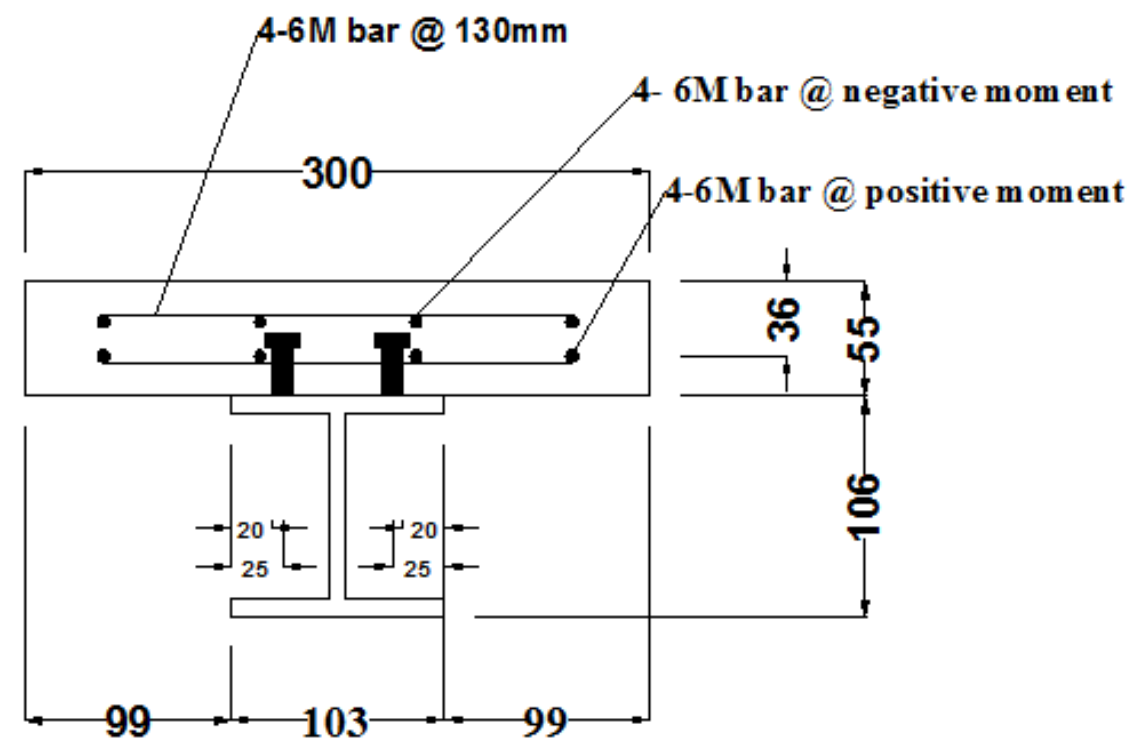

(a) Cross-sectional View

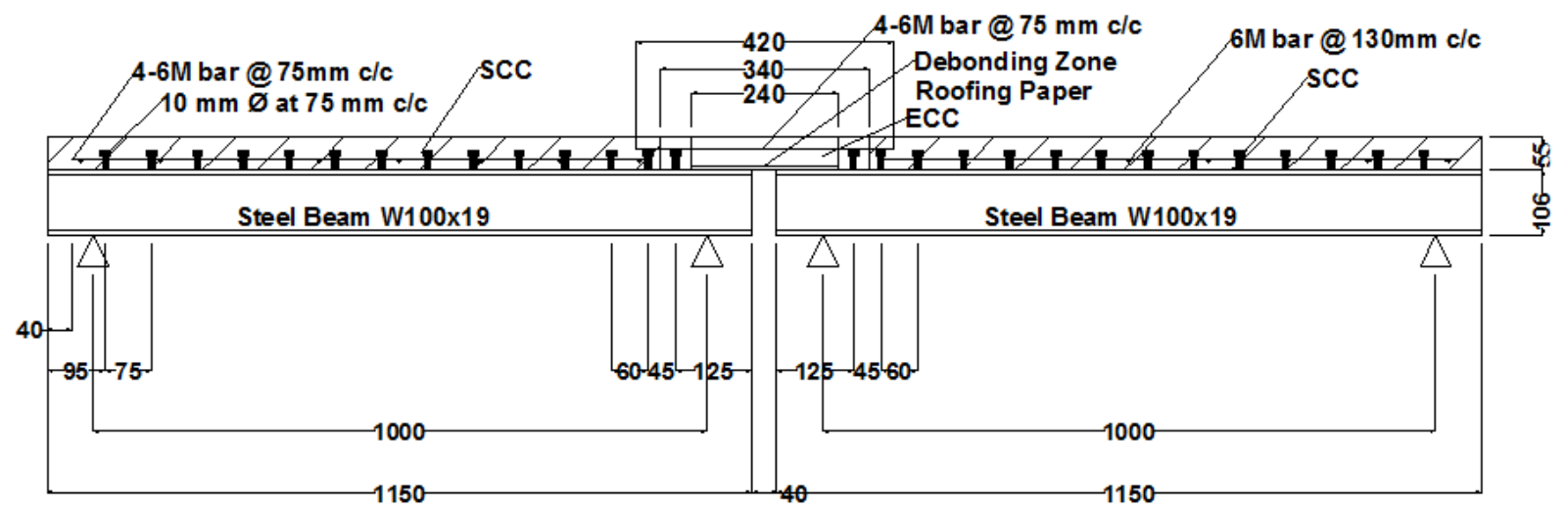

(b) Elevation View

Figure 3.3: Geometry and Reinforcement Details of Full Bridge (Dimensions in mm)

\subsection{Material and Properties}

Seven ECC mixtures and one ready mix SCC mix were used for the deck construction of the scaled down link slabs and full bridge specimen. Seven ECC mixtures were designed by incorporating different types/dosage of fly ash (class CI and F with 55\% (1.2) and 70\% (2.2) cement replacements) and different sand aggregates (crushed sand 'CS', silica sand 'SS' and mortar sand 'MS') were used for construction of link slabs. The SCC mixture was a commercial 
ready mix having $10 \mathrm{~mm}$ maximum size coarse aggregates. For both models a W100 x19 steel structural section in accordance to Canadian Institute of Steel Construction (CISC) (2010) was used as a supporting girders. The reinforcing steel bars were $6 \mathrm{~mm}$ in diameter with a mean yield and ultimate strength of $407 \mathrm{MPa}, 550 \mathrm{MPa}$ and $224 \mathrm{GPa}$, respectively.

\subsubsection{Engineered Cementitious Composites}

Seven ECC mixtures incorporating different types/dosage of fly ash and sand aggregates were developed at Ryerson University over the last 5 years. The mix designs of the ECC mixtures are presented in Table 3.3.

Table 3.3: ECC Mix Design Proportions

\begin{tabular}{|c|c|c|c|c|c|c|c|}
\hline & \multicolumn{7}{|c|}{ Micro-Silica Sand } \\
\hline & \multicolumn{7}{|c|}{ Ingredients per weight of cement } \\
\hline Mixture ID & Water & Cement & FA & Sand & PVA & HRWRA & $\mathrm{W} / \mathrm{b}^{*}$ \\
\hline LS2-ECC-CI-1.2-SS & 0.581 & 1 & 1.2 & 0.798 & 0.045 & 0.009 & 0.27 \\
\hline LS3-ECC-F-2.2-SS & 0.847 & 1 & 2.2 & 1.160 & 0.067 & 0.010 & 0.27 \\
\hline LS4-ECC-F-1.2-SS & 0.581 & 1 & 1.2 & 0.798 & 0.045 & 0.009 & 0.27 \\
\hline LS10-ECC-CI-2.2-SS & 0.847 & 1 & 2.2 & 1.160 & 0.067 & 0.010 & 0.27 \\
\hline \multicolumn{8}{|c|}{ Crushed Sand } \\
\hline LS6-ECC-F-2.2-CS & 0.848 & 1 & 2.2 & 1.159 & 0.069 & 0.010 & 0.27 \\
\hline LS11-ECC-CI-2.2-CS & 0.848 & 1 & 2.2 & 1.159 & 0.069 & 0.010 & 0.27 \\
\hline \multicolumn{8}{|c|}{ Mortar Sand } \\
\hline LS28-ECC-CI-1.2-MS & 0.585 & 1 & 1.2 & 0.798 & 0.046 & 0.009 & 0.27 \\
\hline
\end{tabular}

* W/b- Water to binder ratio; PVA: poly vinyl alcohol fiber, FA: fly ash, 
The cement used for all 7 ECC mixtures was Type GU Portland cement. The fly ashes of class F and class CI conforming to the ASTM C618 (2012) were used. The chemical and physical properties of the Portland cement and fly ashes are presented in Table 3.4. For maintaining the strain hardening characteristic of the ECC mixtures, micro-silica, crushed and mortar sand were used with maximum aggregate sizes of $110 \mu \mathrm{m}, 1.18 \mathrm{~mm}$ and $1.18 \mathrm{~mm}$, respectively. The PVA fibers used for ECC mixes were $39 \mu \mathrm{m}$ in diameter and $8 \mathrm{~mm}$ in length with a tensile strength capacity of $1600 \mathrm{MPa}$. For improvement of workability, the polycarboxylic-ether type highrange water-reducing admixture (HRWRA) with $30 \%$ of solid content was used for all 7 ECC mixtures.

Table 3.4: Physical and Chemical Properties of Portland cement, fly ash F and CI

\begin{tabular}{|c|c|c|c|}
\hline \multicolumn{4}{|c|}{ Chemical Properties } \\
\hline Compositions & Cement & Fly Ash F & Fly Ash CI \\
\hline $\operatorname{Sum}\left(\mathrm{SiO}_{2}+\mathrm{Al}_{2} \mathrm{O}_{3}+\mathrm{Fe}_{2} \mathrm{O}_{3}\right)$ & 27.6 & 85.6 & 76.12 \\
\hline $\mathrm{SiO}_{2}(\%)$ & 19.6 & 59.5 & 41.57 \\
\hline $\mathrm{Al}_{2} \mathrm{O}_{3}(\%)$ & 4.9 & 22.2 & 26.11 \\
\hline $\mathrm{Fe}_{2} \mathrm{O}_{3}(\%)$ & 3.1 & 3.9 & 8.44 \\
\hline $\mathrm{CaO}(\%)$ & 61.4 & 5.57 & 14.3 \\
\hline $\mathrm{MgO}(\%)$ & 3 & - & 3.4 \\
\hline $\mathrm{SO}_{3}(\%)$ & 3.6 & 0.19 & 1.55 \\
\hline Alkalis as $\mathrm{Na} 2 \mathrm{O}$ & 0.7 & 2.75 & 0.71 \\
\hline Loss of Ignition (\%) & 2.3 & 0.21 & 1.49 \\
\hline \multicolumn{4}{|c|}{ Physical Properties } \\
\hline Specific Gravity & 3.15 & 2.18 & 2.43 \\
\hline Water Requirement (\%) & - & 93.4 & 95.9 \\
\hline
\end{tabular}




\subsubsection{Self-Consolidating Concrete}

The self-consolidating concrete (SCC) was used as control mix (representing normal concrete) for construction of $1 / 4^{\text {th }}$ scale link slabs, as well as the simply supported deck spans for the $1 / 6^{\text {th }}$ scale full bridge model. The SCC was made with commercially available dry content (30 kg) pre-packaged bags. The dry content included the nominal aggregate size of $10 \mathrm{~mm}$, Portland cement, silica fume and air-entraining admixtures. For each pre-package bag, a 2.4 liter of water was added for development of the SCC mixture.

\subsubsection{Steel Girder}

The supporting steel girder for the $1 / 4^{\text {th }}$ scale link slab and $1 / 6^{\text {th }}$ scale full bridge models was selected as W100 x19 section. The geometric shape and sectional properties of W100x19 section in accordance to CISC (2010) is presented in Figure 3.4 and Table 3.5.

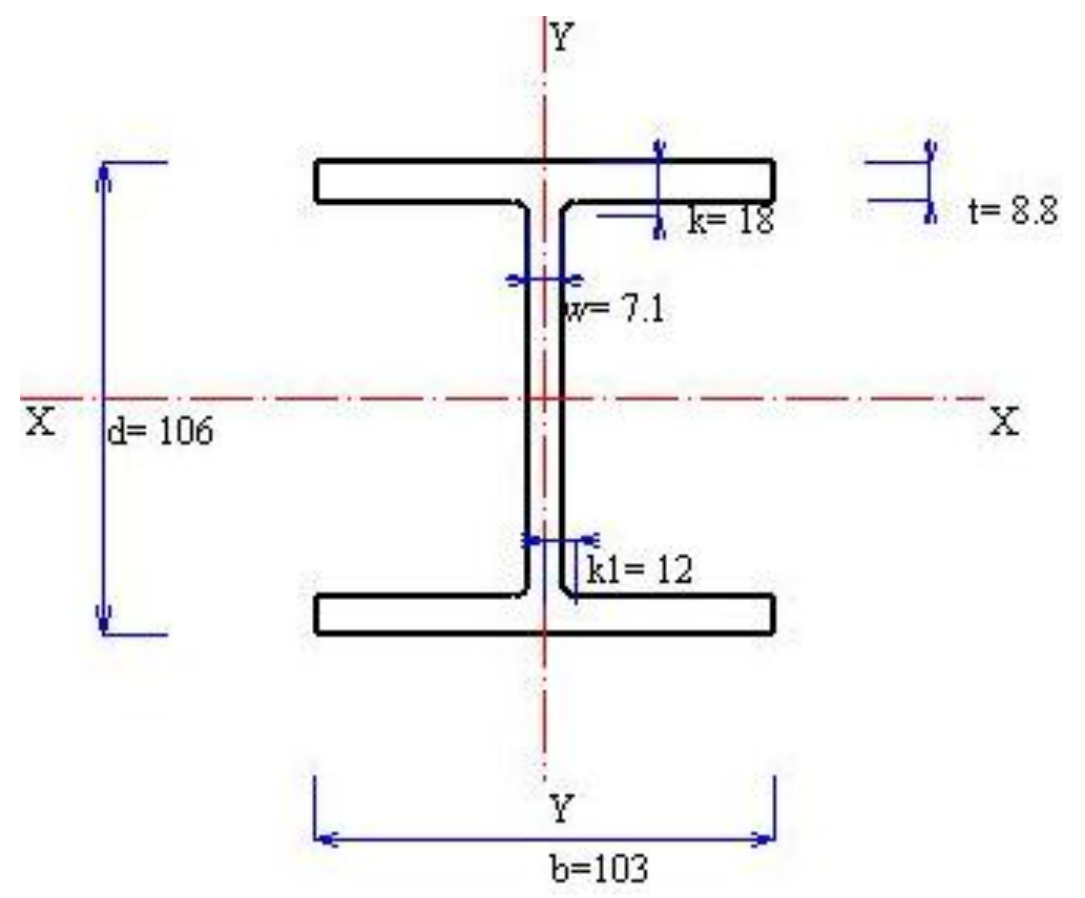

Figure 3.4: Schematic Representation of W100x19 Section as Girder 
Table 3.5: Properties of W100x19 Structural Steel section

\begin{tabular}{|c|c|c|c|c|c|c|c|c|c|c|}
\hline Section & Area & $\begin{array}{c}\mathrm{I}_{\mathrm{x}-\mathrm{x}} \\
10^{6} \mathrm{~mm}^{4}\end{array}$ & $\begin{array}{c}\mathrm{S}_{\mathrm{x}-\mathrm{x}} \\
10^{3} \mathrm{~mm}^{3}\end{array}$ & $\begin{array}{c}\mathrm{I}_{\mathrm{y}-\mathrm{y}} \\
10^{6} \mathrm{~mm}^{4}\end{array}$ & $\begin{array}{c}\mathrm{S}_{\mathrm{y}-\mathrm{y}} \\
10^{3} \mathrm{~mm}^{3}\end{array}$ & $\begin{array}{c}\text { Depth } \\
\mathrm{mm}\end{array}$ & $\begin{array}{c}\text { Flange } \\
\text { Width } \\
\mathrm{mm}\end{array}$ & $\begin{array}{c}\text { Flange } \\
\text { Thickness } \\
\mathrm{mm}\end{array}$ & $\begin{array}{c}\text { Web } \\
\text { Thickness } \\
\mathrm{mm}\end{array}$ & $\begin{array}{c}\text { Yielding } \\
\text { Stress } \mathrm{f}_{\mathrm{y}} \\
\mathrm{MPa}\end{array}$ \\
\hline W100x19 & 2480 & 4.77 & 89.9 & 1.61 & 31.2 & 106 & 103 & 8.8 & 7.1 & 345 \\
\hline
\end{tabular}

\subsubsection{Shear Stud Connector}

The selected shear stud for the composite action of the steel girder and the concrete bridge decks was selected in accordance with CISC (2010). The yielding $\left(f_{y}\right)$ and ultimate stress $\left(F_{u}\right)$ of the shear stud were $350 \mathrm{MPa}$ and $410 \mathrm{MPa}$, respectively. The schematic representation of the shear stud is presented in Figure 3.5.

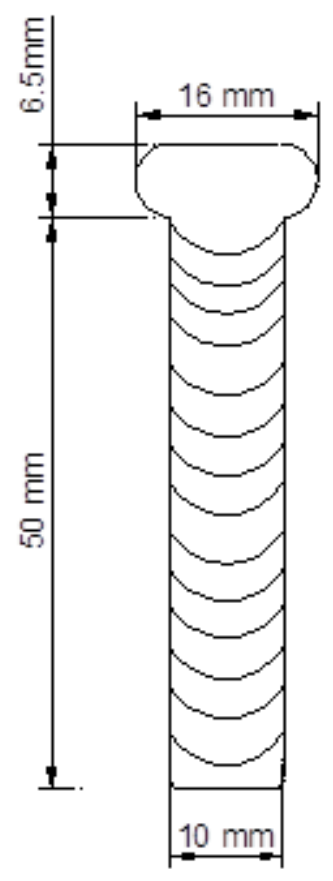

Figure 3.5: Schematic Representation of Shear Stud (Dimensions in mm) 


\subsection{Construction Model Specimens}

This section presents the detail construction methodologies used for experimental investigation including: the production of SCC/ECC mixtures, casting and fabrication sequences of the specimens.

\subsubsection{Mixing Sequences and Production of ECC and SCC}

The seven ECC mixtures used in investigation were produced by using a Hobart Type mixer with 20-liter capacity. The weighted solid contents except for the PVA fibers were introduced into the mixture and mixed for 30 second. After that $90 \%$ of the water was added to the mixer and mixed for additional 2 minutes at a higher speed. Then the remaining water and HRWRA was introduced to the mix (mixed for 1 minute) for the development of a uniform and consistent mortar mixture. Lastly, the PVA fibers were added to the mortar for another 3 minutes of stirring until all fibers were dispersed with mortar mixture. The schematic representation of the mixing sequence is presented in Figure 3.6.

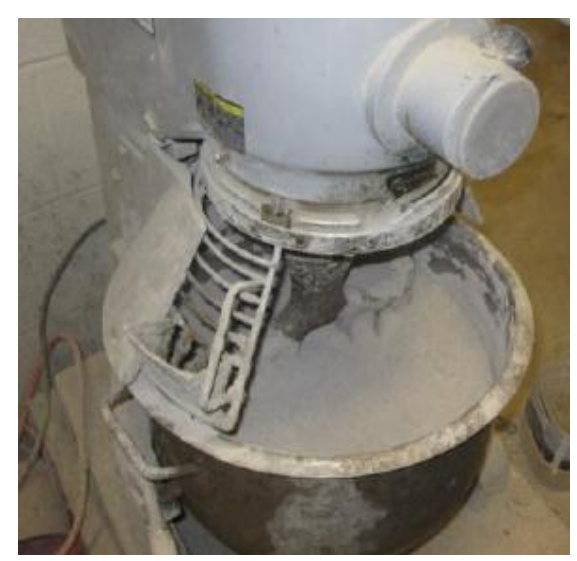

(a) Mixing of Solid Ingredients

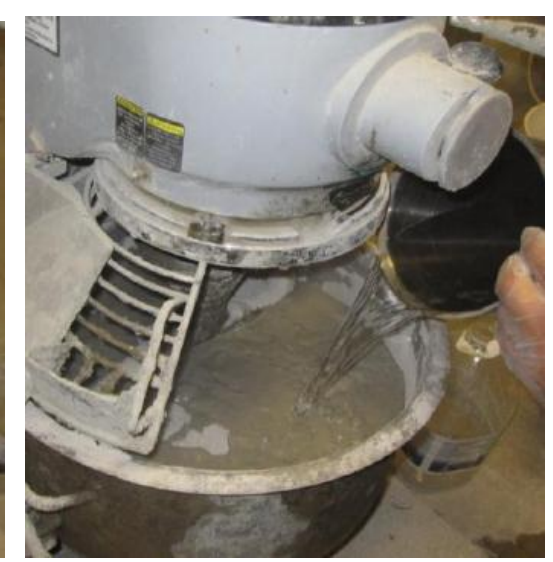

(b) Water\& HRWRA Addition

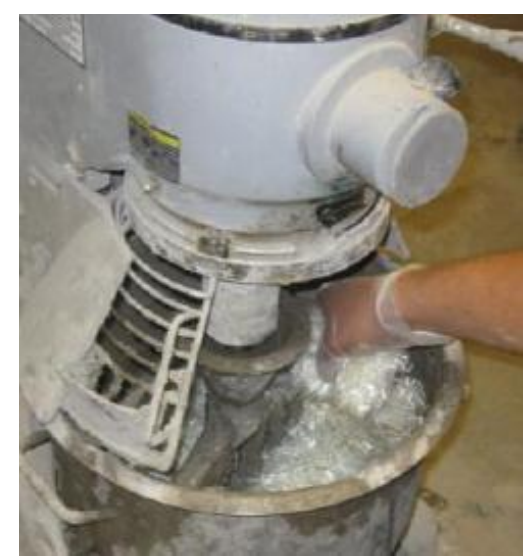

(c) PVA Fiber Addition

Figure 3.6: Mixing Sequences of ECC Mixtures

The 120-liter drum mixer was used for mixing SCC. The dry mix packages were introduced into the mixer for a dry 30 second mixing. After that $75 \%$ of the potable water was added to the dry contents for 2 minutes of mixing. The remaining $25 \%$ of the water was slowly added to the mix 
for additional 2 minutes until the required flowability and workability was achieved. The schematic representation of the mixing sequences is presented in Figure 3.7

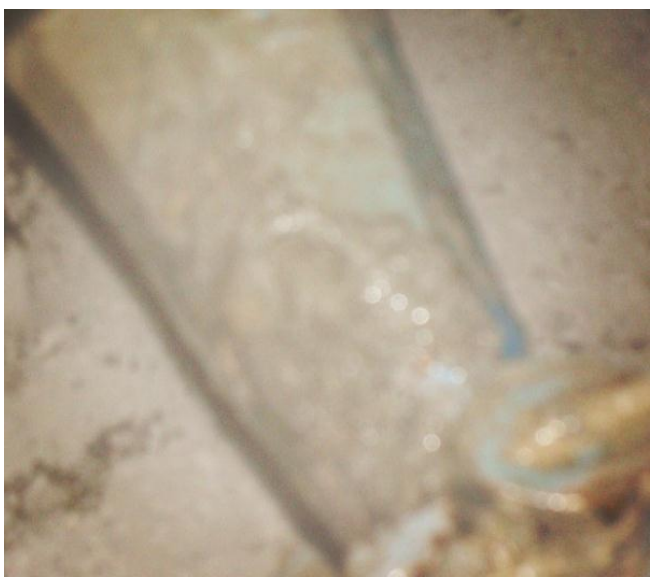

(a) Mixing Dry SCC Ingredient

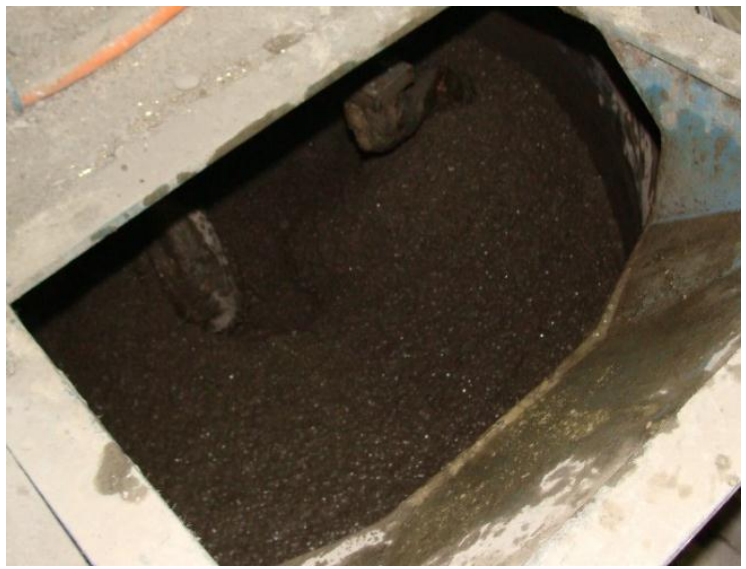

(b) Water Addition

Figure 3.7: Mixing Sequences of SCC Mixture

\subsubsection{Fabrication and Casting of Model Specimens}

Long wooden boards were fastened together for preparing the deck slab of the $1 / 4^{\text {th }}$ scale link slabs and $1 / 6^{\text {th }}$ scale full bridge specimens. For each specimen, the wooden deck mold was clamped and locked into the two separate steel girders at $30 \mathrm{~mm}$ distanced apart. As a barrier for steel and concrete a 15-lb roofing paper was provided in the debonding zone of the link slab.

Similar to the general field practice, the bridge decks were cast initially with flowable SCC mix, and left for 24 hours for setting. Then the link slab segment was cast with ECC or SCC after initial 24 hours. At least three control specimens for each types of concrete in the form of cylinders, beams and cubes were also casted at the same time. All the specimens were cured for 28 days using wet burlaps in the laboratory conditions with a relative humidity and temperature of $50 \% \pm 2.5 \%$ and $24 \pm 2{ }^{\circ} \mathrm{C}$, respectively. The sequential casting process of the $1 / 4^{\text {th }}$ scale link slab and $1 / 6^{\text {th }}$ scale full bridge models are presented in Figures 3.8 and 3.9, respectively. 


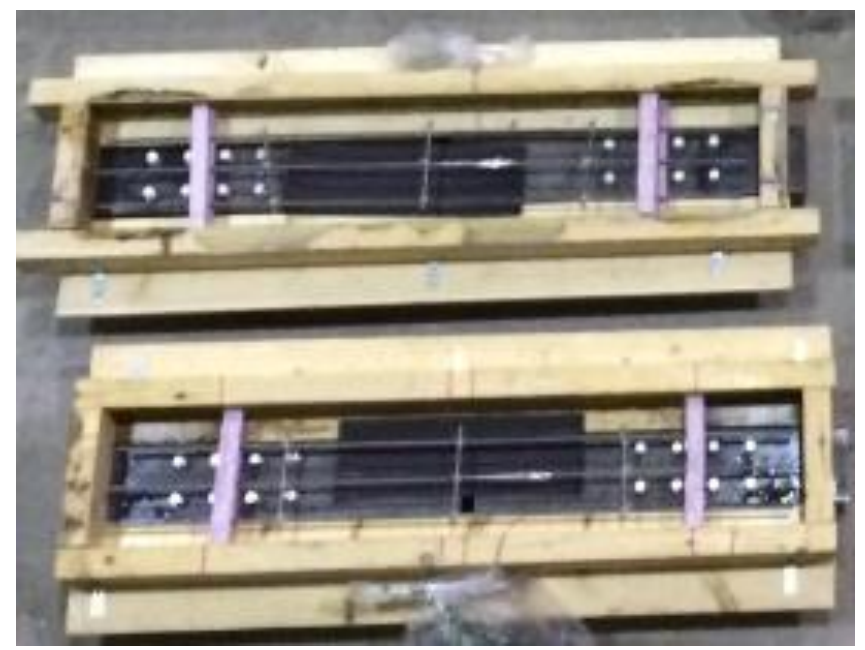

(a ) Mold Preparation

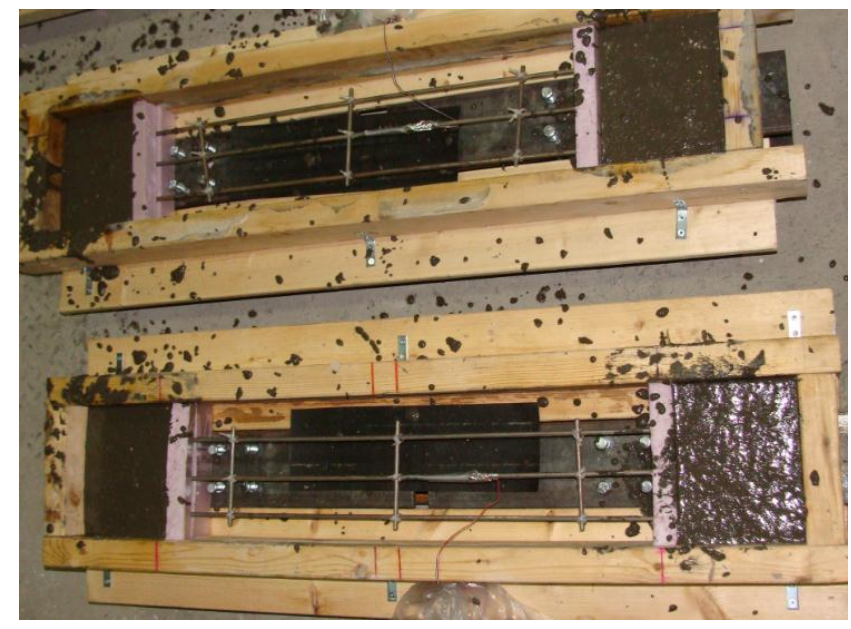

(b) SCC Bridge Deck Casting

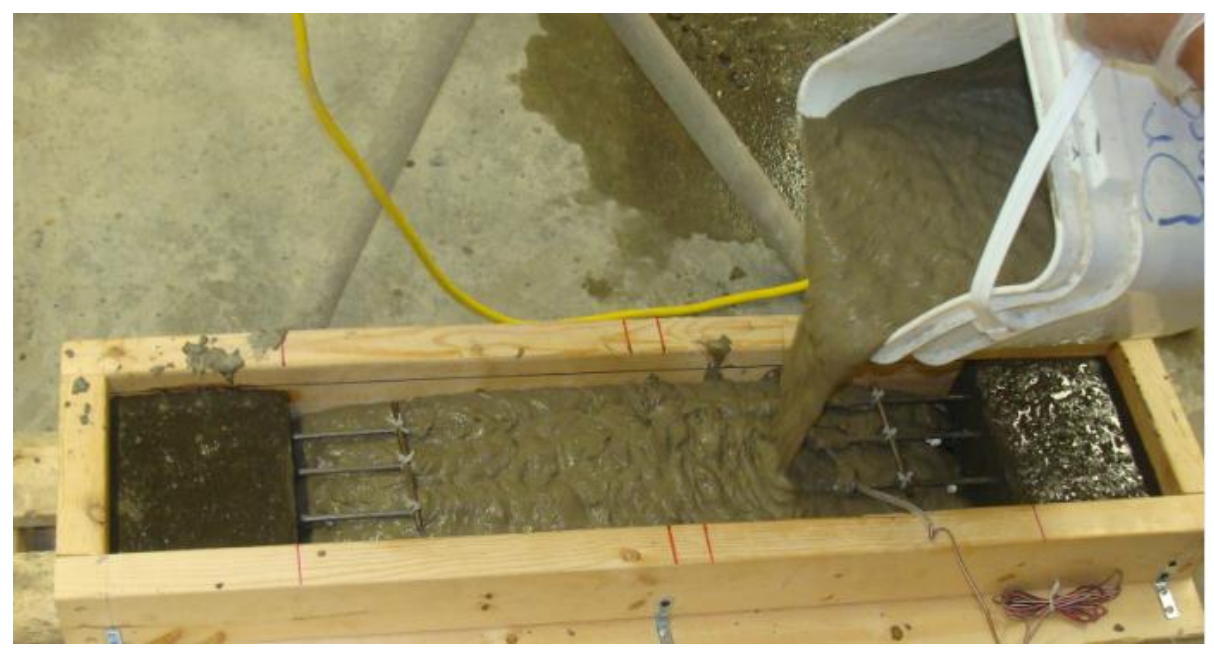

(c) Link Slab Casting

Figure 3.8: Casting Process of 1/4 $4^{\text {th }}$ Scale Link Slab Model 


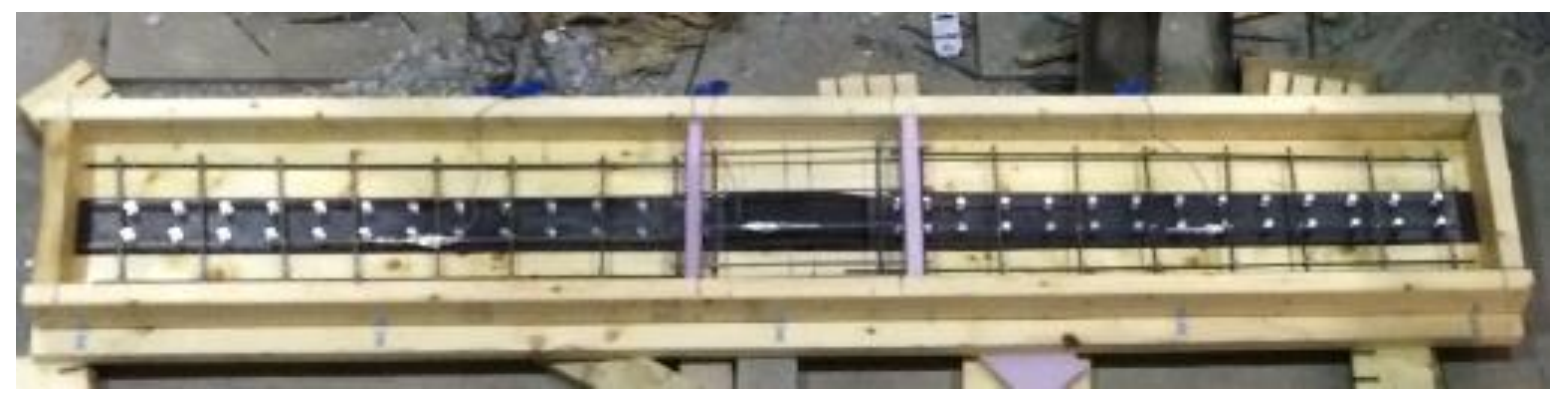

(a ) Mold Preparation

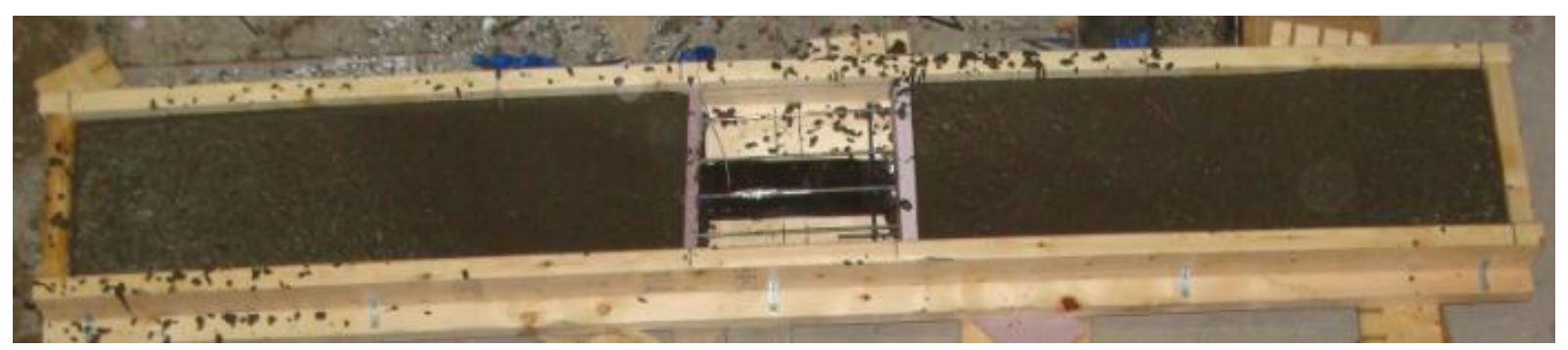

(b) SCC Bridge Deck Casting

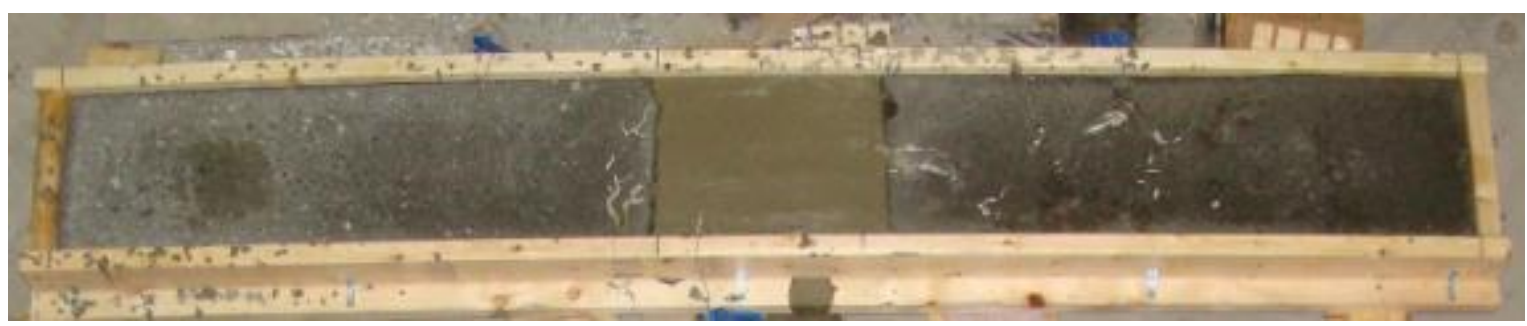

(C) ECC Link Slab Casting

Figure 3.9: Casting Sequence of Full Bridge Model

\subsection{Test Set-Ups, Instrumentation and Testing Procedure}

\subsubsection{Strength Properties of Concretes}

Performance of hardened SCC and ECC control mixtures were measured by mean compressive strength at the age of 28 days or at the testing of model link slab or full bridge specimens. For each concrete type at least 3 control specimens were casted and prepared for the testing. The compression test for cylindrical and cubic samples of SCC and ECC was performed as per ASTM C39 (2003), and ASTM C109 (2011). 
The four-point bending test was performed on the ECC and SCC control prism specimen at 28 days or at the age of testing of link slab/bridge models in accordance to ASTM C78 (2010). Prior to testing, all the prism specimens were sanded for obtaining a flat surface. The four-point bending test was performed using a closed-loop controlled servo-hydraulic system under displacement condition at a loading rate of $0.005 \mathrm{~mm} / \mathrm{s}$. The load and mid-span deflection were recorded on a computerized data acquisition system. The total span length of the flexural specimens was $304.8 \mathrm{~mm}$.

\subsubsection{One Fourth Scale Link Slab Subjected to Monotonic Loading}

All nine link slab specimens were tested under monotonic loading at the age of 28 days for demonstrating the actual loading and support conditions of the real bridge structure. The inflection points spanning $810 \mathrm{~mm}$ were simulated by the pin and roller supports. For practical purpose, the link slab was tested in an inverted orientation for simulating actual link slab behaviour in a joint-free bridge deck. Prior to testing, strain gauges were installed at the midspan location for recording and monitoring the rebar tensile strain and concrete tensile/compressive strains during loading up to failure. Linear variable displacement transformers (LVDTs) were located at different locations for recording and monitoring the deflections. Inclinometer was installed at the support location for recording the support-end rotation. Detailed schematic representation of the link slab test set-ups, including location of the strain gauges, LVDT's and inclinometer are presented in Figure 3.10. 


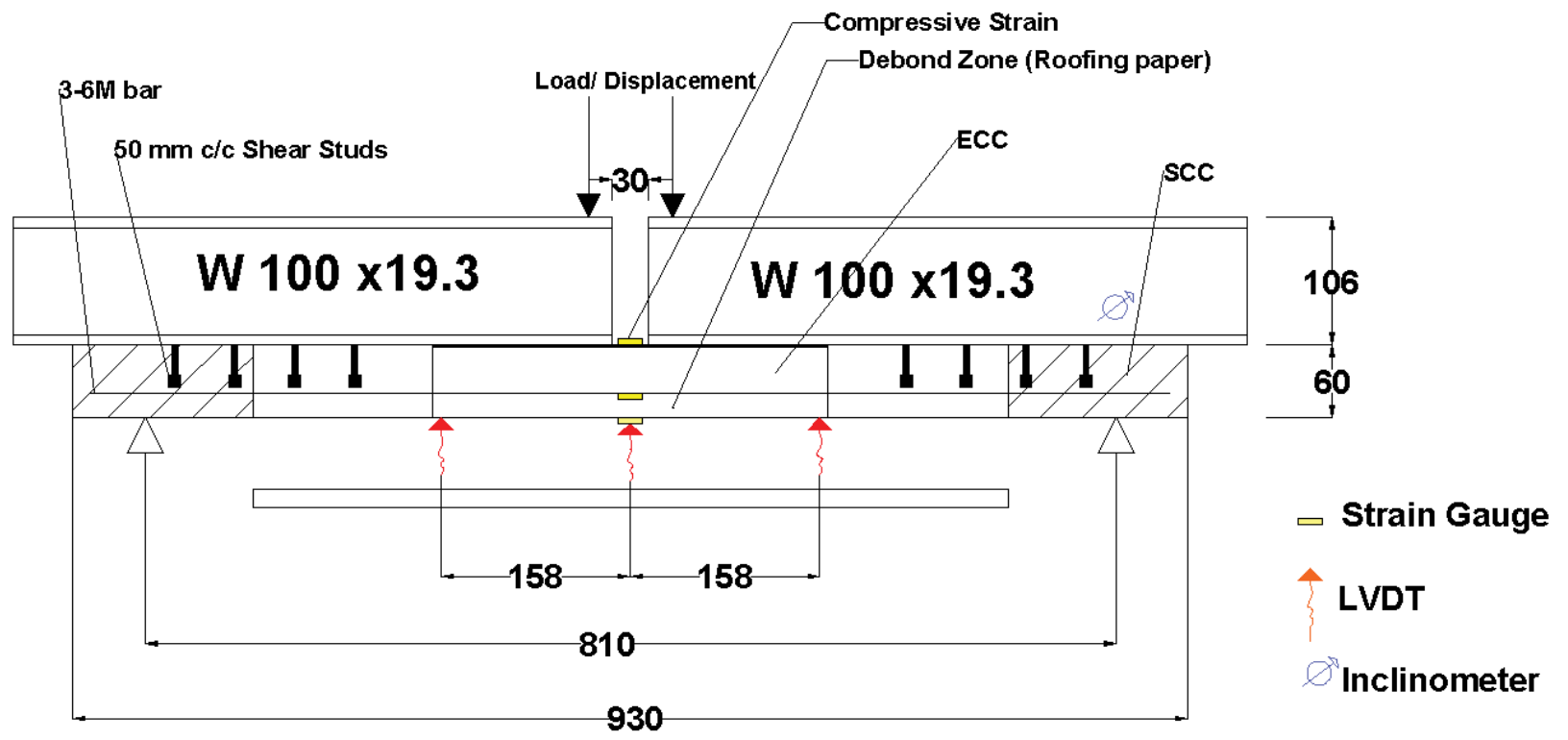

Figure 3.10: Monotonic Test Set-Ups for $1 / 4^{\text {th }}$ Scale Link Slab Specimen (Dimensions in mm)

Same testing procedure was adopted for all nine link slab specimens incorporating different concrete mixtures. The monotonic testing was performed using a closed-loop controlled servohydraulic system under displacement condition at loading rate of $0.005 \mathrm{~mm} / \mathrm{s}$. The loading was continued to post-peak failure, up to $85 \%$ of the ultimate load for determination of the post-peak ductility and energy absorbing capacity. While the load and mid-span deflection were recorded by the MTS machine, additional data acquisition system was used for recording the strain developments, deformation through LVDTs and support-rotation. The crack propagation and failure modes were visually observed and recorded during the test. The crack's width was measured using the crackscope. Figure 3.11 represents the testing instrumentation of the $1 / 4^{\text {th }}$ scale link slab specimen. 


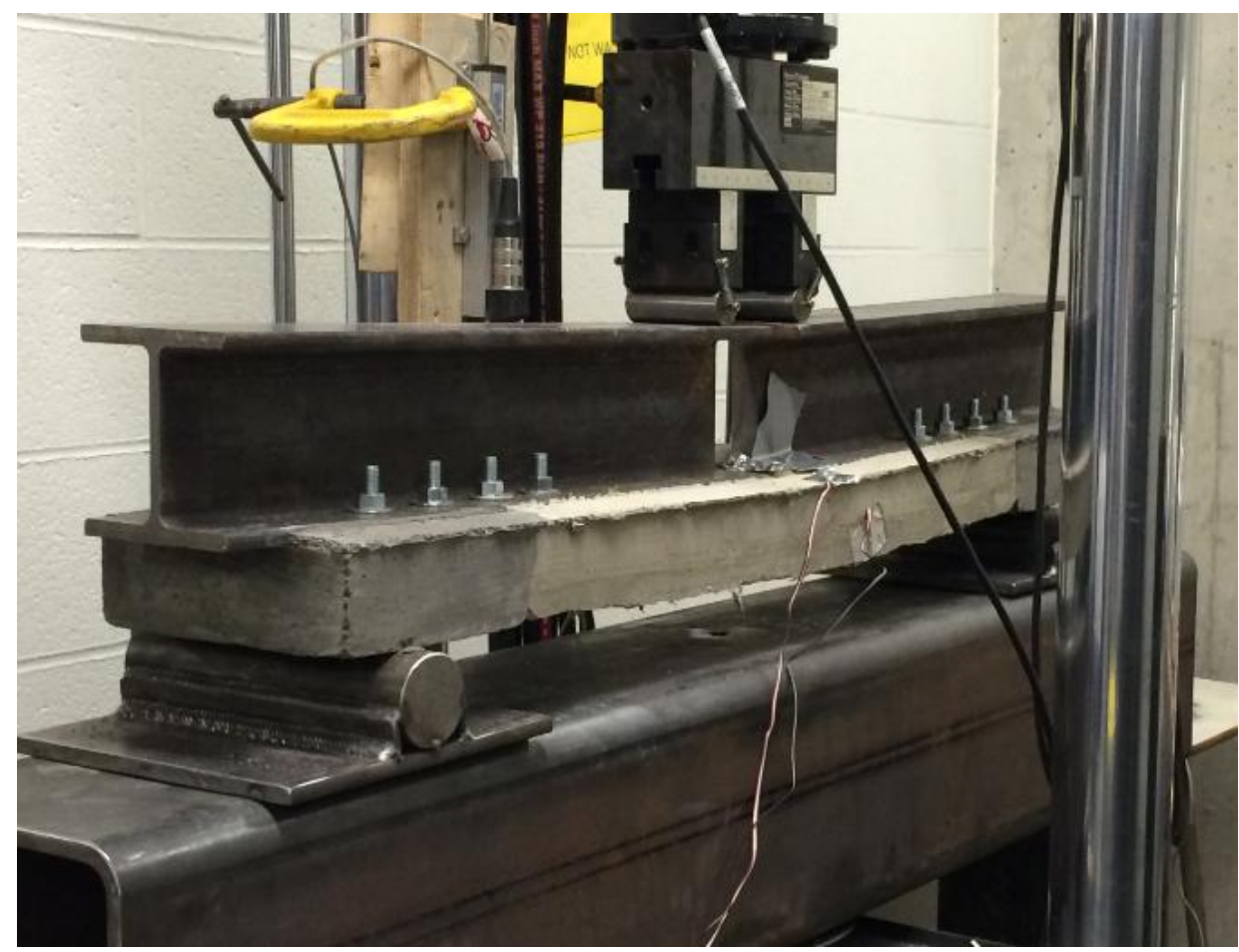

Figure 3.11: Testing and Instrumentation of $1 / 4^{\text {th }}$ Scale Link Slab Specimen

\subsubsection{One Fourth Scale Link Slab Subjected to Flexural Fatigue Loading}

Flexural fatigue tests were performed to investigate the cyclic behavior of the $1 / 4^{\text {th }}$ scale ECC link slab compared with the control SCC link slabs. Overall three ECC and one SCC link slabs were prepared and tested at the age of 28 days. The flexural fatigue testing was performed in three different stages: pre-fatigue behaviour under monotonic loading to failure, fatigue behaviour under cyclic loading at different stress levels and post-fatigue behaviour under monotonic loading to failure. The pre-fatigue monotonic test was performed to evaluate the ultimate strength, bending capacity and strain development of the link slabs and also to determine the applicable fatigue stress levels. After the analysis of the pre-fatigue monotonic testing, the flexural fatigue loading was performed on companion link slab specimens based on two different approaches. The first approach applied different fatigue stress levels of $40 \%$ and $55 \%$ of the ultimate load (determined from pre-fatigue monotonic testing) at a constant 400000 fatigue cycles. The second approach applied constant fatigue stress level of $40 \%$ at $4 \mathrm{~Hz}$ cyclic loading rate (4 cycles per second) with variable fatigue cycles of 400000 and 1000000 . After the fatigue performance, the flexural monotonic test was performed on the exhausted fatigued link slab specimens for determining the residual strength and bending capacity. 
For both pre-fatigue and post-fatigue monotonic performance, same testing procedure and instrumentation as used for the $1 / 4^{\text {th }}$ scale link slab subjected to monotonic loading were adopted (section 3.5.2 and Figure 3.10).

Flexural fatigue testing for both approaches was performed using a closed-loop controlled servohydraulic system. The specimens were pre-monotonically loaded to the mean fatigue stress levels of $40 \%$ and $55 \%$ under load control condition, at a rate of $0.5 \mathrm{kN} / \mathrm{min}$ as a ramp into fatigue loading. Then fatigue loading was applied with an upper and lower limit of $\pm 20 \%$ of the applied mean stress level until the end of the fatigue cycles (400000 and 1 million cycle). During the fatigue flexural tests, the mid-span deflection and deflection evolutions were recorded by the system. Additional data acquisition system was used for recording the maximum concrete (tensile/compressive) and rebar strain developments at the mid-span location (Same instrumentation as Figure 3.10). The crack propagation was visually observed and recorded for every 10000 fatigue cycles.

\subsubsection{One Sixth Scale Full Bridge Subjected to Monotonic Loading}

The full bridge specimen was tested under monotonic loading at the age of 28 days for simulating a reduced scale real bridge structure with connecting ECC link slab. Prior to testing, strain gauges were installed at mid-span location of the SCC spans (where maximum positive bending moment expected) and center of the ECC link slab specimens (where maximum negative moment was expected) for recording the maximum concrete compressive/tensile strain and rebar strains. Additional strain gauges were installed at the location of the inflection points for verification of the location of inflection points as per design guide by Lepech and Li (2009). LVDTs were provided at different locations for measuring the deflection of composite girders and link slab. The inclinometer was installed on the inner support (ECC and SCC interface) for measuring the rotation developed by the ECC link slab. The detailed representation of the experimental devices used for monitoring the full bridge model during testing is presented in Figure 3.12. 


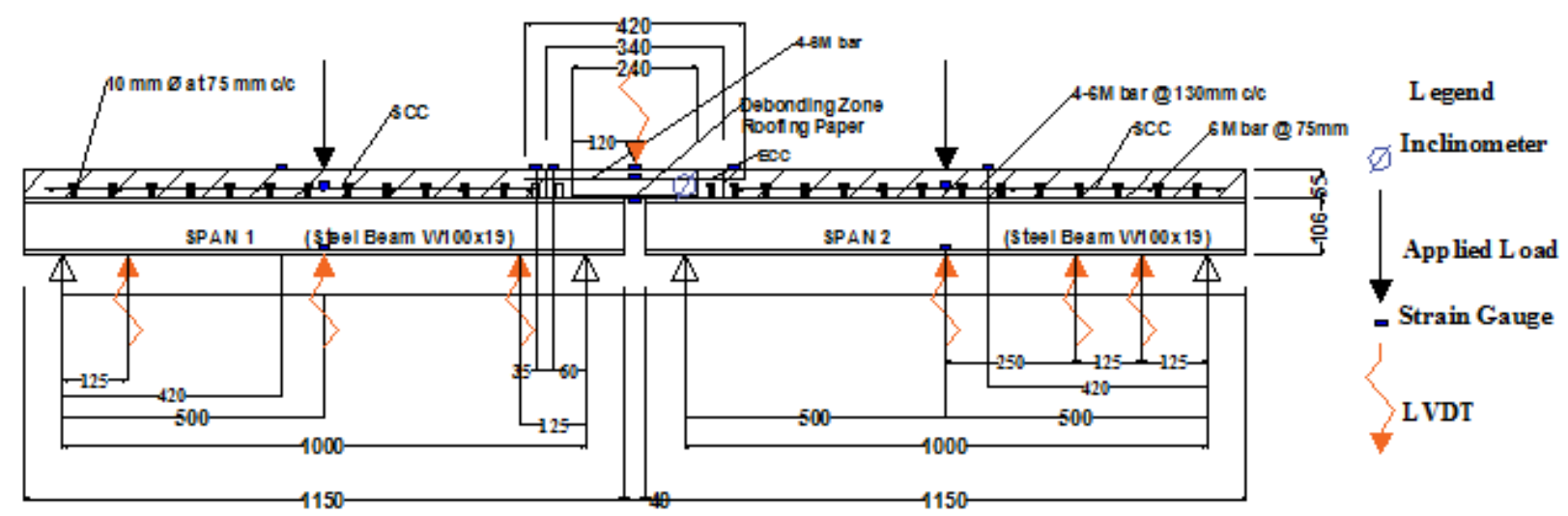

Figure 3.12: Monotonic Test Set-Ups for 1/6th Scale Full Bridge Model (dimensions in mm)

The monotonic testing was performed using a hydraulic actuator system under load control condition at a loading rate of approximately $3 \mathrm{kN} / \mathrm{min}$. The loading was applied at the centre of the SCC simply supporting deck (centre of each of the composite girder) where maximum positive bending moment was expected (Figure 3.12). The applied loading was selected up to service stage load, determined as $50 \%$ of the design load calculated prior to the testing based on the resistance of composite section as per CHBDC (2006) and Lepech and Li (2009) as illustrated in Appendix A.

A data acquisition system was used for recording the load, deflection, strain development and the ECC support end-rotation for the $1 / 6^{\text {th }}$ scale full bridge model at critical locations (Figure 3.12). The testing and instrumentation of the $1 / 6^{\text {th }}$ scale full bridge model is presented in Figure 3.13. 


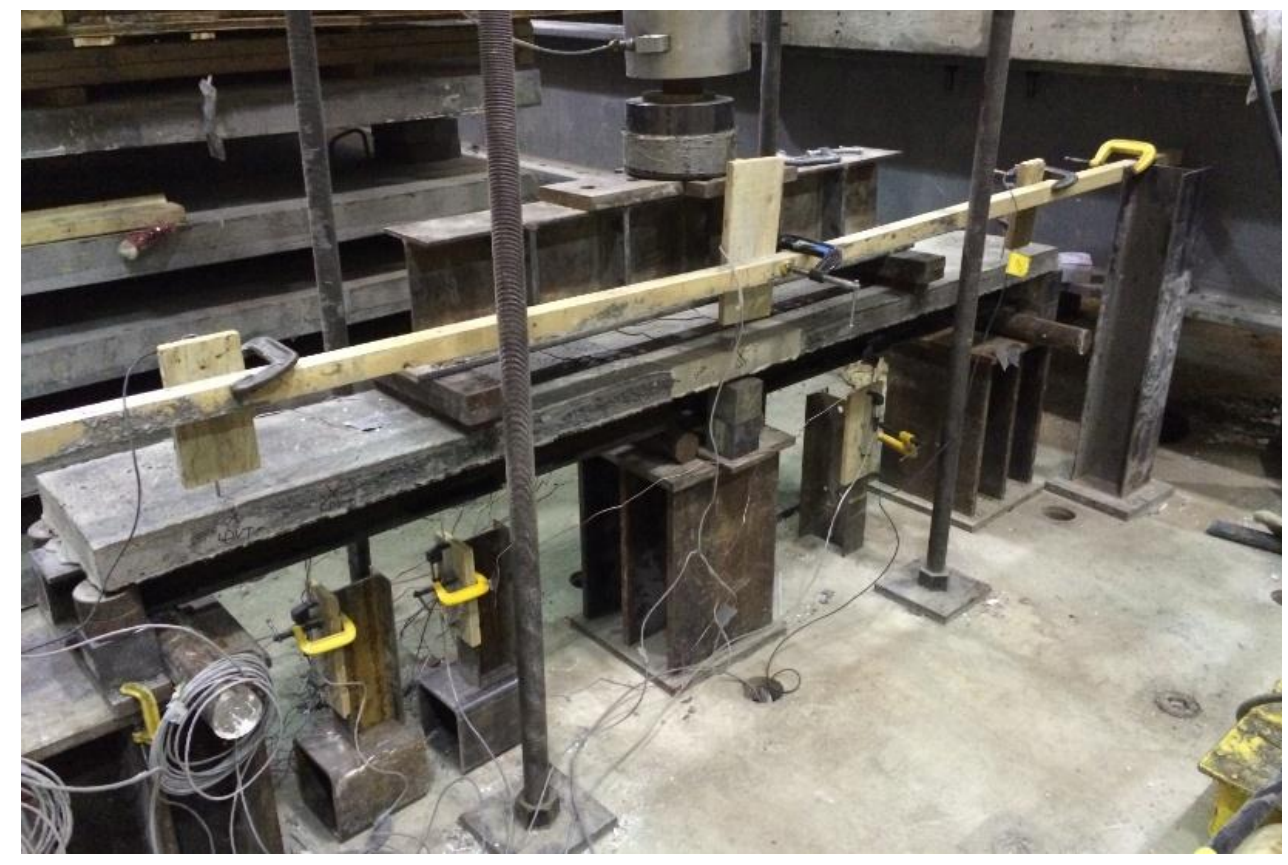

Figure 3.13: Testing Instrumentation of $1 / 6^{\text {th }}$ Scale Full Bridge Model

\subsection{Summary}

This chapter described the experimental investigations on $1 / 4^{\text {th }}$ scale link slab models and $1 / 6^{\text {th }}$ scale full bridge model made with SCC and ECC. The detailed design guidelines and geometric dimensioning of the test specimens (link slabs and full bridge) are presented along with test procedures, instrumentation and testing under monotonic and fatigue flexure loading. 
STRUCTURAL PERFORMANCE OF LINK SLABS UNDER MONOTONIC LOADING

\subsection{Introduction}

This Chapter presents the results of the experimental investigation on $1 / 4^{\text {th }}$ scale link slab specimens subjected to monotonic loadings. The performance is described based on the loaddeflection/moment-rotation response, strain developments, cracking/crack propagation, energy absorption, ductility and failure modes. The influence of seven ECC mix types (based on fly ash types CI and F and the replacement percent 55\% and 70\%) and aggregate types/size (local mortar/crushed sand and silica sand) on the link slab structural performance under monotonic loading is described compared to those made with a self-consolidating concrete (SCC). In addition, results of a test conducted on $1 / 6^{\text {th }}$ scale full bridge with ECC link slab tested under monotonic loading (up to service stage $-50 \%$ of the design load) is described based on loaddeflection/moment-rotation response and strain development (in steel rebar, concrete and steel Ibeam) as well as inflection point identification. The moment resistance of link slab is compared with those obtained from theoretical analyses. In addition, experimentally obtained location of inflection points is compared with those suggested by design specifications.

The properties of ECC and SCC mixtures such as compressive/flexural strengths and bending deflection capacity are also presented.

\subsection{Properties of ECC and SCC mixtures}

The 28 days compressive and flexural strength including mid-span deflection at ultimate load for the seven ECC and one SCC mixtures (mean value of at least three cylinder/beam specimens) are presented in Table 4.1 
Table 4.1: Compressive and Flexural Strength of ECC and SCC Mixes

\begin{tabular}{|c|c|c|c|c|}
\hline $\begin{array}{c}\text { Mix } \\
\text { No. }\end{array}$ & Designation & Compressive Strength (MPa) & $\begin{array}{c}\text { Flexural Strength } \\
(\mathrm{MPa})\end{array}$ & $\begin{array}{c}\text { Mid-Span } \\
\text { Deflection (mm) }\end{array}$ \\
\hline 1 & LS2-ECC-CI-1.2-SS & $52.14 \pm 8.11$ & $5.13 \pm 0.07$ & 2.24 \\
\hline 2 & LS3-ECC-F-2.2-SS & $45.19 \pm 1.30$ & $6.56 \pm 0.25$ & 2.93 \\
\hline 3 & LS4-ECC-F-1.2-SS & $47.55 \pm 1.51$ & $10.13 \pm 1.61$ & 2.52 \\
\hline 4 & LS6-ECC-F-2.2-CS & $50.15 \pm 8.02$ & $10.25 \pm 3.04$ & 4.13 \\
\hline 5 & LS10-ECC-CI-2.2-SS & $53.79 \pm 1.79$ & $7.36 \pm 0.46$ & 5.83 \\
\hline 6 & LS11-ECC-CI-2.2-CS & $57.34 \pm 0.19$ & $5.03 \pm 0.75$ & 3.61 \\
\hline 7 & LS28-ECC-CI-1.2-MS & $55.5 \pm 6.70$ & $11.07 \pm 1.76$ & 1.22 \\
\hline 8 & LS25-SCC & $45 \pm 2.51$ & $4.95 \pm 0.81$ & 0.65 \\
\hline 9 & LS32-SCC & $36.4 \pm 1.38$ & $4.06 \pm 0.24$ & 0.65 \\
\hline
\end{tabular}

The 28 days compressive strength of ECC made with class CI-FA was higher in compare with class F-FA at the same FA replacement. The higher content of Calcium Oxide $(\mathrm{CaO})$ in FA-CI promotes higher and denser hydration products resulting stronger bonds in interfacial transition Zone (ITZ) and higher compressive strength (Alexander et al. 2003). Also the 28 days compressive strength of the ECC mixes reduced at higher SCM replacement rate specifically for class F-FA. This can be attributed to the lower content $\mathrm{CaO}$ and slower hydration rates which resulted in an increased porosity levels between the formed hydration products (Sahmaran et al. 2008).

At each SCM replacement level, the ECC mixes with micro-silica sand yielded lower compressive strength in compare with the mortar and crushed sand. It is observed that the compressive strength of the ECC mixes similarly to the normal concrete are dependent on the maximum aggregate size. The maximum aggregate size for micro-silica sand for these ECC mixes were $0.3 \mathrm{~mm}$ while for crushed and mortar sands were $1.18 \mathrm{~mm}$. The increased maximum aggregate size promotes higher water content in the ITZ, which increases the volume of the paste and the aggregate at stronger bonding (Mehta \& Monteiro, 2006). Therefore the 28 days compressive strength for the ECC mixes with crushed and mortar sands were higher in compare with the micro-silica sand. 
Even though there are variation for the 28 days compressive strength of the proposed ECC mixes, yet the minimum compressive strength of $45 \mathrm{MPa}$ exceeds the strength of the SCC and fulfills the engineering requirements specifically for bridge deck applications.

The flexural strength for all mixes varied from 4.06 to $11.07 \mathrm{MPa}$ and the mid-span deflection varied from 0.65 to $5.83 \mathrm{~mm}$. SCC has shown lower flexural strength of 4.06 MPa and mid-span deflection of $0.65 \mathrm{~mm}$ compared with the ECC specimens. The SCC specimen exhibited a brittle failure after the formation of first crack whereas ECC specimens undergone tensile strain hardening by increasing the load and deflection. The strain hardening behaviour of the ECC is attained by fiber bridging phenomena where the PVA fiber is ruptured to its full strength rather than a pull-out like steel fibers ( $\mathrm{Li}$ et al. 2001).

The test results showed that increased in FA content improved the bending capacity of the ECC mixes while the flexural strength was reduced. The presence of un-hydrated fly ash particles that acts as filling materials results as densification of ITZ and improvement of the frictional bonding between the PVA fiber and the matrix (Hossain \& Sherir, 2014; Yang et al. 2007; Wang \& Li, 2007). However the reduction of the chemical bonding and the toughness of the matrix results as a reduction of the flexural strength.

The increased in maximum aggregate size (MAS) of the sand for the ECC mixes increased the flexural strength while reduced the mid-span deflection. The improved flexural strength resulted from higher degree of aggregate interlocking that enhanced the matrix toughness and work of fracture (Sahmaran et al. 2009). However increased in MAS caused the balling effect of the PVA fibers, preventing them for the adequate coverage of the cement paste and causing the nonuniformity dispersions of the fibers that resulted as reduction of the bending capacity (Hossain \& Sherir, 2014).

\subsection{Structural Performance of $1 / 4^{\text {th }}$ Scale Link Slabs with Different ECC Mixes Subjected to Monotonic Loading}

The structural performance of the $1 / 4^{\text {th }}$ scale link slabs made with seven ECC mixtures and one SCC mix subjected to monotonic loading is described and compared. 


\subsubsection{Experimental Load-Deflection/Moment-Rotation Responses and Theoretical-Code}

\section{Based Analysis}

Table 4.2 summarizes the test results. The typical load-deflection and moment-rotation curves for all the link slab specimens are represented in Figures 4.1 and 4.2. Table 4.2 shows that the ultimate load for various ECC and SCC mixes varied from 5.94 to $12.16 \mathrm{kN}$, and mid-span deflection at ultimate load varied from 6.75 to $12.22 \mathrm{~mm}$. The first cracking load for the ECC mixes did not differ drastically, whereas the mid-span deflection varied from 1.41 to $4.6 \mathrm{~mm}$.

Table 4.2: Summary of Load-Deflection and Moment Rotation Responses

\begin{tabular}{|c|c|c|c|c|c|c|c|}
\hline Link slab Designation & $\begin{array}{l}\text { Ultimate } \\
\text { Load } \\
\text { kN }\end{array}$ & $\begin{array}{c}\text { Ultimate } \\
\text { Deflection } \\
\text { mm }\end{array}$ & $\begin{array}{c}\text { Load } \\
\left(1^{\text {st }}\right. \\
\text { crack }) \\
\mathrm{kN}\end{array}$ & $\begin{array}{l}\text { Deflection } \\
\left(1^{\text {st }} \text { crack }\right) \\
\text { mm }\end{array}$ & $\begin{array}{l}\text { Ultimate } \\
\text { Rotation } \\
\text { radian }\end{array}$ & $\begin{array}{l}\text { Ultimate } \\
\text { Moment } \\
\text { kN.m }\end{array}$ & $\begin{array}{c}\text { Theoretical } \\
\text { Moment } \\
\text { kN.m } \\
\text { (Eq.2.15) }\end{array}$ \\
\hline -ECC-CI-1.2-SS & 9.89 & 10.45 & 3.25 & 2.01 & 0.0351 & 1.88 & 1.29 \\
\hline LS3-ECC-F-2.2-SS & 10.51 & 12.22 & 3.25 & 1.89 & 0.0285 & 2.00 & 1.29 \\
\hline LS4-ECC-F-1.2-SS & 10.4 & 9.39 & 3.5 & 1.63 & 0.0301 & 1.98 & 1.29 \\
\hline LS6-ECC-F-2.2-CS & 10.94 & 11.44 & 3.25 & 1.76 & 0.0278 & 2.08 & 1.29 \\
\hline LS10-ECC-CI-2.2-SS & 8.79 & 11.61 & 3.25 & 3.09 & 0.0444 & 1.67 & 1.29 \\
\hline LS11-ECC-CI-2.2-CS & 10.04 & 12.04 & 3.5 & 2.91 & 0.0445 & 1.91 & 1.29 \\
\hline LS28-ECC-CI-1.2-MS & 12.16 & 7.60 & 3.10 & 1.41 & 0.0206 & 2.31 & 1.29 \\
\hline LS25-SCC & 6.54 & 14.7 & 4.86 & 0.9 & 0.0383 & 1.26 & 1.25 \\
\hline LS32-SCC & 5.94 & 6.75 & 5.13 & 4.6 & 0.0222 & 1.28 & 1.25 \\
\hline
\end{tabular}

Note: The theoretical moments for ECC are determined based on Eq.2.15 


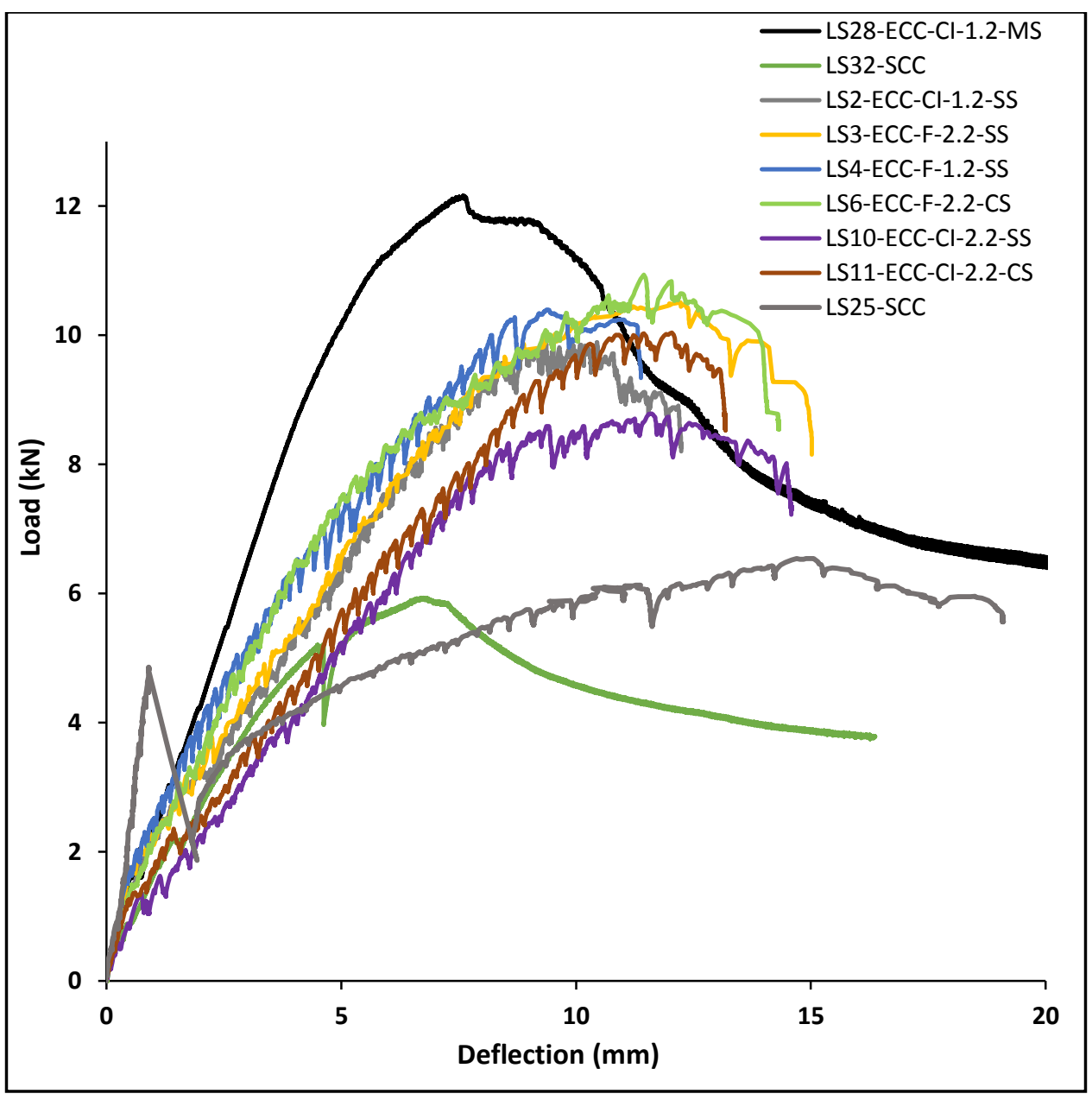

Figure 4.1: Comparison of Load-Deflection Response of Different Concrete Mixes 


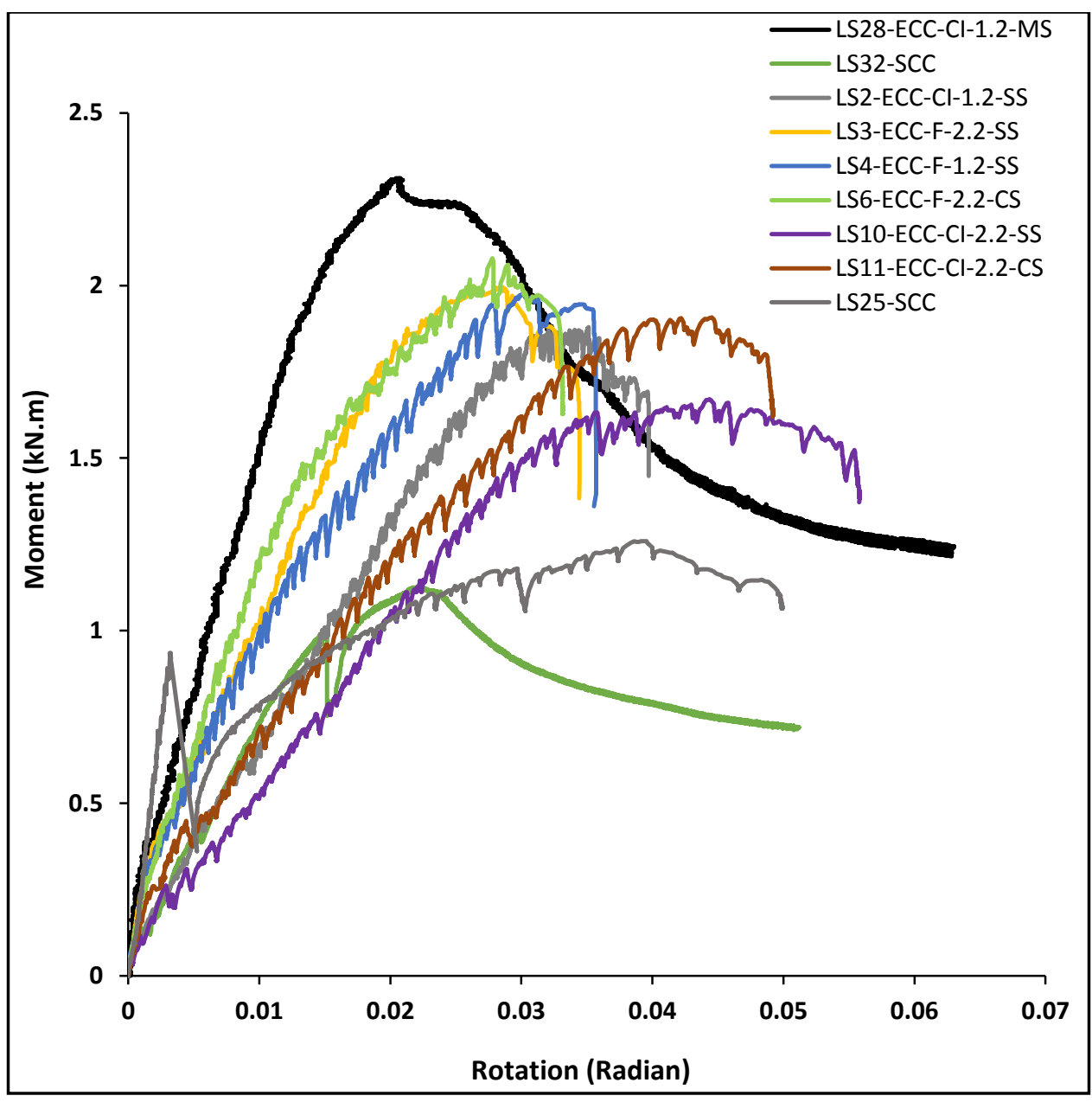

Figure 4.2: Comparison of Moment-Rotation Responses of Different Concrete Mixes

\subsubsection{Performance of ECC and SCC Link Slab}

The comparative load-deflection and moment-rotation responses for the ECC and SCC link slabs are presented in Figures 4.3. 


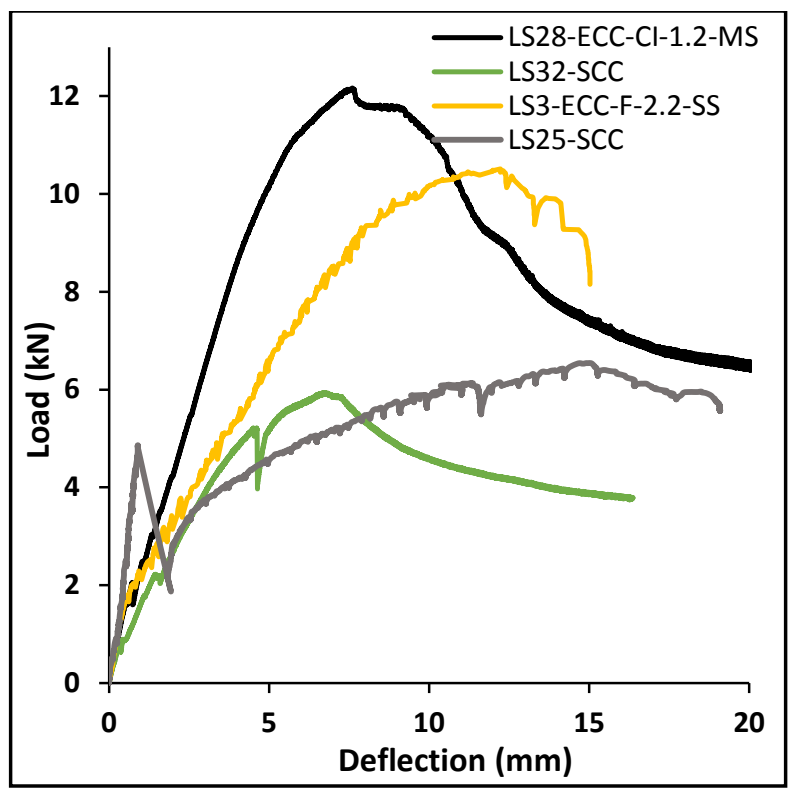

(a)Load-Deflection Response

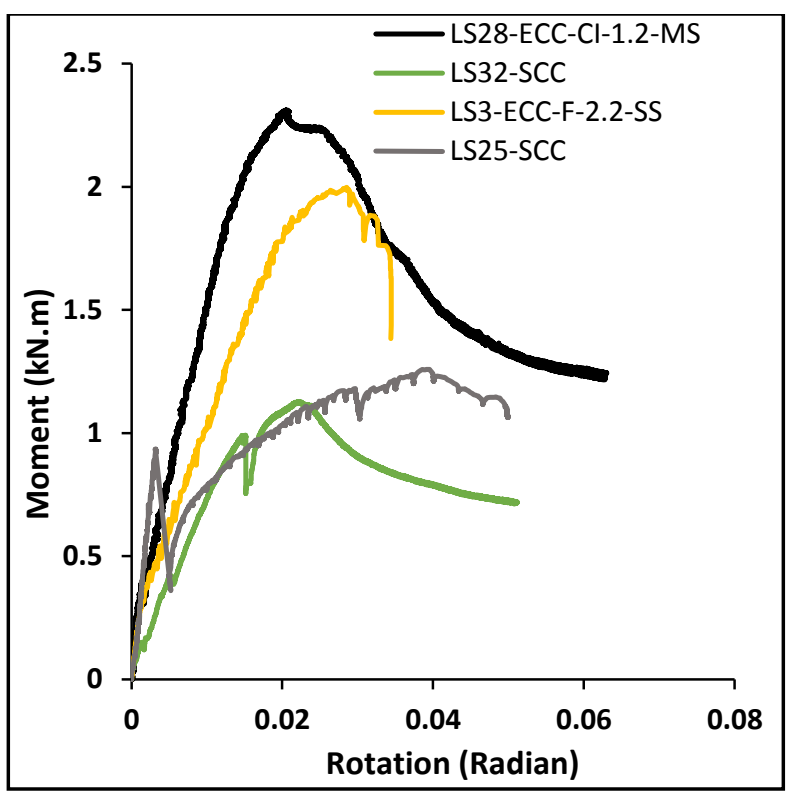

(b) Moment-Rotation Response

Figure 4.3: Comparison of Load-Deflection and Moment-Rotation Response of ECC and SCC Link Slabs

As it is seen from Figure 4.3 that there is a significant difference between load-deflection responses of ECC and SCC link slabs. For all ECC link slabs, a steady increase in deflection was evidenced when the applied loading was increased. This proves that all ECC link slabs clearly defined the ductility and strain hardening behaviour without the aid of the reinforcing bars. Unlike ECC, SCC link slab experienced a sudden drop of load when the first crack was formed. This pattern demonstrates the brittle response of the SCC at the first crack where load is transferred to the steel bar and as result load increased again before failure - through the SCC and steel bond mechanism the second peak/ ultimate loading was achieved.

The moment-rotation responses showed similar patterns of load-deflections for the ECC and SCC link slabs. The ultimate moment capacity for all ECC link slab was higher compared to SCC link slabs. As it is observed from Table 4.2, the theoretical moment capacity of the ECC link slabs calculated by the Equation. 2.15 proposed by Lepech \& Li (2009) are underestimated compared with the experimental moments. This is attributed to the conservative assumption of the tensile capacity and strain hardening behaviour of the ECC. Also additional factors related to mix design parameters, fiber bridging, multi-cracking characteristics and PVA fiber-matrix 
interaction were not properly taken into account. Unlike ECC, the theoretical moment capacity of the SCC was very close to its experimental value.

\subsubsection{Influence of Fly Ash on Link Slab Behaviour}

The increase in FA replacement with cement (55\% to $70 \%$ or 1.2 to 2.2 ) for both class $\mathrm{CI}$ and $\mathrm{F}$ did not show a significant influence on the ultimate load. However, it is evidenced from Figure 4.4 that the increase in both types of FA replacement increased the mid-span deflection and improved the bending capacity of link slab. The increase in FA replacement resulted in the reduction of the chemical bonding and toughness among the PVA fibers and matrix yet improved the interfacial frictional bonding in order to achieve higher deflection and bending capacity (Wang \& Li, 2007; Sahmaran et al. 2008). The increased deflection and bending capacity (lower rotational stiffness) of the link slabs also improves the function of the joint-free bridge decks since it will allow the simply supported adjacent spans to deflect freely and separately from each other, rather than the formation of continuous stiff bridge spans (Lepech \& Li, 2009).

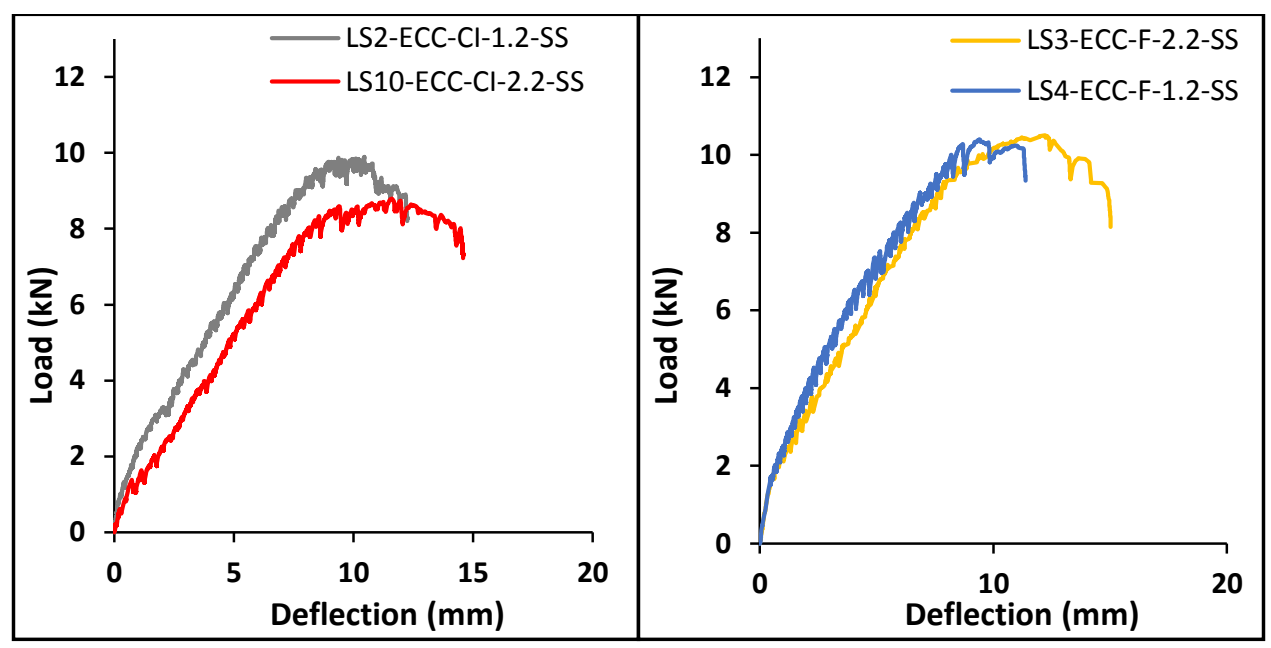

Figure 4.4: Load-Deflection Responses for ECC mixes with variable FA Replacement

\subsubsection{Influence of Different Aggregate Sizes}

As it can be observed from Figure 4.5, the use of ECC made with larger aggregate size (CS or MS has larger aggregate size than SS) improved the ultimate load capacity of link slab but reduced the mid-span deflection capacity, specifically for LS28-ECC-CI-1.2-MS. The larger aggregate size produced higher degree of aggregate interlocking which improved the load 
capacity of the link slabs as observed for specimen LS28-ECC-CI-1.2-MS as suggested by Sahmaran et al. (2009). In addition, the increased ball size of the aggregates for crushed and mortar sand prevented the fibers to be coated with the matrix, which attributed to the reduction of the fiber-matrix frictional bonding and lower deflection/bending capacity (Sahmaran et al. 2009). Although the ultimate loading capacity is increased, the lower deflection and bending capacity may decrease the ductility (flexibility) of the link slabs - leading to the formation of continuous stiff bridge deck with lower rotation capacity of the simply supported adjacent spans connected by link slabs (Lepech \& Li, 2009). However, ECC made with mortar sand and crushed sand in combination with class F or CI fly ash showed better flexure fatigue performance producing lower damage in terms of displacement evolution (Sherir, 2012) and suggested to be more suitable for link slab applications.

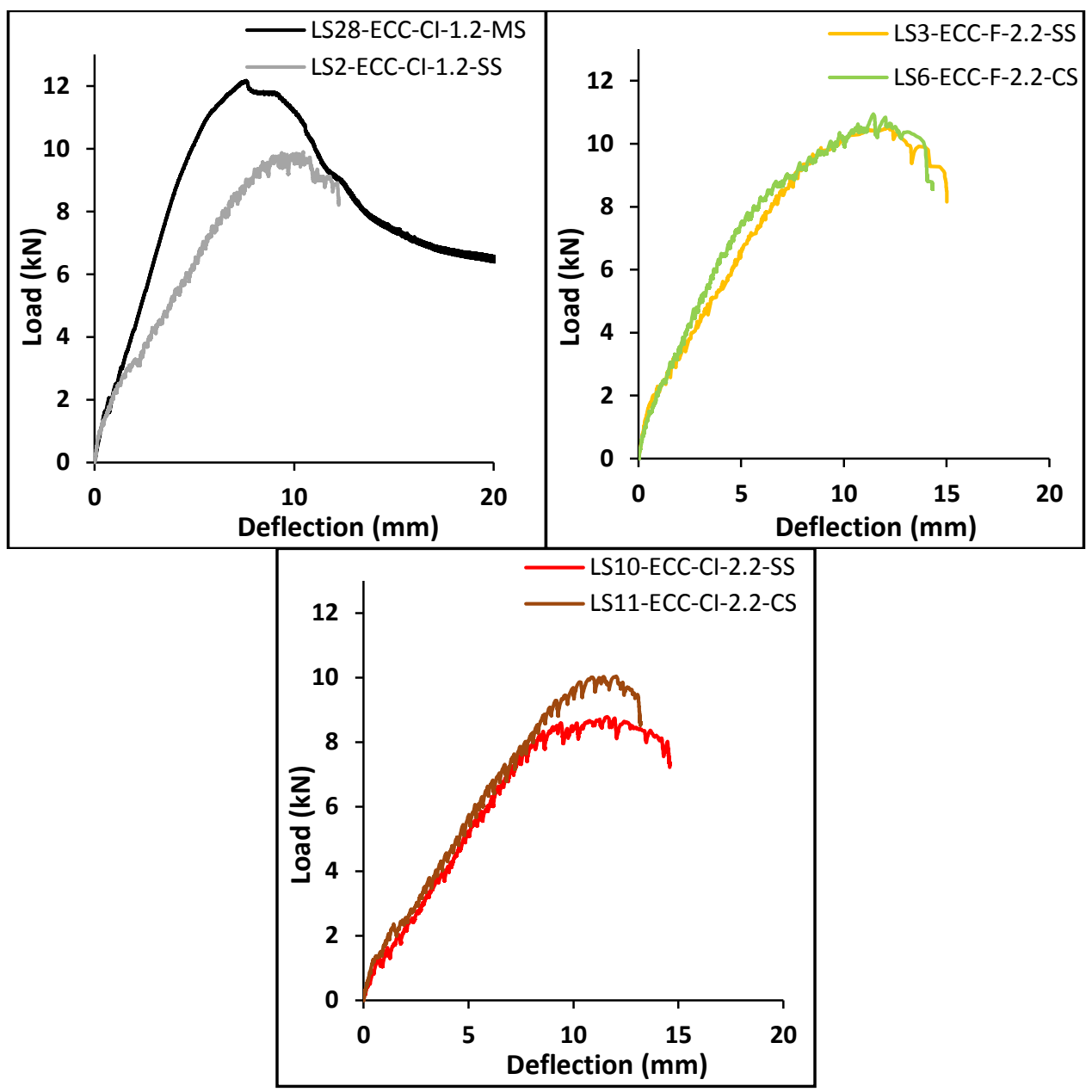

Figure 4.5: Load-Deflection Responses for ECC mixes with Different Sand Size 


\subsubsection{Strain Development}

Concrete tensile/compressive and rebar strain developments for the seven ECC and two SCC link slabs at ultimate loading are summarized in Table 4.3 and Figures 4.6 and 4.7 respectively.

Table 4.3: Summary of Strain Development for Different Link Slabs

\begin{tabular}{|c|c|c|c|c|c|}
\hline Designation & $\begin{array}{c}\text { Ultimate/peak } \\
\text { Load }(\mathrm{kN})\end{array}$ & $\begin{array}{l}\text { Concrete } \\
\text { Tensile Strain } \\
\text { at peak load } \\
\text { (Micro-Strain) }\end{array}$ & $\begin{array}{l}\text { Rebar Strain at } \\
\text { peak load } \\
\text { (Micro-Strain) }\end{array}$ & $\begin{array}{c}\text { Concrete } \\
\text { Compressive } \\
\text { Strain at } \\
\text { peak load } \\
\text { (Micro- } \\
\text { Strain) }\end{array}$ & $\begin{array}{c}\text { Load at Rebar } \\
\text { yield }(\mathrm{kN})\end{array}$ \\
\hline LS2-ECC-CI-1.2-SS & 9.89 & No reading & 2646 & -2396.0 & 8.3 \\
\hline LS3-ECC-F-2.2-SS & 10.51 & 1803 & 1297 & -3863.0 & Not Yielded \\
\hline LS4-ECC-F-1.2-SS & 10.4 & 5656 & 1974 & -3073.0 & 9.49 \\
\hline LS6-ECC-F-2.2-CS & 10.94 & 8560 & 1631 & -3765.0 & Not Yielded \\
\hline LS10-ECC-CI-2.2-SS & 8.79 & No reading & No reading & -1290.0 & Not Yielded \\
\hline LS11-ECC-CI-2.2-CS & 10.04 & 2267 & $\begin{array}{c}70 \text { (strain gauge } \\
\text { damaged) }\end{array}$ & -2492.0 & Not Yielded \\
\hline LS28-ECC-CI-1.2-MS & 12.16 & 5106 & 3172 & -1481.0 & 9.17 \\
\hline LS25-SCC & 6.54 & 146 (at $4.3 \mathrm{kN})$ & 2465 & -4395 & 5.66 \\
\hline LS32-SCC & 5.94 & No reading & 2723.36 & -783.1 & 4.41 \\
\hline
\end{tabular}




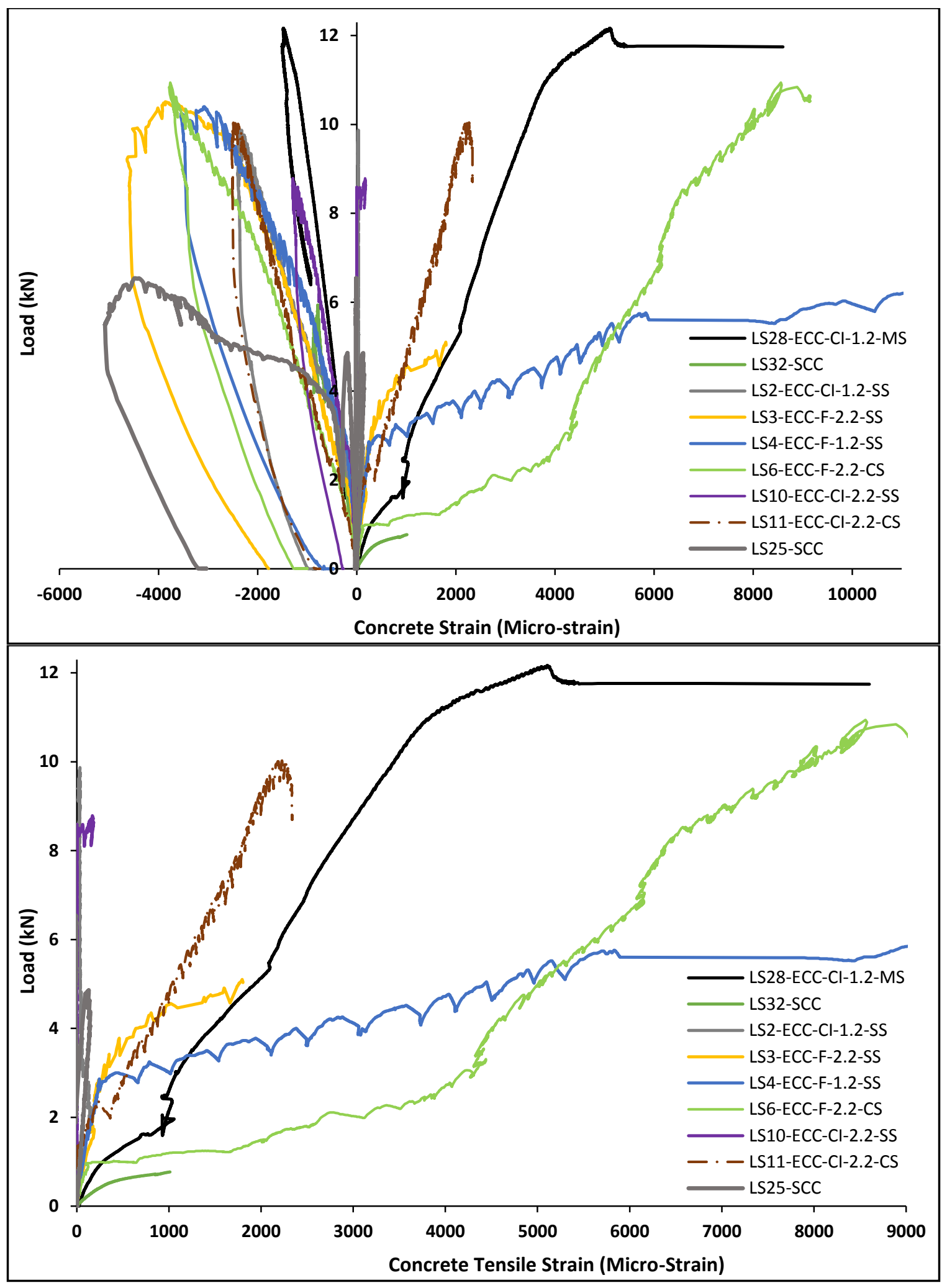

Figure 4.6: Concrete Strain Developments for Different Concrete Mixes 


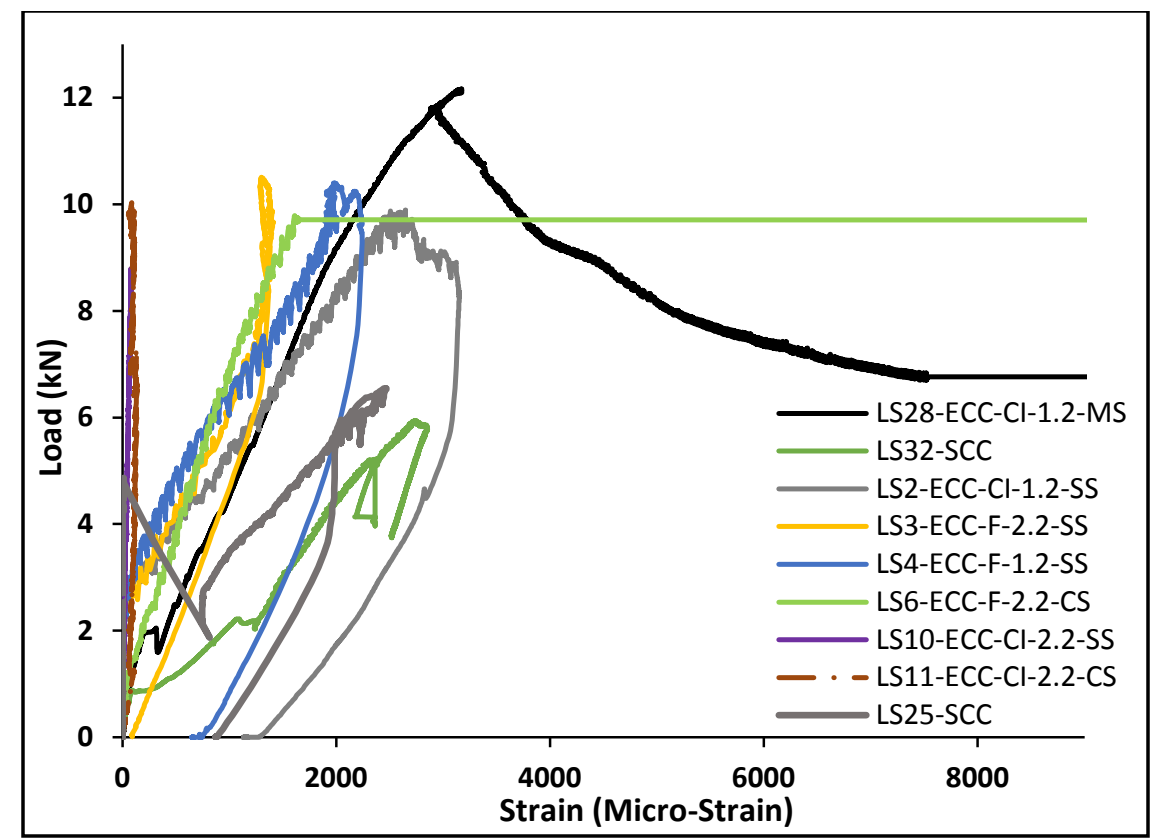

Figure 4.7: Rebar Strain Developments for Different Concrete Mixes

\subsubsection{Performance of ECC and SCC Link Slab}

Typical load-strain curves for the ECC and SCC link slabs are presented in Figure 4.8 to differentiate the concrete and rebar strain development among ECC and SCC.

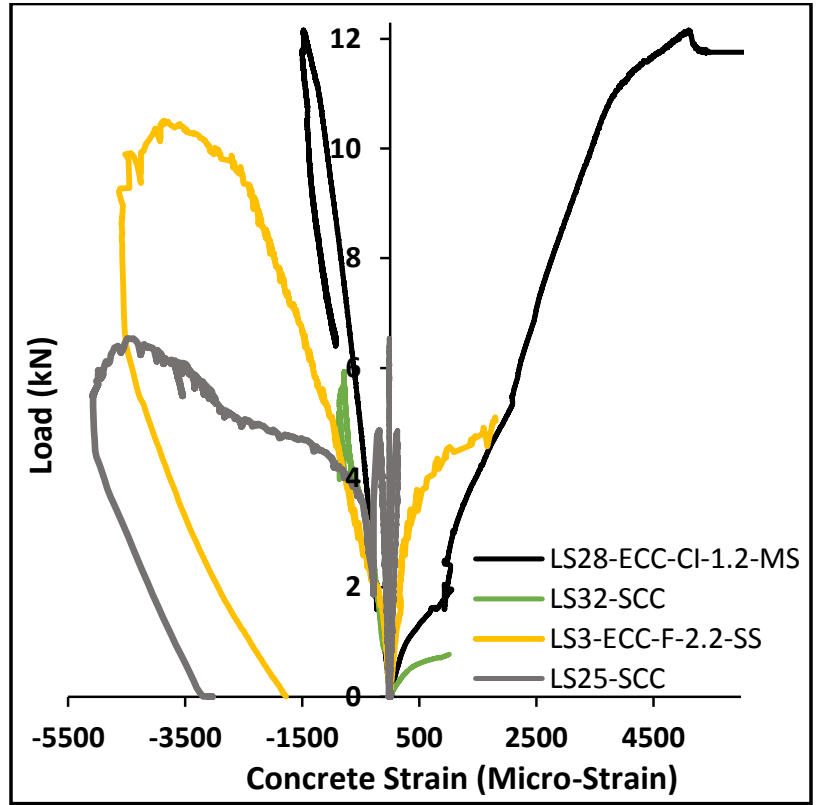

(a)Concrete Tensile Strain Development

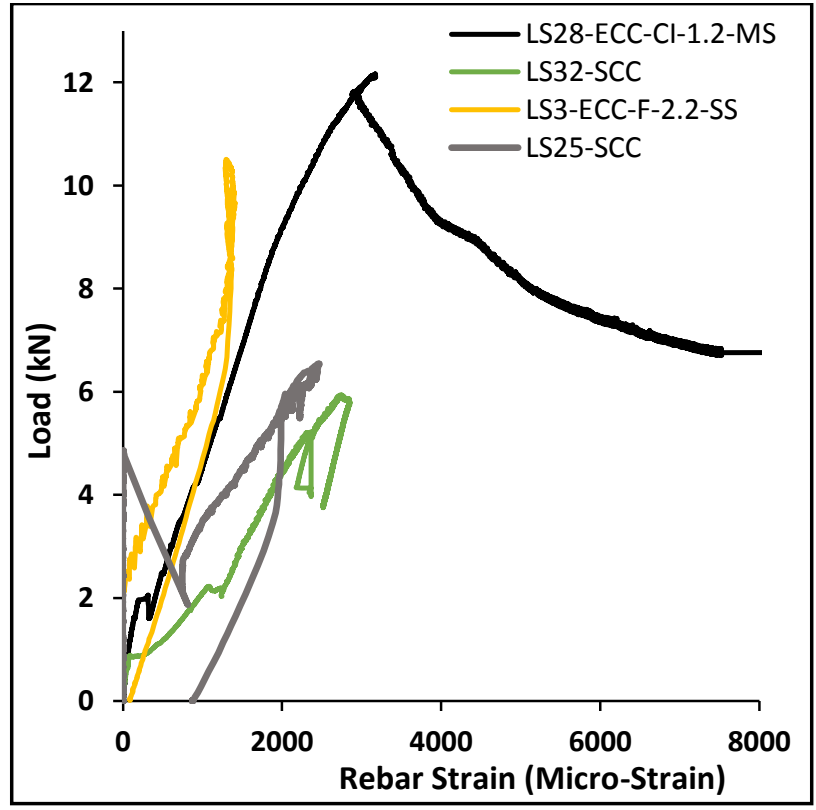

(b) Rebar Strain Development

Figure 4.8: Strain Developments for ECC and SCC Link Slabs 
As it is observed from Table 4.3 and Figure 4.8, the concrete tensile/compressive strains for all ECC link slabs were much higher than SCC links slabs reached the yielding stage at the ultimate loading, except for LS2-ECC-CI-1.2-SS and LS10-ECC-CI-2.2-SS where the stain gauges broke during test. The rebar strain development was also lower in ECC link slabs and yielding of the rebar occurred at higher load. This can be attributed to the fiber bridging and micro-cracking characteristics where at onset of cracking, load is gradually transferred to the steel bar. In SCC link slabs, at the formation of a major crack, load was transferred to the rebar suddenly causing them to be highly stressed and subsequently yield at lower load. Hence, after the formation of the crack ECC's tensile strain increased gradually unlike SCC where all the tensile stresses were transferred to the steel rebar. The increased tensile strain in ECC is caused by the fiber bridging phenomena where PVA fiber is ruptured to its ultimate tensile strength capacity rather than a pull out ( $\mathrm{Li}$ et al. 2001). The lower bond stresses are formed between the steel rebar and ECC matrix due to the less confinement effect of the PVA fibers that eliminates the shear lag effect (Fischer \& Li, 2002; Hossain \& Anwar, 2014). Therefore the unified combination of ECC's tensile and steel rebar strain cause a high ductility, increase ultimate load and high energy absorption for all ECC's link slabs.

\subsubsection{Influence of Different Fly Ash Replacement on Strain Development}

Increase in FA content improves the tensile strain capacity of the concrete. However, this is not evident from the concrete strain development in Figure 4.9. It should be noted that due to the sensitivity of the strain gauges and breakage at earlier stage of the test, the results for the concrete tensile strain of LS3-ECC-F-2.2- might not be precise. However by observing the lower rebar strain for LS3-ECC-F-2.2-SS in compare with LS4-ECC-F-1.2-SS, it is evidenced that higher concrete tensile strain was developed at higher FA replacement rate. The higher rebar tensile strain development is also attributed to lower tensile strength of ECC with high volume of fly ash as a result of transfer of load to the rebar due to earlier crack development. The increase in FA replacement rate enhanced the interfacial frictional bonding while reducing the matrix toughness and chemical bonding among the fiber and matrix. This property attributes to the increased long term tensile ductility of ECC by $3 \%$ as reported by Wang \& Li (2007). 


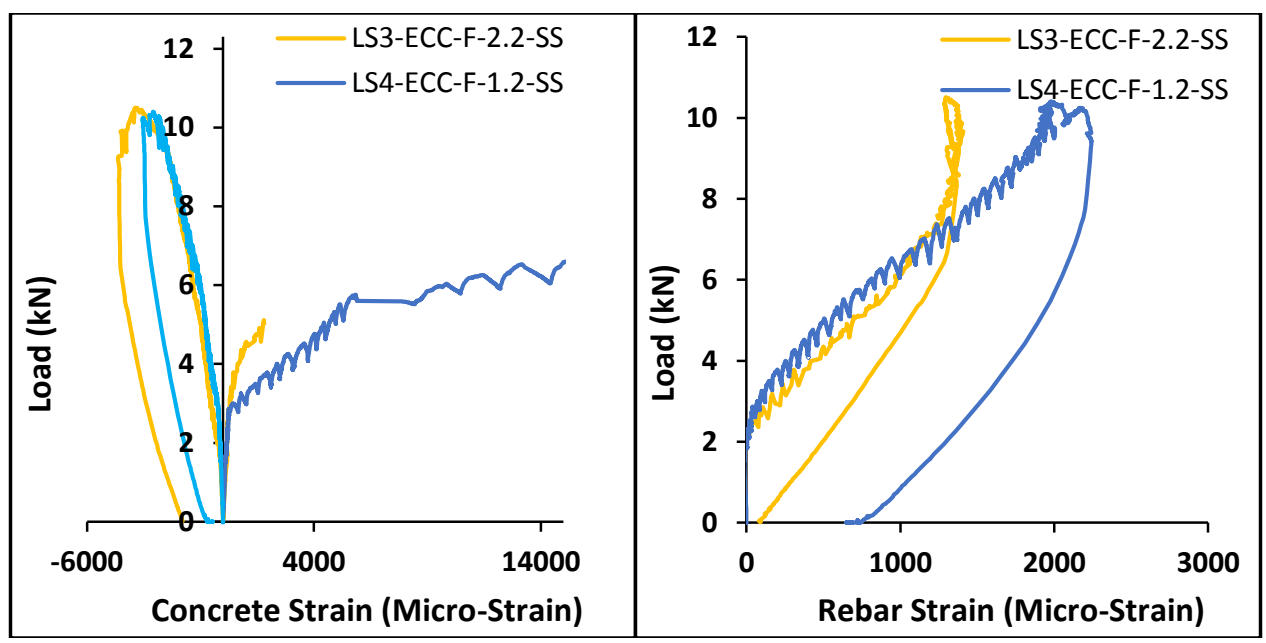

Figure 4.9: Concrete and Rebar Strain Development for ECC with Different FA Replacement

\subsubsection{Different Aggregate Size}

ECC mixes with CS (larger aggregate sizes) developed higher strain compared to SS (lower aggregate size). The contribution of the aggregate interlocking for larger maximum of the crushed and mortar sand aggregate size may have increased the tensile strain capacity of the ECC link slabs (Hossain \& Anwar, 2014).

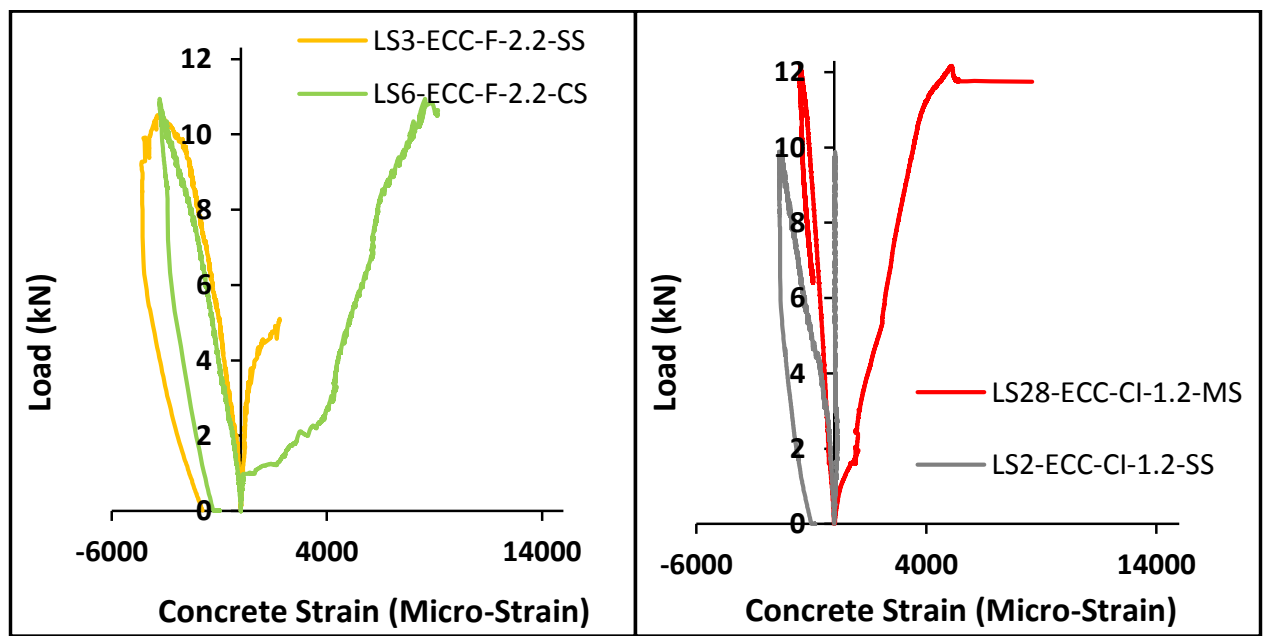

Figure 4.10: Concrete Strains Development for ECC Link Slabs with Different Sand Sizes 

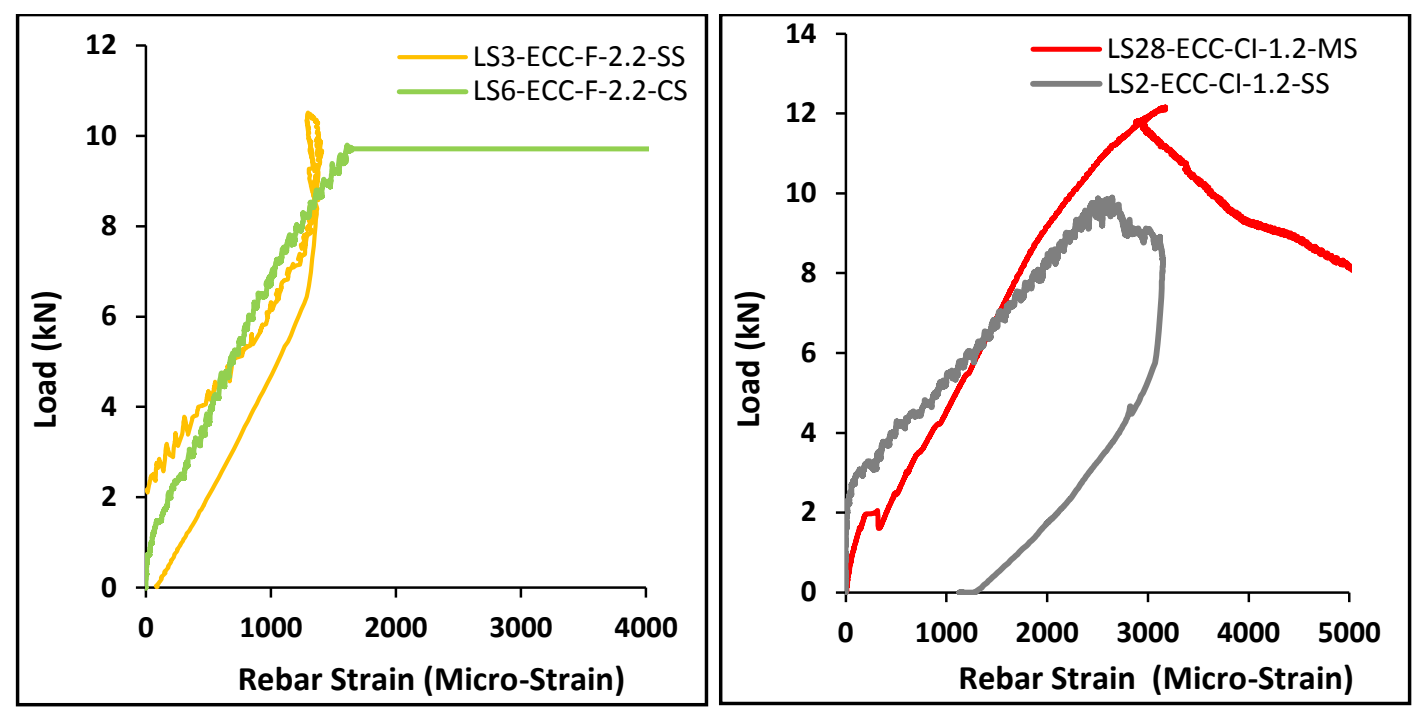

Figure 4.11: Rebar Strain Developments for ECC Link Slabs with Different Sand Sizes

\subsubsection{Crack Characterization}

The cracks for all ECC and SCC link slabs were formed at the tension faces and were extended across the entire slab width indicating flexural behavior. For all link slabs the cracks were developed only in the debonding zone as can be seen in Figure 4.12, no cracks were formed within the transition zone. This observation proved that $5 \%$ debonding zone and $2.5 \%$ transition zone length with the addition of the shear studs as proposed by Qian et al. (2009) was sufficient for maintaining the stress concentration within the link slab. With increasing load and deflection, multiple micro-cracking occurred for the ECC link slabs and the crack width increased until it stabilized between 50 to $115 \mu \mathrm{m}$ before the failure. The bending failure of the ECC link slabs occurred when the fiber bridging was reached for one of the cracks resulting in localized deformation. In contrast for SCC link slab a major crack was formed at the first crack loading and as the load was increased the crack width increased drastically to $3 \mathrm{~mm}$ until it reached the failure (Figure 4.13). All crack width measurements were performed in the unloading stage by using crack microscope. The crack closure was observed for all ECC link slabs during the unloading stage by $30 \%$. The summary of the crack characterization for all link slabs in terms of the number of the cracks and the range of crack width are presented in Table 4.4. The range of the cracks widths were measured for at least 10 major cracks development in the centre of the link slabs. 
Table 4.4: Crack Characterization for Different Link Slabs

\begin{tabular}{|c|c|c|}
\hline Designation & No of micro-crack & $\begin{array}{c}\text { Range of Crack Width } \\
(\mu \mathrm{m})\end{array}$ \\
\hline LS2-ECC-CI-1.2-SS & 26 & $50-75$ \\
\hline LS3-ECC-F-2.2-SS & 48 & $50-75$ \\
\hline LS4-ECC-F-1.2-SS & 30 & $50-75$ \\
\hline LS6-ECC-F-2.2-CS & 15 & $50-75$ \\
\hline LS10-ECC-CI-2.2-SS & 25 & $50-75$ \\
\hline LS11-ECC-CI-2.2-CS & 11 & $50-75$ \\
\hline LS28-ECC-CI-1.2-MS & 15 & $50-115$ \\
\hline LS25-SCC & 1 major crack & 3200 \\
\hline LS32-SCC & 1 major crack & 3000 \\
\hline
\end{tabular}

It is noted from Table 4.4 that the crack width for all ECC link slabs were below $115 \mu \mathrm{m}$ in contrast to the SCC link slabs which was $3 \mathrm{~mm}$. In terms of the durability and serviceability state, the crack widths for the ECC links slabs were below the current AASHTO Standards Specification for Highway Bridges (2002) which is $330 \mu \mathrm{m}$. 


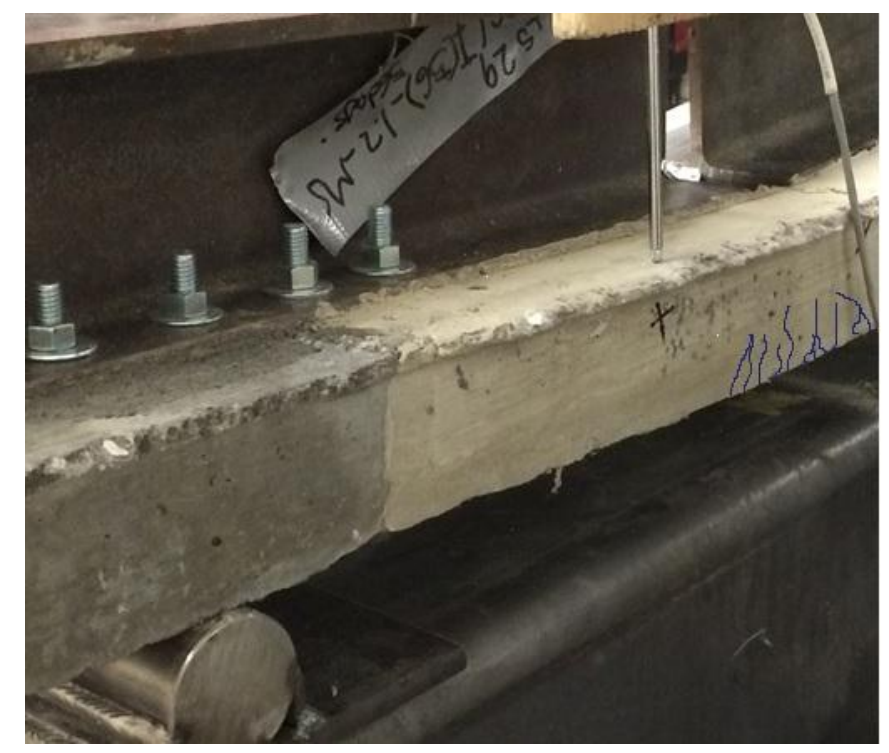

Figure 4. 12: Crack Characterization in Transition Zone

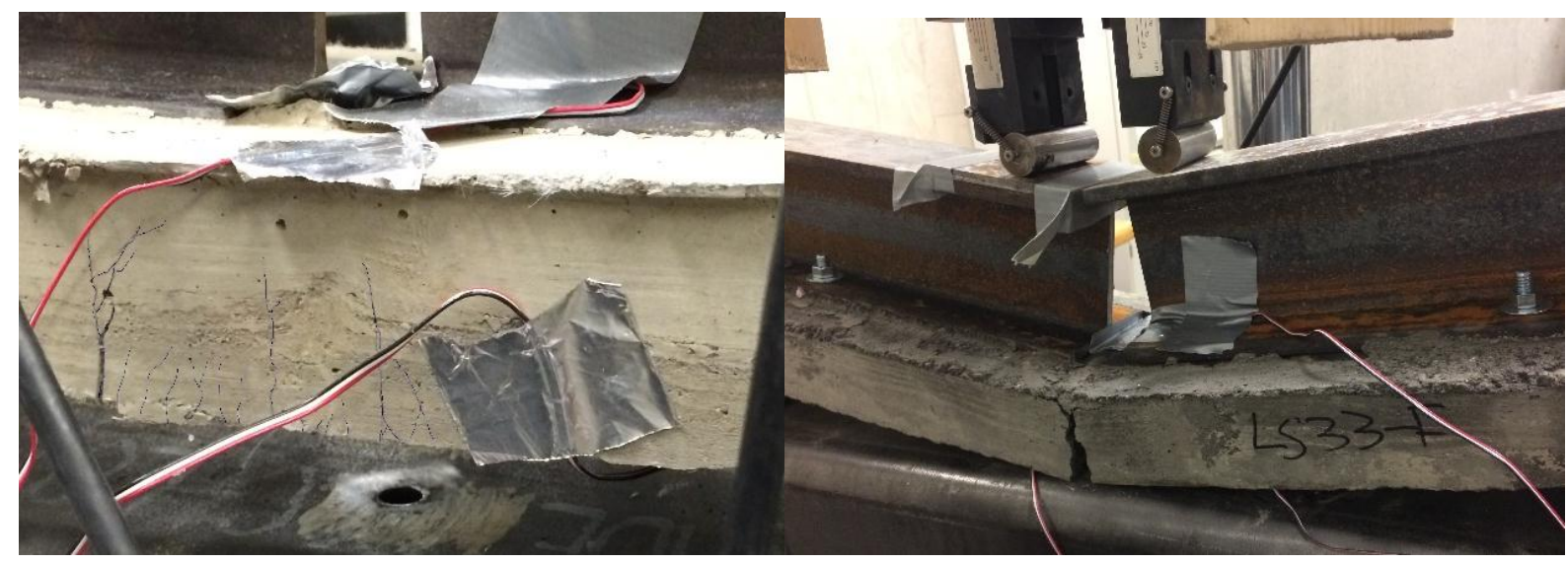

(a)ECC Link Slab

(b) SCC Link Slab

Figure 4.13: Crack Propagation and Failure of ECC and SCC link slabs

The number of the micro-cracks increased when the FA content increased from 1.2 to 2.2 for the ECC link slabs as higher FA content lowered the matrix toughness, which resulted as the easier work of fracture.

Use of Class CI fly ash decreased the number of cracks compared to fly ash class F. Use of CS or MS also reduced the number of micro-cracks compared to those with SS (Table 4.4). Class CI fly ash produces ECCs with higher matrix toughness (because of more calcium content) compared to those with class $\mathrm{F}$ and hence, produces lower number of cracks. The increase in 
maximum size of aggregate (MAS) results in better aggregate interlocking which increases the matrix toughness and work of fracture for cracks propagation (Sahmaran et al. 2009). Within the same MAS, mortar and crushed sand; the link slabs with the crushed sand exhibited lower number of the cracks and crack widths in compare with the mortar sand. Once again the angular shape of the crushed sand provides better aggregate interlocking which enhances the fracture work in compare with the mortar sand (which has rounded particle).

\subsubsection{Energy Absorbing Capacity and Ductility of Link Slabs}

The energy absorbing capacity for the link slabs (summarized in Table 4.5) was determined by the area under the load-deflection curves (Figure 4.1) up to the post-peak load of $85 \%$ of the ultimate/peak load. From Table 4.5, it is observed that all ECC link slabs have higher energy absorbing capacity compared to their SCC counterparts. Even the minimum energy absorbing capacity of 81.2 joules for ECC link slab is 2.5 times higher than 35.3 Joules of SCC link slab. The high energy absorption capacity indicates the superior strain hardening behavior of the ECC mixes. As it is observed from the load-deflection response in Figure 4.1, the high energy absorption capacity of ECC link slabs were associated with the higher ultimate load and deformation capacity (ductility) compared to SCC.

The ductility index was determined based on the ratio of energy at the $85 \%$ of the peak load to the peak load energy of the link slabs (AASHTO, 2012; Wang \& Belarbi, 2011). While the energy based ductility indexes for all ECC link slabs were greater than their SCC counterpart, they also satisfied the proposed ranges of 12-25 of the ASTM C1018 (1997) standard for the fiber reinforced concrete for the post-peak failure. The high ductility index proves that ECC at post failure maintains its strength which attributes to its ductile failure in contrast to the brittle failure of the SCC link slab.

The high energy absorbing and ductility performance make ECC an excellent material for the construction of link slab s in comparison to the SCC. This attribute allows the flexible ECC link slab to form hinges and allows the adjacent simply supported bridge spans to deform freely. 
Table 4.5: Energy Absorption and Ductility Responses of Link Slabs

\begin{tabular}{|c|c|c|c|c|}
\hline Designation & $\begin{array}{c}\text { Energy at 85\% } \\
\text { ultimate load } \\
(\mathrm{J})\end{array}$ & $\begin{array}{c}\text { Energy ratio } \\
\text { with respect to } \\
\text { SCC }\end{array}$ & Ductility Index & $\begin{array}{c}\text { Ductility ratio } \\
\text { with respect to } \\
\text { SCC }\end{array}$ \\
\hline LS2-ECC-CI-1.2-SS & 81.6 & 2.31 & 19.778 & 1.47 \\
\hline LS3-ECC-F-2.2-SS & 111.59 & 3.16 & 29.189 & 2.16 \\
\hline LS4-ECC-F-1.2-SS & 81.25 & 2.3 & 24.167 & 1.79 \\
\hline LS6-ECC-F-2.2-CS & 107.57 & 3.06 & 32.766 & 2.43 \\
\hline LS10-ECC-CI-2.2-SS & 88.18 & 2.49 & 15.979 & 1.19 \\
\hline LS11-ECC-CI-2.2-CS & 85.05 & 2.41 & 14.398 & 1.07 \\
\hline LS28-ECC-CI-1.2-MS & 92.84 & 2.63 & 37.220 & 2.76 \\
\hline LS25-SCC & 37.4 & 1.05 & 14.55 & 1.07 \\
\hline LS32-SCC & 35.31 & 1 & 13.477 & 1 \\
\hline
\end{tabular}

The increased FA content resulted as a higher energy absorption capacity and ductility index for the ECC link slabs. The increased ductility index at higher FA content indicates the improved bending capacity response at post failure. As previously stated, the improved ductility of the ECC by increasing the FA content resulted from the reduction of the toughness matrix while improving the frictional bonding of the matrix and the PVA fiber which improves the bending capacity and the ductility index. The energy absorbing capacity and ductility index were improved at higher MAS of sand due to the improved ultimate strength capacity and increased in stiffness of the matrix. The higher energy absorbing capacity followed by fiber bridging characteristic at the post-peak failure improved the ductility index of the ECC mixes with increase in MAS.

\subsubsection{Stiffness}

The initial stiffness of all link slab specimens calculated from load-deformation responses is tabulated in Table 4.6. The comparative stiffness plots for the ECC and SCC link slabs are also presented in Figure 4.14. 
Table 4.6: Summary of Link Slab's stiffness

\begin{tabular}{|c|c|c|}
\hline Link Slab Designation & $\begin{array}{c}\text { First cracking } \\
\text { Load }(\mathrm{kN})\end{array}$ & $\begin{array}{c}\text { First Cracking } \\
\text { Stiffness }(\mathrm{kN} / \mathrm{m})\end{array}$ \\
\hline LS2-ECC-CI-1.2-SS & 3.25 & 120.8 \\
\hline LS3-ECC-F-2.2-SS & 3.25 & 161.4 \\
\hline LS4-ECC-F-1.2-SS & 3.5 & 201.5 \\
\hline LS6-ECC-F-2.2-CS & 3.25 & 173.3 \\
\hline LS10-ECC-CI-2.2-SS & 3.25 & 98.7 \\
\hline LS11-ECC-CI-2.2-CS & 3.5 & 112.8 \\
\hline LS28-ECC-CI-1.2-MS & 3.10 & 205.7 \\
\hline LS25-SCC & 4.86 & 500.1 \\
\hline LS32-SCC & 5.13 & 300 \\
\hline
\end{tabular}

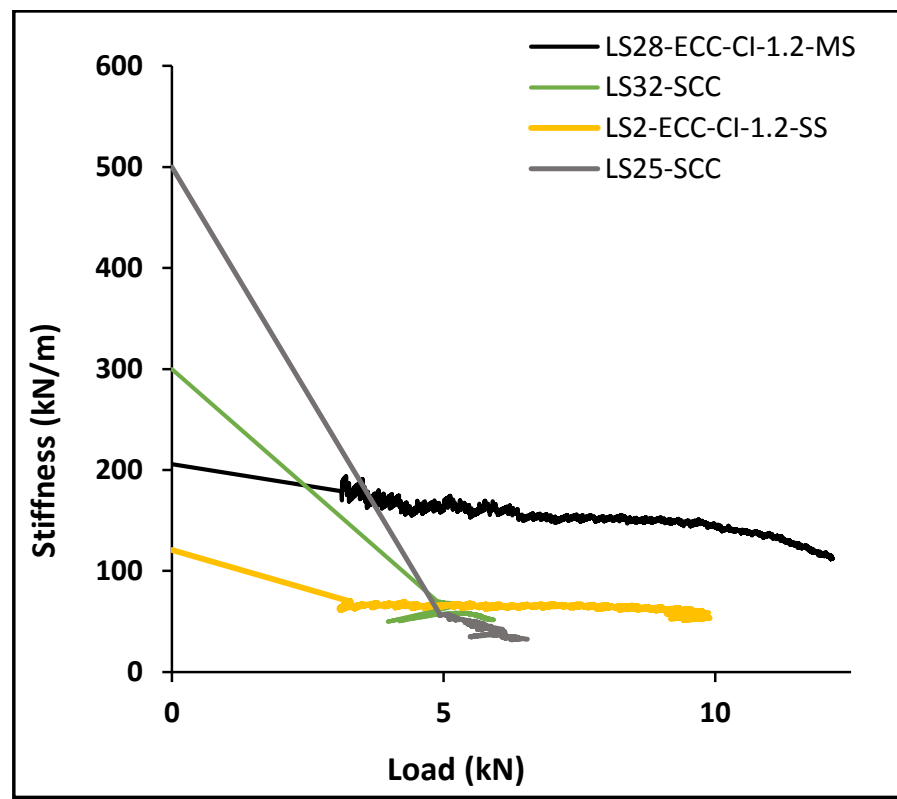

Figure 4.14: Stiffness of ECC and SCC Link Slabs 
The initial stiffness of the ECC link slabs were are around $205 \mathrm{kN} / \mathrm{m}$ and steady decreased with the increase in load until reached to $100 \mathrm{kN} / \mathrm{m}$ at ultimate loading. In contrast, the initial stiffness for the SCC link slabs was higher up to the first crack load showing a value of 500 $\mathrm{kN} / \mathrm{m}$ and decreased rapidly with the increase of load to $75 \mathrm{kN} / \mathrm{m}$ before converges to zero at ultimate loading. The steady state stiffness for the ECC link slabs after the first crack load demonstrates the fiber bridging and strain hardening characteristics.

Additional plots are presented in Figure 4.15 to study the influence of different fly ash content and different aggregate size on the stiffness degradation of ECC link slabs.
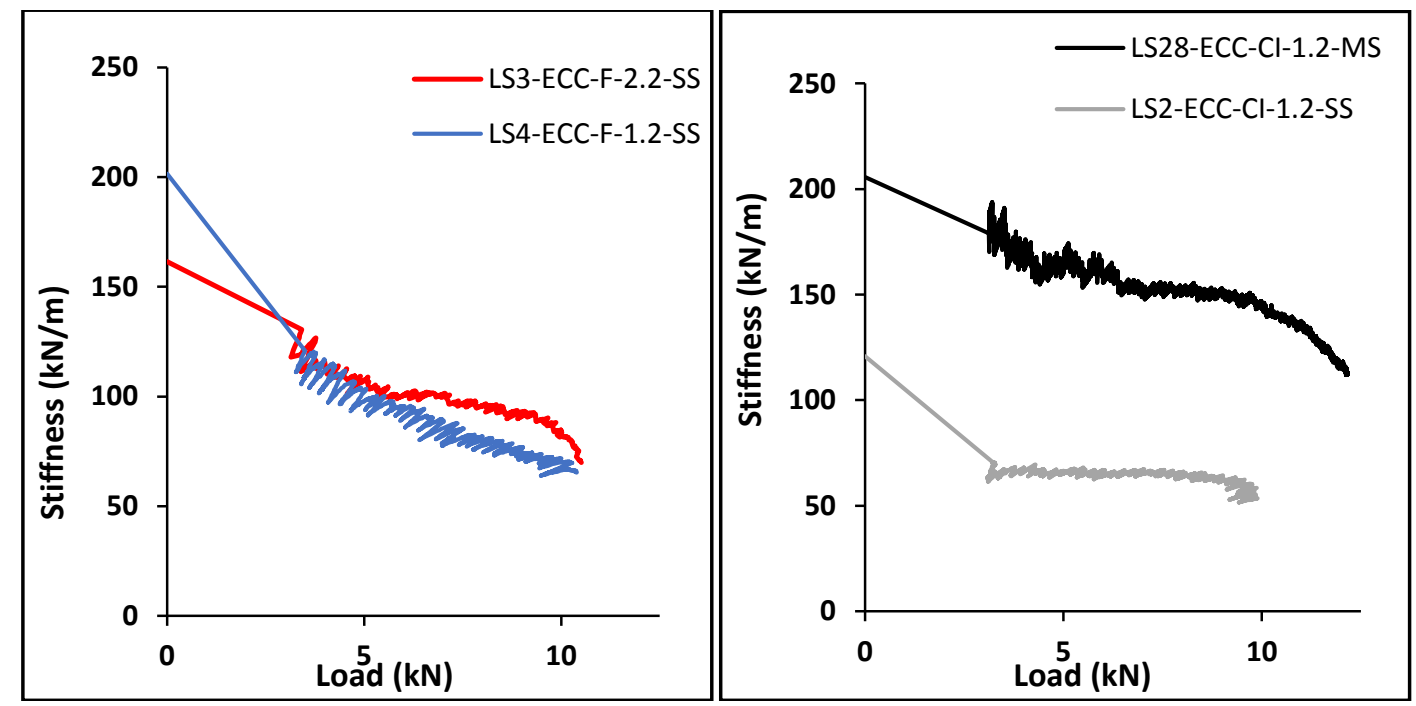

(a) ECC Link Slabs at different FA content

(b) ECC Link Slabs at different aggregate sizes

Figure 4.15: Stiffness evolution of ECC Link Slabs with Load

The lower fly ash content exhibits higher initial stiffness as it is visualized by Figure 4.15(a). However, after first cracking, the stiffness degradation is not influenced by the fly ash content. In contrast, the stiffness of the mortar sand based ECC link slab (at first cracking and ultimate load) is found to be higher compared with silica sand ECC. The stiffness of mortar sand based ECC link slab at pre-cracking and at ultimate loading were $205 \mathrm{kN} / \mathrm{m}$ and $100 \mathrm{kN} / \mathrm{m}$, respectively whereas those for silica sand based ECC link slab were $120 \mathrm{kN} / \mathrm{m}$ to $50 \mathrm{kN} / \mathrm{m}$, respectively. The 
higher stiffness for the mortar sand based ECC link slab is attained by larger aggregate size that improves the loading capacity through aggregate interlocking through enhanced friction.

\subsection{Structure Performance and Evaluation of a Scaled Down Full Bridge with ECC Link Slab Subjected to Static Loading}

For a comprehensive study of a link slab application, two $1 / 6^{\text {th }}$ scale simply supported full bridge

spans (composite Span 1 and Span 2: made steel I-beam and concrete deck connected through shear studs) with connecting ECC link slab (Figure 4.16) were designed and tested under monotonic loading within the elastic limit (up to service stage - 50\% of the design load). The full bridge model was adopted from the full-scale bridge tested by Caner \& Zia (1998) and was designed in accordance to CHBDC (2006). The ECC mix with mortar sand and 55\% fly ash CI (ECC-CI-1.2-MS) was used for the link slab construction and SCC was used for the adjacent bridge deck portions. This section presents the results of this experimental investigation in terms of the load-deformation/rotation responses, followed by comparative analysis with available theoretical models. In addition experimentally obtained location of inflection points was compared with those suggested by design specification.

\subsubsection{Load-Deformation/Moment-Rotation Responses and Theoretical/Code Based Analyses}

The load-deformation responses for the SCC simply supported spans (Span 1 and Span 2) and the ECC link slab were monitored through the linear variable differential transformers (LVDT) installed at strategic locations including at the maximum moment location through a computer aided data acquisition system. The applied loading was selected as 50\% of the design load of the bridge span (normally considered in a real bridge structure at the service load stage) for analyzing the performance of ECC link slab. After extensive analysis and design, the applied service load for each simply supported composite bridge deck span was selected as $50.49 \mathrm{kN}$. For a comprehensive understanding a schematic representation of the full joint-free bridge model showing applied loading points and instrumentation (such as location of strain gauge and LVDTs inclinometer including their numbers) is presented in Figure 4.16. 


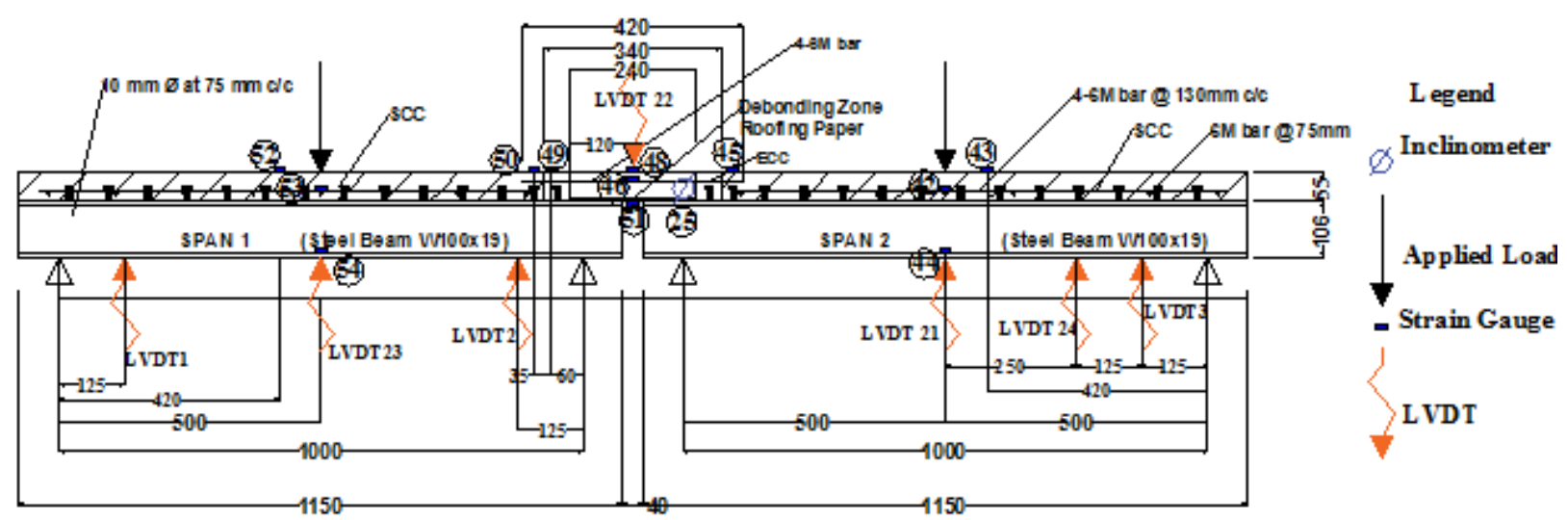

Figure 4.16: Schematic Representation instrumentations locations and designations for the $1 / 6^{\text {th }}$ Scale Full Bridge Model (dimensions are in $\mathrm{mm}$ )

For validation of simply supporting performance of the adjacent spans, the experimental deflection $(\Delta)$ and support end rotation $(\theta)$ at the applied loading of $50.49 \mathrm{kN}$ on each span were compared with those calculated based on theoretical calculations [Equations 4.1 and 4.2].

$$
\begin{aligned}
& \Delta=\frac{P L^{3}}{48 E I} \\
& \theta=\frac{P L^{2}}{16 E I}
\end{aligned}
$$

where P, L, E and I denotes applied loading on each span at midpoint length of the spans, modulus of elasticity and second moment of inertia of the composite bridge span.

The experimental load-deformation/rotation responses for the full bridge structure are presented in Figures 4.17 and 4.18. Due to similar behaviour of adjacent spans, it was decided to only present the results for the SCC-SPAN 2 (SP2-SCC) and ECC link slab (LS-ECC) (Figure 4.16). Table 4.7 summarizes the key results from the experiments and theoretical analysis. 
Table 4.7: Key results from Load-Deformation/Moment Responses of the Full Bridge Models with ECC Link Slab

\begin{tabular}{|c|c|c|c|c|c|c|c|}
\hline & & & \multicolumn{2}{|c|}{ Experimental } & \multicolumn{2}{|c|}{$\begin{array}{c}\text { Theotical (Based on SCC } \\
\text { simple span) }\end{array}$} \\
\hline Section & $\begin{array}{c}\text { Reinforcing } \\
\text { Ratio }\end{array}$ & $\begin{array}{c}\text { Applied } \\
\text { Load } \\
(\mathrm{kN})\end{array}$ & $\begin{array}{c}\text { Applied } \\
\text { Moment } \\
(\mathrm{kN} . \mathrm{m})\end{array}$ & $\begin{array}{c}\text { Maximum } \\
\text { Deflection } \\
(\mathrm{mm})\end{array}$ & $\begin{array}{c}\text { Maximum } \\
\text { Rotation } \\
\text { (Radian) }\end{array}$ & $\begin{array}{c}\text { Deflection at } \\
\text { Maximum } \\
\text { Applied } \\
\text { Load (mm) }\end{array}$ & $\begin{array}{c}\text { Rotation at } \\
\text { Maximum } \\
\text { Applied Load } \\
\text { (Radian) }\end{array}$ \\
\hline SP2-SCC & 0.01 & 50.49 & 12.62 & $\begin{array}{c}0.987 \\
\text { (downward) }\end{array}$ & $0.00303^{* *}$ & 0.862 & 0.00258 \\
\hline LS-ECC & 0.01 & 0 & $1.67^{*}$ & $\begin{array}{c}0.315 \\
\text { (upward) }\end{array}$ & $0.00268^{* * *}$ & 0 & 0.00258 \\
\hline
\end{tabular}

*Induced Moment calculated by Equation 2.6

** Outer SCC support

${ }^{* * *}$ Inner SCC support (ECC and SCC interface)

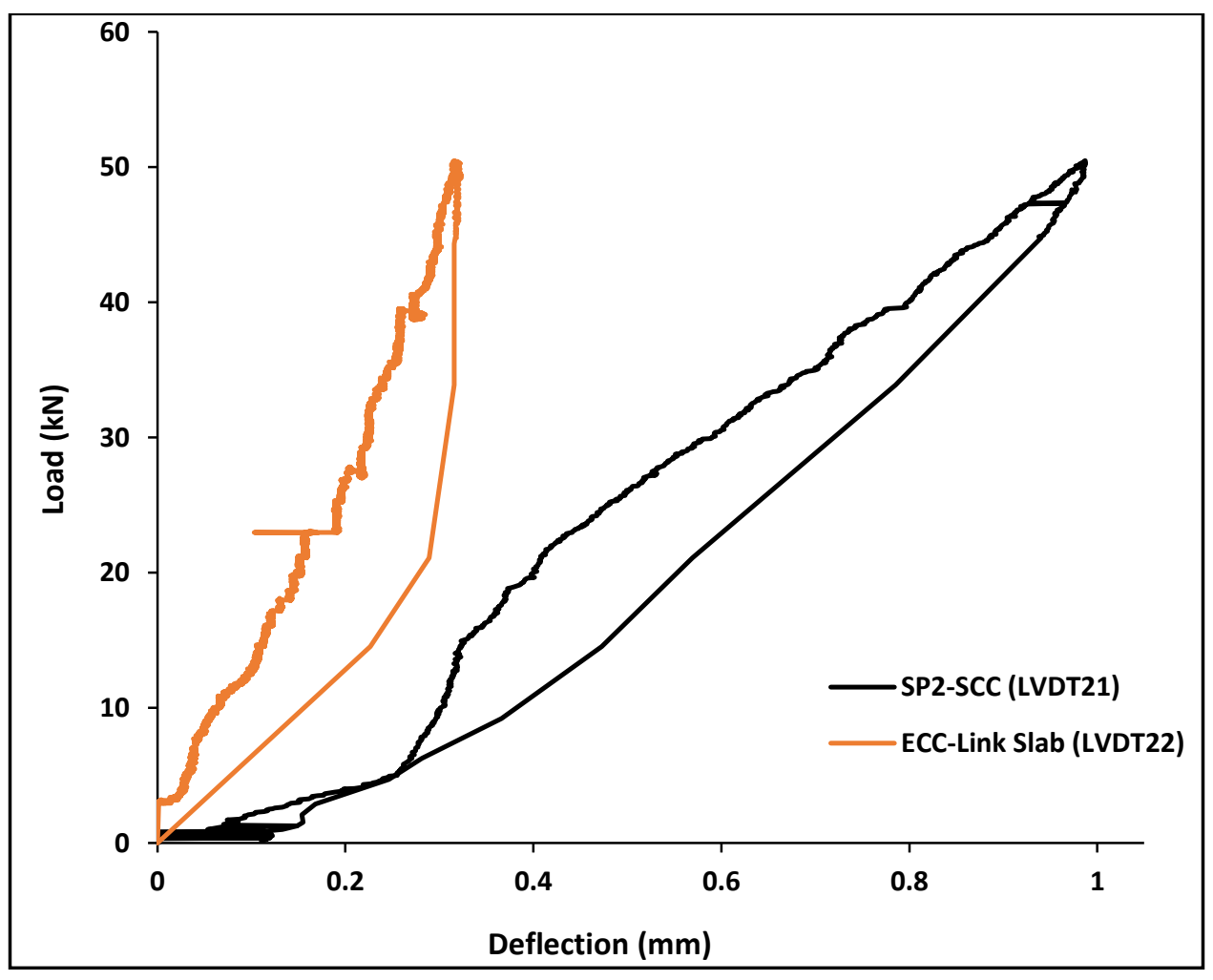

Figure 4.17: Load-Deflection Response of a Full Bridge with ECC Link Slab 
As it was expected, the SCC spans deformed downward while the ECC link slab deformed upward due to the continuity of the bridge deck and development of positive and negative moment. For applied loading of $50.49 \mathrm{kN}$ (at service load-stage), the mid-span deflections for the SP2-SCC and LS-ECC were $0.987 \mathrm{~mm}$ downward and $0.315 \mathrm{~mm}$ upward, respectively (Table 4.7).

The linear load-deflection response presented in Figure 4.17 demonstrates that ECC-Link Slab and SP2-SCC are within the elastic limits as the test was originally designed to be conducted at the service stage. At the service load stage, the induced moment on the ECC link slab was 1.67 kN.m (calculated by Equation 2.6), only $10 \%$ of the designed ultimate ECC link slab capacity. The low induced moment justifies the small deflections on the ECC link slab. The small induced moment at the service load stage indicates the prolonged life for the ECC link slab. Based on these analysis, the failure of the SCC bridge span within the full bridge is expected to occur rather than the ECC link slab.

The experimental mid-span deflection for the SP2-SCC span was compared with theoretical simple span deflection (calculated using Equation 4.1) at the maximum applied loading. The theoretical deflection $(0.862 \mathrm{~mm})$ was slightly lower than the experimental deflection $(0.987$ $\mathrm{mm}$ ) - such negligible difference between them proves that full bridge model behaved as a two simply supported spans with a connecting ECC link slab. This proves that flexible ECC link slab allows the rotation of adjacent bridge girder as desired. 


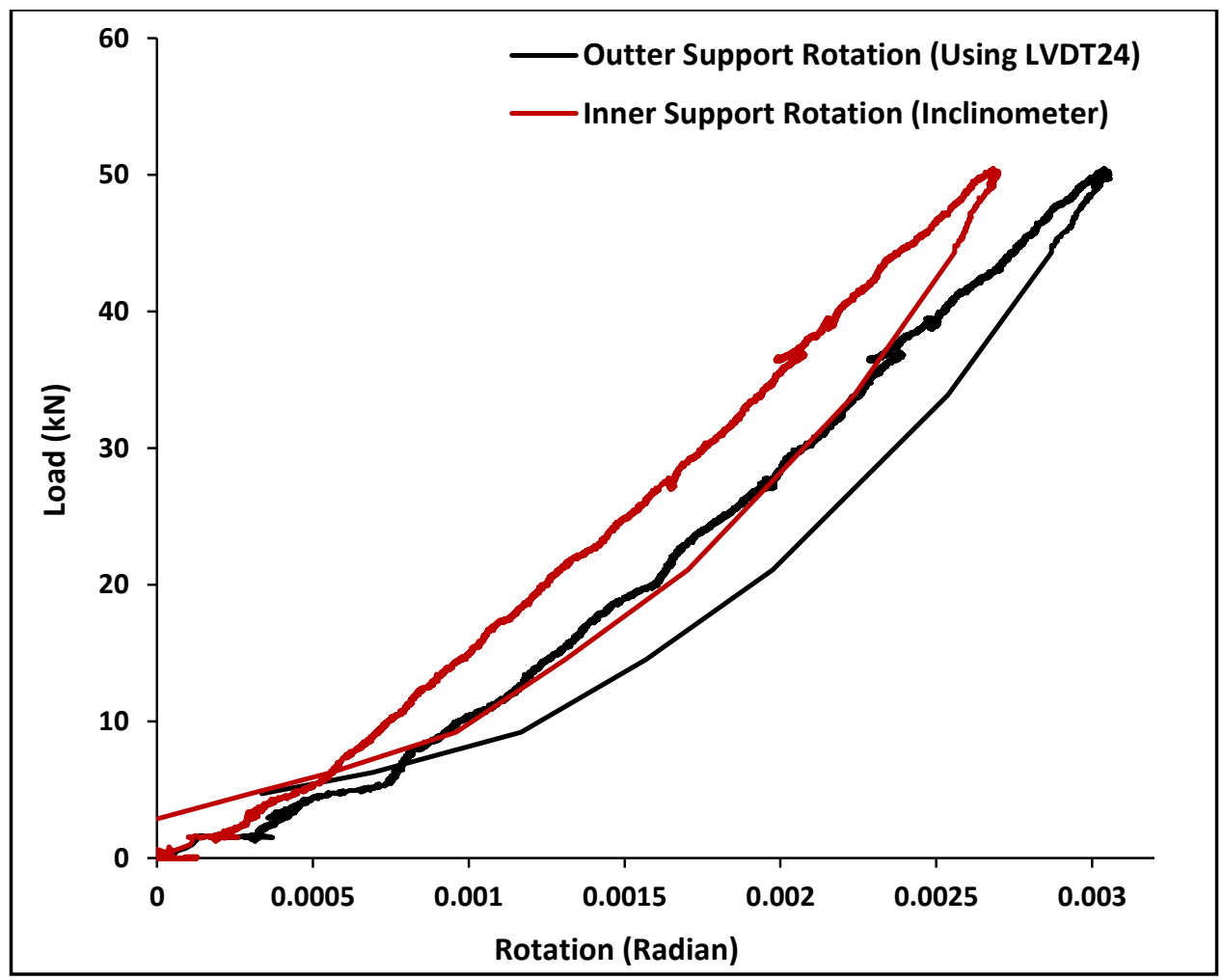

Figure 4.18: Load-Rotation Response of Full Bridge with ECC Link Slab

While the concrete deck was continuous due to the connecting ECC link slab, the steel girders for the SCC spans were designed as simply supported. In theory, equivalent inner and outer support rotations for the SCC spans are required for allowing the steel girders to deform freely as simply supported spans.

From the experimental results presented in Figure 4.18 and Table 4.7 it is observed that the inner support rotation (LS-ECC and SP2-SCC interface) was smaller in compare with the outer support (SP2-SCC). The inner and outer support rotation at service load-stage of $50.49 \mathrm{kN}$ were 0.00268 and 0.00303 radian respectively. Even though ECC link slab exhibits a high bending capacity associated with low stiffness, it restrained the movement of the support rotation therefore a small difference is evidenced between the inner and outer support. The negligible difference (only 11.5\%) among the inner and outer support rotation, followed by comparative analysis of experimental and theoretical (Equation 4.2) support end rotation proves that ECC link slab with low stiffness/high flexibility and high ductility maintains the simply supporting 
performance of the adjacent bridge girders (similar to a construction joints used between two adjacent spans in traditional bridge construction).

The experimental support end rotations (both inner and outer support) at service load stage satisfy the maximum allowable AASHTO (2012) end rotations of 0.00375 radian. These attributes prove that ECC is a suitable material for the link slab application since it satisfies the ultimate and serviceability limit states.

\subsubsection{Strain Development Characteristics}

As it was expected, tensile strain/stresses were developed at the bottom flanges of the steel Igirders for the SCC spans and on top of the ECC link slab due to the developments of the positive and negative moments. The summary of the strain developments for the composite SCC sections (including concrete, rebar and steel girder), and ECC link slabs are presented in Table 4.8. Figure 4.19 presents the development of strain (concrete/rebar/steel I-girder) with load for SCC girder and ECC link slab (location of numbered gauges are shown in Figure 4.16.

Table 4.8: Strain Developments for the Full Bridge with ECC Link Slab

\begin{tabular}{|c|c|c|c|c|c|}
\hline & & & \multicolumn{3}{|c|}{ Strain Development } \\
\hline Section & $\begin{array}{c}\text { Reinforci } \\
\text { ng Ratio }\end{array}$ & $\begin{array}{c}\text { Applied } \\
\text { Loading } \\
(\mathrm{kN})\end{array}$ & Tensile (micro-Strain) & $\begin{array}{c}\text { Concrete } \\
\text { Compressive } \\
(\text { micro-strain) }\end{array}$ & $\begin{array}{c}\text { Rebar } \\
\text { (micro- } \\
\text { strain) }\end{array}$ \\
\hline LS-ECC & 0.012 & 50.49 & 101 (Concrete, top of ECC link slab ) & -41 & +64 \\
\hline SP2-SCC & 0.012 & 50.49 & 438 (bottom flange of steel girder) & -282 & -259 \\
\hline
\end{tabular}

- Compression strain; + tensile strain 


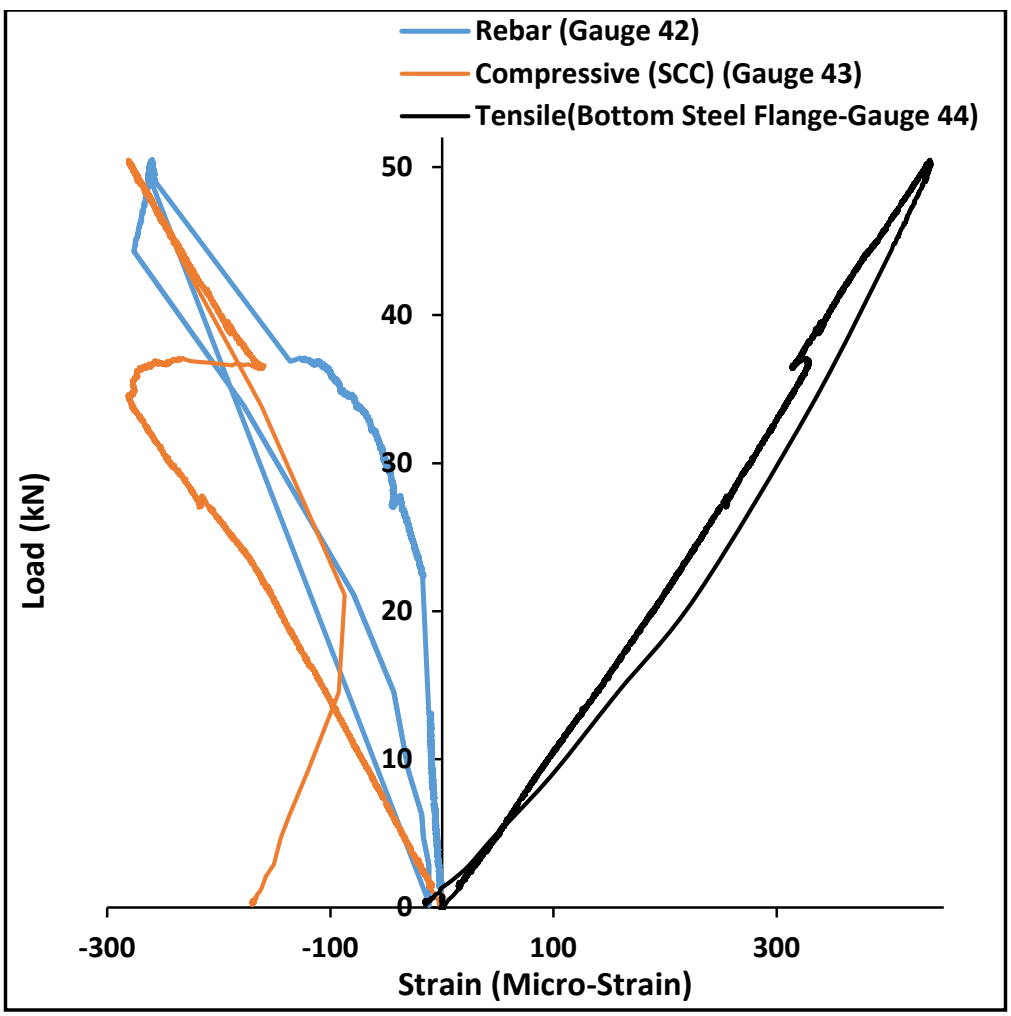

(a) SP2-SCC

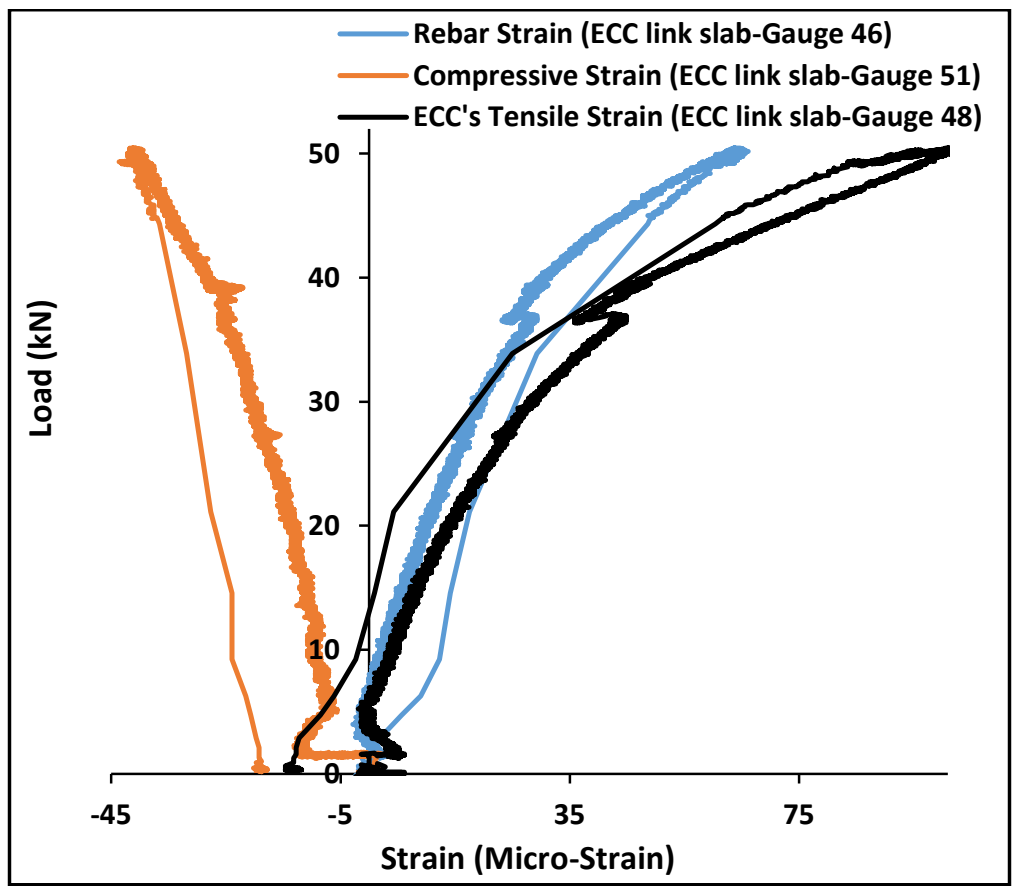

(b ) LS-ECC

Figure 4.19: Strain Developments for a Full Bridge with ECC Link Slab 
It can be noted from Figure 4.19(a) that the SP2-SCC (including compressive strain in concrete and rebar and tensile strain at the bottom flange of steel girder) demonstrate elastic linear strain developments. The compressive strain development for the SP2-SCC rebar indicates that the concrete deck is under compression and signifies that location of the elastic neutral axis is within the web of the steel girder which confirms the theoretical location of the neutral axis.

At the service load stage, the ECC link slab exhibited low strain developments (Figure 4.19b and Table 4.8). The negligible concrete tensile and rebar strain developments (only 101 micro-strain and 64 micro-strains) indicates the unused high strength capacity of the ECC link slab even at service load of adjacent girder. The strain development characteristics also justifies that SCC sections will fail in prior to the ECC link slab. As a result, a further reduction of the reinforcing bar is recommended for reducing the stiffness of the ECC link slab due to the strain hardening characteristic and high tensile strain capacity.

\subsubsection{Comparative Analysis of Experimental and Theoretical Location of Inflection Points}

The zero strain development along the length of the bridge span demonstrates the location of the hinges and the points of the inflections in the bridge spans (Figure 3.1). The distance between these points of inflections represents the length of the link slab specimen (Lepech \& Li, 2009; Caner \&Zia, 1998). Based on the stiffness of the link slab, the location of inflection point varies from 0 and $20 \%$ of the span's length. For the ECC link slab with a low stiffness and higher bending capacity the points of inflection is recommended as $7.5 \%$ of the adjacent bridge spans (Lepech \& Li, 2009). The top fiber strain developments (Gauges 52, 50, 49, 48, 45, 43) for the full bridge model (along the length of the bridge) was used for determining the experimental location of the inflection points/hinge formation. The experimental hinge location and total length of the link slab are illustrated in Figures 4.20 and 4.21 respectively. 


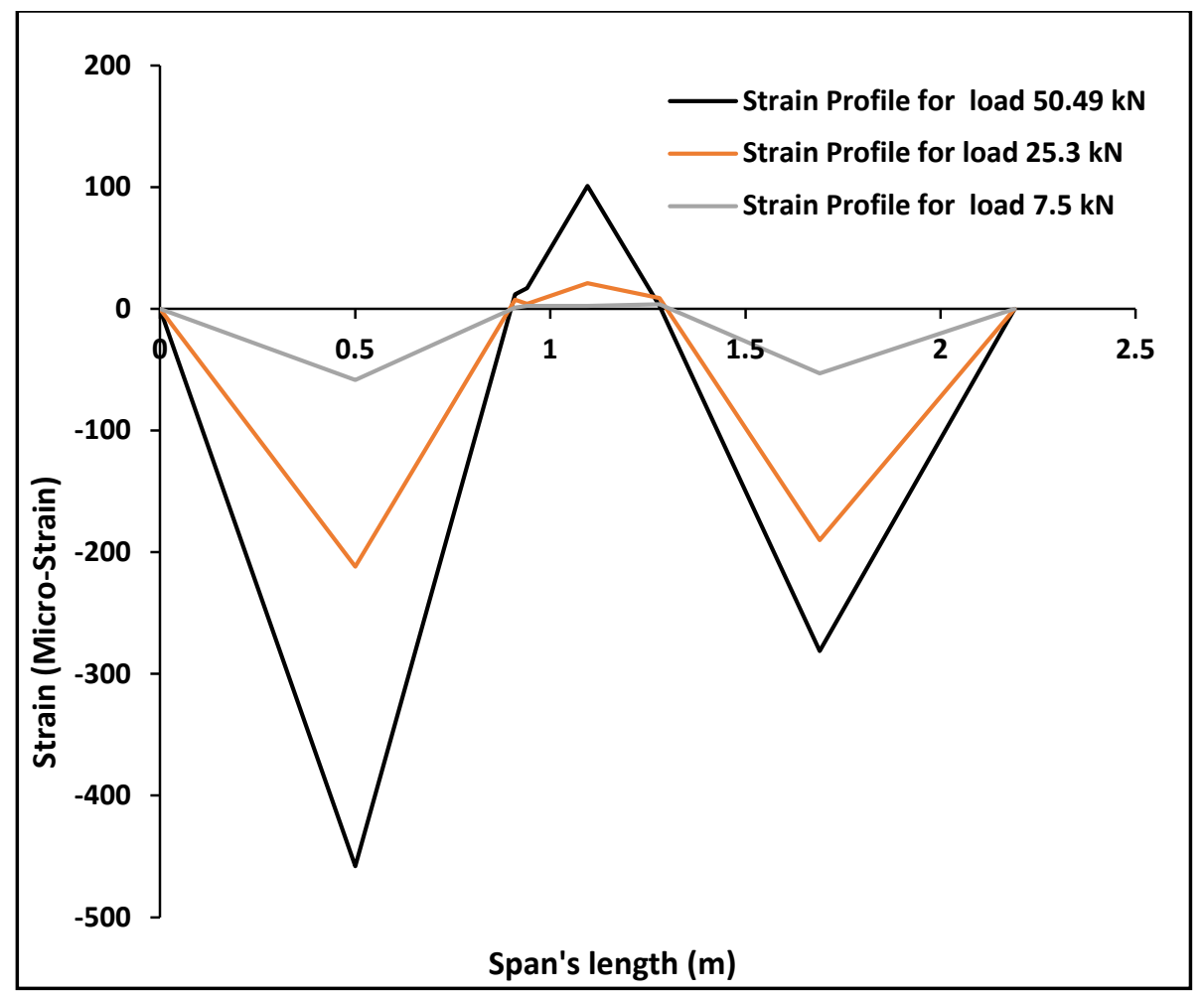

Figure 4.20: Top Fiber Strain Profile for Full Bridge with ECC Link Slab at Different Loading

As it is observed from Figure 4.20 and 4.21, for various load levels, the hinges were formed at $910 \mathrm{~mm}$ and $1280 \mathrm{~mm}$ from the left support (location of zero strain) on the adjacent bridge spans. As a result, the total length of the link slab is found to be $370 \mathrm{~mm}$.

While the experimental length of the link slab was $370 \mathrm{~mm}$, the design length was limited to 340 mm (designed according to Lepech \& Li, 2009 approach). The small difference between the experimental and design length of the link slab (ratio of experimental to design length of 1.08) was influenced by the stiffness of the ECC link slab that provided rotational restraint to the adjacent spans. In the experimental full bridge, the hinges were formed at $9 \%$ of the adjacent spans rather than $7.5 \%$ suggested by the design specification. However, only $8 \%$ difference between experimental and design recommendation seemed to be very good. The high ductility and flexibility of the ECC link slab are exhibited and capability of ECC link slab in allowing adjacent spans to deform (rotate) freely for maintaining the traditional simply support span design approach is demonstrated. 


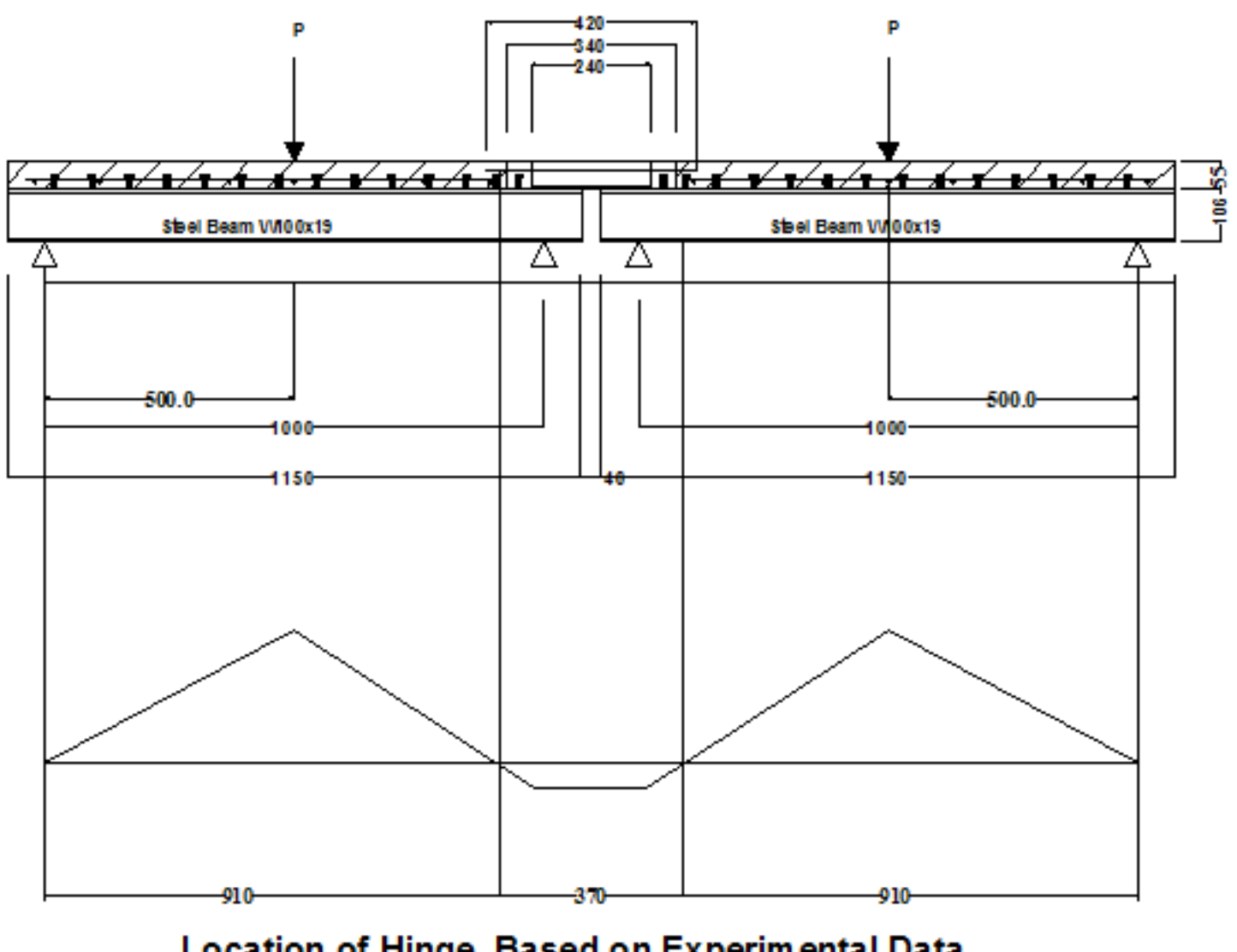

Figure 4.21: Schematic Representation for Location of Inflection Points (Dimensions are in $\mathrm{mm})$

\subsection{Summary}

This chapter described the results of for monotonic performance of the $1 / 4^{\text {th }}$ scale link slab specimens incorporating different green cost-effective ECC mixes subjected to failure under monotonic loading. In addition, the performance of ECC link slab is demonstrated by conducting test on a $1 / 6^{\text {th }}$ scale joint-free full bridge model having two simply supported spans subjected to monotonic loading up to service stage. The results of the $1 / 6^{\text {th }}$ scale full bridge with ECC link slab were evaluated and discussed with available design guidelines proposed by other scholars. The experimental and theoretical analyses confirmed the viability of ECC link slab to construct joint-free bridges satisfying serviceability limit and design specifications. 


\section{CHAPTER FIVE \\ FATIGUE PERFORMANCE OF ONE FOURTH SCALE LINK SLABS}

\subsection{Introduction}

The green sustainable ECC mix made with mortar sand and fly ash CI with good performance (in terms of strain hardening and multiple cracking characteristics (ECC-CI-1.2-MS) was selected to evaluate the flexural fatigue performance of the one-fourth scale link slab specimens. The flexural fatigue testing was performed in three different stages: pre-fatigue behaviour under monotonic loading to failure, fatigue behaviour under cyclic loading at different stress levels and post-fatigue behaviour under monotonic loading to failure. The pre-fatigue monotonic test was performed to evaluate the ultimate strength, bending capacity and strain development of the link slabs and also to determine the applicable fatigue stress levels. After the analysis of the prefatigue monotonic testing, the flexural fatigue loading was performed on companion link slab specimens based on two different approaches. The first approach applied different fatigue stress levels of $40 \%$ and $55 \%$ of the ultimate load (determined from pre-fatigue monotonic testing) at a constant 400000 fatigue cycles. The second approach applied constant fatigue stress level of $40 \%$ at $4 \mathrm{~Hz}$ cyclic loading rate (4 cycles per second) with variable fatigue cycles of 400000 and 1000000. After the fatigue performance, the flexural monotonic test was performed on the exhausted fatigued link slab specimens to determining the residual strength, strain, rotation, energy and stiffness. For a comparative analysis SCC link slabs were also tested under the same conditions. However, it should be noted that SCC link slabs could not be tested at high stress level (at 55\%) and high fatigue cycles (100000) as they failed before reaching the first fatigue cycle exhibiting poor performance under fatigue loading. Therefore, there was no available data for the SCC link slabs at 55\% fatigue stress level and 1000000 fatigue cycle.

This chapter presents the results of the flexural fatigue performance of the $1 / 4^{\text {th }}$ scale link slabs tested in three different stages under pre-fatigue monotonic (already described in Chapter 3 but presented in this chapter from fatigue point of view to compare pre-and post-fatigue behaviour), fatigue and post-fatigue monotonic loading. The fatigue performance for both approaches (variable fatigue stress levels and cycles) are evaluated based on load-deformation responses, 
strain developments, crack characterization, energy absorbing capacity, ductility index and stiffness.

\subsection{Performance of Link Slabs at Different Fatigue Stress Levels}

\subsubsection{Fatigue Performance}

To avoid slippage of the specimens, the link slabs were subjected to pre-monotonic loadings of $40 \%$ and $55 \%$ of the ultimate loads (determined from by ECC and SCC control link slab specimens subjected to monotonic loading to failure) as a ramp into the flexural fatigue loading. In the subsequent fatigue loading, the $40 \%$ and $55 \%$ stresses were selected as the mean fatigue stress levels with a stress range of $\pm 20 \%$ of the ultimate load. As a result the stress ranged from $20 \%$ to $60 \%$ of the ultimate load for the link slab specimen subjected to $40 \%$ mean fatigue stress level. Similarly for the 55\% mean stress level, the applied fatigue stress varied from $35 \%$ to $75 \%$ of the ultimate load.

The SCC link slab subjected to higher fatigue stress range of $\pm 20 \%$ failed at the beginning of the fatigue testing before completing the first cycle. Due to the weak response of the SCC, it was decided to reduce the stress of the SCC link slabs to $\pm 5 \%$ of the mean stress level.

\subsubsection{Load-Deflection Responses and Deflection Evolution}

During the fatigue loading, the mid-span deflection was recorded on the data acquisition system for every cycle. The load deflection responses for the ECC and SCC link slabs at variable fatigue stress levels of $40 \% \pm 20,55 \% \pm 20$ and $40 \% \pm 5$ are presented in Figure 5.1 and key results are summarized in Table 5.1. For comprehensive understanding of stress variations, the mean fatigue stress levels for each link slab specimens are also presented in Figure 5.1. 


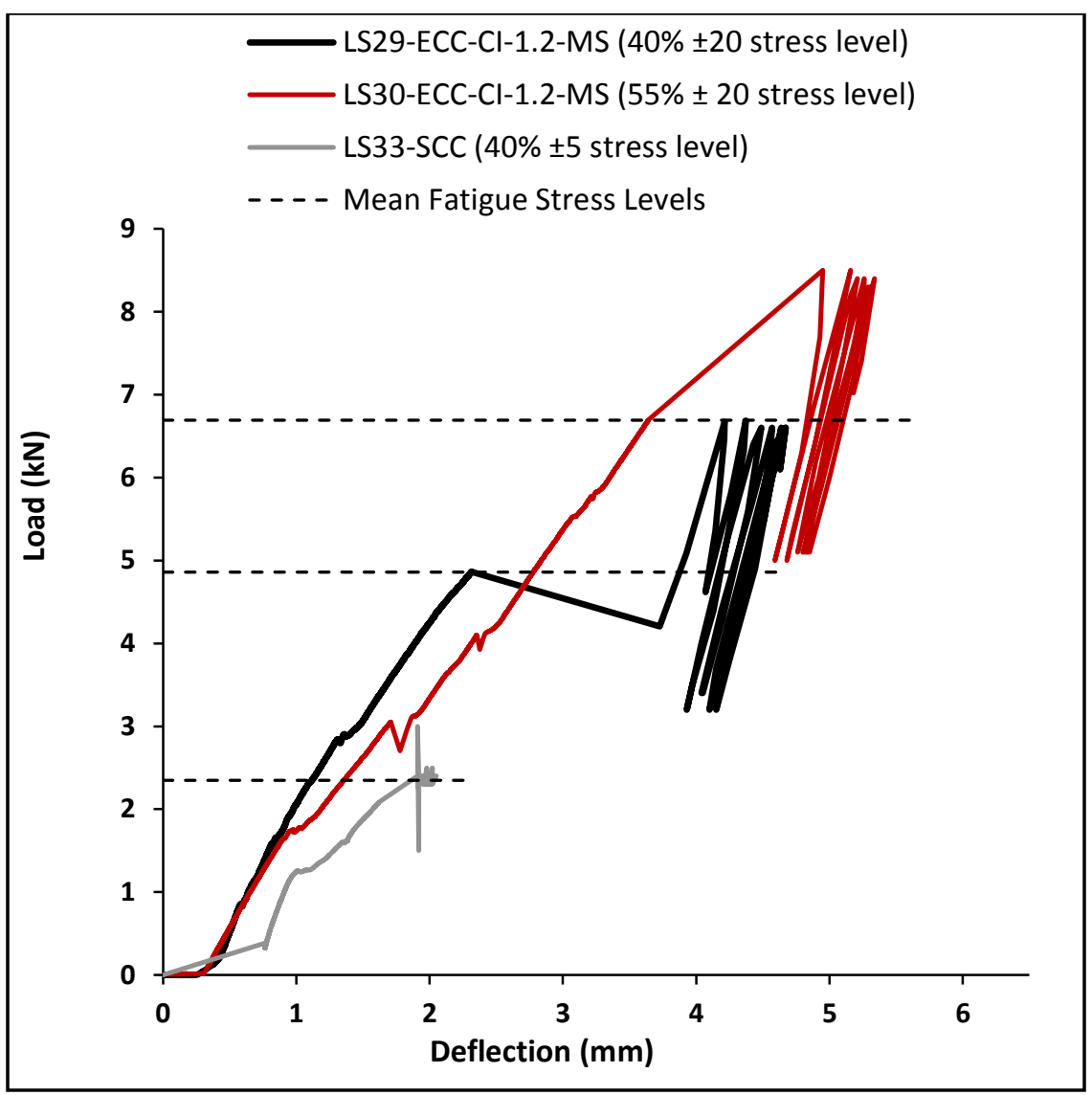

(a) Load-Deflection Response

Figure5.1: Load-Deflection Responses of Link Slabs at Different Fatigue Stress Level

Table5.1: Mid-Span Deflection Evolution at Different Fatigue Stress Level

\begin{tabular}{|c|c|c|c|c|c|c|c|c|}
\hline Designation & $\begin{array}{c}\text { Ultimate } \\
\text { Load } \\
(\mathrm{kN})\end{array}$ & $\begin{array}{c}\text { Mean } \\
\text { Fatigue } \\
\text { Stress } \\
\text { Level } \\
(\%)\end{array}$ & $\begin{array}{c}\text { Fatigue } \\
\text { Stress } \\
\text { Range } \\
(\%)\end{array}$ & $\begin{array}{c}\text { Applied } \\
\text { Fatigue } \\
\text { Loading } \\
(\mathrm{kN})\end{array}$ & $\begin{array}{c}\text { Initial } \\
\text { Deflection } \\
(\mathrm{mm})\end{array}$ & $\begin{array}{c}\text { Deflection } \\
\text { Evolution } \\
\text { for the first } \\
10000 \\
\text { fatigue } \\
\text { cycle }(\mathrm{mm})\end{array}$ & $\begin{array}{c}\text { Final } \\
\text { Deflection } \\
(\mathrm{mm})\end{array}$ & $\begin{array}{c}\text { Difference } \\
\text { between } \\
\text { First and } \\
\text { Last value } \\
\text { of Mid- } \\
\text { Span } \\
\text { Deflection } \\
(\mathrm{mm})\end{array}$ \\
\hline $\begin{array}{c}\text { LS29-ECC-CI- } \\
1.2-M S\end{array}$ & 12.16 & $40 \%$ & $\pm 20 \%$ & $4.86 \pm 2.43$ & 2.31 & 4.1 & 4.7 & 2.39 \\
\hline $\begin{array}{c}\text { LS30-ECC-CI- } \\
1.2-\text {-MS }\end{array}$ & 12.16 & $55 \%$ & $\pm 20 \%$ & $6.69 \pm 2.43$ & 3.63 & 4.9 & 5.35 & 1.72 \\
\hline LS33-SCC & 5.93 & $40 \%$ & $\pm 5 \%$ & $2.37 \pm 0.1$ & 1.62 & 1.91 & 2.04 & 0.42 \\
\hline
\end{tabular}

"Ultimate Load for each link slabs based on pre-fatigue monotonic performance 
It is observed from Figure 5.1 that the mid-span deflection for the ECC link slabs (at $40 \% \pm 20 \%$ and $55 \% \pm 20 \%$ stress level) increased drastically during fatigue loading due to formation of larger deflection band widths in compare with the SCC link slab (at 40\% \pm 5 fatigue stress level) with no band width development. While the increase in deflection for the SCC link slab at $40 \%$ \pm 5 stress level was only $0.42 \mathrm{~mm}$, the increase for both ECC link slabs at $40 \% \pm 20$ and $55 \% \pm 20$ stress level were $2.39 \mathrm{~mm}$ and $1.79 \mathrm{~mm}$, respectively (Table 5.1). The large deflection band width for the ECC link slabs demonstrate a large bending capacity and strain hardening characteristic even at the high fatigue stress range ( $\pm 20 \%$ of ECC's ultimate loading). This shows that after formation of cracks under repetitive fatigue loading at high stress range of $\pm 20 \%$, the bending capacity of the ECC is enhanced; therefore ECC controls the fatigue performance. As previously stated, the SCC link slab at the same high stress range of $\pm 20 \%$ failed before completing a cycle.

From the mid-span deflection evolution curve (Figure 5.2(a)), it is observed that all link slab specimens (ECC and SCC) deform more at the initial fatigue cycles. The ECC link slab at $40 \% \pm$ 20 fatigue stress level deforms from $2.31 \mathrm{~mm}$ to $4.10 \mathrm{~mm}$ and the SCC link slab at $40 \% \pm 5 \%$ fatigue stress level deforms from 1.62 to $1.91 \mathrm{~mm}$ at the initial 10000 fatigue cycle (Figure 5.2(a)). The high deflection evolution at the initial fatigue cycle was caused by the stress jump from the mean stress (attained by the monotonic loading) to high fatigue stress ranges $( \pm 20 \%$ for the ECC and $\pm 5 \%$ for the SCC link slabs).

It is also noted from Table 5.1 and Figure 5.1 that larger deflection band width was developed for the ECC link slab at $40 \% \pm 20$ fatigue stress level in compare with the ECC specimen at 55\% \pm 20 stress level. The change in mid-span deflection for the ECC link slab at $40 \% \pm 20$ was 2.39 $\mathrm{mm}$ whereas the change for the ECC link slab at 55\% \pm 20 stress level was $1.72 \mathrm{~mm}$ only (Table 5.1). The smaller change in deflection for the ECC link slabs at $55 \% \pm 20$ stress level was due to the increased damage level (lowering its subsequent fatigue resistance) during the pre-fatigue loading. The imposed high pre-fatigue stress level (55\% of ECC's ultimate load) increased the mid-span deflection (associated with more concrete cracking and high steel strain development) and damage level for LS30-ECC-CI-1.2-MS (55\% \pm 20$)$ before initiation of the fatigue loading. The increase in pre-fatigue damage level followed by intensive fatigue loading $( \pm 20 \%)$ led to a failure of the fibers and link slab specimen. 
Similarly, the change in deflection evolution at initial 10000 fatigue cycle (Figure 5.2a), for the ECC link slabs subjected to $40 \% \pm 20$ and $55 \% \pm 20$ fatigue stress levels are higher in compare to the full fatigue cycles (Figure 5.2b) due to same reason of stress jump from the mean to high range of fatigue loading ( $\pm 20 \%$ of ECC's ultimate load). Same is also true for SCC link slab.

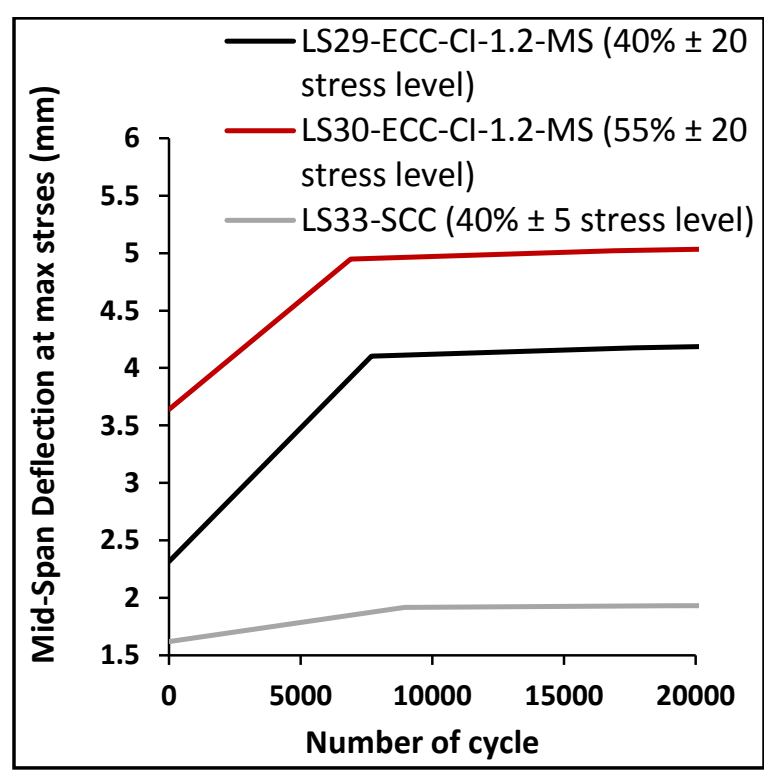

(a) Deflection Evolution at Initial 10000 Fatigue Cycle

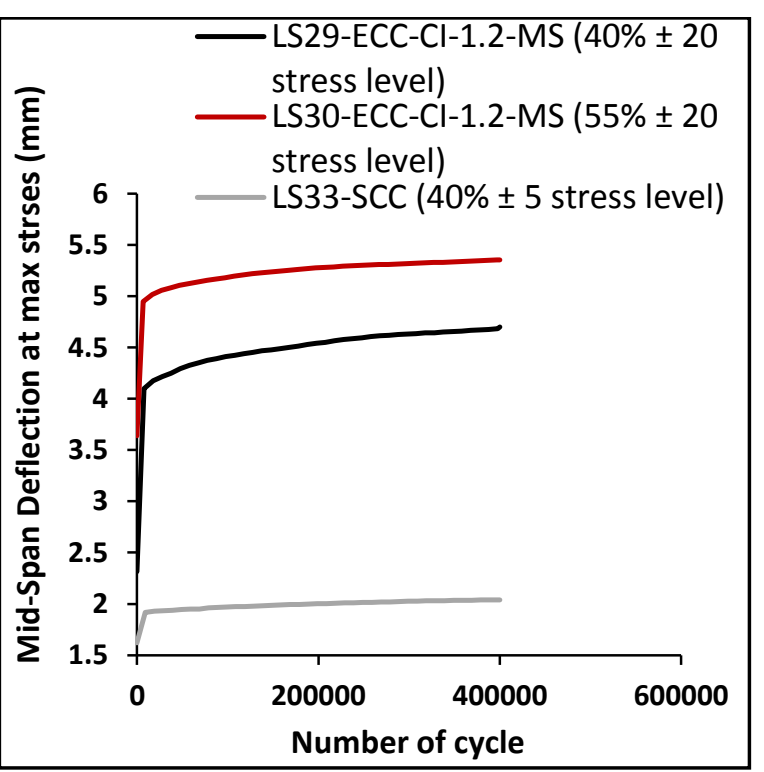

(b) Deflection Evolution at Full Fatigue Cycle Figure5.2: Mid-span Deflection Responses at Different Fatigue Stress Level

\subsubsection{Strain Developments}

During fatigue performance concrete and rebar strain developments due to applied fatigue loading were monitored and recorded for every cycle using a data acquisition system. The concrete tensile and compressive strain followed by rebar strain developments for the link slabs at different fatigue stress levels are presented in Figures 5.3 and key findings are summarized in Table 5.2. 


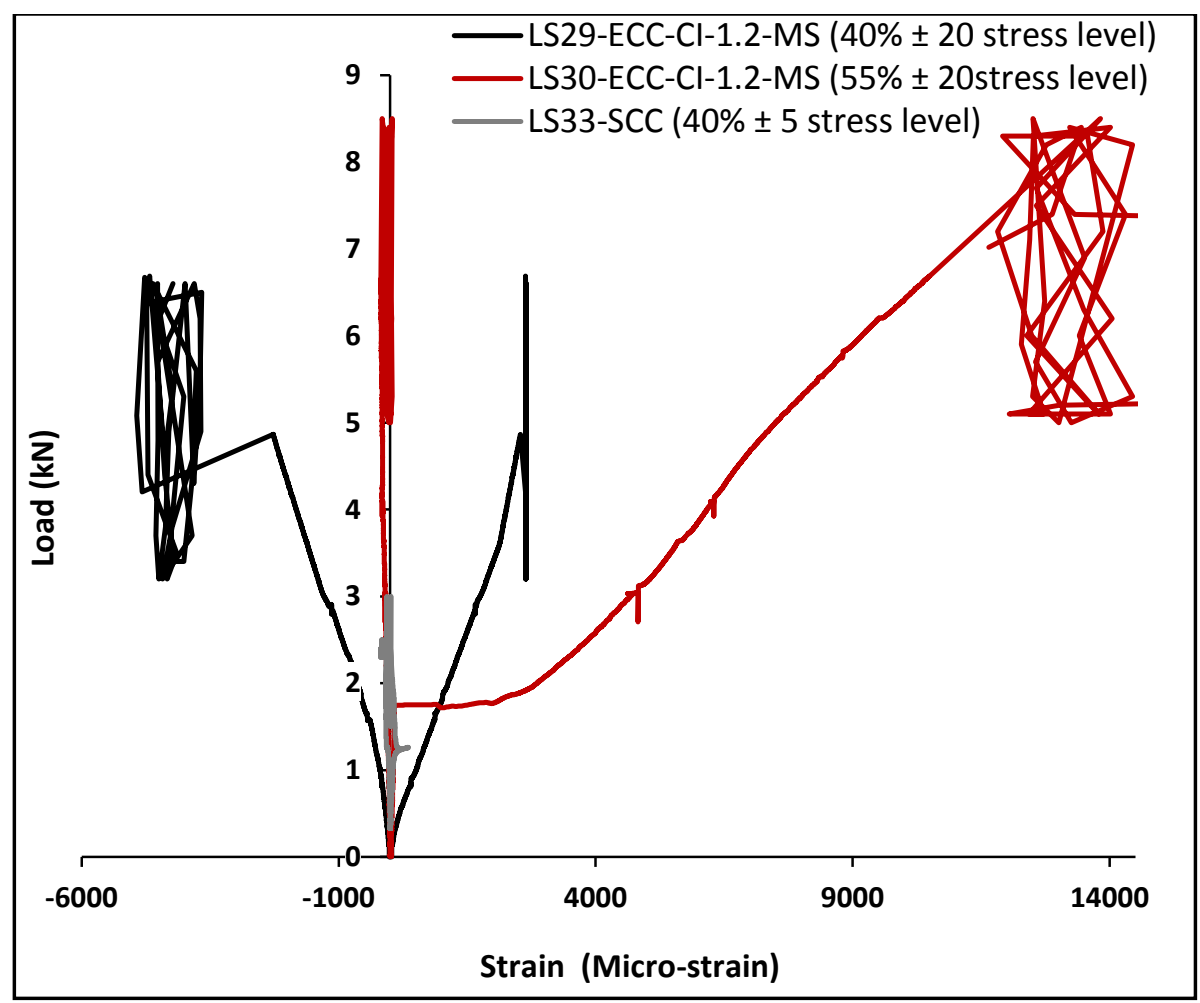

(a) Concrete Strain Developments

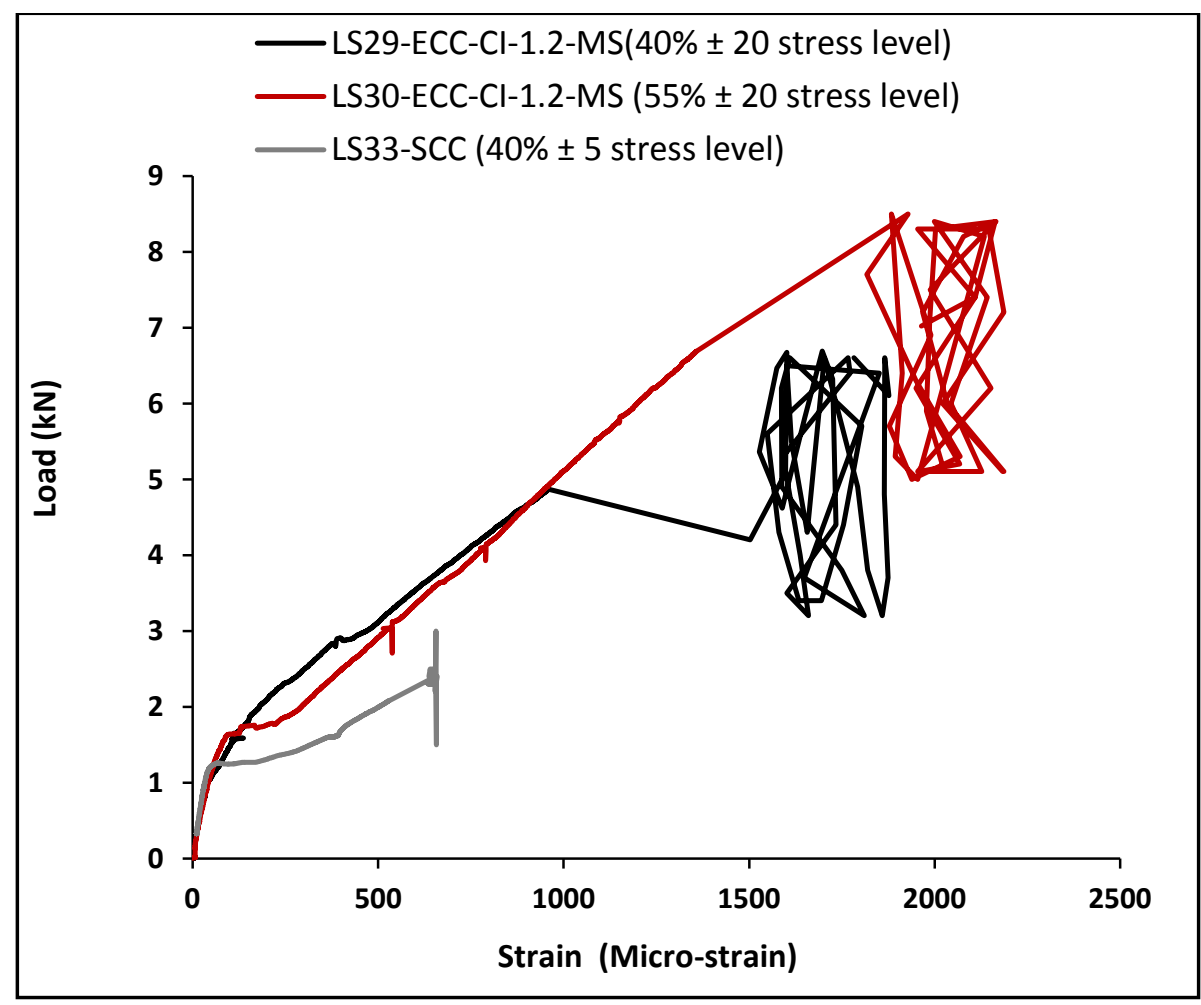

(b) Rebar Strain Development

Figure 5.3: Strain Developments for the Link Slab specimens at Different Fatigue Stress Levels 
Table 5.2: Strain Development of Link Slab During Fatigue Performance at Different Fatigue

Stress Levels

\begin{tabular}{|c|c|c|c|c|c|c|c|c|}
\hline Designation & $\begin{array}{c}\text { Fatigue } \\
\text { Stress } \\
\text { Level } \\
(\%)\end{array}$ & $\begin{array}{c}\text { Applied } \\
\text { Fatigue } \\
\text { Loading } \\
(\mathrm{kN})\end{array}$ & $\begin{array}{c}\text { Initial } \\
\text { Concrete } \\
\text { Tensile } \\
\text { Strain } \\
(\text { Micro- } \\
\text { Strain) }\end{array}$ & $\begin{array}{c}\text { Final } \\
\text { Concrete } \\
\text { Tensile } \\
\text { Strain } \\
(\text { Micro- } \\
\text { Strain) }\end{array}$ & $\begin{array}{c}\text { Initial } \\
\text { Concrete } \\
\text { Compressive } \\
\text { Strain } \\
(\text { Micro- } \\
\text { Strain) }\end{array}$ & $\begin{array}{c}\text { Final } \\
\text { Concrete } \\
\text { Compressive } \\
\text { Strain } \\
\text { (Micro- } \\
\text { Strain) }\end{array}$ & $\begin{array}{c}\text { Initial } \\
\text { Rebar } \\
\text { Strain } \\
\text { (Micro- } \\
\text { Strain) }\end{array}$ & $\begin{array}{c}\text { Final } \\
\text { Rebar } \\
\text { Strain } \\
\text { (Micro- } \\
\text { Strain) }\end{array}$ \\
\hline $\begin{array}{c}\text { LS29-ECC- } \\
\text { CI-1.2-MS }\end{array}$ & $40 \% \pm 20$ & $\begin{array}{c}4.86 \\
\pm 2.43\end{array}$ & 2536.1 & 2647.1 & -2281.5 & -4227.3 & 961.3 & 1782.1 \\
\hline $\begin{array}{c}\text { LS30-ECC- } \\
\text { CI-1.2-MS }\end{array}$ & $55 \% \pm 20$ & $\begin{array}{c}6.69 \\
\pm 2.43\end{array}$ & 10496.4 & 11653.3 & -181.3 & $-25.1 *$ & 1358.6 & 1964.3 \\
\hline LS33-SCC & $40 \% \pm 5$ & $2.37 \pm 0.1$ & 41.5 & $0 *$ & -93.1 & -184.2 & 529.5 & 645.8 \\
\hline
\end{tabular}

*Strain gauge damaged

As it is evidenced from Figure 5.3(a), no concrete tensile strain band width was formed for the SCC link slab subjected to $40 \% \pm 5 \%$ stress level. In fact, SCC concrete tensile strain was much lower at the beginning of fatigue performance because of stress release due to crack formation. Figure 5.4(a) also shows lower concrete tensile strain development at the initial fatigue cycle (at 10000 cycle). The rebar strain development was increased from 529.5 to 640 micro-strain for the first10000 fatigue cycle (Figure 5.4b). The increase in rebar strain for the SCC link slab at $40 \% \pm 5 \%$ may be associated with the transfer of load due to crack formation to the steel reinforcement. It is also evidenced (Figure 5.4b) that beyond the first 10000 fatigue cycle, rebar strain development remained constant since the applied stress range was very low $( \pm 5 \%$ of the mean stress level). The strain development characteristics justifies that the flexural fatigue resistance of SCC link slab is derived predominantly from the rebar contribution. In contrast ECC link slab at higher fatigue stress range $( \pm 20 \%)$ developed larger concrete tensile strain band width (in compare with SCC) during the fatigue loading (Figure 5.3a). The large tensile strain band width for the ECC link slab demonstrates its strain hardening characteristic that allows more bending and higher strain development compared to its SCC counterpart. Although the rebar strain was increased for the ECC link slab at $40 \% \pm 20 \%$ stress level specifically for the first 10000 cycles, but it did not reach the yield strain (2000 micro-strain) even at the end of the 400000 fatigue cycles (Figure 5.4a and Table 5.2). This is indication of damage in ECC due to micro-crack formation during fatigue loading and gradual transfer of load to the steel rebar causing an increase in rebar strain. The higher increase in rebar strain for the ECC link slab was 
caused by higher fatigue stress range of $\pm 20 \%$ in compare with the SCC link slab (at $\pm 5 \%$ fatigue stress range). The strain development signifies that ECC plays a significant role in enhancing flexural fatigue resistance and in mitigating damage.

The ECC tensile strain development for the link slab tested at higher fatigue stress level of $(55 \% \pm 20 \%)$ was greater compared to specimen tested at $40 \% \pm 20 \%$ stress level as indicated by the formation of larger tensile strain band width (Figure 5.3a and Figure 5.4a). However, developed ECC tensile strain was still lower compared to its tensile strain capacity 0.05 . The rebar strain was close to the yield strain at the beginning of the fatigue loading and reached the yield strain of 2000 micro-strain at 147000 fatigue cycle. The increased rebar strain at 147000 fatigue cycle justifies that stresses were transferred to the reinforcing bars due to formation of micro-cracks along with rupturing of PVA fibers bridging the crack width. The rebar tensile strain for the ECC link slab tested at $55 \% \pm 20 \%$ fluctuated at yield strain beyond 147000 fatigue cycle showing an increasing trend (Figure 5.4b). Overall, the large width of strain band development (both steel and concrete) for ECC links slabs compared to their SCC counterparts is an indication of ECC's superior performance in terms of inducing greater flexibility, ductility and energy absorbing capacity to the link slab.

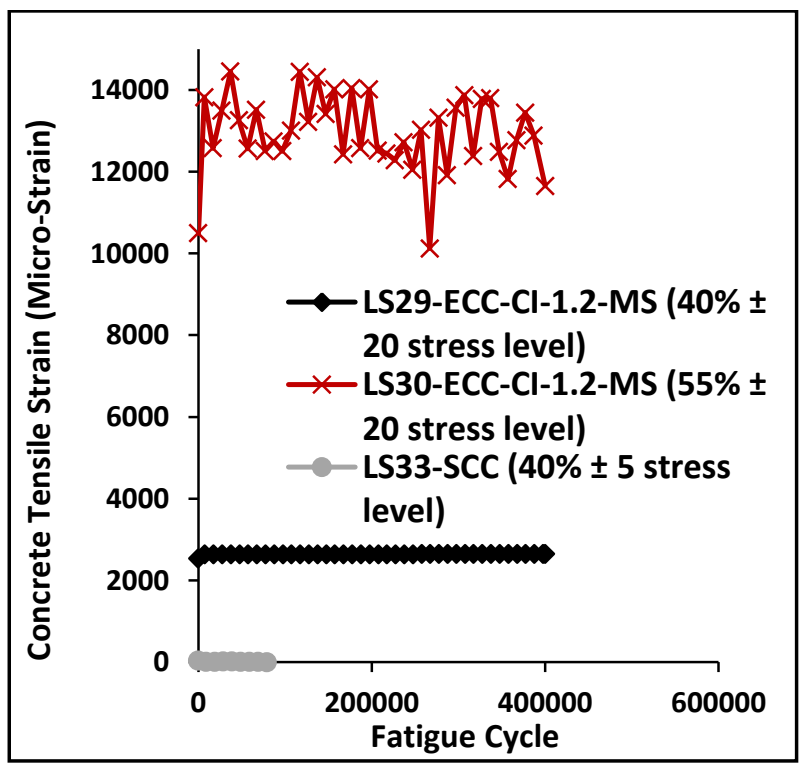

(a) Concrete Tensile Strain

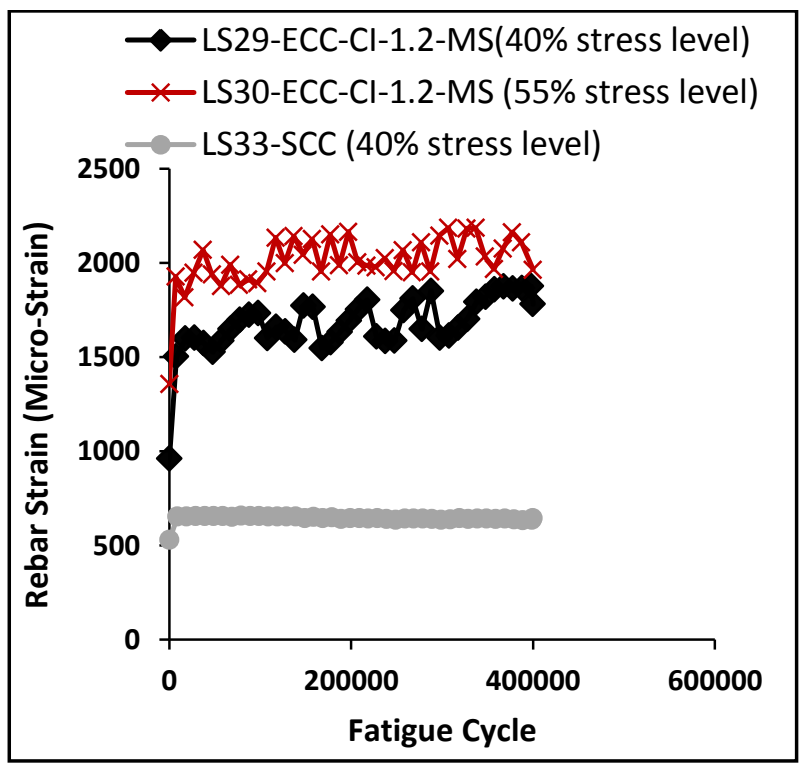

(b) Rebar Strain

Figure 5.4: Strain Development Evolution for Link Slabs Subjected to Different Fatigue Stress Level 


\subsubsection{Evolution of Stiffness}

The evolution stiffness of the $1 / 4^{\text {th }}$ scale link slabs during the fatigue loading showing a trend of degradation is presented in Figure 5.5. Table 5.3 summarizes the initial stiffness and stiffness at final fatigue cycle of 400000 for SCC and ECC link slabs.

Table 5.3: Stiffness Degradation of Link Slabs at Different Fatigue Stress Level

\begin{tabular}{|c|c|c|c|c|}
\hline Designation & $\begin{array}{c}\text { Fatigue Stress } \\
\text { Level }(\%)\end{array}$ & $\begin{array}{c}\text { Applied Fatigue } \\
\text { Loading }(\mathrm{kN})\end{array}$ & $\begin{array}{c}\text { Initial Stiffness } \\
(\mathrm{kN} / \mathrm{mm})\end{array}$ & $\begin{array}{c}\text { Stiffness at end of } \\
\text { fatigue cycle } \\
(\mathrm{kN} / \mathrm{mm})\end{array}$ \\
\hline LS29-ECC-CI-1.2-MS & $40 \% \pm 20$ & $4.86 \pm 2.43$ & 2.10 & 1.42 \\
\hline LS30-ECC-CI-1.2-MS & $55 \% \pm 20$ & $6.69 \pm 2.43$ & 1.85 & 1.25 \\
\hline LS33-SCC & $40 \% \pm 5$ & $2.37 \pm 0.1$ & 2.33 & 1.10 \\
\hline
\end{tabular}

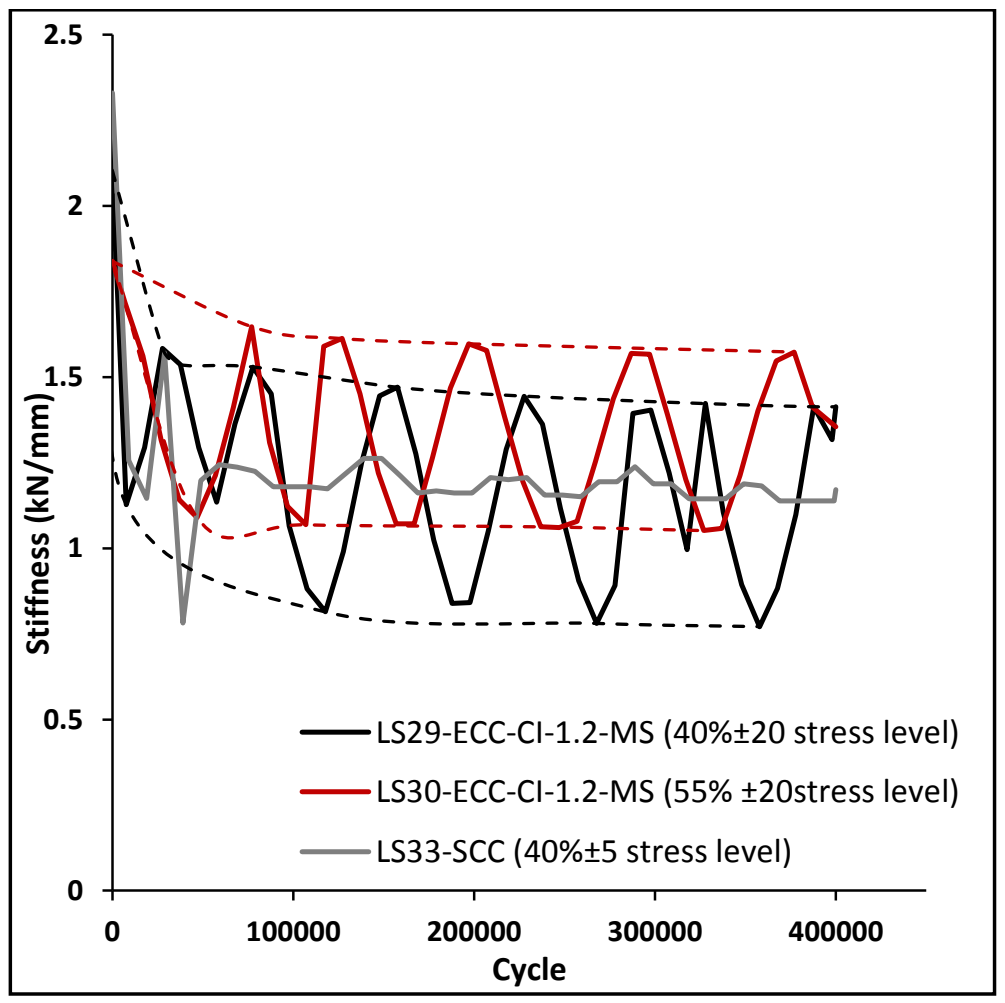

Figure 5.5: Stiffness Degradation of Link Slabs at Different Fatigue Stress Level 
Figure 5.5 shows that the stiffness of the ECC link slabs oscillates due to fatigue loading application in the maximum and minimum stress levels as expected. The concrete cracking initiation results in stiffness degradation, but due to fiber bridging and strain hardening characteristic of the ECC, the recovery of stiffness is better in ECC compared to SCC. Although the stiffness for the ECC link slabs are recovered but due to the repetitive fatigue loading, gradual stiffness degradation is observed similar to SCC justifying the difference between initial and final stiffness. The initial stiffness (before the fatigue performance) for the ECC link slabs tested at $40 \% \pm 20 \%$ stress level was $2.10 \mathrm{kN} / \mathrm{mm}$ and the stiffness was reduced to 1.41 $\mathrm{kN} / \mathrm{mm}$ at end of the fatigue performance - showing a decrease of 33\% (Table 5.3).

In contrast the SCC link slab initially demonstrated large stiffness $(2.33 \mathrm{kN} / \mathrm{mm})$ before the fatigue performance (Table 5.3). However the stiffness was dropped significantly from 2.33 $\mathrm{kN} / \mathrm{mm}$ to $0.78 \mathrm{kN} / \mathrm{mm}$ at 30000 fatigue cycle) (a decrease of about $66 \%$ ) due to major crack formation (Figure 5.5). Beyond 30000 fatigue cycles, gradual stiffness degradation was observed without major stiffness degradation. The stiffness response for the ECC link slab tested at $40 \%$ $\pm 20 \%$ and $55 \% \pm 20 \%$ with respect to the fatigue cycle are very similar (Figure 5.5). The stiffness for the ECC link slab tested at $55 \% \pm 20 \%$ stress level was reduced from $1.85 \mathrm{kN} / \mathrm{mm}$ to $1.25 \mathrm{kN} / \mathrm{mm}$ - a decrease of about $32 \%$ (Table 5.3). The broad band of stiffness fluctuations for ECC links slabs compared to SCC is due to higher stress levels of fatigue loading. The higher stiffness degradation of SCC link slab at low fatigue cycles and low stress levels clearly demonstrates SCC's lower fatigue resistance and strength/stiffness retaining capacity compared to ECC. The sudden transfer of load from concrete to rebar at the onset of a major crack with large crack width is attributed to SCC's such inferior performance.

\subsubsection{Crack Characterization}

Flexural cracks were developed predominantly at mid span of the link slabs from the tension face and gradually propagated towards the compression face (Figure 5.6). The number of cracks were monitored for every 10000 cycles while the crack widths were measured by crack microscope after completing 400000 fatigue cycles. The summary of the crack characteristics in terms of the number of the cracks and averaged crack width for the link slabs at different fatigue stress levels are presented in Table 5.4. 
Table 5.4: Crack Characterization of Link Slabs at Different Fatigue Stress Level

\begin{tabular}{|c|c|c|c|c|}
\hline Designation & $\begin{array}{c}\text { Mean Stress } \\
\text { Level }\end{array}$ & $\begin{array}{c}\text { Fatigue } \\
\text { Stress } \\
\text { Range }(\%)\end{array}$ & $\begin{array}{c}\text { Number of cracks after } \\
400000 \text { fatigue cycle }\end{array}$ & $\begin{array}{c}\text { Crack widths after } 400000 \\
\text { fatigue cycle }(\mu \mathrm{m})\end{array}$ \\
\hline LS29-ECC-CI-1.2-MS & $40 \%$ & $\pm 20 \%$ & 17 & 100 \\
\hline LS30-ECC-CI-1.2-MS & $55 \%$ & $\pm 20 \%$ & $\begin{array}{c}16 \text { micro-cracks and } 2 \\
\text { major cracks }\end{array}$ & 150 \\
\hline LS33-SCC & $40 \%$ & $\pm 5 \%$ & 1 Major crack & 1000 \\
\hline
\end{tabular}

The first cracking appeared during pre-monotonic loading for all ECC link slabs followed by initiation of additional micro-cracks during flexural fatigue loading. In contrast, the first cracking for the SCC link slab tested at $40 \% \pm 5 \%$ stress level appeared at the first fatigue cycle, even though the stress range was reduced to 5\%. A major crack formed at the mid-span of the SCC link slab at first fatigue cycle. As the number of the cycles increased, the crack width grew wider and formed a major crack of $1 \mathrm{~mm}$ crack width (Table 5.4). The increase of crack width to $1 \mathrm{~mm}$ after repeated fatigue loading can be attributed to the reduction of the bond strength among the reinforcing bars and the concrete (Zanuy et al. 2011).

In contrast a comparatively large number of cracks (eighteen) cracks were developed during fatigue loading in ECC link slabs. It should be noted that crack widths for all ECC link slabs remained below $560 \mu \mathrm{m}$ after 400000 fatigue cycle due to fiber bridging phenomena (Table 5.4).

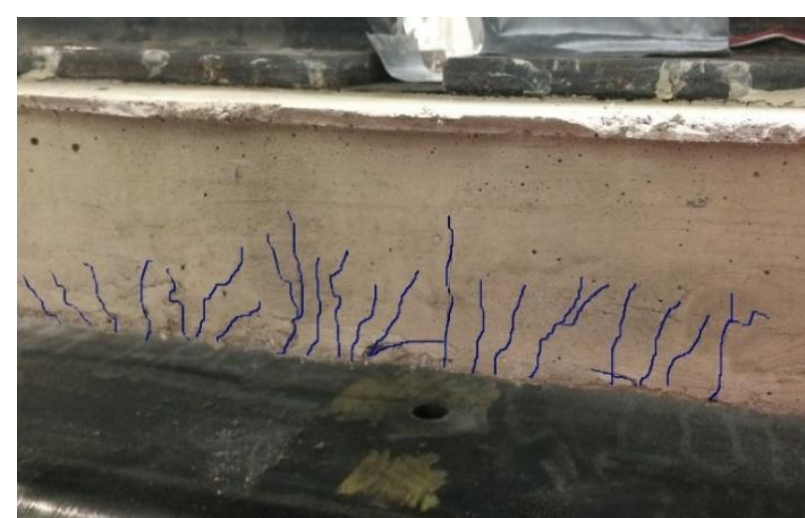

(a) LS29-ECC-CI-1.2-MS (at 40\% $20 \%$ stress level)

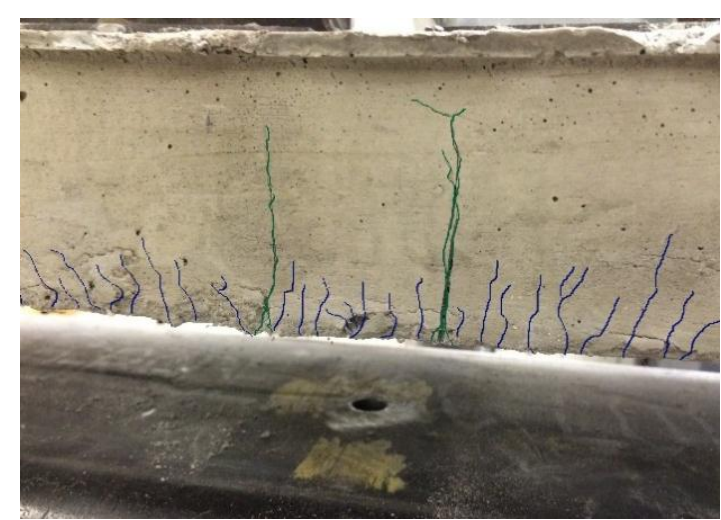

(b) LS30-ECC-CI-1.2-MS (at 55\% $\pm 20 \%$ stress level) 


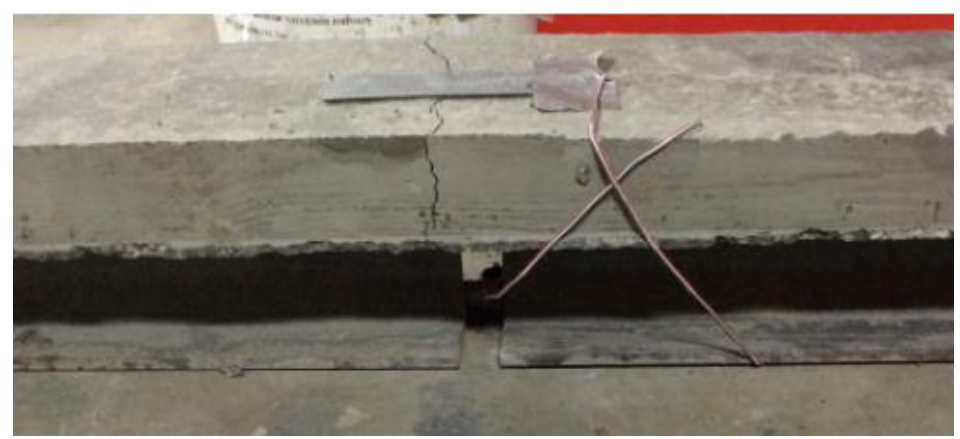

(c) LS33-SCC (at 40\% $\pm 5 \%$ stress level)

Figure 5.6: Crack Propagation of Link Slabs at Different Fatigue Stress Level

It is observed from Figure 5.6 and Table 5.4 that the high fatigue stress level developed higher number of cracks and large crack widths. Micro-cracks were formed initially for the link slab subjected to $55 \%$ stress level along with two additional major cracks after the PVA fiber was ruptured at 147000 cycles. The crack widths as it is represented by green colour in Figure 5.6(b) grew wider until it reached $560 \mu \mathrm{m}$ due to the presence of the reinforcing bar. In contrast the crack widths for the ECC link slab at $40 \% \pm 20 \%$ stress level remained below $100 \mu \mathrm{m}$. The lower crack width of ECC link slabs signifies the long-term durability performance of ECC link slabs in bridge deck construction.

\subsubsection{Post-Fatigue Monotonic Performance}

The exhausted fatigued link slabs tested at different stress levels was subjected to flexural monotonic loading to failure in order to determine the fatigue residual load-deflection response, strength, strain characteristics, energy absorbing capacity and ductility.

\subsubsection{Load-Deflection/Moment-Rotation Responses and Comparison with Theory}

The residual load-deformation and moment-rotation responses of the fatigued link slabs at different stress levels were compared to those of control non-fatigued link slabs in Figures 5.7 and 5.8. Table 5.5a and 5.5b summarizes ultimate load/moment and ultimate deflection/rotation of both SCC and ECC link slabs. Experimental moment capacity of SCC and ECC link slab specimens are compared with those obtained theoretically from Equation 2.15 (described in Chapter 2) in Table 5.5a. The experimental moment capacity of ECC link slab is found to be 
1.79 times higher than theoretical because of the contribution of fiber in strength enhancement. This is attributed to the fact that the PVA fiber contribution to the strength enhancement is taken into account conservatively in the theoretical Equation 2.15. On the other hand, theoretically predicted moment capacity of SCC link slab is found to be very close to the experimental value. Equation 2.15 should be modified for the prediction of residual moment capacity of both SCC and ECC link slab subjected fatigue loading by taking into account strength degradation.

Table 5.5a: Summary of Post Fatigue Load-Deflection and Moment-Rotation Responses of the Link Slabs at different Stress Level

\begin{tabular}{|c|c|c|c|c|c|c|c|c|}
\hline Designation & $\begin{array}{c}\text { Fatigue } \\
\text { Mean } \\
\text { Stress } \\
\text { Level } \\
(\%)\end{array}$ & $\begin{array}{c}\text { Fatigue } \\
\text { Stress } \\
\text { Range } \\
(\%)\end{array}$ & $\begin{array}{c}\text { Ultimate } \\
\text { Load (kN) }\end{array}$ & $\begin{array}{l}\text { Ultimate } \\
\text { Deflection } \\
\quad(\mathrm{mm})\end{array}$ & $\begin{array}{l}\text { Ultimate } \\
\text { Rotation } \\
\qquad\left(\theta_{\text {ult }}\right) \\
\text { (Radian) }\end{array}$ & $\begin{array}{c}\text { Ratio } \\
\theta_{\text {ult }} / \\
\theta_{\text {Allow }}\end{array}$ & $\begin{array}{c}\text { Expt. } \\
\text { Ultimate } \\
\text { Moment } \\
\left(\mathrm{M}_{\mathrm{ult}}\right) \\
(\mathrm{kN} . \mathrm{m})\end{array}$ & $\begin{array}{l}\text { Ratio } \\
\mathbf{M}_{\text {ult }} / \\
\mathbf{M}_{\text {des }}^{*}\end{array}$ \\
\hline LS28-ECC-CI-1.2-MS & 0 & 0 & 12.16 & 7.59 & 0.020594 & 5.49 & 2.31 & 1.79 \\
\hline LS29-ECC-CI-1.2-MS & $40 \%$ & $\pm 20 \%$ & $9.60(-21 \%)$ & $3.48(54 \%)$ & 0.009425 & 2.51 & 1.82 & 1.45 \\
\hline LS30-ECC-CI-1.2-MS & $55 \%$ & $\pm 20 \%$ & $5.12(-58 \%)$ & $2.31(69 \%)$ & 0.006256 & 1.69 & 0.97 & 0.75 \\
\hline LS32-SCC & 0 & 0 & 5.93 & 6.74 & 0.022226 & 5.92 & 1.27 & 1.02 \\
\hline LS33-SCC & $40 \%$ & $\pm 5 \%$ & $2.57(-57 \%)$ & $2.01(70 \%)$ & 0.006376 & 1.7 & 0.48 & 0.38 \\
\hline
\end{tabular}

$\theta_{\text {Allow }}$ represents the maximum allowable AASHTO's rotation of 0.00375 radian

$* \mathrm{M}_{\mathrm{des}}$ represents design moment calculated based on Eq. 2.15

Value in the brackets represent \% strength/deflection reduction compared to control non-fatigued specimens

Table 5.6b: Load levels at Allowable Rotation Limit at different Stress Level

\begin{tabular}{|c|c|c|c|c|c|c|c|}
\hline Designation & $\begin{array}{c}\text { Fatigue } \\
\text { Mean } \\
\text { Stress } \\
\text { Level } \\
(\%)\end{array}$ & $\begin{array}{c}\text { Fatigue } \\
\text { Stress } \\
\text { Range } \\
(\%)\end{array}$ & $\begin{array}{c}\text { Ultimate } \\
\text { Load } \\
(\mathrm{kN})\end{array}$ & $\begin{array}{c}\text { Ultimate } \\
\text { Rotation } \\
\left(\theta_{\text {ult }}\right) \\
(\text { Radian })\end{array}$ & $\begin{array}{c}\text { Expt. } \\
\text { Ultimate } \\
\text { Moment } \\
\left(\mathrm{M}_{\text {ult }}\right) \\
(\mathrm{kN} . \mathrm{m})\end{array}$ & $\begin{array}{c}\mathrm{M}_{\text {exp }} \text { at } \\
\theta_{\text {Allow }} \\
(\mathrm{kN} . \mathrm{m})\end{array}$ & $\begin{array}{c}\text { Load level } \\
\text { at } \theta_{\text {Allow }}\end{array}$ \\
\hline LS28-ECC-CI-1.2-MS & 0 & 0 & 12.16 & 0.020594 & 2.31 & 0.65 & $28 \%$ \\
\hline LS29-ECC-CI-1.2-MS & $40 \%$ & $\pm 20 \%$ & 9.60 & 0.009425 & 1.82 & 0.75 & $41 \%$ \\
\hline LS30-ECC-CI-1.2-MS & $55 \%$ & $\pm 20 \%$ & 5.12 & 0.006256 & 0.97 & 0.85 & $87 \%$ \\
\hline LS32-SCC & 0 & 0 & 5.93 & 0.022226 & 1.27 & 1.02 & $80 \%$ \\
\hline LS33-SCC & $40 \%$ & $\pm 5 \%$ & 2.57 & 0.006376 & 0.48 & 0.38 & $80 \%$ \\
\hline
\end{tabular}




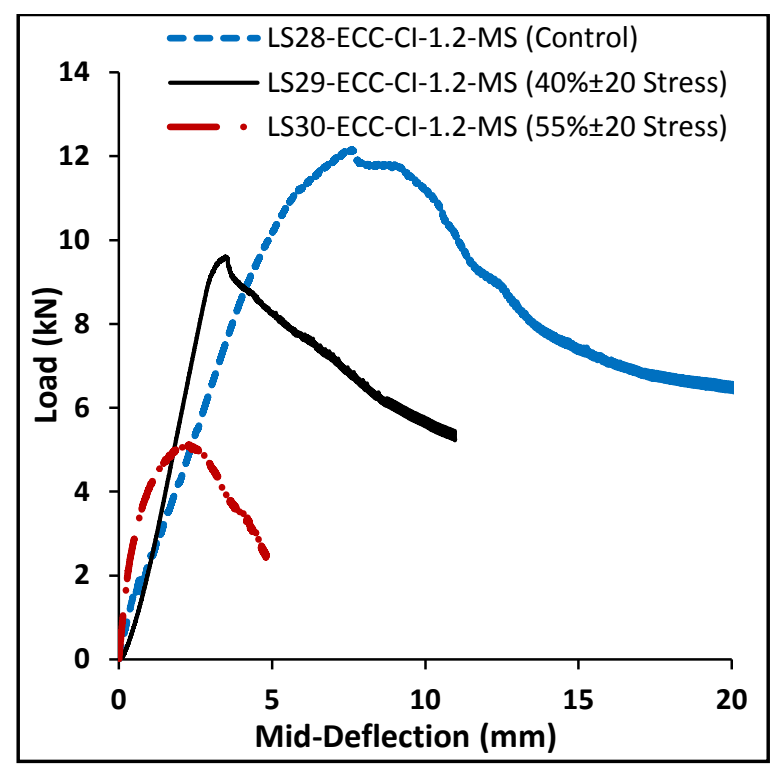

(a) ECC Link Slabs

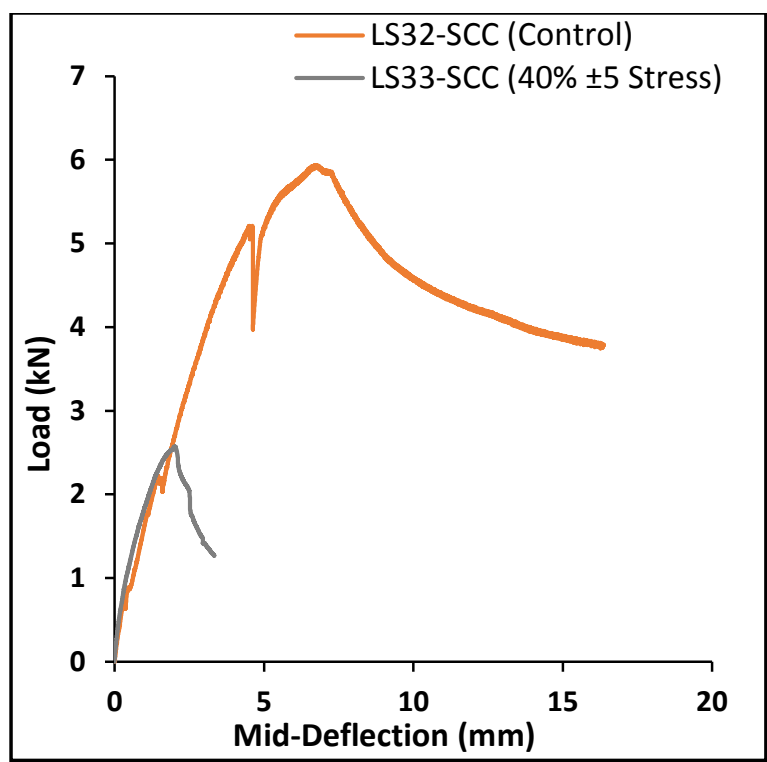

(b) SCC Link Slabs

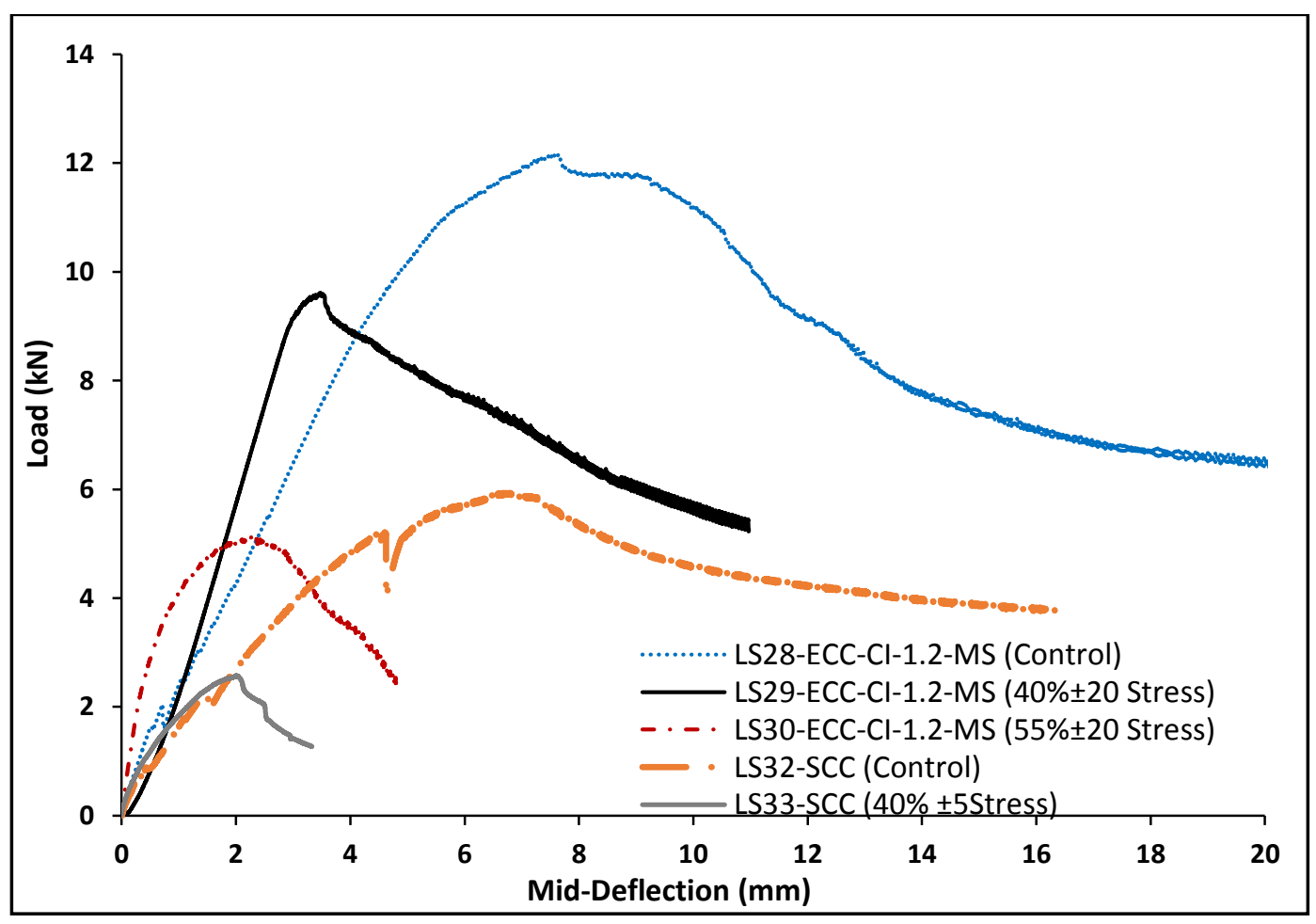

(c ) Link Slabs at different fatigue stress level

Figure 5.7: Post Fatigue Load-Deflection Responses of the Link Slabs 


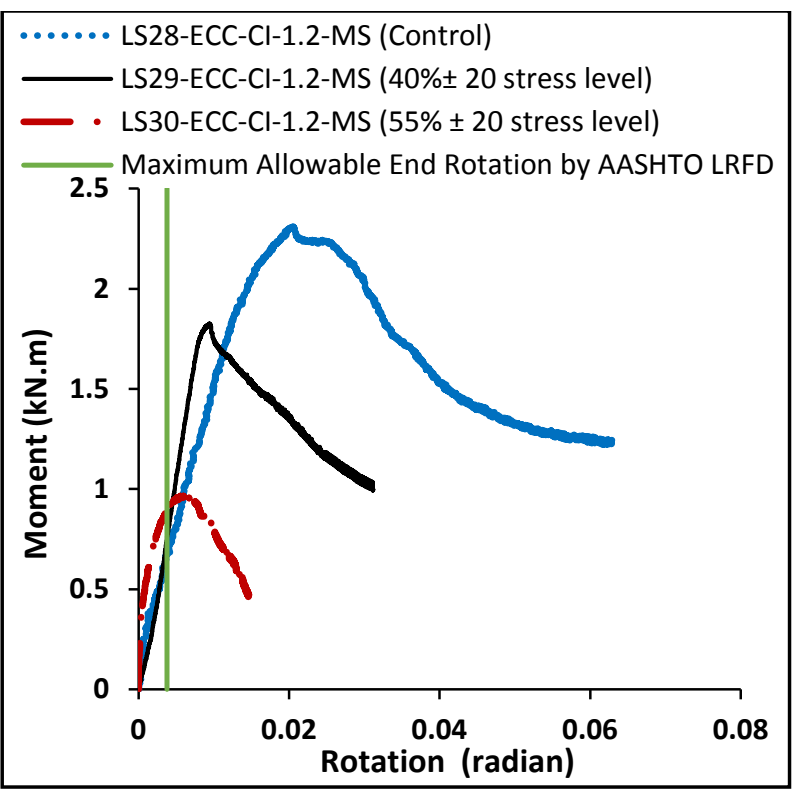

(a) ECC Link Slabs

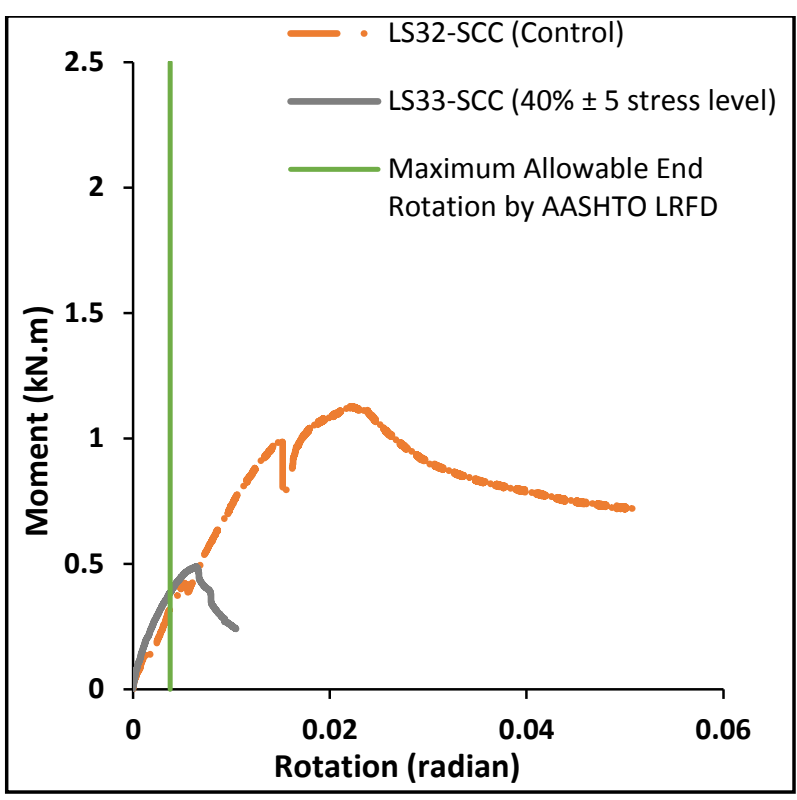

(b) SCC Link Slabs

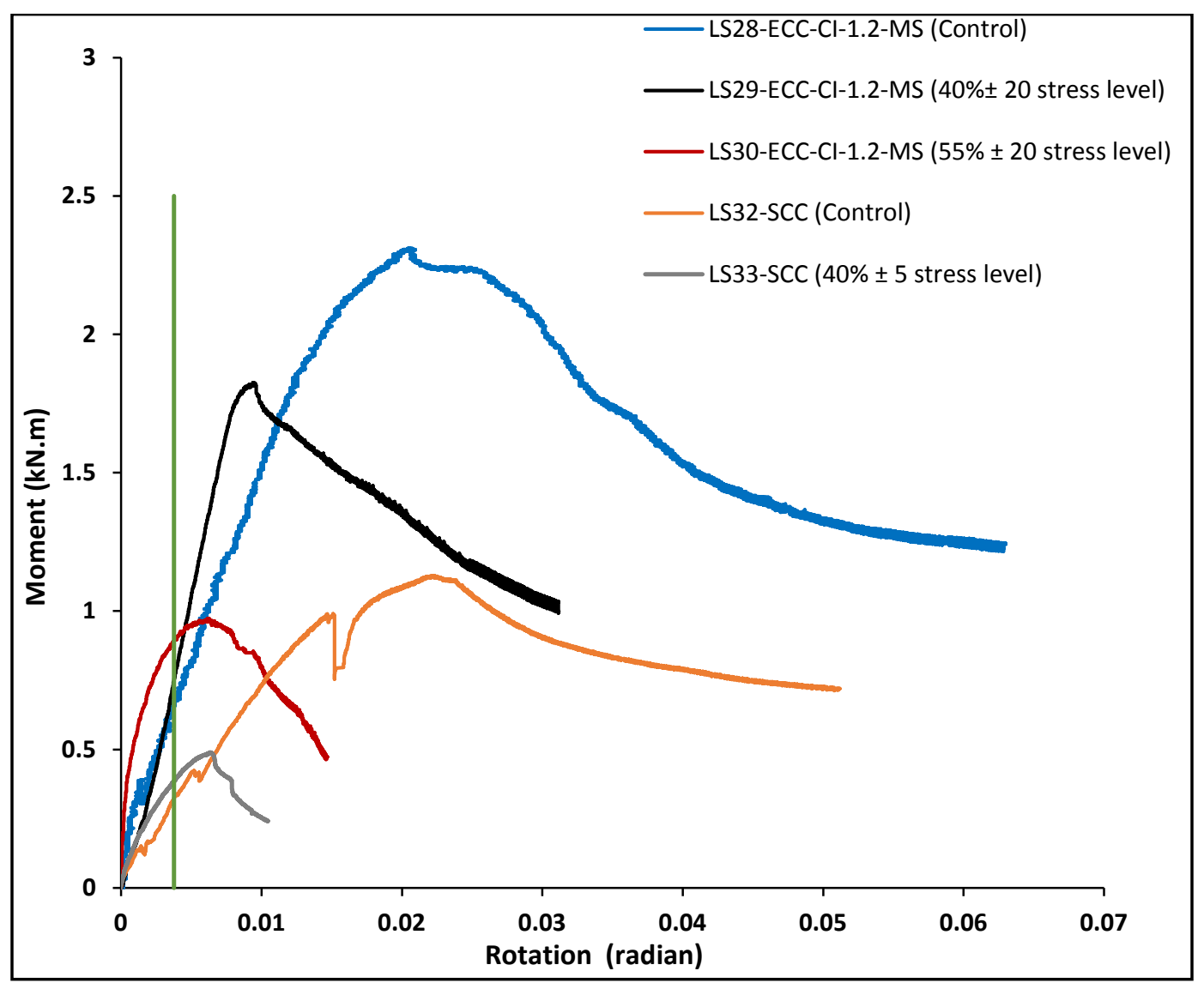

(c ) Link Slabs at different fatigue stress level

Figure 5.8: Post Fatigue Moment-Rotation Responses of the Link Slabs 
The ultimate load and mid-span deflection envelope of the fatigued link slabs were reduced significantly (showing lower strength and deflection capacities) in compare with their control non-fatigue specimens. The ultimate load and the mid-span deflection for the SCC link slab was reduced by $57 \%$ and $70 \%$, respectively in compare to the control specimen (pre-fatigue monotonic specimen) (Table 5.5a). On the other hand, the ultimate load and the mid-span deflection for the ECC link slabs tested at $40 \% \pm 20 \%$ level was reduced by $21 \%$ and $54 \%$, respectively - showing significantly better strength and deformation retaining capacity compared to those made with SCC.

This shows that SCC exhibited more damage in compare with the ECC link slabs even though its fatigue stress range was limited to $\pm 5 \%$. The load-deformation response of the SCC link slabs simulates that bending stresses in the post-cracking stages were carried only by the reinforcements. This demonstrates the loss of concrete stiffness under fatigue loading and proves the small residual strength and bending capacity of the SCC link slab was achieved by the reinforcing bar only. In contrast the ECC link slab at the same mean stress level but higher fatigue stress range exhibited greater residual ultimate load and bending capacity (ductility) due to its multiple cracking characteristic and strain hardening behaviour that is attained by the PVA fibers (Suthiwarapirak et al. 2004).

The residual strength and bending capacity for the ECC link slab were reduced significantly at higher stress level $(55 \% \pm 20 \%)$ by $58 \%$ and $69 \%$, respectively (Table 5.5). The steep slope at the post-peak failure of the load-deflection response in Figure 5.7(a) indicates the brittle failure of the ECC link slab at $55 \% \pm 20$ fatigue stress level. This characteristic demonstrates the loss of the ECC tensile strain hardening, and proves that PVA fibers were ruptured during the fatigue loading. Further, the small increase in residual ultimate load and deflection at the post-monotonic loading was due to the provided minimum steel reinforcing bars. In contrast the strain hardening characteristic of the PVA fibers within the ECC link slab at $40 \% \pm 20 \%$ stress levels were maintained since the post-peak failure slope of the load-deflection response was similar to its non-fatigued controlled specimen. Therefore the design fatigue stress level for ECC link slab should be limited to $40 \% \pm 20 \%$ for satisfying the ultimate and serviceability limit states.

From Figure 5.8, it is evidenced that after fatigue loading, the residual support end-rotations of the damaged link slabs are satisfying the maximum AASHTO LRFD (2012) serviceability limit 
of 0.00375 radian at ultimate load. However, the SCC link slab exhibited a since the end-rotation of 0.00375 radian was attained at $80 \%$ of the ultimate loading (far above than service load level range of 40\%-55\%), near the failure point of the specimen (Figure 5.8, Table 5.8b) - hence appeared to be not suitable for link slab applications. In contrast, the ECC link slab at same mean stress level $(40 \%)$ but higher fatigue stress range $( \pm 20 \%)$ demonstrated the residual allowable rotation at only $40 \%$ of the ultimate load - so even after 400000 fatigue cycles, they satisfy rotation limit). The high residual strength and satisfactory end-rotation retention proved the strain hardening and multiple cracking characteristics of the ECC link slab. The ECC link slab tested at higher fatigue stress level of $55 \% \pm 20 \%$ showed more damage and attained allowable end-rotation of 0.00375 radian at $87 \%$ of the ultimate loading (far above than service load level range of $40 \%-55 \%$ ), (Figure 5.8, Table 5.8b). The post-fatigue monotonic tests demonstrated better structural performance of the ECC link slab compared to SCC ones. It should be noted that control ECC link slab (without subjected to fatigue loading) attained allowable end-rotation of 0.00375 radian at only $27 \%$ of the ultimate loading (far lower than service load level range of $40 \%-55 \%$ ) - this demonstrates superior flexibility of links slab specimens which is essential for such applications).

\subsubsection{Post-Fatigue Strain Developments}

For a comprehensive analysis, the post fatigue residual concrete and rebar strain development are compared with the pre-fatigue and fatigue strain developments for the link slab specimens at different fatigue stress levels. The comparative analysis of concrete and rebar strain development for the ECC and SCC link slab at 40\% 20 and 40\% \pm 5 fatigue stress levels are presented in Figures 5.9 and 5.10, respectively. Also the summary of the residual strain development at the ultimate load for the fatigued link slabs at different stress levels are presented in Figure 5.11 and Table 5.6. 


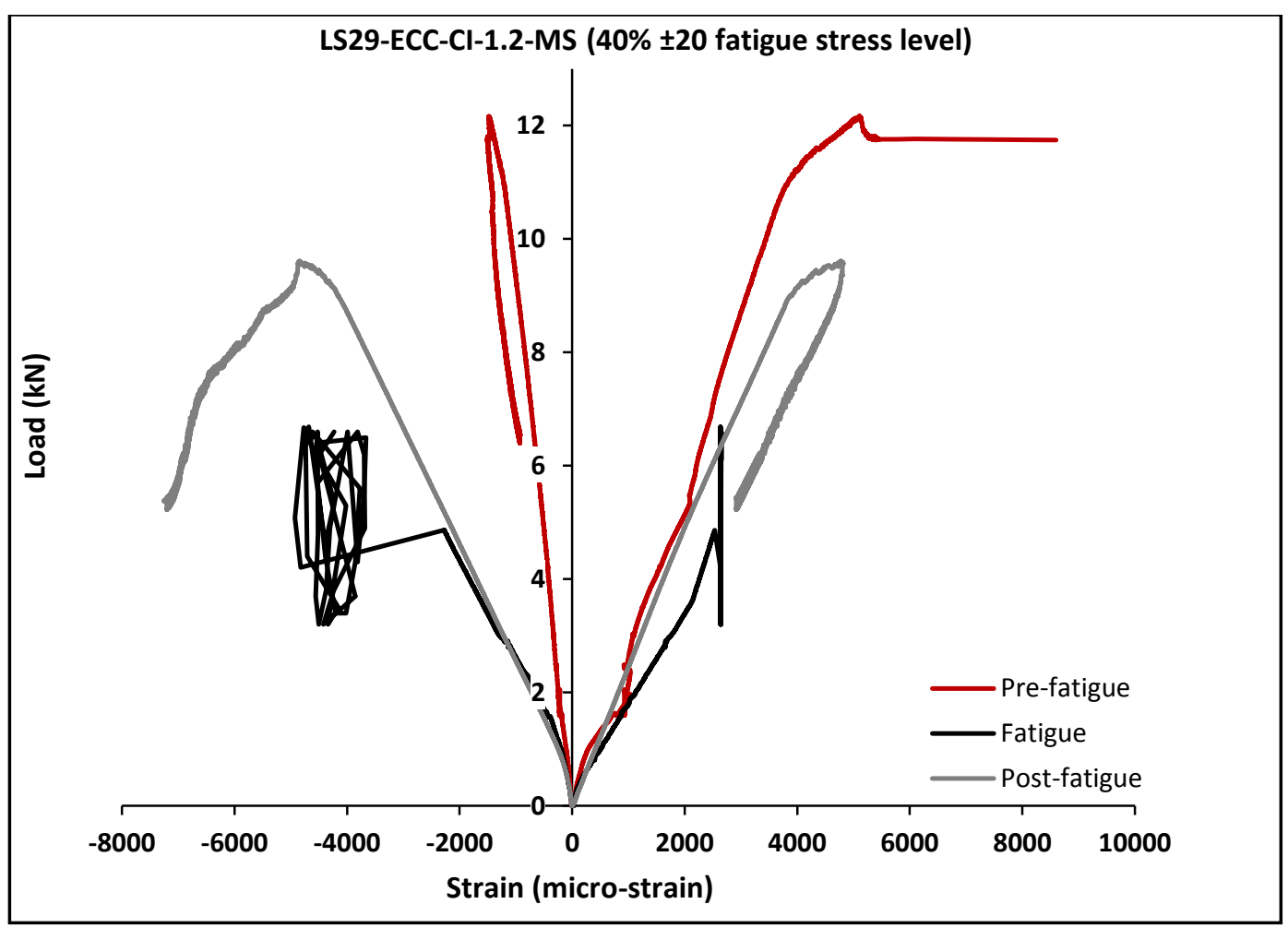

(a) Concrete strain for LS-29-ECC-CI-1.2-MS (40\% \pm 20$)$

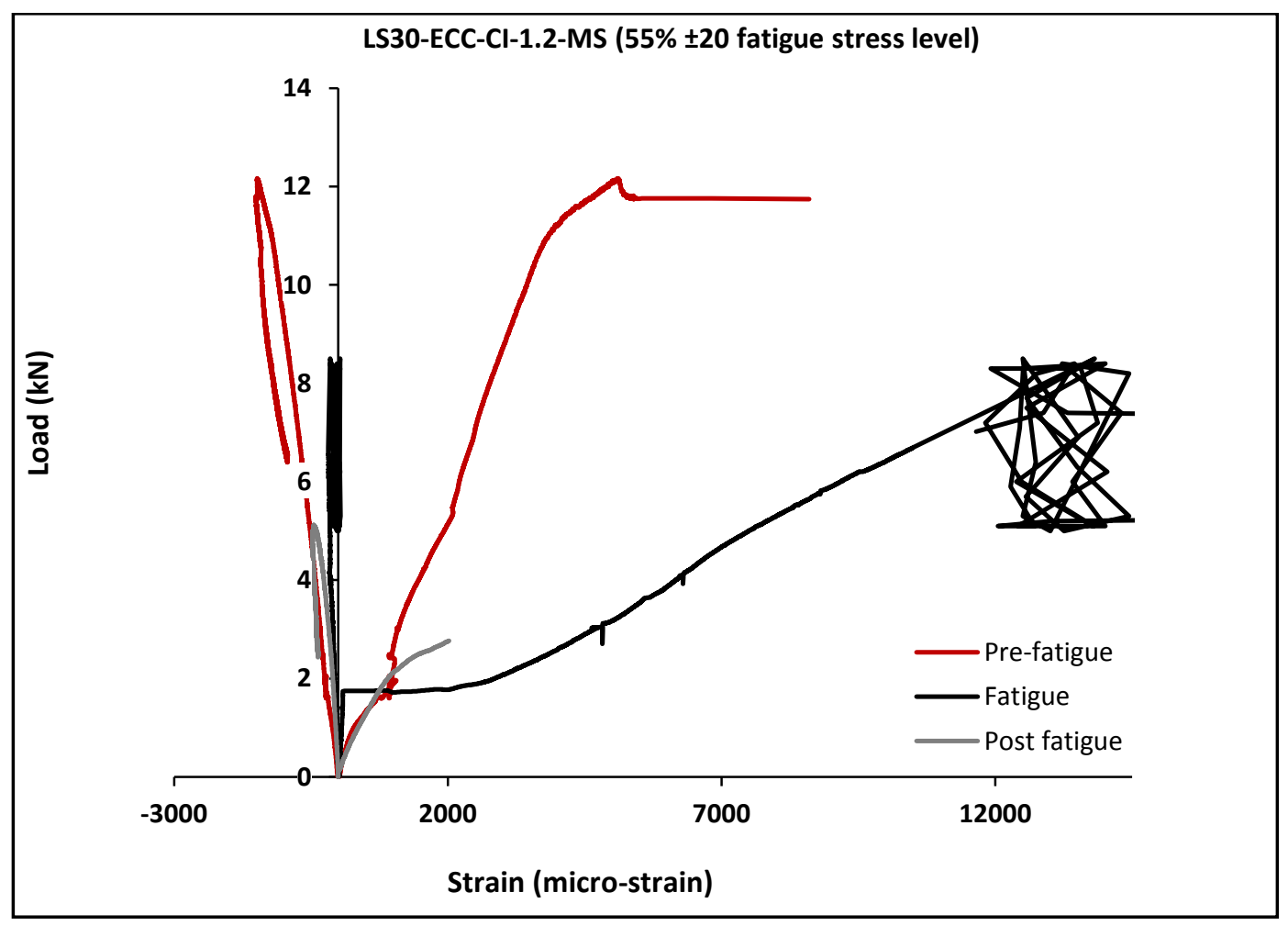

(b) Concrete strain for LS-30-ECC-CI-1.2-MS (55\% \pm 20$)$ 


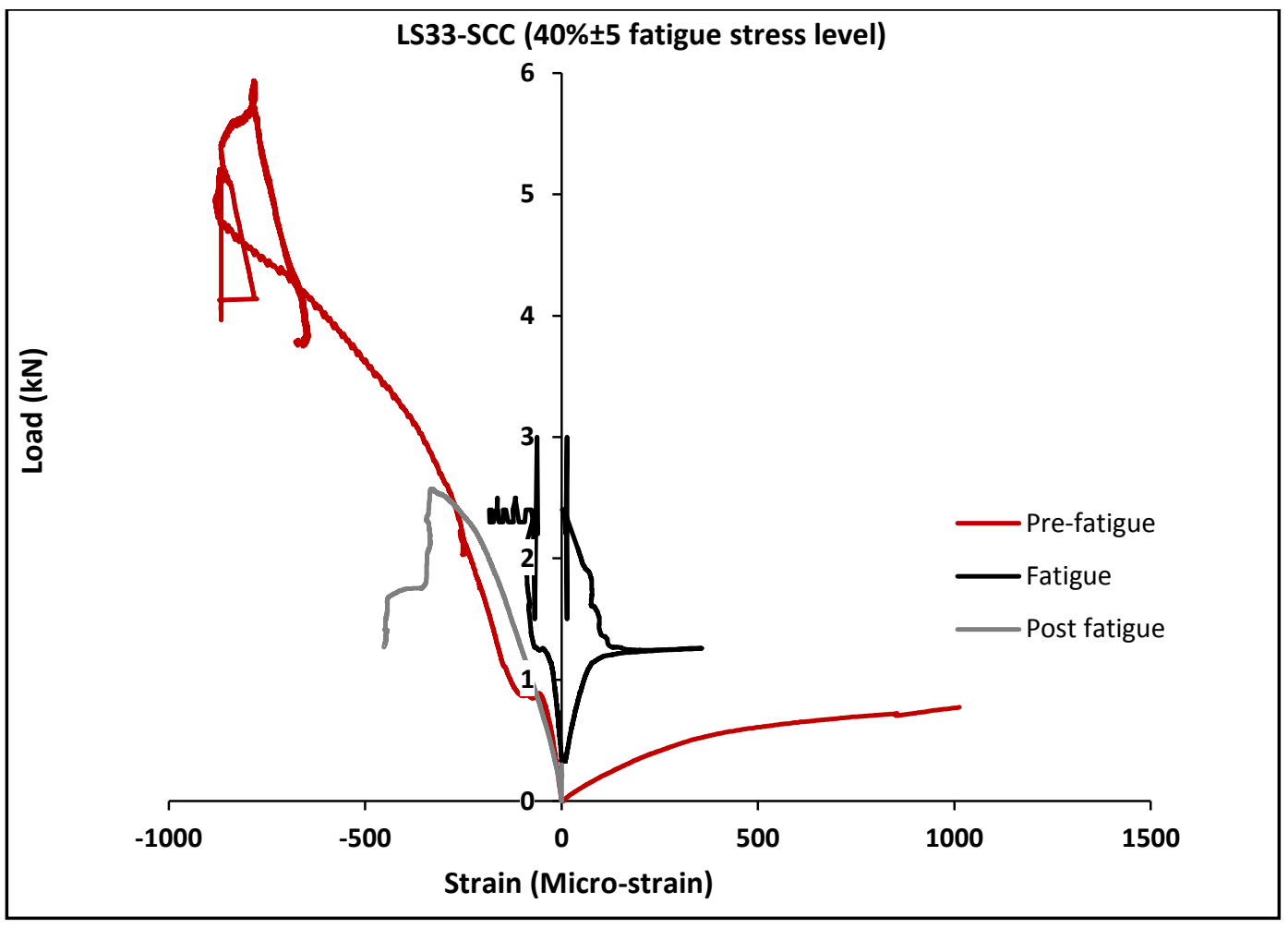

(c) Concrete strain for LS33-SCC $(40 \% \pm 5)$

Figure 5.9: Concrete Strain Development at Pre-Fatigue, Fatigue and Post-Fatigue of Link Slabs at Different Fatigue Stress Levels

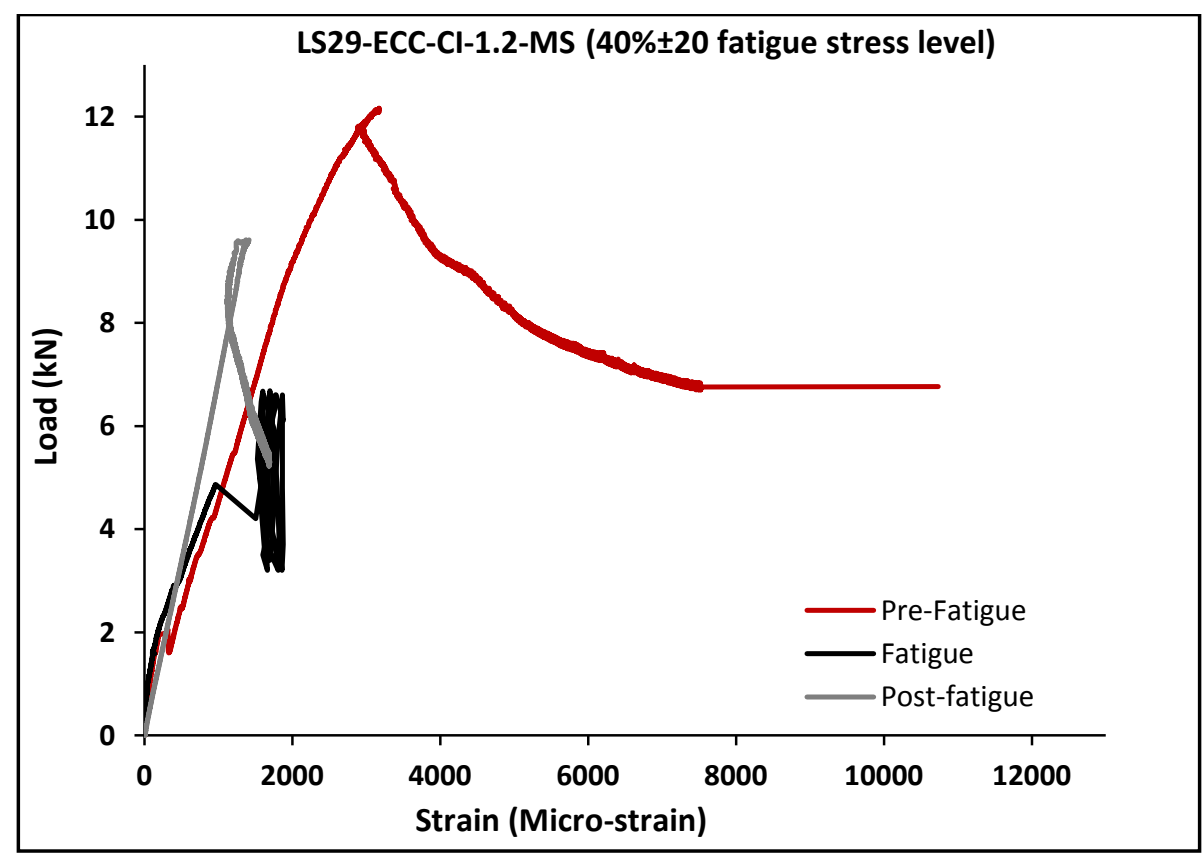

(a) Rebar strain for LS-29-ECC-CI-1.2-MS (40\% \pm 20$)$ 


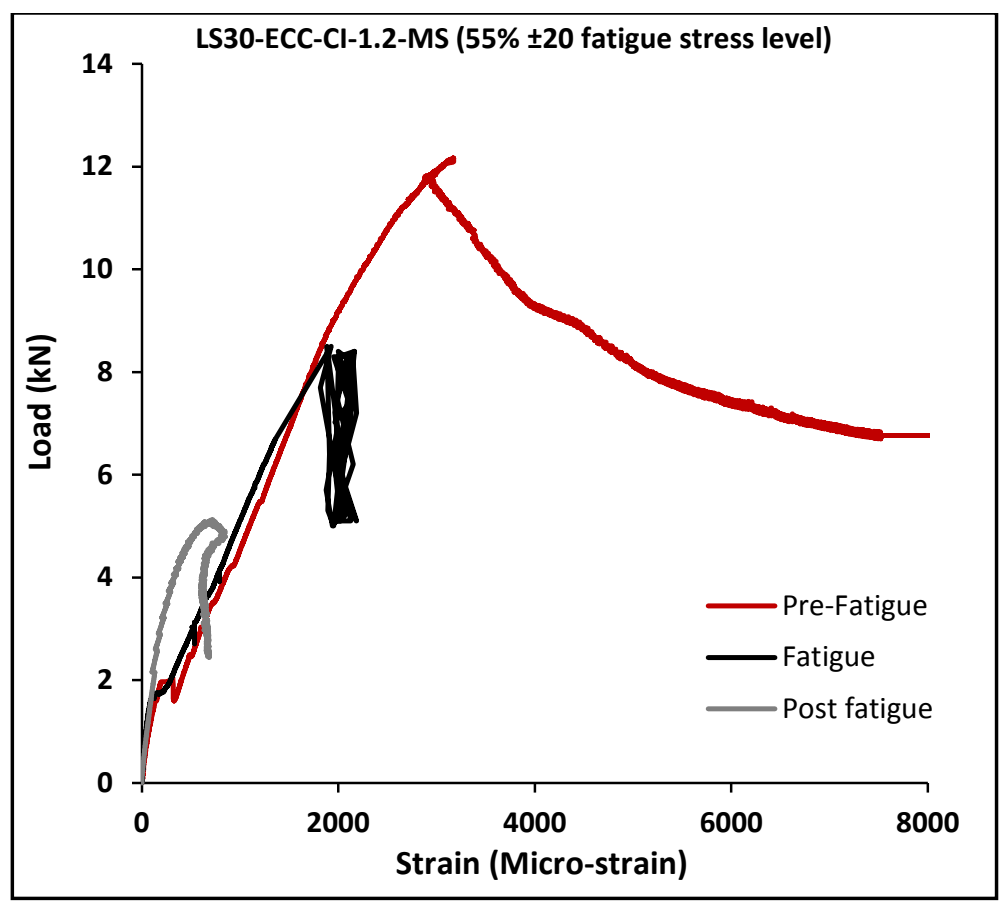

(b) Rebar strain for LS-30-ECC-CI-1.2-MS (55\% \pm 20$)$

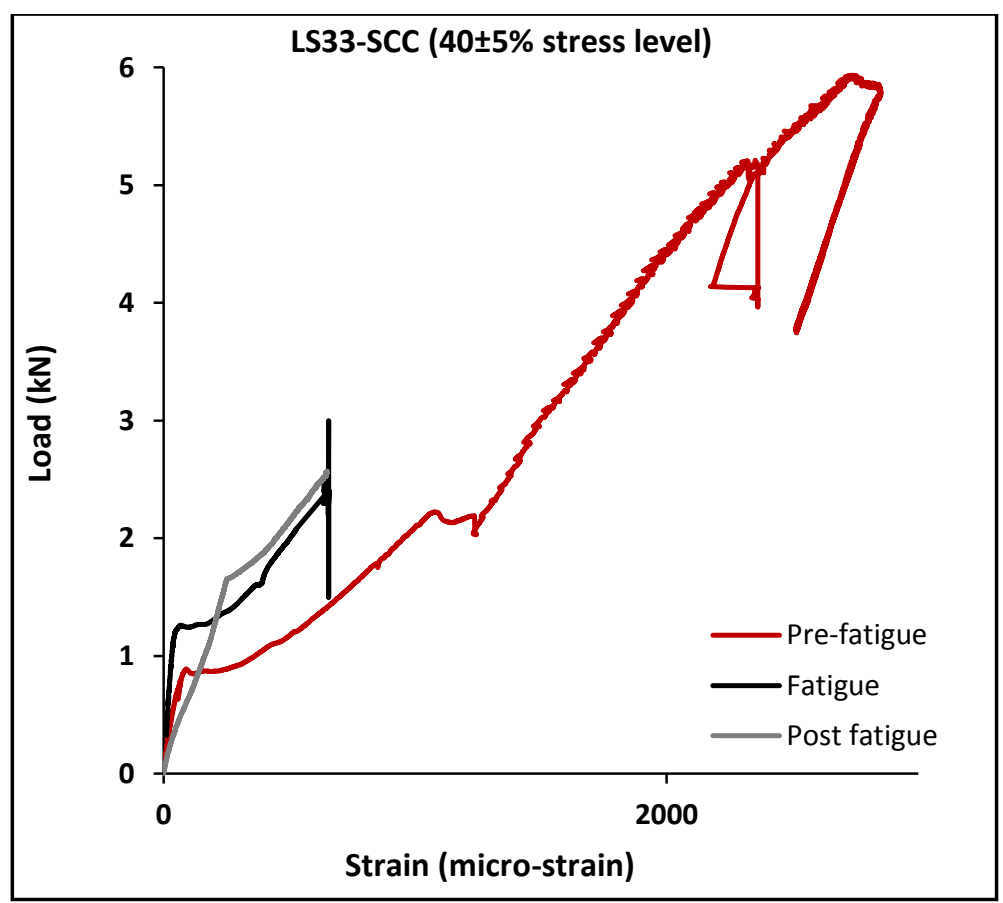

(c) Rebar strain for LS33-SCC $(40 \% \pm 5)$

Figure 5.10: Rebar Strain Development at Pre-Fatigue, Fatigue and Post Fatigue of Link Slabs at Different Fatigue Stress Level 


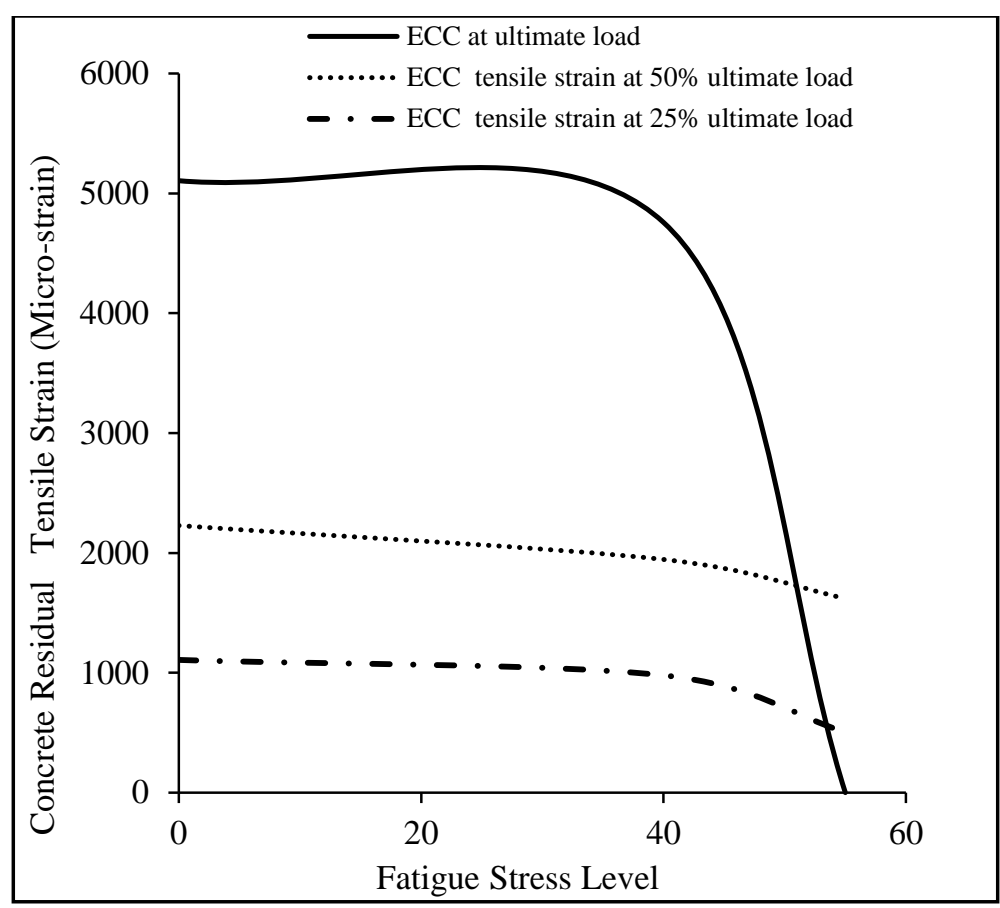

(a) Concrete Tensile Strain

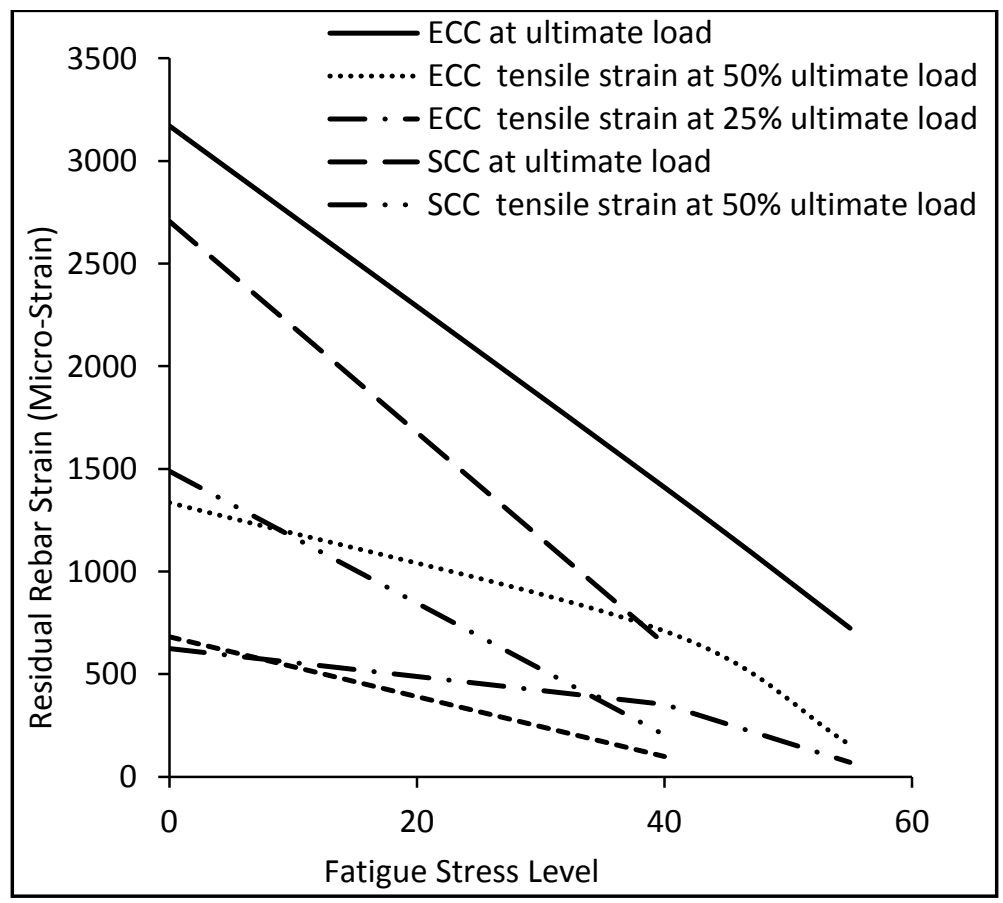

(a) Rebar Strain

Figure 5.11: Summary of Post Fatigue Strain Developments for Link Slabs Subjected to Different Fatigue Stress Level 
Table 5.7: Post Fatigue Strain Developments for the Link Slabs at Different Fatigue Stress Level

\begin{tabular}{|c|c|c|c|c|c|}
\hline Designation & $\begin{array}{c}\text { Fatigue Mean } \\
\text { Stress Level } \\
(\%)\end{array}$ & $\begin{array}{c}\text { Fatigue Stress } \\
\text { Range }(\%)\end{array}$ & $\begin{array}{c}\text { Tensile Strain at } \\
\text { Ultimate Load } \\
\text { (Micro-Strain) }\end{array}$ & $\begin{array}{c}\text { Rebar Strain at } \\
\text { Ultimate Load } \\
\text { (Micro-Strain) }\end{array}$ & $\begin{array}{c}\text { Compressive } \\
\text { Strain at } \\
\text { Ultimate Load } \\
\text { (Micro-strain) }\end{array}$ \\
\hline LS28-ECC-CI-1.2-MS & 0 & 0 & 5106 & 3172 & -1481 \\
\hline LS29-ECC-CI-1.2-MS & 40 & \pm 20 & $4777(-6 \%)$ & $1368(-57 \%)$ & -4855 \\
\hline LS30-ECC-CI-1.2-MS & 55 & \pm 20 & $0^{*}$ & $724(-77 \%)$ & -4465 \\
\hline LS32-SCC & 0 & 0 & $0^{*}$ & 2723 & -783 \\
\hline LS33-SCC & 40 & \pm 5 & $0^{*}$ & $651(-76 \%)$ & -329 \\
\hline
\end{tabular}

*damaged

The post fatigued strain development (in concrete and steel) for the link slab specimen was significantly lower in compare with the non-fatigued controlled link slabs (pre-fatigued specimens) (Figure 5.9-5.11). In general, strain (both concrete and steel) decreases with the increase of stress level (Figure 5.11). At the onset of concrete cracking in the SCC link slab, the stress is transferred to the steel rebar causing high stress development and subsequent yielding at failure load (as evident from 2723 micro-strain, Table 5.6). During fatigue loading, the loss of concrete tensile strain due to the crack formation for the SCC link slab resulted as a tension stiffening at the end of the first cycle which caused the bond reduction between the concrete and the rebar (Chen et al. 2011; ACI ,1992). The loss of concrete tensile strain and the transferred stresses to the rebar caused the significant plastic deformation for the rebar. From Figure 5.10(c), it is observed that for the same reinforcing ratio, the residual rebar strain for the SCC was significantly lower in compare with the ECC link slab (Figure 5.10a), even though the peak stress range for the ECC was 15\% higher than SCC link slab. The small residual rebar strain (651 micro-strain) in compare to the pre-fatigue rebar strain development indicated the bond degradation of steel-SCC due to fatigue loading. Based on the characteristics of the residual rebar strain, it is proved that the failure of the SCC link slab was dependent to the performance and failure of the rebar (Zanuy et al. 2011). In contrast, the high residual rebar strain for the ECC link slab (Figure 5.10a and Table 5.6) in compare with the pre-fatigue monotonic rebar strain development demonstrate the active presence of the concrete tensile strain during the fatigue loading. Although the concrete tensile strain was reduced in compare with the non-fatigued ECC link slab, but the loss of both concrete and rebar strain was not significant. The high residual 
strain development of the fatigued ECC link slabs proves ECC's stiffness remains unchanged during the fatigue loading ( $\mathrm{Li}, 2004)$.

As it is observed from Figure 5.9 (b), the ECC link slab subjected to 55\% mean fatigue stress level exhibited a similar residual strain development like SCC. Low residual ECC tensile strain development (Figure 5.9b), and small residual rebar strain (Figure 5.10b) is observed for the ECC link slab at 55\% mean fatigue stress level. The high stress fatigued loading ruptured the PVA fiber at early fatigue cycle which caused the stress transfer to the reinforcing bar. The accumulation of the internal defects, such as formation of larger crack width prior to 147000 fatigue cycles resulted in an increased plastic deformation and degradation of the steel rebar. In contrast the residual concrete tensile and rebar strain development for the ECC link slab at $40 \%$ mean fatigue stress level was $6 \%$ and 57\%lower than the non-fatigued control specimens (Table 5.6). Based on the residual strain characteristic it is suggested to limit the design mean fatigue stress level to $40 \% \pm 20 \%$ in order to increase the service life of the link slab.

\subsubsection{Energy Absorbing Capacity and Ductility Index}

The energy ductility index and the energy absorbing capacity of the non-fatigued and fatigued ECC and SCC link slabs subjected monotonic loading to failure are summarized in Table 5.7.

Table 5.8: Energy Absorption and Ductility Index of Link Slabs at Different Fatigue Stress

\begin{tabular}{|l|l|l|l|l|l|}
\hline Designation & $\begin{array}{l}\text { Fatigue } \\
\text { Cycle }\end{array}$ & $\begin{array}{l}\text { Fatigue Mean } \\
\text { Stress Level }\end{array}$ & $\begin{array}{l}\text { Fatigue Peak } \\
\text { Stress Amplitude }\end{array}$ & $\begin{array}{l}\text { Energy } \\
\text { (Joules })\end{array}$ & $\begin{array}{l}\text { Ductility } \\
\text { Index }\end{array}$ \\
\hline LS28-ECC-CI-1.2-MS & 0 & 0 & 0 & 93.125 & 37.220 \\
\hline LS29-ECC-CI-1.2-MS & 400000 & $40 \%$ & $\pm 20 \%$ & 31.372 & 16.902 \\
\hline LS30-ECC-CI-1.2-MS & 400000 & $55 \%$ & $\pm 20 \%$ & 13.293 & 2.298 \\
\hline LS32-SCC & 400000 & 0 & 0 & 35.62 & 13.477 \\
\hline LS33-SCC & 400000 & $40 \%$ & $\pm 5 \%$ & 4.035 & 2.522 \\
\hline
\end{tabular}

From Table 5.7, it can be noted that the fatigued link slabs had shown lower residual energy absorbing capacity and ductility index than non-fatigued control specimens. Non-fatigued ECC 
link slabs showed 2.6 and 2.7 times higher energy absorbing capacity and ductility index than their SCC counterparts. ECC link slabs also exhibited higher post-fatigues residual energy absorbing capacity and ductility than their SCC counterparts at both low and high fatigue stress levels. Even at higher fatigue stress level of $40 \% \pm 20 \%$, the ECC link slab demonstrated 7.85 and 6.70 times higher energy absorbing capacity and ductility index, respectively compared with the SCC link slab (tested at $40 \% \pm 5 \%$ stress level).

The structural response of the ECC link slabs at $55 \% \pm 20 \%$ fatigue stress level was similar to the SCC specimen at $40 \% \pm 5 \%$. The energy absorbing capacity and ductility index of the ECC link slab at $55 \% \pm 20$ were 13.3 joules and 2.3, respectively which is 86 lower than the pre-fatigued control specimen and $58 \%$ lower than the link slab specimen subjected to t $40 \% \pm 20 \%$ stress level (Table 5.7).

The low residual energy absorbing capacity and ductility of the ECC link slab at $55 \% \pm 20$ fatigue stress level confirmed the brittleness of the specimen due degradation and accumulated damage. The Canadian Highway Bridge Design Code CHBDC (2006) limits the maximum fatigue stress level to $65 \%$ for the concrete bridge deck. Therefore based on the observed characteristics, it is recommended to limit the maximum design fatigue stress level of the ECC link slab within the elastic range up to maximum $60 \%$ of ultimate capacity of the link slab.

\subsection{Behaviour ECC Link Slabs subjected to Different Fatigue Cycles at Constant Fatigue Stress Level}

This section presents the results for the structural performance of ECC link slabs subjected to different fatigue cycles of 400000 and 1000000 at the fixed stress level of $40 \% \pm 20 \%$. It was decided to test the ECC specimens only due to the weak response of the SCC link slab subjected to flexural fatigue loading up to 400000 cycles. 


\subsubsection{Fatigue Performance}

\subsubsection{Load-Deflection Response and Deflection Evolution}

The load-deflection response and deflection evolution of ECC link slab specimens subjected to 400000 and 1 million fatigue cycles are illustrated in Figures 5.12 and 5.13. The results of deflection evolution is summarized in Table 5.8.

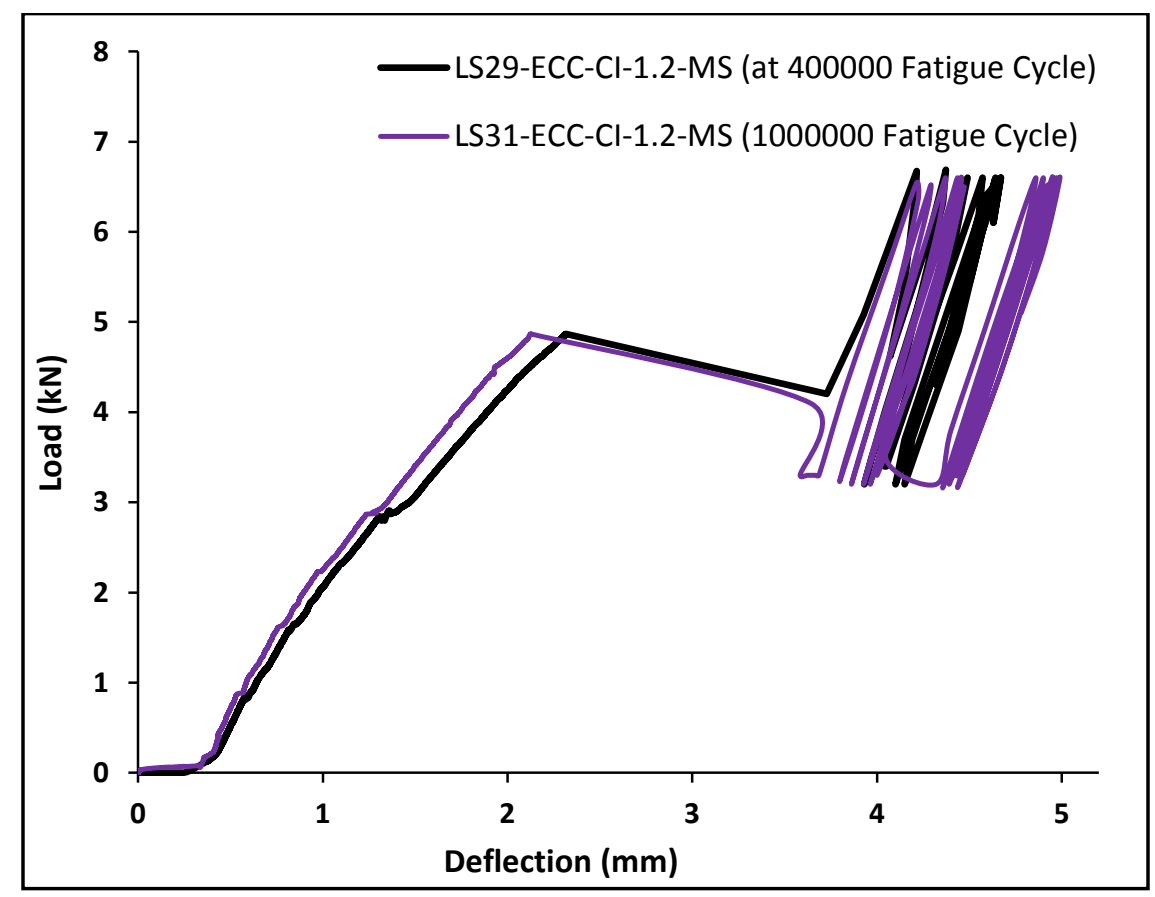

Figure 5.12: Load-Deformation Responses of ECC Link Slabs at Different Fatigue Cycles 


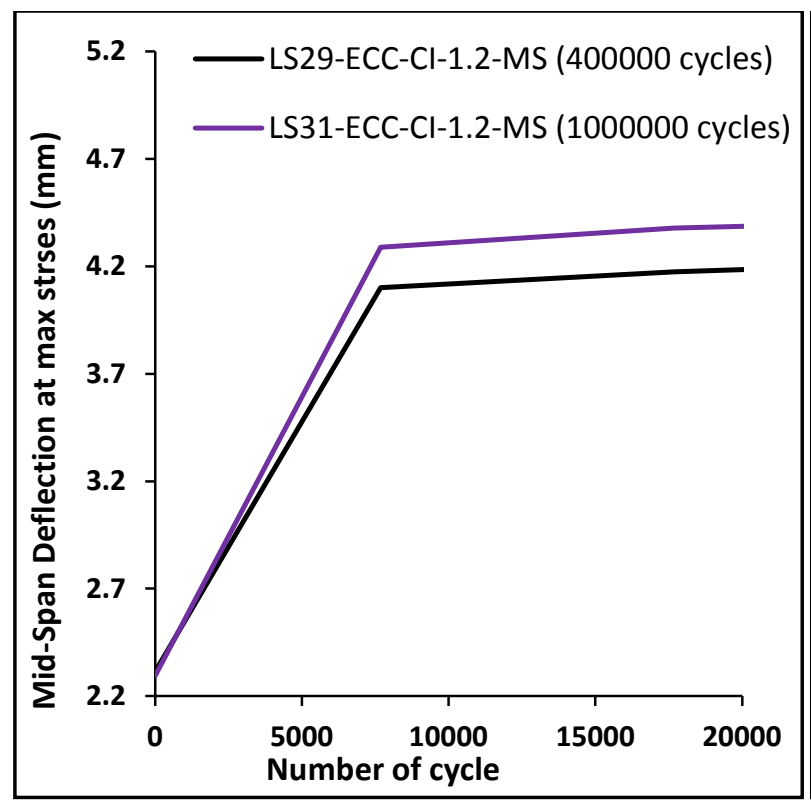

(a) Initial 10000Fatigue Cycle

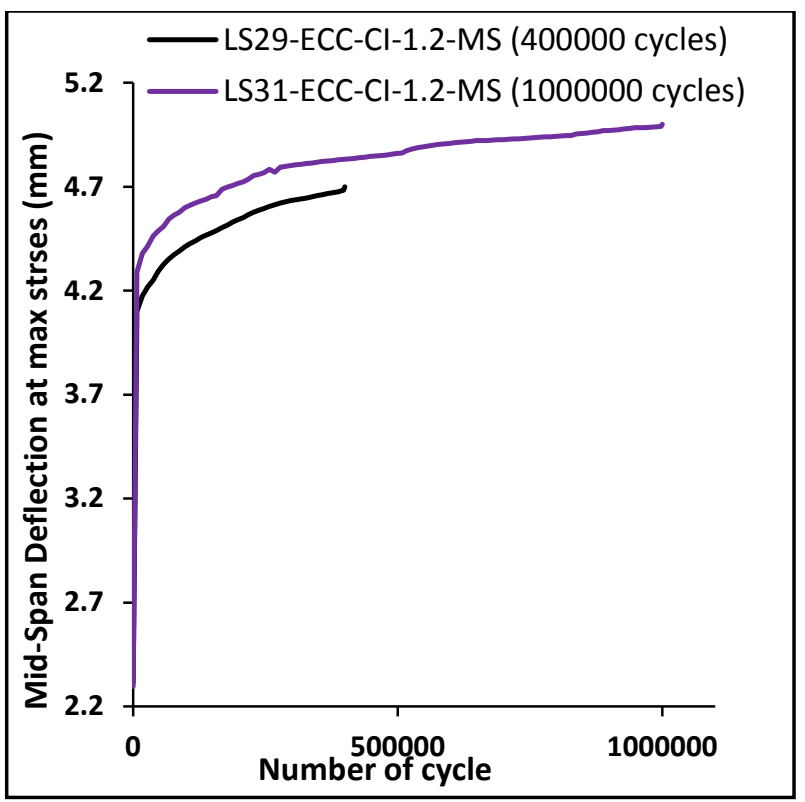

(b) Full Fatigue Cycle

Figure 5.13: Mid-Span Deflection Evolution of ECC Link Slabs at Different Fatigue Cycles

Table 5.9: Mid-Span Deflection Evolution at Different Fatigue Cycles

\begin{tabular}{|c|c|c|c|c|}
\hline & & $\begin{array}{c}\text { Difference Between } \\
\text { First and Initial } \\
\text { Designation }\end{array}$ & Fatigue Cycle & Fatigue \\
& & $\begin{array}{c}\text { Mid-Span Deflection } \\
(\mathrm{mm})\end{array}$ & $\begin{array}{c}\text { Difference Between } \\
\text { First and Last value of } \\
\text { Cycles }\end{array}$ & $\begin{array}{c}\text { Mid-Span Deflection } \\
(\mathrm{mm})\end{array}$ \\
\hline LS29-ECC-CI-1.2-MS & 10000 & 1.787 & 400000 & 2.39 \\
\hline LS31-ECC-CI-1.2-MS & 10000 & 1.850 & 1000000 & 2.87 \\
\hline
\end{tabular}

Figure 5.12 shows the formation of large deflection band width for the ECC link slab subjected to higher number of fatigue cycles. The deflection band width of link slab subjected to the 1 million fatigue cycles increased from $2.1 \mathrm{~mm}$ to $5 \mathrm{~mm}$, whereas the band width for the ECC link slab at 400000 cycle varied from $2.2 \mathrm{~mm}$ to $4.59 \mathrm{~mm}$. The larger bending capacity is also justified through Figure 5.13 (b) due to increase in mid-span deflection evolution at maximum stress level. Once again the development higher deflection evolution (bending capacity) at higher fatigue cycles ( 1 million cycle) is attributed to the fiber bridging characteristics of the ECC. 
Although the link slab at higher fatigue cycle deflected more, but the change in deflection evolution with respect to 400000 fatigue cycle was not significant; it only deflected $0.41 \mathrm{~mm}$ more. It is clearly observed that the increase in deflection evolution was higher for both link slabs at the initial fatigue cycles (Figure 5.13 and Table 5.8) due to the increased stress shift from pre-monotonic to fatigue loading. However with increasing fatigue cycle the mid-span deflection evolution becomes negligible in compare with initial fatigue cycle. The gradual increase in deflection evolution specifically after 700000 fatigue cycle demonstrates the rupture of fibers.

\subsubsection{Strain Development}

The concrete and rebar strain development for the ECC link slabs at different fatigue cycles was recorded during the fatigue loading. The key features of concrete (tensile and compressive) and rebar strain developments for the ECC link slabs at different fatigue cycles of 400000 and 1 million are tabulated in Table 5.9. The concrete and steel strain evolution with load and number of fatigue cycles is illustrated in Figures 5.14 and 5.15.

Table 5.10: Strain Development of Link Slab During Fatigue Performance at Different Fatigue Cycle

\begin{tabular}{|c|c|c|c|c|c|c|c|}
\hline \multirow{2}{*}{ Designation } & \multirow{2}{*}{$\begin{array}{c}\text { Initial } \\
\text { Fatigue } \\
\text { Cycle }\end{array}$} & $\begin{array}{c}\text { Tensile } \\
\text { Strain } \\
\text { (Micro- } \\
\text { Strain) }\end{array}$ & $\begin{array}{c}\text { Final } \\
\text { Concrete } \\
\text { Tensile } \\
\text { Strain } \\
\text { (Micro- } \\
\text { Strain) }\end{array}$ & $\begin{array}{c}\text { Initial } \\
\text { Concrete } \\
\text { Compresiv } \\
\text { e Strain } \\
\text { (Micro- } \\
\text { Strain) }\end{array}$ & $\begin{array}{c}\text { Final } \\
\text { Concrete } \\
\text { Compressiv } \\
\text { e Strain } \\
\text { (Micro- } \\
\text { Strain) }\end{array}$ & $\begin{array}{c}\text { Initial } \\
\text { Rebar } \\
\text { Strain } \\
\text { (Micro- } \\
\text { Strain) }\end{array}$ & $\begin{array}{c}\text { Final } \\
\text { Rebar } \\
\text { Strain } \\
\text { (Micro- } \\
\text { Strain) }\end{array}$ \\
\hline LS29-ECC-CI-1.2-MS & 400000 & 2536.1 & 2647.1 & -2281.5 & -4227.3 & 961.3 & 1782.1 \\
\hline LS31-ECC-CI-1.2-MS & 1 million & 2643.0 & 3234.3 & -2010.7 & -2207.3 & 1038.5 & 2093.5 \\
\hline
\end{tabular}




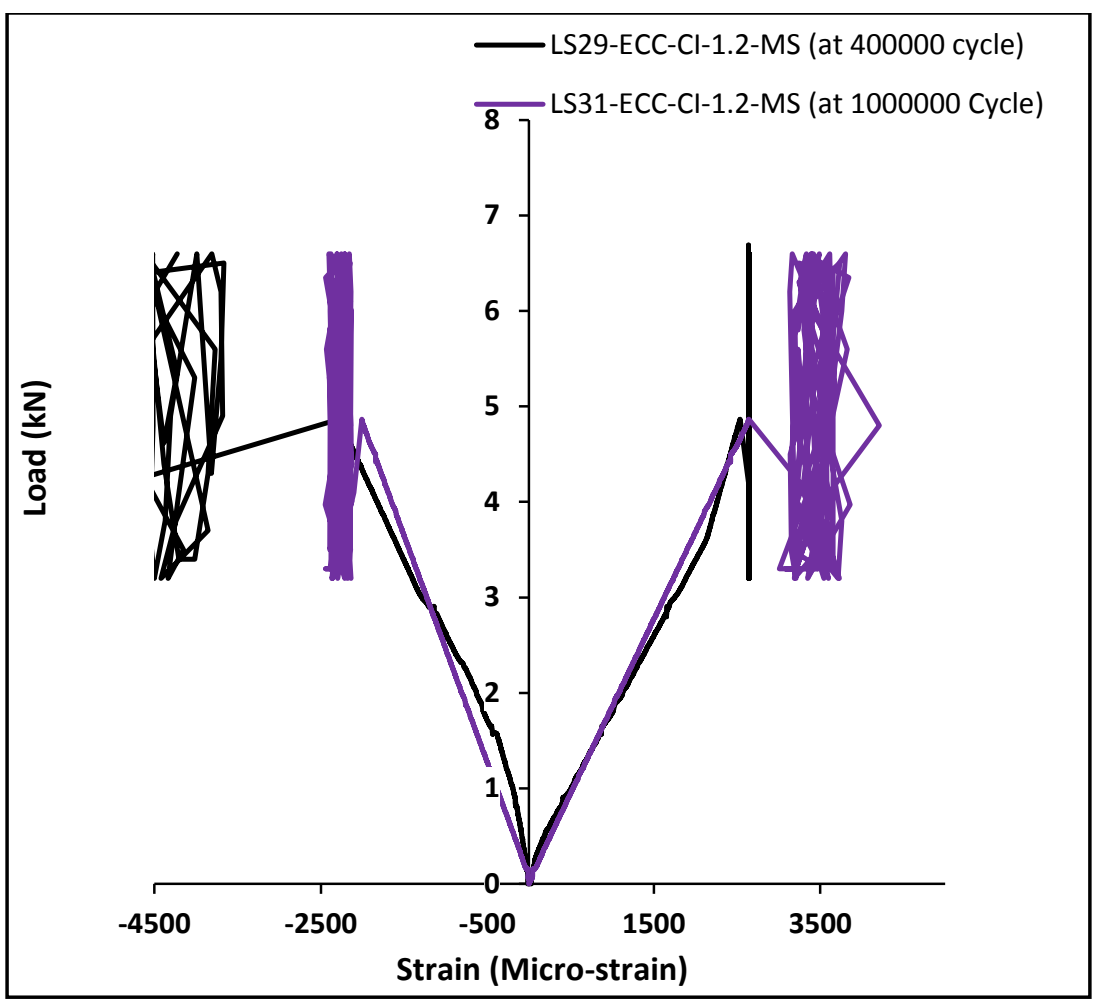

(a) Concrete Tensile/Compressive Strain

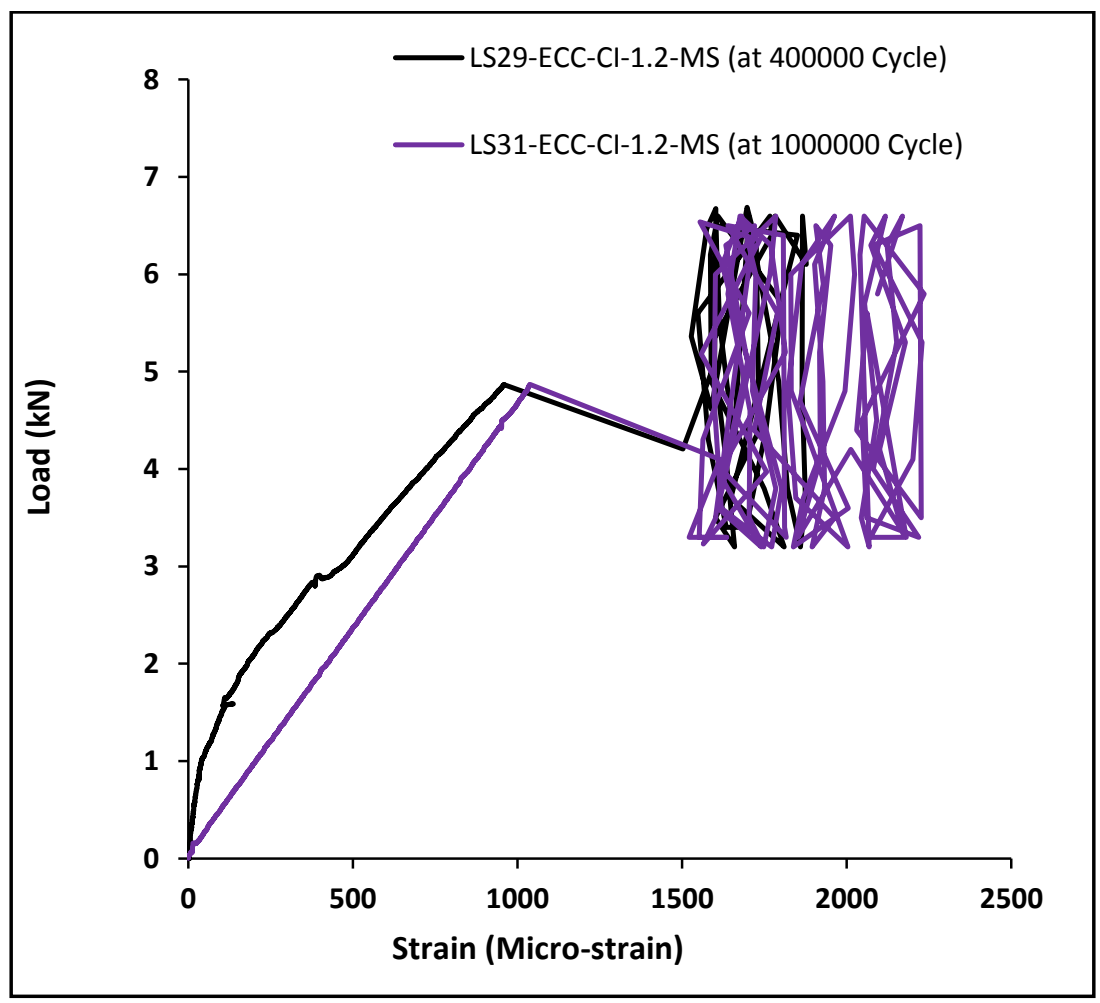

(b) Rebar Strain

Figure 5.14: Strain Development for ECC Link Slabs at Different Fatigue Cycles 


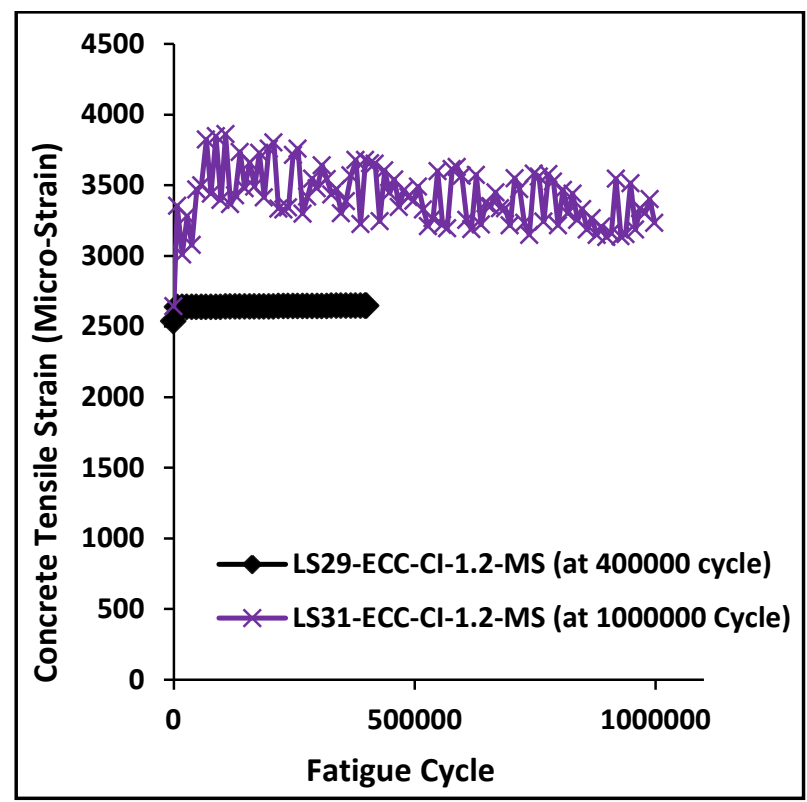

(a) Concrete Tensile Strain

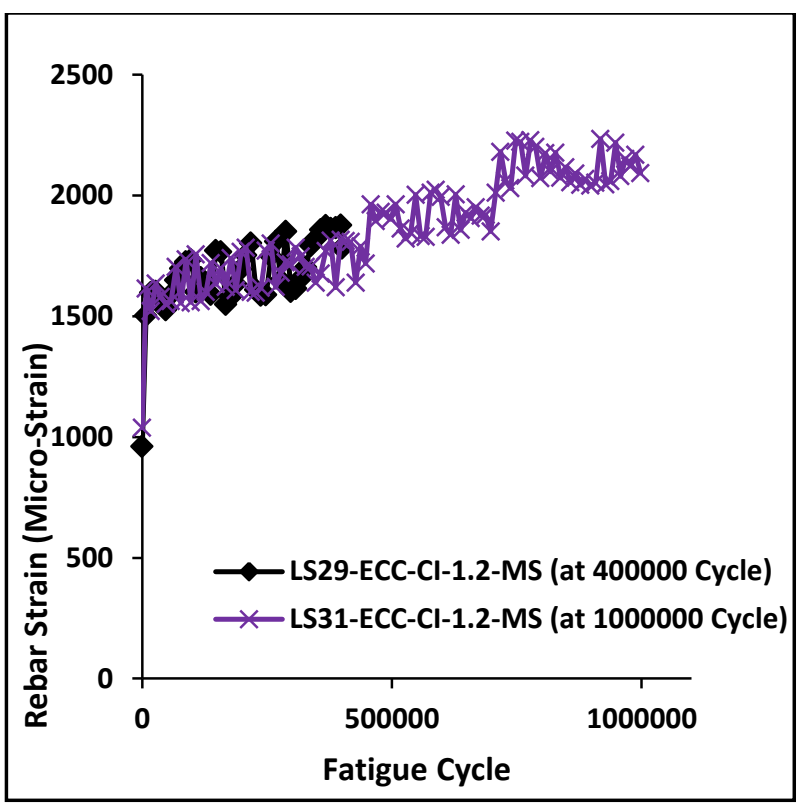

(b) Rebar Strain

Figure 5.15: Strain Development Evolution of ECC Link Slabs at Different Fatigue Cycle

From Figure 5.14, it is observed that ECC link slab at 400000 fatigue cycles developed lower tensile strain band width (strain development) compared with that subjected to 1million fatigue cycle. The ECC tensile strain band for link slab subjected to 1million fatigue cycle was increased from 2643 micro-strain to 3234 micro-strain during the fatigue loading. On the other hand, the ECC tensile strain band width for the link slab subjected to 400000 fatigue cycles increased from 2536 micro-strain to 2647 micro-strain (Table 5.9). The larger concrete tensile band at 1 million cycles demonstrated higher damage level in compare with the ECC link slab at 400000 fatigue cycles. Although the damage level was increased at 1 million cycles but the tensile strain did not reach ECC's ultimate tensile strain capacity of 0.05 (means ECC can endure more fatigue cycles) and suffered much lower degradation compared to what observed for SCC link slab subjected to 400000 cycles.

Similar pattern was also observed for the rebar strain development for the ECC link slab at 1million fatigue cycles (Figure 5.14b). The rebar strain band width for the ECC link slab at 1million fatigue cycle increased from 1038 micro-strain to 2093 Micro-strain during fatigue loading (Figure 5.14b and Table 5.9). The rebar strain reached the yielding strain of 2000 microstrain at 700000 fatigue cycle as it is evidenced from Figure 5.15(b). The strain development and 
deflection evolution characteristics confirmed initiation of rebar yielding at 700000 fatigue cycles - an indicator of degradation of strength and stiffness of ECC link slabs.

\subsubsection{Stiffness Evolution}

The variation of stiffness with number of fatigue cycles up to 1 million is presented in Figure 5.16.

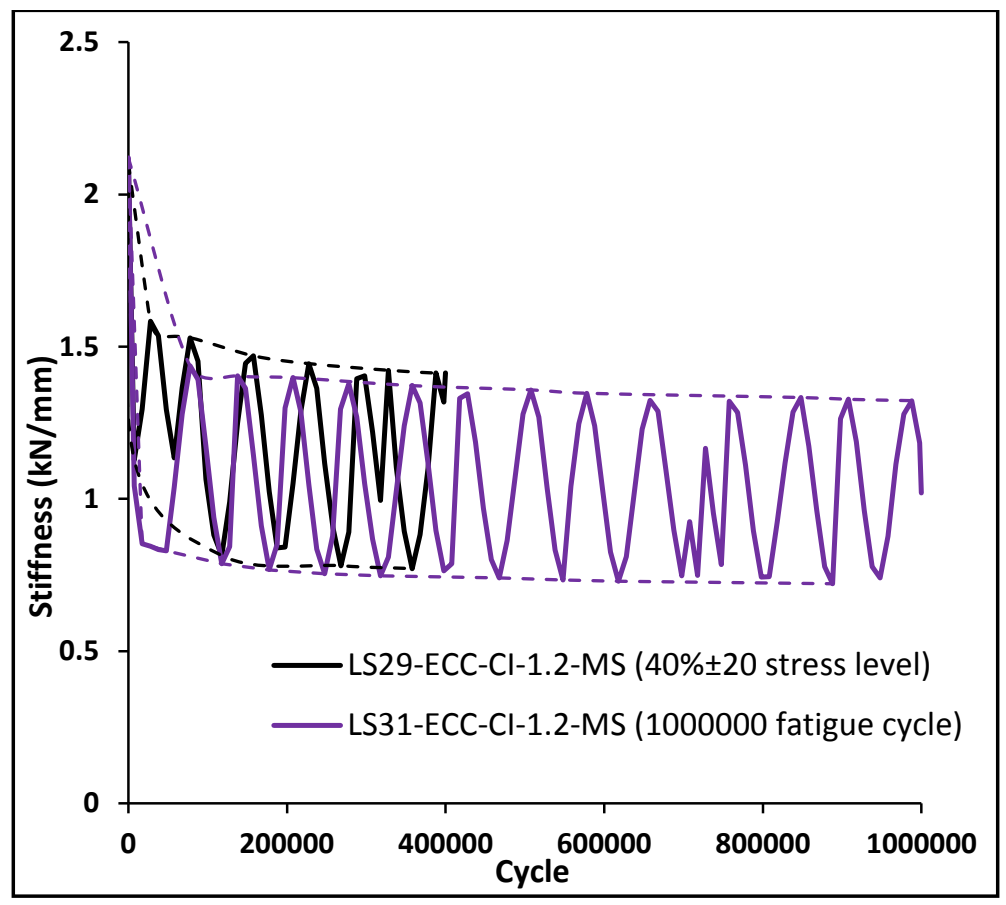

Figure 5.16: Stiffness Degradation of Link Slab Specimens at Different Fatigue Cycles

As previously discussed, the stiffness degraded significantly for the initial fatigue cycle due to concrete crack formation caused by high fatigue stress range $( \pm 20 \%)$. However with fiber bridging characteristic the stiffness of the link slabs were stabilized and a gradual decrease in stiffness with increasing fatigue cycle is observed (as indicated by the dotted lines connecting the upper and lower peak points) showing the variation of stiffness. The oscillating stiffness pattern was due to the stress level range ( $\pm 20 \%$ from the mean $40 \%$ ). Table 5.10 summarizes the initial and final stiffness of link slab specimens subjected to different fatigue cycles of 400000 and 1 million. 
Table 5.11: Stiffness Degradation of Link Slab Specimens at Different Fatigue Cycles

\begin{tabular}{|c|c|c|c|}
\hline Designation & Fatigue Cycle & $\begin{array}{c}\text { Initial Stiffness } \\
(\mathrm{kN} / \mathrm{mm})\end{array}$ & $\begin{array}{c}\text { Stiffness at end of } \\
\text { fatigue cycle } \\
(\mathrm{kN} / \mathrm{mm})\end{array}$ \\
\hline LS29-ECC-CI-1.2-MS & 400000 & 2.10 & 1.42 \\
\hline LS31-ECC-CI-1.2-MS & 1000000 & 2.1 & 1.01 \\
\hline
\end{tabular}

The initial stiffness for the ECC link slab at 1million fatigue cycle was $2.193 \mathrm{kN} / \mathrm{mm}$ and at the end of the fatigue loading (end of 1million fatigue cycle) it was reduced to $1.01 \mathrm{kN} / \mathrm{mm}$ showing a decrease of about 54\% (Table 5.10). At 700000 fatigue cycle, the stiffness was reduced to 0.7 $\mathrm{kN} / \mathrm{mm}$, but it recovers to $1.2 \mathrm{kN} / \mathrm{mm}$ (Figure 5.16). This demonstrates that PVA fibers were ruptured at 700000 fatigue cycle and the stiffness recovery was attained by the presence of steel reinforcement (stress transfer mechanism). It can also be derived from Table 5.10 that the stiffness was reduced by $32 \%$ at 400000 cycles. Such degradation of stiffness with increased fatigue cycles (as observed in this study) can be used to predict the service life (in terms of cycles needed to degrade the stiffness to zero) of the link slab specimens.

\subsubsection{Crack Characterization}

The cracking information were monitored at the end of every 10000 cycles. The number of cracks and the crack width at mid-span location were recorded at the end of the fatigue performance. The experimental results for the crack characterization are presented in Table 5.11 and the development of cracks in the link slab is shown in Figure 5.17.

Table 5.12: Crack Characterization of the ECC Link Slab at Different Fatigue Cycle

\begin{tabular}{|c|c|c|c|}
\hline Designation & $\begin{array}{c}\text { Fatigue } \\
\text { Cycles }\end{array}$ & $\begin{array}{c}\text { Number of cracks after } \\
400000 \text { fatigue cycle }\end{array}$ & $\begin{array}{c}\text { Crack widths after } 400000 \text { fatigue } \\
\text { cycle }(\mu \mathrm{m})\end{array}$ \\
\hline LS29-ECC-CI-1.2-MS & 400000 & 17 Micro-Crack & 100 \\
\hline LS31-ECC-CI-1.2-MS & 1000000 & $\begin{array}{c}24 \text { Micro-Crack } \\
1 \text { Major Crack }\end{array}$ & 550 \\
\hline
\end{tabular}




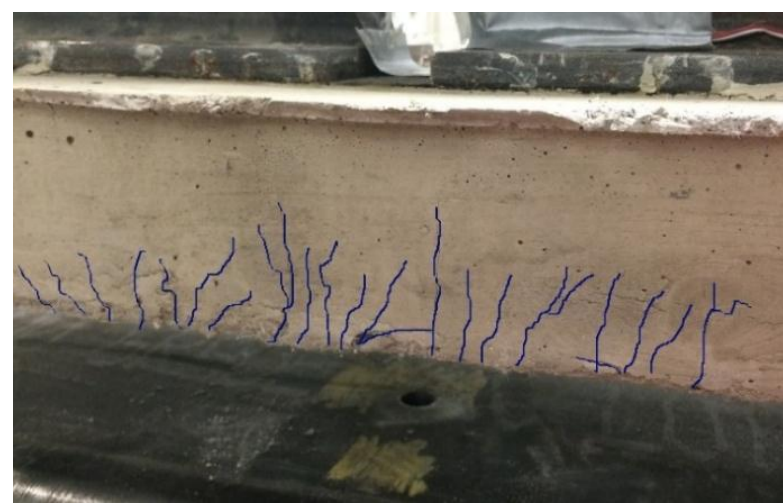

(a) LS29-ECC-CI-1.2-MS (at 400000 fatigue Cycle)

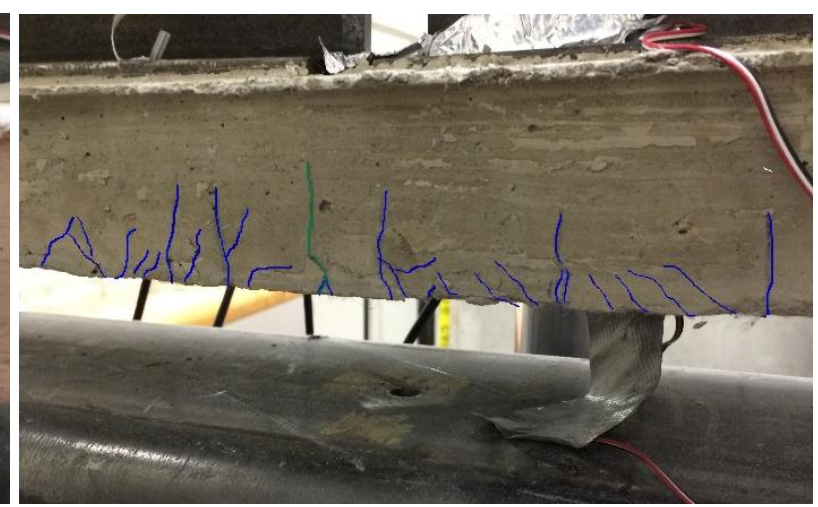

(b) LS31-ECC-CI-1.2-MS (at 1000000 fatigue cycle)

Figure 5.17: Crack Characterization of ECC Link Slabs at Different Fatigue Cycle

At initial fatigue cycle, multiple-micro cracks were initiated due to the stress shift from premonotonic to fatigue loading. Additional micro-cracks were propagated at the mid-span location with increasing number of the fatigue cycles. As it is evidenced from Figure 5.17(b), a major crack was developed at the mid-span location of link slab at 500000 fatigue cycle. The crack width increased significantly until the PVA fibers were ruptured at 700000 fatigue cycle. The ruptured PVA fibers through the cracks - a sign of damage in ECC, but ECC link slabs continued to take 1 million cycles. On unloading after 1 million cycles, the crack widths remained below $550 \mu \mathrm{m}$. The small crack width demonstrated the combined contribution of aggregate interlocking and crack bridging characteristic of the PVA fibers (Hossain \& Anwar, 2014). Although the major crack width for the ECC link slab at 1 million fatigue cycle is above the limitation of AASHTO's LRFD (2012) and CHBDC (2006), yet it still can maintain adequate durability requirement.

\subsubsection{Post Fatigue Monotonic Performance of ECC Link Slabs at Different Fatigue Cycles} At the end of the fatigue flexural loading, the ECC link slab specimens were tested under monotonic loading to failure for determining the residual strength, deflection, stiffness and failure characteristics compared with the control non-fatigued counterparts. 


\subsubsection{Experimental Load-Deflection/Moment-Rotation Responses and Theoretical-Code}

\section{Based Analysis}

The summary of residual load-deformation and moment rotation responses of the ECC link slabs at different fatigue cycles are compared with those of non-fatigued control specimens Figures 5.18 and 5.19 .

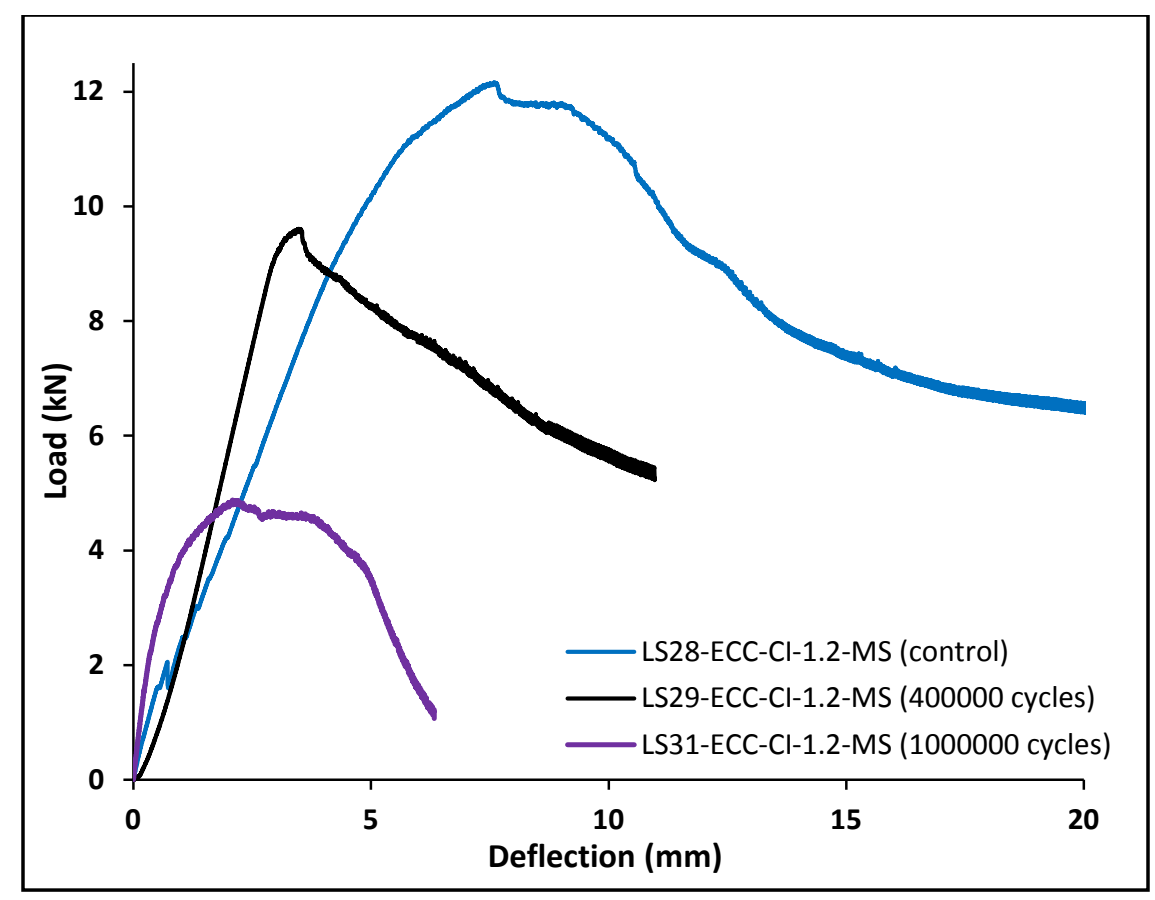

Figure 5.18: Post Fatigue Load-Deformation Response of ECC Link Slabs at Different Fatigue Cycle

The ultimate strength and mid-span deflection reduced significantly with increasing number of the fatigue cycle. The ECC link slab at 400000 fatigue cycle maintained $79 \%$ of the ultimate strength and $46 \%$ of the bending capacity of non-fatigued control specimen. On the other hand, at 1 million fatigue cycle both strength and mid-span deflection were reduced to $40 \%$ and $27 \%$ compared with the non-fatigued control specimen, respectively (Table 5.12). Strength and bending capacity degradation of the fatigued specimens especially at high fatigue cycles were attributed to the lowering of crack bridging ability due to the rupture PVA fiber, stress transfer from ECC to rebar, crack closing and opening during fatigue loading and steel-ECC bond degradation. 
Table 5. 13: Residual Load-Deformation and Moment-Rotation Responses of ECC Link Slabs at Different Fatigue Cycles

\begin{tabular}{|c|c|c|c|c|c|c|c|c|c|}
\hline Designation & $\begin{array}{c}\text { Fatigue } \\
\text { Cycle }\end{array}$ & $\begin{array}{c}\text { Ultimate } \\
\text { Load } \\
(\mathrm{kN})\end{array}$ & $\begin{array}{c}\text { Ultimate } \\
\text { Deflection } \\
(\mathrm{mm})\end{array}$ & $\begin{array}{c}\text { Ultimate } \\
\text { Rotation } \\
\theta_{\text {exp }} \\
(\text { radian })\end{array}$ & $\begin{array}{c}\text { Ratio } \\
\theta_{\text {exp }} /\end{array}$ & $\begin{array}{c}\text { Ultimate } \\
\theta_{\text {Allow }} \\
\text { Moment } \\
(\mathrm{Mex}) \\
(\mathrm{kN} . \mathrm{m})\end{array}$ & $\begin{array}{c}\text { Ratio } \\
\mathrm{M}_{\mathrm{ex}} / \\
\mathrm{M}_{\mathrm{des}}^{*}\end{array}$ & $\begin{array}{c}\mathrm{M}_{\text {exp }} \text { at } \\
(\mathrm{kN} . \mathrm{m})\end{array}$ & $\begin{array}{c}\text { Ratio } \\
\mathrm{M}_{\text {exp }} \text { at } \\
\theta_{\text {Allow }} / \\
\mathrm{M}_{\mathrm{ex}}\end{array}$ \\
\hline $\begin{array}{c}\text { LS28-ECC- } \\
\text { CI-1.2-MS }\end{array}$ & 0 & 12.16 & 7.60 & 0.020594 & 5.49 & 2.31 & 1.79 & 0.65 & 0.28 \\
\hline $\begin{array}{c}\text { LS29-ECC- } \\
\text { CI-1.2-MS }\end{array}$ & 400000 & $\begin{array}{c}9.61 \\
(-21 \%)\end{array}$ & $\begin{array}{c}3.48 \\
(-54 \%)\end{array}$ & 0.009425 & 2.51 & 1.83 & 1.45 & 0.73 & 0.40 \\
\hline $\begin{array}{c}\text { LS31-ECC- } \\
\text { CI-1.2-MS }\end{array}$ & 1000000 & $\begin{array}{c}4.87 \\
(-60 \%)\end{array}$ & $\begin{array}{c}2.09 \\
(-73 \%)\end{array}$ & 0.006223 & 1.65 & 0.925 & 0.72 & 0.8 & 0.86 \\
\hline
\end{tabular}

$\theta_{\text {Allow }}$ represents the maximum allowable AASHTO's rotation of 0.00375 radian

$* \mathrm{M}_{\text {des }}$ calculated by Equation 2.15

*values in brackets represents \% reduction of ultimate load and deflection compared to non-fatigued specimens

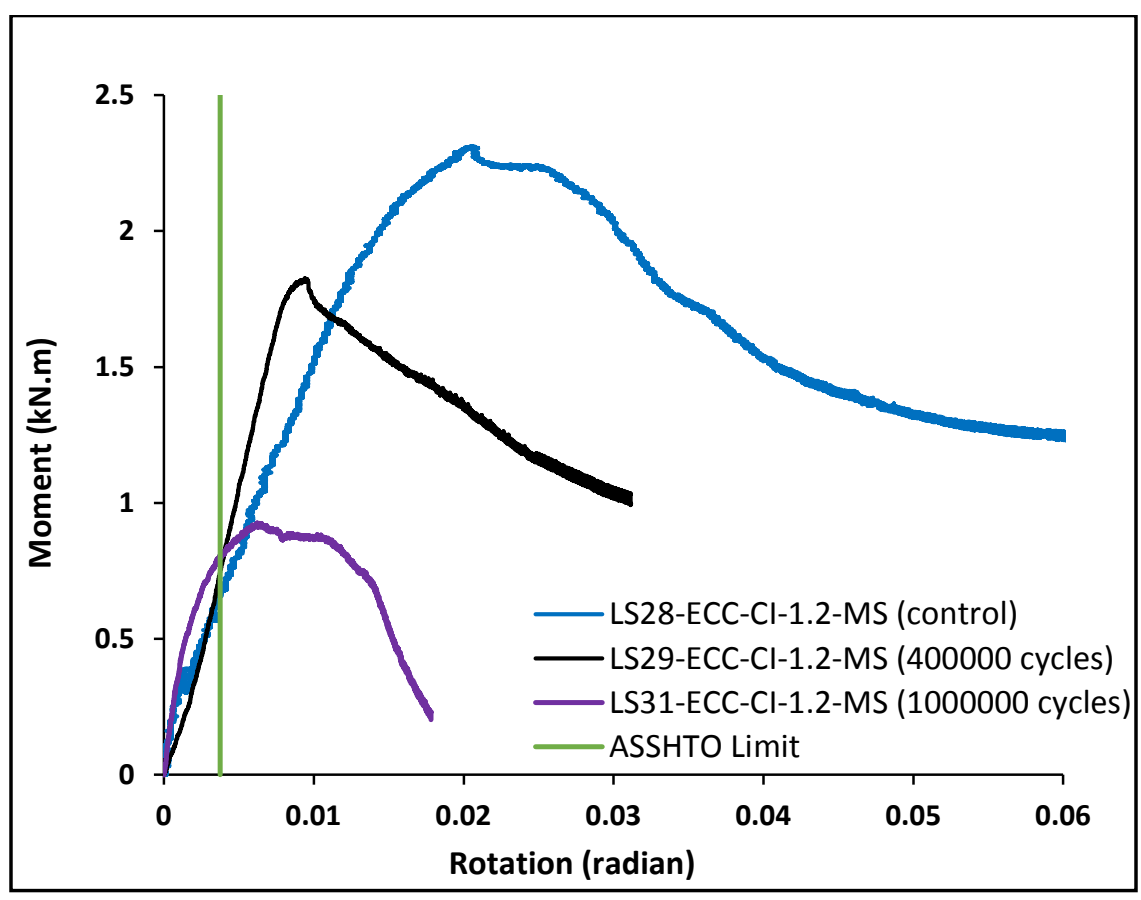

Figure 5 19: Residual Moment-Rotation Responses of ECC Link Slab at Different Fatigue Cycle 
Figure 5.19 compares the residual moment-rotation responses fatigued specimens compared with non-fatigued control ones. As expected, at higher fatigue cycles the moment capacity and support rotation decreased due to the development of more fatigue damages. Although for the purpose of the link slab, the moment capacity is not a significant parameter in compare with the end-rotation, but a reasonable factor of safety with respect to the design moment is required for failure prevention. Through the comparison of the experimental to theoretical design moment (based on Equation 2.15), it is observed that at 1 million fatigue cycle, the factor of safety for the ultimate moment was reduced to 0.72 (ratio of experimental to theoretical values) in compare with 1.45 for the link slab specimen subjected to 400000 fatigued cycle (Table 5.12). The factor of safety of below 1 can be used to justify the failure of the link slab at 1 million fatigue cycle.

At higher fatigue cycles, the residual support end rotation of the link slab satisfied the maximum allowable AASHTO's LRFD end rotation of 0.00375 radian, but with lower factor of safety of 1.65 (Table 5.12). As it is evidenced from Figure 5.19 and Table 5.12 the AASHTO's design end rotation for the 1 million fatigue cycle link slab was attained at $86 \%$ of the ultimate moment, close to the failure. Whereas the end rotation for ECC link slab at 400000 fatigue cycle was achieved at $40 \%$ of the ultimate load. Therefore the design fatigue cycle for the ECC link slab at $4 \mathrm{~Hz}$ amplitude and $40 \% \pm 20 \%$ fatigue stress level has to be limited to 700000 cycle (at the initiation of yielding of steel) for satisfying both ultimate and fatigue limit state design.

\subsubsection{Strain Developments}

The concrete and rebar strain development for the ECC link slabs at different fatigue cycles at three stages of non-fatigued, fatigued and post-fatigue are illustrated in Figures 5.20 and 5.21. Table 5.13 summarizes ultimate residual strain developments of the fatigued link slabs at different cycles. 


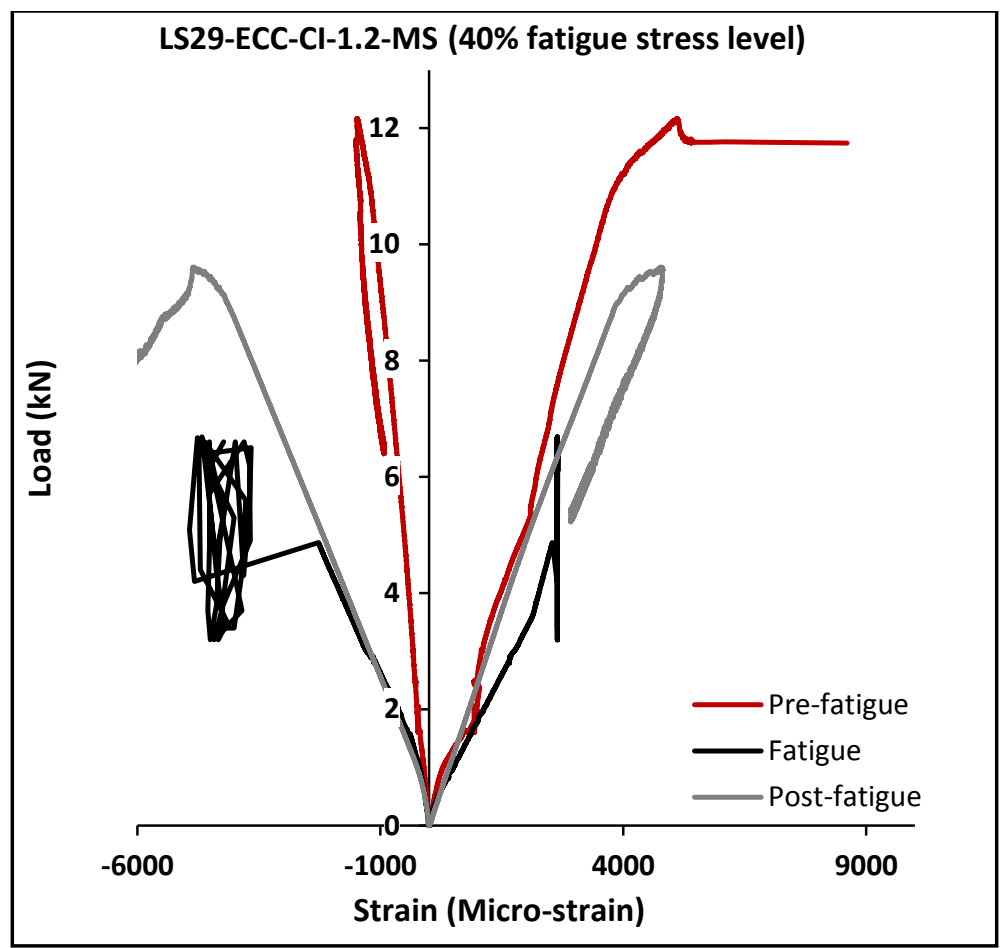

(a) Concrete strain LS-29-ECC-CI-1.2-MS (400000)

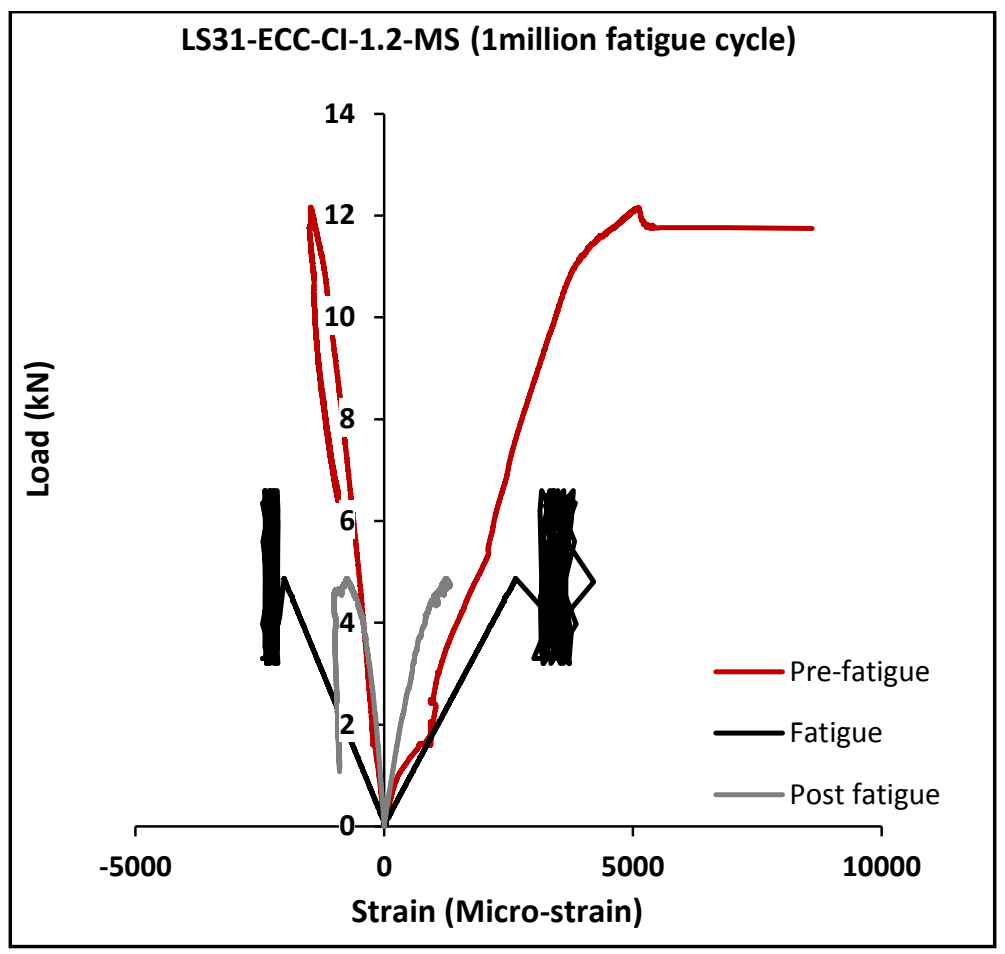

(b) Concrete strain LS31- ECC-CI-1.2-MS (1million)

Figure 5.20: Post Fatigue Concrete Strain Development for the ECC Link Slabs at Different Fatigue Cycle 


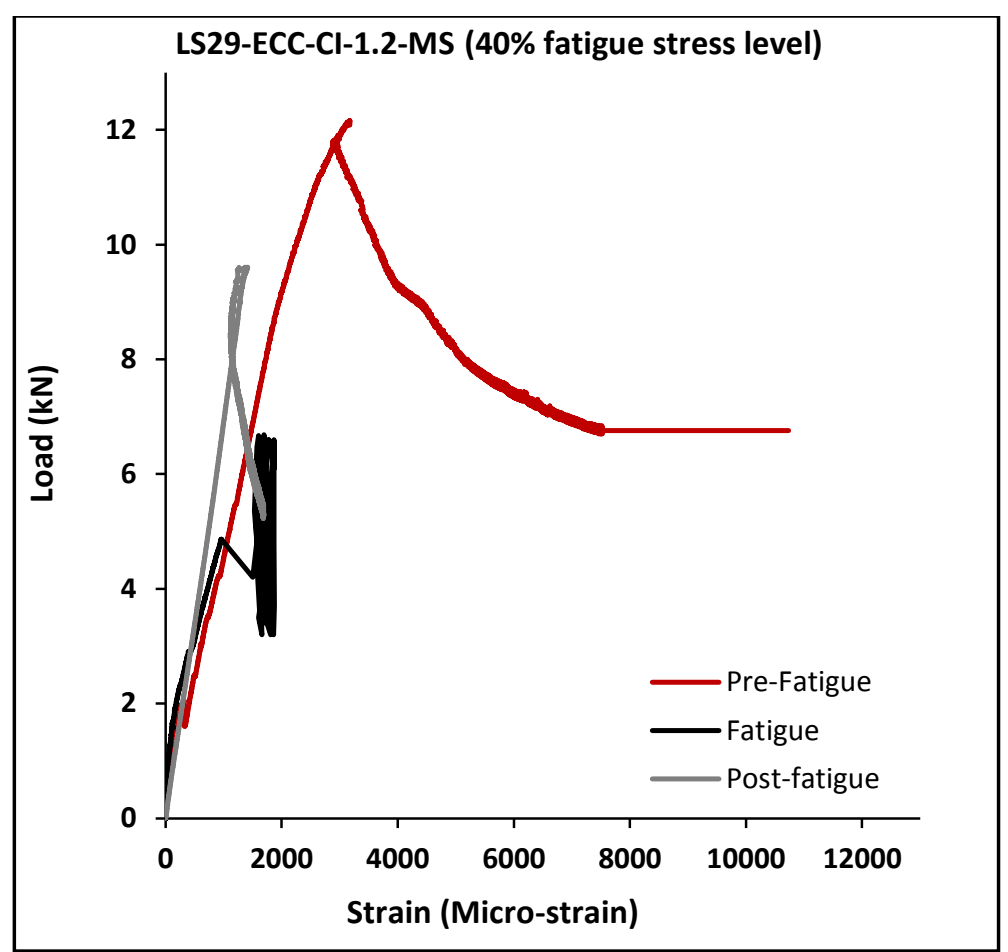

(a) Rebar strain LS-29-ECC-CI-1.2-MS (400000)

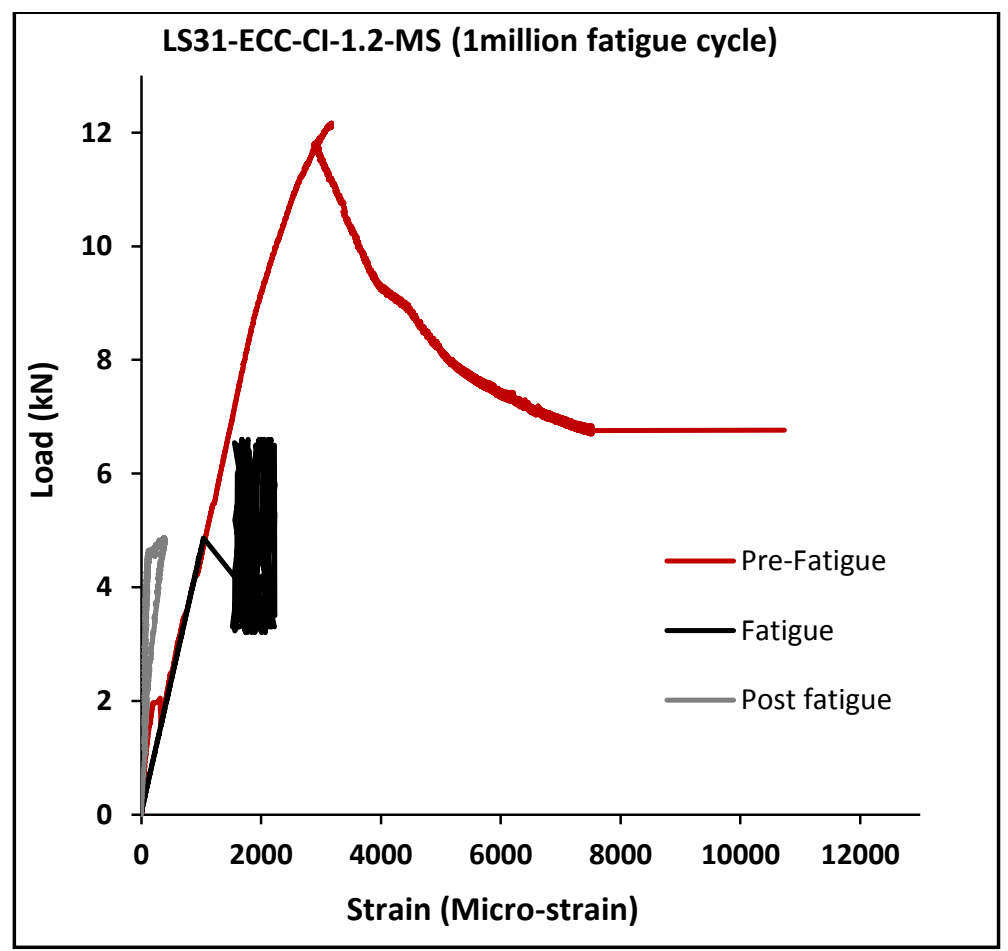

(b) Rebar strain LS31- ECC-CI-1.2-MS (1million)

Figure 5.21: Post Fatigue Rebar Strain Development for the ECC Link Slabs at Different Fatigue Cycle 
Table 5.14: Residual Strain Development of the ECC Link Slab at Different Fatigue Cycle

\begin{tabular}{|c|c|c|c|c|c|}
\hline Designation & $\begin{array}{c}\text { Fatigue } \\
\text { Cycle }\end{array}$ & $\begin{array}{c}\text { Ultimate } \\
\text { Load } \\
(\mathrm{kN})\end{array}$ & $\begin{array}{c}\text { Ultimate } \\
\text { Tensile Strain } \\
\text { (Micro-Strain) }\end{array}$ & $\begin{array}{c}\text { Ultimate } \\
\text { Rebar Strain } \\
\text { (Micro-Strain) }\end{array}$ & $\begin{array}{c}\text { Ultimate } \\
\text { Compressive Strain } \\
\text { (Micro-Strain) }\end{array}$ \\
\hline LS28-ECC-CI-1.2-MS & 0 & 12.164 & 5106 & 3172 & -1481 \\
\hline LS29-ECC-CI-1.2-MS & 400000 & 9.609 & 4777.02 & 1368.08 & -4855.08 \\
\hline LS31-ECC-CI-1.2-MS & 1000000 & 4.873 & $0 *$ & 386.314 & -739.581 \\
\hline
\end{tabular}

*Strain gauge damaged

As per Figure 5.20 and 5.21, both concrete and rebar strain development are found to be reduced significantly with increasing number fatigue cycles due to accumulated damage during fatigue loading causing reduction of strength and bending capacity. The rebar strain was reduced to 386 micro-strain - a reduction of about $88 \%$ compare with the non-fatigued link slab specimen (Table 5.13).

\subsubsection{Energy Absorbing Capacity and Ductility Responses}

The summary of the residual energy absorbing capacity and the ductility index for the fatigued ECC link slab at different cycles are presented in Table 5.14

Table 5.15: Residual Energy Absorbing Capacity and Ductility Index of the ECC Link Slabs at Different Fatigue Cycle

\begin{tabular}{|c|c|c|c|}
\hline Designation & Fatigue Cycle & $\begin{array}{c}\text { Energy Absorbing Capacity } \\
(\mathrm{J})\end{array}$ & Ductility Index \\
\hline LS28-ECC-CI-1.2-MS & 0 & 93.13 & 37.22 \\
\hline LS29-ECC-CI-1.2-MS & 400000 & 31.37 & 16.90 \\
\hline LS31-ECC-CI-1.2-MS & 1000000 & 16.00 & 4.08 \\
\hline
\end{tabular}

The energy absorbing capacity and the ductility index reduced with the increase of fatigue cycles. The residual energy absorbing capacity and ductility index of the link slab at 1million fatigue cycle were 16.0 joules and 4.08 , respectively - $83 \%$ and $89 \%$, respectively lower than the non-fatigued specimen. The small residual energy absorbing capacity and ductility index were attained by the strain hardening characteristic of the steel rebar after excessive plastic 
deformation during fatigue loading. These characteristics justified the failure of the link slab specimen subjected to 1 million fatigue cycle.

\subsection{Summary}

This chapter analyzed and discussed the fatigue performance of the link slab specimens at different stages of pre-fatigue, fatigue and post-fatigue by two different approaches of variable fatigue stress level and fatigue cycles. The ECC link slabs demonstrated a prolonged life in compare with SCC link slabs even though it was subjected to higher fatigue stress range $( \pm 20 \%)$. Among the ECC link slabs, the failure of specimens at $55 \% \pm 20 \%$ stress level and 1 million fatigue cycle were justified through the fatigue and post fatigue responses. 


\section{CHAPTER SIX CONCLUSIONS}

\subsection{General}

This thesis described the structural performance of reduced scale link slabs subjected to monotonic and fatigue loading. Various concrete materials, including seven different types of engineered cementitious composite (ECC) mixtures and a control self-consolidating concrete (SCC) were used for analyzing their influence on flexural monotonic performance of $1 / 4^{\text {th }}$ scale model link slab specimens. The variables in the ECC mixtures included types of fly ash (Class CI or F), percentage of fly ash as cement replacement (55\% and 70\%) and types of sand (silica sand or local crushed sand). The variables in the fatigue loading included: stress levels ( $40 \% \pm 20 \%$ to $55 \% \pm 20 \%$ of peak load and number of cycles up to 1 million. All ECC link slabs showed superior performance in terms of ductility, crack width, crack propagation, and strain hardening behaviour compared with their SCC counterparts. In phase I (flexural performance study under monotonic loading), the mortar sand based ECC with 50\% replacement of fly ash CI showed comparatively better performance in terms of higher ultimate strength, energy absorbing capacity and higher ductility index/bending capacity in compare with other ECC mixes. This green and cost-effective ECC mix was selected for the second and third phases of experimental investigation namely fatigue performance (Phase II) under cyclic loading and structural behaviour of a joint-free $1 / 6^{\text {th }}$ scale full bridge model with ECC link slab under static loading (Phase III). High fatigue stress levels $(40 \% \pm 20 \%$ and $55 \% \pm 20 \%$ for ECC link slab and $40 \% \pm 5 \%$ for SCC link slab) and cycles (ranging from 400000 to 1 million) were applied to link slab specimens to study effect of stress levels and fatigue cycles on deflection, stress, cracking and stiffness evolutions during fatigue testing as well post-fatigue residual strength, stiffness, ductility, energy absorbing capacity. The same ECC mix was used for the one sixth scale full bridge model (two adjacent simply supported span with connecting ECC link slab) subjected to static monotonic loading (up to service stage - 50\% of the design load) to study loaddisplacement/moment-rotation response and stress development. The experimental results are compared with those obtained from existing theoretical models to verify critical design issues such as location of inflection points (in joint-free bridge deck with ECC link slab), strength of the link slab, support rotation. 


\subsection{Conclusions}

The following conclusions are drawn from experimental and theoretical investigations on link slabs as well as joint-free bridge deck with link slab:

- All seven ECC mixtures have the minimum 28 days compressive strength of $45 \mathrm{MPa}$ and flexural strength of $4.5 \mathrm{MPa}$ which are considered to be adequate for bridge deck application.

- Link slabs with all seven types of ECC mixtures (Phase I-investigation) showed better performance in terms of higher ultimate strength $(>8.79 \mathrm{kN})$, ductility (a ductility index $>14.4$ ), support end rotation (satisfying the allowable AASHTO's (2012) rotation of 0.00375 radian at $25 \%$ of ultimate load), smaller crack widths $(<100 \mu \mathrm{m})$, and high energy absorption capacity (> 81.6 Joules) in compare with SCC (normal concrete) link slab counterparts. ECC link slabs exhibited superior strain hardening behaviour over SCC link slab can be attributed due to the fiber bridging characteristics in the post-cracking stage. The brittle fracture of the SCC link slab showed no strain hardening capacity while causing high interfacial shear and subsequent steel concrete interfacial bond forces, leading to higher rebar strain development at lower load level. The rebar strain development for all ECC link slabs increased near the ultimate loading (at $85 \%$ of ultimate load), rather than first cracking load. All ECC link slab failed under ductile mode where brittle failure was governed for SCC link slab. This proved the fact that the functionality of original simply supported bridges with a continuous deck should be maintained due to high flexibility of ECC link slabs that will allow the adjacent girders to deform freely (in case of joint-free bridge deck), while the deck was restrained.

- ECC link slabs with crushed and mortar sand showed higher ultimate load and energy absorbing capacity compared to their silica sand counterparts. Link slabs with higher fly ash content developed lower ultimate load and energy absorbing capacity, but enhanced bending capacity/ductility. Overall, performance of all ECC based link slabs is comparable and satisfactory, but for maintaining the simply supporting action of the bridge girders in joint-free bridge deck construction, a superior ductility with lower 
structural stiffness is required. The optimized ECC mix that offers the ductility, lower structural stiffness while economical is crushed/mortar sand based ones at higher $(70 \%)$ fly ash content.

- Existing Code based/other theoretical specifications underestimated the flexural strength of ECC link slab while predicted strength of SCC link slabs was very close to those obtained from experiments. The existing design equations should be revised to predict reasonably the flexural strength of ECC link slabs.

- The mortar sand based ECC link slab (Phase II: investigation) showed good structural performance subjected to high fatigue stress level (maximum 60\% and 75\%), in compare with SCC link slab (45\%). After intense fatigue stress level, the ultimate strength, rebar and concrete strain developments, ductility and energy absorbing capacity were reduced only by $20 \%$ of the non-fatigued specimen whereas the SCC link slab with lower fatigue stress level (maximum 45\%) was reduced by $60 \%$ of its controlled specimen. While the PVA fibers were mainly responsible for resisting the high fatigue stress levels for the ECC link slabs, the steel rebar resisted the fatigue loading for the SCC link slab. Therefore, with low reinforcing ratio, the SCC link slab demonstrated a poor performance under fatigue loading. Although ECC link slab showed satisfactory fatigue performance, but the maximum fatigue stress level for the ECC link slab should be limited to $60 \%$ of its ultimate strength for acceptable ultimate, durability and serviceability limit state.

- At the constant fatigue stress level (maximum 60\%), the ECC link slab was considered to have failed at 1million fatigue cycle. The ruptured PVA fibers at high fatigue cycle caused a ductile failure of the ECC link slab. The failure was confirmed with a low residual ultimate strength (75\% lower than non-fatigued specimen), low ductility, energy absorbing capacity, large crack width formation (visible rupture fibers) with a fractured steel rebar. For satisfactory ultimate, durability and serviceability limit state, based on these investigation, the maximum fatigue cycle for the ECC link slab should be limited to 500000 fatigue cycles. However, it should be noted that frequency of fatigue load application was much higher in the experimental investigation. 
- In Phase III, ECC link slab (with mortar sand and 50\% fly ash CI content as used in Phase II) showed satisfactory structural performance in a reduced scale full bridge model at service load stage. The induced moment on the link slab due to applied loading only reached $10 \%$ of the ultimate strength capacity (of the ECC link slab). The experimental results with a minor difference $(<10 \%)$ satisfied the theoretical deflection and support end rotations (as suggested by the existing Codes) for simply supporting bridge structure. The experimental results with less $16 \%$ difference also satisfied the existing Code based/ theoretical models for the location of the hinges (inflection points) in a joint free bridge decks with two simply supported adjacent spans connected with a link slab.

The study confirmed the viability of constructing link slabs using higher fly ash content and local crushed/mortar sand based ECCs for a cost-effective sustainable joint-free bridge decks with satisfactory structural performance under monotonic and fatigue loading.

\subsection{Recommendations for Future Work}

Further experimental and theoretical investigations with varying parameters such as debond zone length, reinforcing ratio, loading types (static and fatigue) and concrete types are to be conducted to understand the link slab behaviour and to develop guidelines/specifications for the design of link slab as well as joint-free bridges with link slab.. The following recommendations are suggested for further research studies:

- Additional fatigue tests are to be conducted on beam specimens with different ECC mixtures for comprehensive understanding of material properties and performance subjected to high fatigue stress level and cycles.

- Comprehensive fatigue tests are to be conducted $\mathrm{r}$ on link slabs using different green ECC mixtures to evaluate the performance under high fatigue stress level and cycles to develop design guidelines and to predict service life of link slabs. 
- More investigations are to be conducted on joint-free bridge decks with ECC link slabs under fatigue loading to develop design guidelines for joint-free bridges for practical applications.

- Finite element (FE) modeling should be carried out based on experimental investigations. After verification of the FE model with experimental results, extensive numerical modelling with varying structural parameters such as reinforcing ratio, debond zone length, loading cases (monotonic, fatigue and creep) and concrete types is to be conducted for evaluating their influence on structural performance. Aftermath, additional experimental investigations are required for the verification of new numerical/analytical models.

- Field demonstration of green ECC link slab in a real bridge structure is required for complete evaluation of the link slab performance and development of defined design guidelines. 


\section{References}

AASHTO. (2002). Standard Specifications for Highway Bridges, 17th Edition, Washington DC: AASHTO.

AASHTO. (2012). AASHTO LRFD Bridge Design Specifications, $6^{\text {th }}$ Edition, Washington DC: AASHTO.

ACI Committee 215. (1992). Considerations for Design of Concrete Structures Subjected to Fatigue Loading (ACI 215R-92), American Concrete Institute, Detroit.

Alampalli, S. and Yannotti, A.P. (1998). In-service Performance of Integral Bridges and Joint less Decks. Transportation Research Record; 1624(98) pp. 1-7.

Alexander, M. G. Jaufeerally, H. and Mackechnie, J. R. (2003). Structural and Durability Properties of Concrete Made by Corex Slag. Research Monograph No. 6, Departments of Civil Engineering University of Cape Town, South Africa.

ASTM C39. (2003). Standard Test Method for Compressive Strength of Cylindrical Concrete Specimens. American Society for Testing and Materials, West Conshohocken, PA, USA.

ASTM C78/ C78M. (2010). Standard Test Method for Flexural Strength of Concrete (Using Simple Beam with Third-Point Loading), West Conshohocken, PA, USA.

ASTM C1018. (1997). ASTM C1018-97, Standard Test Method for Flexural Toughness and First-Crack Strength of Fiber-Reinforced Concrete (Using Beam With Third-Point Loading) (Withdrawn 2006), West Conshohocken, PA, USA.

ASTM C 618. (2012). Standard Specifications for Coal Fly Ash and Raw or Calcined Natural Pozzolan For Use In Concrete. American Society for Testing and Materials, West Conshohocken, PA, USA.

Au, A. Lam, C. Au, J. and Tharmabala, B. (2013). Eliminating Deck Joints Using Debonded Link Slab: Research and Field Test in Ontario. Journal of Bridge Engineering, 18(8), pp. 768-778. 
Au, A. and Lam, C. (2009). Experimental Investigation of Link Slab Performance Using ScaledDown Models. Ministry of Transportation Highway Standards Branch Report (Bro-041). Ontario Minitistry of Transportation. Ontario. Canada.

Bisaillon, A. Rivest, M. and Malhotra, V. (1994). Performance of High Volume Fly Ash Concrete in Large Experimental Monoliths. ACI Materials Journal, 91(2), pp. 178-187.

Caner, A. and Zia, P. (1998). Behavior and Design of Link Slabs with Jointless Bridge Deck. PCI Journal. pp. 68-80.

CHBDC. (2006). Canadian Highway Bridge Design Code, $10^{\text {th }}$ Edition, Mississauga, Canadian Standard Association.

Chen, H. J. Liu, T. H. Tang, C. W. and Wen, P. T. (2011). Influence of High-Cycle Fatigue on the Tension Stiffening Behavior of Flexural Reinforced Lightweight Aggregate Concrete Beams. Structural Engineering and Mechanics Journal, 40(4), pp. 1-20.

CISC. (2010). Handbook of Steel Construction, $10^{\text {th }}$ edition, Ontario, Canada: CISC.

Fischer, G. and Li, V.C. (2003). Intrinsic Response Control of Moment Resisting Frames Utilizing Advanced Composite Material and Structural Elements. ACI Structural Journal, 100(1), pp.166-176.

Gastal, F. and Zia, P. (1989), Analysis of Bridges Beams with Joint Less Decks, Proceedings of IASBE Symposium, Lisbon.

Gilani, A. (2001). Link slabs for Simply Supported Bridges Incorporating Engineered Cementitious Composites. MDOT SPR-54181. Structural Research Unit, MDOT, USA.

Giordano, L. and Mancini, G. (2009). Fatigue Behavior Simulation of Bridge Deck Repaired with Self Compacting Concrete. Journal of Advanced Concrete Technology, 7(3), pp. 415-424.

Hossain, K.M.A and Anwar, M.S. (2014). Strength and Deformation Characteristic of ECC Link Slab in Joint-Free Bridge Decks, Istanbul Bridge Conference, August, Istanbul, Turkey. 
Hossain, K.M.A. and Sherir, M. (2014). Fracture Energy Characteristics of Engineered Cementitious Composites Incorporating Different Aggregates. CSCE 2014 4th International Structural Specialty Conference, Halifax, Canada.

Hussian, S. E. and Rasheeduzzafar, M. (1994). Corrosion Resistance Performance of Fly Ash Blended Cement Concrete. ACI Materials Journal, 91(3), pp. 264-272.

JCI-DFRCC Committee. (2003). DFRCC Terminology and Application Concepts. Journal of Advanced Concrete Technology, 1(3), pp. 335-340.

Kanda, T. and Li, V. C. (1998). Multiple Cracking Sequence and Saturation in Fiber Reinforced Cementitious Composites. Concrete Research and Technology, JCI, 9(2), pp. 19-33.

Karahan, O. Hossain, K.M.A. Ozbay, E. Lachemi, M. and Sancak, E. (2012). Effect of Metakaolin Content on the Properties Self-consolidating Lightweight Concrete. Construction and Building Materials, 31(6), pp. 320-325.

Keoleian, G. Kendall, A. Chandler, R. Helfand, G. Lepech, M. and Li, V.C. (2005). Life Cycle Model for Evaluating the Sustainability of Bridge Decks, Proc. $4^{\text {th }}$ International Workshop on Life Cycle Cost Analysis and Design of Civil Infrastructure Systems, Florida, pp. 8-11.

Kim, Y.Y. Fischer, G. and Li, V.C. (2004). Performance of Bridge Deck Link Slabs Designed with Ductile ECC. ACI Structural Journal, 1(6), pp. 792-801.

Kosmatka, S. and Panarese, W. (1988). Design and control of concrete mixtures. $13^{\text {th }}$ Edition. Skokie, IL: Portland Cement Association, 205.

Kuroda, M. Watanabe, T. and Terashi, N. (2000). Increase of Bond Strength at Interfacial Transition Zone by the Use of Fly Ash. Cement and Concrete Research, 30(2), pp. 253258. 
Lam, C. Lai, D. Au, J. Lim, L. Young, W. and Tharmabala, B. (2008). Development of Concrete Link Slabs to Eliminate Bridge Expansion Joints over Piers. Paper prepared for presentation at the Bridges - Links to a Sustainable Future (B) Session of the 2008 Annual Conference of the Transportation Association of Canada Toronto, Ontario.

Lepech, M. and Li, V. (2005b). Durability and Long Term Performance of Engineered Cementitious Composites. Honolulu, Hawaii, In Proceedings of International RILEM Workshop on HPFRCC in Structural Applications, pp. 165-174.

Lepech, M.D. and Li, V.C. (2006). Long Term Durability Performance of Engineered Cementitious Composites, J Restor Build Monum, 12(2), pp. 119-132.

Lepech, M.D. and Li, V.C. (2008). Large Scale Processing of Engineered Cementitious Composites, ACI Material Journal, 105(4), pp.358-366.

Lepech, M. D. and Li, V. C. (2009). Application of ECC for Bridge Deck Link Slabs. RILEM Journal of Materials and Structures, 42(9), pp. 1185-1195.

Li, V. C. (2011). High-Ductility Concrete for Resilient Infrastructures. Journal of Advanced and High-Performance Materials, pp. 16-21.

Li, V.C. Wang, S. and Wu, C. (2001). Tensile Strain-Hardening Behavior of Polyvinyl Alcohol Engineered Cementitious Composite (PVA-ECC). ACI materials journal, 98(6), pp. 483492.

Li, V.C. Lepech, M.D. and Li, M. (2005). Field Demonstration of Durable Link Slabs for Jointless Bridge Decks Based on the Strain-Hardening Cementitious Composites, Michigan Department of Transportation Report No. RC-1471, pp. 1-147.

Li, V.C. Fischer, G. Kim, Y.Y. Lepech, M. Qian, S. Weimann, M. and Wang, S. (2003). Durable Link Slabs For Jointless Bridge Decks Based on Strain-Hardening Cementitious Composites, Report for Michigan Department of Transportation RC- 1438.

Li, V.C. (1993). From Micromechanics to Structural Engineering-The Design of Cementitious Composites for Civil Engineering Applications, JSCE J of Structural Mechanics and Earthquake Engineering, 10(2), pp.37-48. 
Li, V. Mishra, D. and Wu, H. (1995). Matrix Design for Pseudo Strain-Hardening Fiber Reinforced Cementitious Composites. RILEM Journal of Materials and Structures, 28(183), pp. 586-595.

Li, V. C. Wang, S. Ogawa, A. and Saito, T. (2002). Interface tailoring for strain-hardening PVAECC. ACI Materials Journal; 99(5), pp. 463-472.

Li, V.C. (1998). ECC Tailored Composites through Micromechanical Modeling. Fiber Reinforced Concrete: Present and the Future Edited by Banthia et al., CSCE. Montreal, pp. 64-97.

Li, V.C. and Kanda, T. (1998). Engineered cementitious composites for structural applications. Journal of Materials in Civil Engineering. 10(2), pp. 66-69.

Li, V.C. (2003). Engineered cementitious composites (ECC) - A review of the material and its Applications. Journal of Advanced Concrete Technology, 1(3), pp. 215-230.

Lin, Z. Kanda, T. and Li, V. C. (1999). On Interface Property Characterization and Performance of Fiber Reinforced Cementitious Composites. Concrete Science and Engineering, RILEM, 1, 173-184.

Matsumoto, T. (1998). Fracture Mechanics Approach to Fatigue Life of Discontinuous Fiber Reinforced Composites. PhD thesis, Dept. of Civil and Environmental Engineering, University of Michigan, Ann Arbor, Michigan, pp. 274.

Maulin, B.M. (2012), Fresh/Mechanical/Durability Properties and Structural Performance of Engineered Cementitious Composite (ECC). Published master's thesis, Ryerson University, Toronto Canada.

Mehta, P. K. and Monteiro, P. J. M. (2006). Concrete: Structure, Properties, and Materials, Third Edition, New York, McGraw Hill.

Mindess, S. Young, J.F. and Darwin, D. (2003). Concrete. $2^{\text {nd }}$ Edition, Pearson Education, Inc.

Nawy, E. (2008). Concrete Construction and Engineering Handbook, Second Edition, New York, CRC Press. 
Neville, A.M. (2002). Properties of Concrete. Fourth and Final Edition, John Wiley \& Sons, New York, pp. 884.

Özbay, E. Karahan, O. Lachemi, M. Hossain, K. M. A. and Atis C. D. (2013). Dual Effectiveness of Freezing-Thawing and Sulfate Attack on High-Volume SlagIncorporated ECC. Composites Part B: Engineering, 45(1), pp. 1384-1390.

Özbay, E. Karahan, O. Lachemi, M. Hossain, K.M.A. and Atis, C.D. (2012). Investigation of Properties of Engineered Cementitious Composites Incorporating High Volumes of Fly Ash and Metakaolin. ACI materials journal, 109(5), pp. 565-571.

Peled, A. and Shah, P. S. (2003). Processing Effect in Cementitious Composites: Extrusion and Casting, Journal of Materials in Civil Engineering. 15(2), pp. 192-199.

Qian, S. Lepech, M.D. Kim, Y.Y. and Li, V.C. (2009). Introduction of Transition Zone Design for Bridge Deck Link Slabs Using Ductile Concrete. ACI structural journal, 106(1), pp. 96-105.

Ranade, R. Zhang, J. Lynch, J. P. and Li, V. C. (2014). Influence of Micro-Cracking on the Composite Resistivity of Engineered Cementitious Composites. Cement and Concrete Research, 58(1), pp. 1-12.

Sahmaran, M. Yaman, I.and Tokyay, M. (2008). Transport and Mechanical Properties of SelfConsolidating Concrete with High Volume Fly Ash. Cement and Concrete Composites, 31(2), pp. 99-106.

Sahmaran, M. Lachemi, M. Hossain, K. M.A. and Li, V.C. (2009). Influence of Aggregate Type and Size on Ductility and Mechanical Properties of Engineered Cementitious Composites. ACI Material Journal, 106(3), pp. 308-316.

Sahmaran, M. Lachemi, M. Hossain K. M.A. Ranade, R. and Li, V.C. (2010). Internal Curing of ECC's for Prevention of Early Age Autogenous Shrinkage Cracking. Cement and Concrete Research, 39(10), pp. 893-901 
Sherir, M. (2012), Fracture Energy, Fatigue and Creep Properties of Engineered Cementitious Composites Incorporating Fly Ash/ Slag With Different Aggregates. Published master's thesis, Ryerson University, Toronto Canada.

Suthiwarapirak, P. Matsumoto, T. and Kanda, T. (2004). Multiple Cracking and Fiber Bridging Characteristic of Engineered Cementitious Composites under Fatigue Flexure. Journal of Material in Civil Engineering, 16(5), pp. 433-443.

Wang, S. and Li, V.C. (2003). Tailoring of PVA Fiber/Matrix Interface for Engineered Cementitious Composite (ECC). (Plenary Lecture), Proceeding Fiber Society 2003 Symposium in Advanced Flexible Materials and Structures: Engineering with Fiber, Loughborough, UK, pp.91-92.

Wang, S. and Li, V. C. (2007). Engineered Cementitious Composites with High-Volume Fly Ash. ACI materials journal, 104(3), pp. 233-241.

Wang, H. and Belarbi, A. (2011). Ductility Characteristics of Fiber-Reinforced-Concrete Beams Reinforced with FRP Rebars. Construction and Building Material Journal, 25(5), pp. 2391-2401.

Weimann, M.B. and Li, V. C. (2003). Hygral Behavior of Engineered Cementitious Composites (ECC). International Journal for Restoration of Buildings and Monuments, 9(5), pp. 513534.

Yang, E. Yang, Y. and Li, V.C. (2007). Use of High Volumes of Fly Ash to Improve ECC Mechanical Properties and Material Greenness. ACI Materials Journal, (104-M68), pp.303-311.

Zanuy, C. Maya, L.F. Albajar, L. and Fuente, P.D. (2011). Transverse Fatigue Behavior of Lightly Reinforced Concrete Bridge Decks. Journal of Engineering Structure, 33(10), pp. 2839-2849.

Zhang, J. and Li, V. C. (2002). Monotonic and Fatigue Performance in Bending of Fiber Reinforced Engineered Cementitious Composite In Overlay System. Cement and Concrete Research, 32, pp. 415-423. 
Zia, P. Caner, A. and El-Safte, A. (1995) Jointless bridge decks research project 23241-94-4. Center for Transportation Engineering Studies, North Carolina State, pp. 1-117.

Zuk, W. (1981). "Joint less Bridges”, Research Report No. FHWA/VA-81/48, Virginia Highway and Transportation Research Council. Charlottesville, Virginia, USA. 


\section{Appendix A}

\section{Resisting Moment Capacity for $1 / 4^{\text {th }}$ Scale ECC Link Slab}

The moment capacity for the $1 / 4^{\text {th }}$ scale link slabs is designed in accordance to existing guidelines proposed by Caner \& Zia (1998) and Lepech \& Li (2009). The reinforcing ratio for the link slab is selected to satisfy the stress criterion $\left(\mathrm{f}_{\mathrm{s}}<0.4 \mathrm{f}_{\mathrm{y}}\right)$ at an imposed end rotation of 0.0015 radian. This is the expected end rotation angle derived by Caner and Zia (1998). The applied/induced moment in the link slab is calculated by Equation 2.6.

$M_{l s}=\frac{2 E_{E C C I} I_{l s}}{L_{d z}} \theta$

$\mathrm{M}_{1 \mathrm{~s}}=\frac{2 * 18 * 1000 * 3.15 * 10^{6} * 0.0015}{330}=0.515 \mathrm{kN} . \mathrm{m}$

where $\mathrm{E}_{\mathrm{ECC}}$ is the modulus of elasticity of the $\mathrm{ECC}, \theta$ is the imposed end rotation angle and $\mathrm{I}_{\mathrm{ls}}$ represents the uncracked moment of inertia as per Equation 2.7

$I_{l s}=\frac{B_{l s} t^{3}}{12}$

$\mathrm{I}_{\mathrm{Is}}=\frac{(175)(60)^{3}}{12}=3.15^{*} 10^{6} \mathrm{~mm}^{4}$

where $\mathrm{B}_{\mathrm{ls}}$ and $\mathrm{t}$ denotes the width and thickness of the link slab, respectively.

The use of uncracked moment of inertia results as a higher applied moment in the link slab (as it is evidenced from Equation 2.6). The higher calculation of induced/applied moment introduces additional conservisim and safety for the link slab design, since ECC link slab is intended to function in the micro-crack state (with lower moment of inertia) rather than uncracked state. Iterative design procedure (adopted by Lepech $\& \mathrm{Li}(2009)$ ) is used to determine the adequate reinforcing ratio, starting with the minimum steel ratio ( $\rho=1.1 \%$ as per AASHTO (2012) code). Through the analysis, the selected reinforcing ratio is adjusted accordingly to resist the applied moment imposed by the girders end-rotation. 
A non-linear sectional analysis is considered (based on the assumption that ECC material remains perfectly elastic-plastic in service) for calculating the resisting moment capacity of the ECC link slab. For safe and conservative design, the strain hardening characteristic of the ECC material is neglected after the first cracking. Therefore the design yield strain and stress of $0.02 \%$ and 3.45 MPa respectively was selected for the ECC material (Lepech \& Li, 2009).

For calculating the resisting moment capacity, the location of the neutral axis of the section is determined through the forces of equilibrium (Equations 2.10 to 2.13 and Figure A.1). Prior to calculating the neutral axis, the location of the stress 'kink' $(n)$ in the tension region of the section is determined (based on Equation 2.9) due to the elastic-plastic tensile response of ECC material.

$n=\frac{\varepsilon_{y-E C C}}{0.4 \varepsilon_{y-S t e e l}}$

$n=\frac{0.02 \%}{0.4(0.002)}=0.25$

where $n$ represents the yield strain ratio, $\varepsilon_{\mathrm{y}-\mathrm{ECC}}$ and $\varepsilon_{\mathrm{y}-\text { Steel }}$ denote the yield strain of the elasticplastic behaviour of ECC and steel reinforcement, respectively.
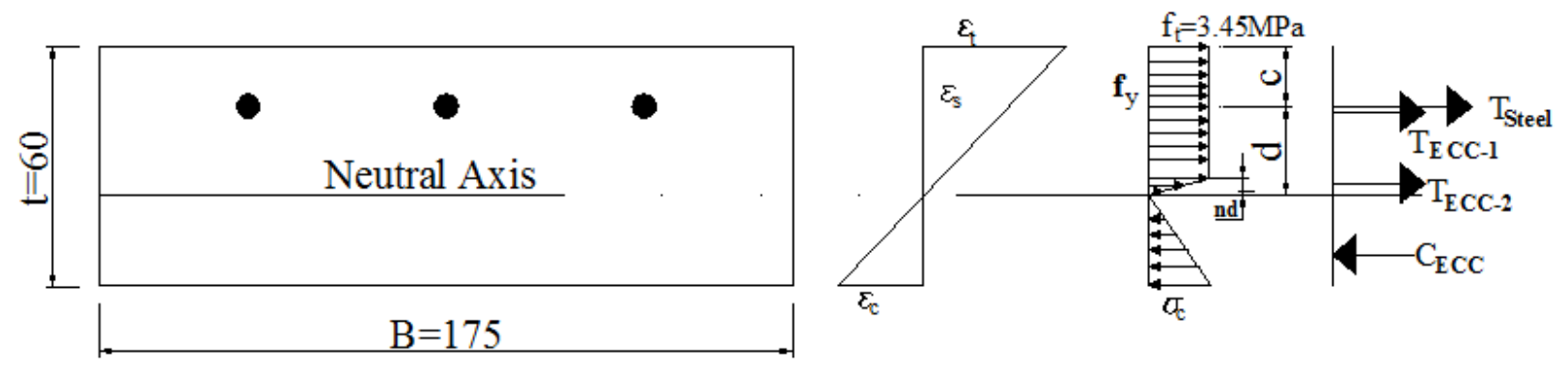

Figure A.1: Stress and Strain Distribution in the ECC Link Slab Cross Section 


$$
\begin{aligned}
& \mathrm{T}_{\text {steel }}=\left(0.4 \mathrm{f}_{\mathrm{y}-\text { steel }}\right) \mathrm{As} \\
& \mathrm{T}_{\text {steel }}=(0.4(375))(3 * 28.27)=12.72 \mathrm{kN} \\
& \mathrm{T}_{\mathrm{ECC}-1}=\mathrm{f}_{\mathrm{t}}[(1-\mathrm{n}) \mathrm{d}+\mathrm{c}] \mathrm{b} \\
& \mathrm{T}_{\mathrm{ECC}-1}=3.45[(1-.25) \mathrm{d}+20]^{* 175} \\
& \mathrm{~T}_{\mathrm{ECC}-1}=452.8 \mathrm{~d}+12075 \\
& \mathrm{~T}_{\mathrm{ECC}-2}=0.5 \mathrm{f}_{\mathrm{t}} \mathrm{ndb} \\
& \mathrm{T}_{\mathrm{ECC}-2}=0.5 * 3.45 * .25 * \mathrm{~d}^{*} 175 \\
& \mathrm{~T}_{\mathrm{ECC}-2}=75.47 \mathrm{~d} \\
& \mathrm{C}_{\mathrm{ECC}}=0.5 \mathrm{f}_{\mathrm{t}}\left(\frac{1}{n d}\right)\left(\mathrm{t}_{\mathrm{s}}-\mathrm{d}-\mathrm{c}\right)^{2} \mathrm{~b} \\
& \mathrm{C}_{\mathrm{ECC}}=0.5 * 3.45\left(\frac{1}{0.25 d}\right)(60-\mathrm{d}-20)^{2} * 175 \\
& \mathrm{C}_{\mathrm{ECC}}=1932000 / \mathrm{d}-96600+1207.5 \mathrm{~d}
\end{aligned}
$$

The location of the neutral axis for the section based on the equilibrium of the forces is determined as per Equation 2.14.

$\mathrm{T}_{\text {steel }}+\mathrm{T}_{\mathrm{ECC} 1}+\mathrm{T}_{\mathrm{ECC} 2}=\mathrm{C}_{\mathrm{ECC}}$

$679.2 d^{2}-121395 \mathrm{~d}+1932000=0$

$\mathrm{d}=17.65 \mathrm{~mm}$

After substituting $\mathrm{d}=17.56 \mathrm{~mm}$ back into the (Equations 2.10-2.13), the tensile and compressive forces are equal to:

$\mathrm{T}_{\text {steel }}=12.72 \mathrm{kN}$

$\mathrm{T}_{\mathrm{ECC}-1}=20.06 \mathrm{kN}$

$\mathrm{T}_{\mathrm{ECC}-2}=1.33 \mathrm{kN}$

$\mathrm{C}_{\mathrm{ECC}}=34.17 \mathrm{kN}$ 
The resisting moment capacity, $\mathrm{M}_{\mathrm{r}-\mathrm{ls}}$ is calculated by summing the contribution of all forces about the neutral axis as per Equation 2.15 (for provided steel reinforcement ratio of $\rho=0.011$ ).

$$
\begin{aligned}
& M_{r-l s}=\left\{T_{\text {Steel }} d+T_{E C C-1}\left(\frac{(1-n) d+c}{2}+n d\right)+T_{E C C-2}\left(\frac{2}{3}\right) n d+C_{E C C}\left(\frac{2}{3}\right)\left(t_{s}-d-c\right)\right\}\left(\frac{1}{1000}\right) \\
& M_{r-l s}=\left\{12.72 * 17.65+20.06\left(\frac{(1-0.25) 17.65+20}{2}+0.25 * 17.65\right)+1.33 * 0.25 * 17.65\right. \\
& \left.+34.17\left(\frac{2}{3}\right)(60-17.65-20)\right\}\left(\frac{1}{1000}\right) \\
& M_{r-l s}=1.294 k N . m \\
& M_{r-l s}>\mathrm{M}_{\text {applied }}
\end{aligned}
$$

The steel reinforcing ratio of $\rho=0.011$ is adequate for resisting the applied/induced moment on the link slab. With the finalized reinforcing ratio, the adequate spacing of the longitudinal rebar is determined by Equation 2.16.

$$
\begin{aligned}
& S=\frac{A_{\text {bar }}}{\rho t_{s}} \\
& S=\frac{26.27}{(0.011 * 60)} \\
& S \sim 50 \mathrm{~mm}
\end{aligned}
$$




\section{Resisting Moment Capacity for $1 / 6^{\text {th }}$ Scale Full Bridge Model}

The resisting positive moment for the $1 / 6^{\text {th }}$ scale full bridge model is designed to resist the applied/induced moment at the service load stage for the imposed end rotation of 0.00375 radian (AASHTO, 2012). For validating the simply supporting performance of the girders, the bridge is considered as two simple spans SCC sections, connected by ECC link slab. Due to the symmetry, only one of the SCC spans is considered for determining the resisting positive moment capacity.

The applied load and moment for the SCC simple span composite section is determined based on Equation A1.

$\theta=\frac{P L^{2}}{16 E I}$

$0.00375=\frac{P(1000)^{2}}{16(200000)\left(0.65 \times 10^{7}\right)}$

$\mathrm{P}=75 \mathrm{kN}$

$\mathrm{M}_{\text {Applied }}=19 \mathrm{kN} . \mathrm{m}$

where $\mathrm{P}$ denotes the applied load, E, I and $\theta$ symbolize the transformed section modulus of elasticity (considering steel girders modulus), transformed moment of inertia (for transformed steel section) and girders support end rotation respectively.

The SCC composite section is designed to resist the applied moment of 19 kN.m. Prior to calculating the moment capacity for one of the SCC spans the equilibrium of forces is used to locate the plastic neutral axis of the SCC composite section. The location of the plastic neutral axis is determined using Equations A2 to A7 (through iterative calculation). Initially the location of neutral axis is assumed to be within the concrete deck slab. Figure A.2 presents the resisting forces across the depth of the SCC section, assuming that plastic neutral axis is located within the concrete deck slab. 


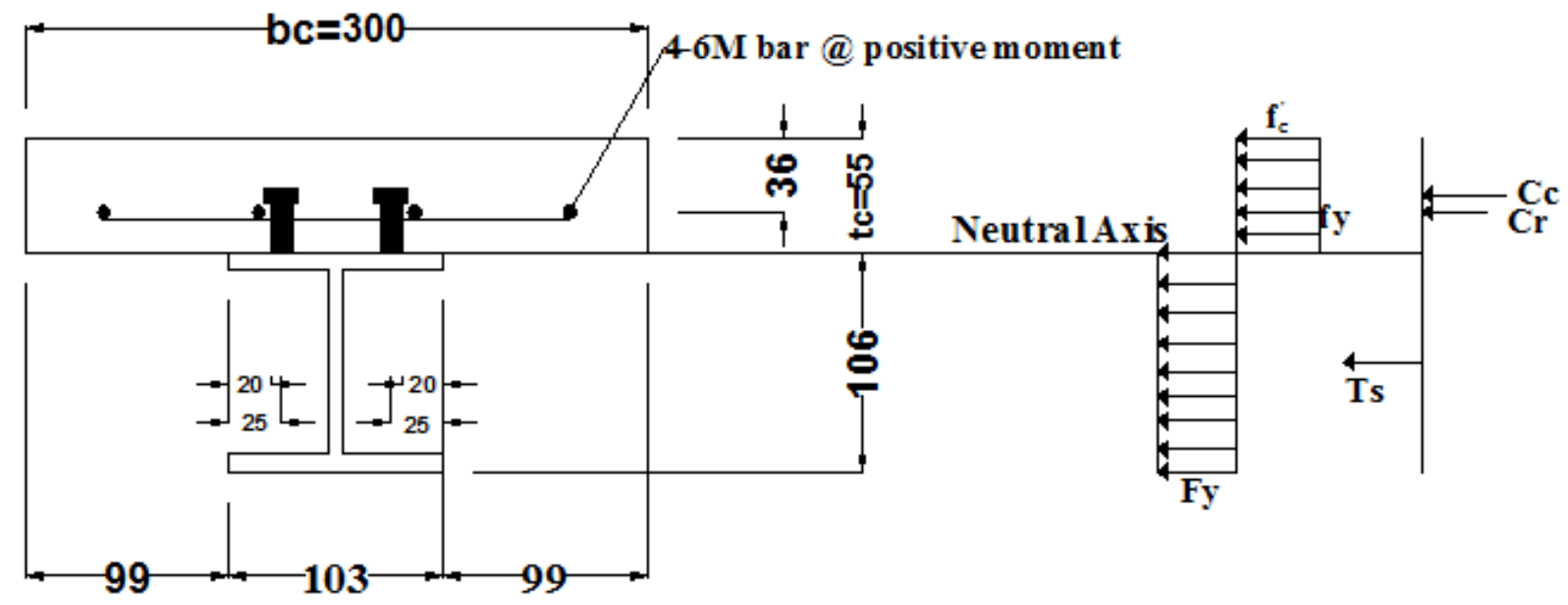

Figure A.2: Resisting Forces along the Depth of the SCC Section

$\mathrm{C}_{\mathrm{c}}=0.85 \mathrm{~b}_{\mathrm{e}} \mathrm{t}_{\mathrm{c}} \mathrm{f}^{\prime}{ }_{\mathrm{c}}$

$\mathrm{C}_{\mathrm{c}}=0.85(300)(55)(36.4)$

$\mathrm{C}_{\mathrm{c}}=510.5 \mathrm{kN}$

where $\mathrm{C}_{\mathrm{c}}$ denotes the concrete resisting compressive force $(\mathrm{kN}), b_{e}, t_{c}, f_{c}$ are representing width, thickness and compressive strength of concrete deck slab.

$\mathrm{C}_{\mathrm{r}}=\mathrm{A}_{\mathrm{r}} \mathrm{f}_{\mathrm{y}}$

$\mathrm{C}_{\mathrm{r}}=(113.08)(375)$

$\mathrm{C}_{\mathrm{r}}=45.2 \mathrm{kN}$

where $C_{r}$ designates the resisting compressive force for the steel rebar, $A_{r}$ denotes the total area of steel rebar and $\mathrm{f}_{\mathrm{y}}$ symbolizes the yielding strength of the steel reinforcement.

$\mathrm{T}_{\mathrm{s}}=\mathrm{A}_{\mathrm{s}} \mathrm{F}_{\mathrm{y}}$

$\mathrm{T}_{\mathrm{s}}=(2480)(350)$

$\mathrm{T}_{\mathrm{s}}=868 \mathrm{kN}$

where $T_{s}, A_{s}$ and $F_{y}$ denotes the resisting tensile force, area and yield strength of the steel girder. 
Based on the equilibrium of the forces $\left(\mathrm{C}_{\mathrm{c}}+\mathrm{C}_{\mathrm{r}}<\mathrm{T}_{\mathrm{s}}\right)$ it is proven that plastic neutral axis is located within the steel girders top flange (as it is illustrated in Figure A.3). The residual compressive force for the steel girders top flange is calculated per Equation A5.

$\mathrm{C}_{\mathrm{s}}=0.5\left(\mathrm{~A}_{\mathrm{s}} \mathrm{F}_{\mathrm{y}}-\mathrm{C}_{\mathrm{c}}-\mathrm{C}_{\mathrm{r}}\right)$

$\mathrm{C}_{\mathrm{s}}=0.5[(2480(350)-510510-45200]$

$\mathrm{C}_{\mathrm{s}}=156.5 \mathrm{kN}$

where $C_{s}$ denotes the resisting compressive force for the steel girder and $A_{s}, F_{y}$ symbolize the area of the steel and yielding strength of the steel girder, W100x19.

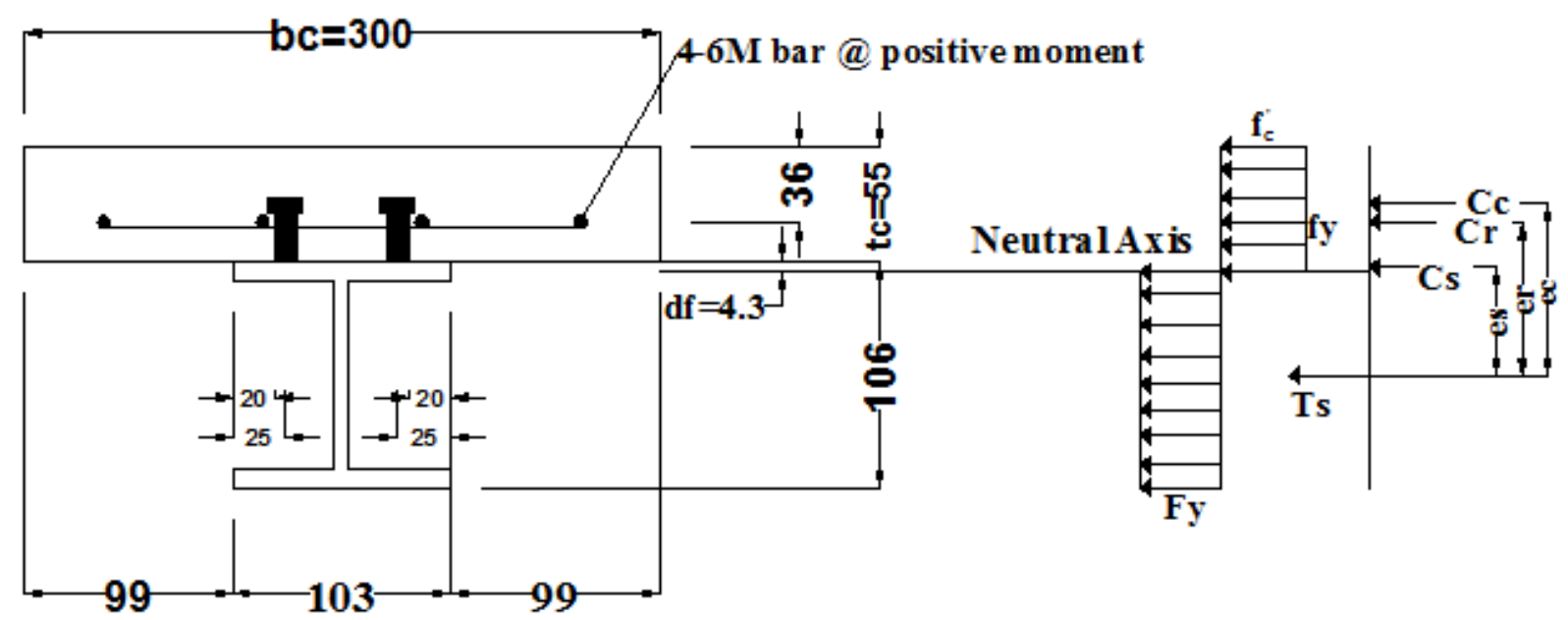

Figure A.3: Resisting Forces along the Depth of the SCC Section for Location of Plastic Neutral Within Steel Girder

Since the plastic neutral axis is located within the steel girder, the resisting tensile force for the steel girder is reduced further for maintaining the equilibrium of forces. The residual tensile force of the steel girder (W100x19) is calculated per Equation A6. 
$\mathrm{T}_{\mathrm{s}}=\mathrm{A}_{\mathrm{s}} \mathrm{F}_{\mathrm{y}}-\mathrm{C}_{\mathrm{s}}$

$\mathrm{T}_{\mathrm{s}}=(2480)(350)-156500$

$\mathrm{T}_{\mathrm{s}}=711.5 \mathrm{kN}$

The location/total depth of the compressive force $\left(\mathrm{d}_{\mathrm{f}}\right)$ for the steel girder is calculated per Equation A7 and illustrated in Figure A.3 by considering the resisting compressive force of the steel girder $\left(\mathrm{C}_{\mathrm{s}}\right)$.

$\mathrm{C}_{\mathrm{s}}=\mathrm{b}_{\mathrm{f}} \mathrm{d}_{\mathrm{f}} \mathrm{F}_{\mathrm{y}}$

$156500=(103)\left(d_{f}\right)(350)$

$\mathrm{d}_{\mathrm{f}}=4.34 \mathrm{~mm}$

The plastic neutral axis (as illustrated by Figure A.3) is located within the steel's girder top flange since $d_{f}$ is less than the thickness of the steel girders flange $(4.34<9.89 \mathrm{~mm})$

The resisting positive moment for the composite SCC section is determined based on the contributions of the forces about the tensile force in the steel girder $T_{s}$ (Figure A.3). The resisting moment capacity is determined based on Equation A8.

$M_{r}=C_{c} e_{c}+C_{r} e_{r}+C_{s} e_{s}$

$\mathrm{M}_{\mathrm{r}}=(510.5)(0.161-0.0437-0.055 / 2)+(42.41)(0.161-0.0437-0.036)+(132.3)(0.106-0.00434 / 2-$

$0.0437)$

$\mathrm{M}_{\mathrm{r}}=57 \mathrm{kN} \cdot \mathrm{m}$

where $M_{r}$ denotes the resisting moment capacity and $e_{c}, e_{r}, e_{s}$ denotes the distance from the resisting tensile force $T_{\mathrm{s}}$ to the concrete, rebar and steel girders compressive forces (Figure A.2).

The resisting moment capacity for the SCC composite section is satisfying the applied moment at the imposed end rotation of 0.00375 radian, since $\mathrm{M}_{\mathrm{r}}>\mathrm{M}_{\text {Applied }}$. 
The same procedure adopted in APPENDIX A for Resisting Moment capacity of the $1 / 4^{\text {th }}$ Scale ECC Link Slab is used to determine the resisting moment capacity for the ECC link slab of the $1 / 6^{\text {th }}$ scale full bridge model with a small modification. The applied moment in the ECC link slab for the $1 / 6^{\text {th }}$ scale full bridge model is considered at imposed serviceable end rotation of 0.00375 radian. Using Equation 2.6, the applied moment in the ECC link slab for imposed end rotation of 0.00375 radian is $2.3 \mathrm{kN} . \mathrm{m}$. The resisting moment capacity for the ECC link slab (Equation 2.15) is $2.89 \mathrm{kN} . \mathrm{m}$. 